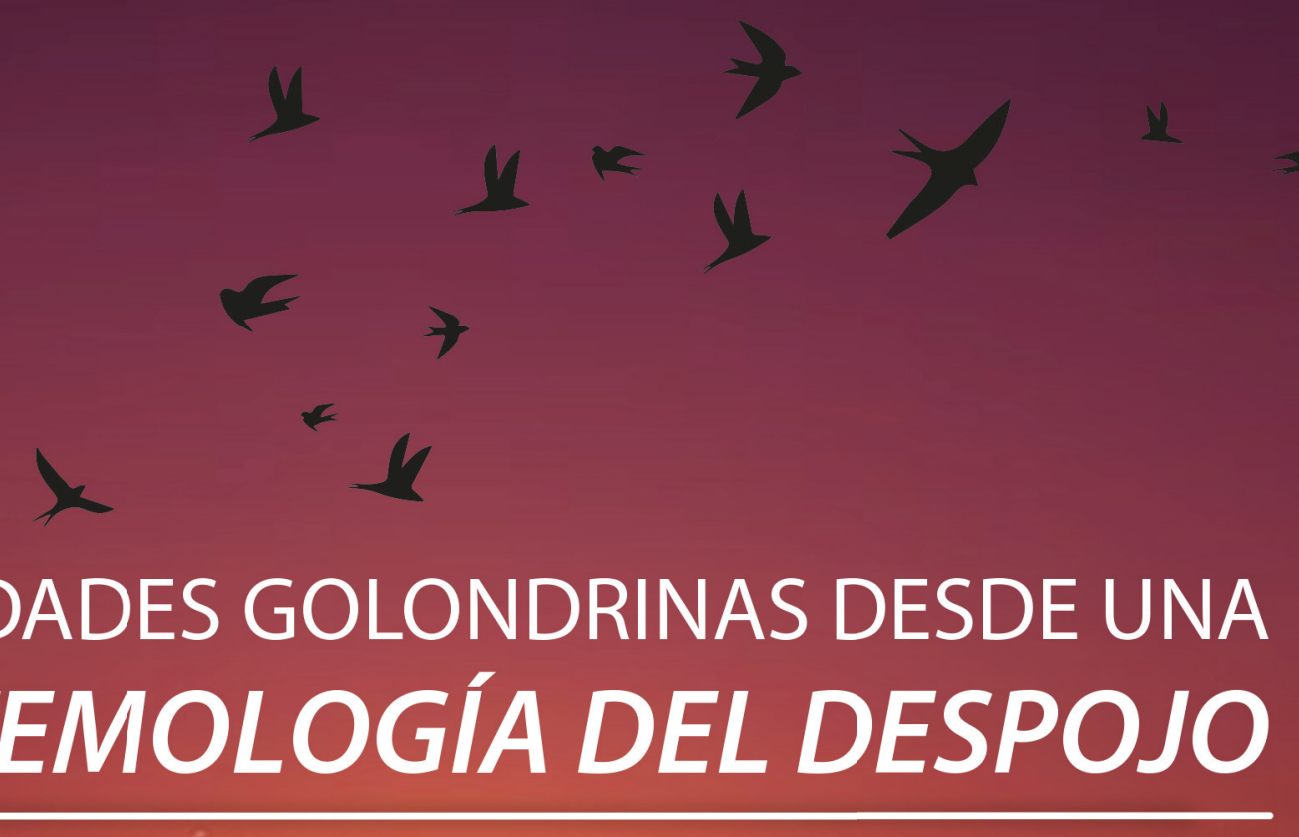

Estudio de caso sobre las prácticas político comunicacionales de las feminidades travestis y trans migrantes peruanas en La Plata: las charapas

Autora: Lic. Claudia Vásquez Haro 



\section{UNIVERSIDAD NACIONAL DE LA PLATA \\ FACULTAD DE PERIODISMO Y COMUNICACIÓN SOCIAL \\ DOCTORADO EN COMUNICACIÓN SOCIAL}

Identidades Golondrinas desde una Epistemología del Despojo

Estudio de caso sobre las prácticas político-comunicacionales

de las feminidades travestis y trans migrantes peruanas en La Plata:

las charapas

Autora:

Lic. Claudia Vásquez Haro

Directoras:

Dra. Florencia Saintout (UNLP) y

Adriana Archenti (UNLP)

Asesora:

Mgter. Verónica Andrea González (UNC)

La Plata, Provincia de Buenos Aires, Argentina.

Año 2020 


\section{AGRADECIMIENTOS}

Esta producción académica es en memoria y reconocimiento de todas aquellas travestis y trans que fueron expulsadas de la familia heterosexual, que migraron y con su lucha y aportes fortalecieron al movimiento travesti y trans de Argentina y se constituyeron en sujetas de derecho.

Mi infinito agradecimiento a Las Charapas, y a las compañeras de OTRANS ARGENTINA, quienes con sus testimonios me enseñaron modos plurales, colectivos y subjetivizantes de organización, acción y lucha. De articulación, construcción de alianzas estratégicas y Coalicionar con otres. Especialmente a Karola Macedo Flores, Vicky Minaya Pinchi, Koral Chota Flores, Aradia Garcia Mujica, Toni Domínguez y Lucas Bazterrica, con quienes caminamos el territorio juntes.

A Luciana Sánchez, Coralia Ojea, y a Jonathan Mastrangelo, por su contribución desde el campo jurídico a la militancia travesti y trans.

A la Universidad Nacional de La Plata y a la Facultad de Periodismo y Comunicación Social por la formación académica, que en calidad de becaría posibilito la materialización de esta investigación. Por ser una aliada estratégica que habilita espacios de discusión, intercambio y producción de conocimiento y pensamiento crítico.

A mis directoras, Florencia Saintout y Adriana Archenti, quienes con sus saberes y formación académica guiaron este viaje que no estuvo exento de vacilaciones y vicisitudes.

A Verónica Andrea González, quien fue un puntal en este largo proceso de investigación, a través del acompañamiento y asesoramiento. Y a su compromiso militante, ético y político con el transfeminismo.

A mi madre, Juana Margarita Haro Morales, por su amor incondicional y acompañarme en cada momento de mi vida. Por su ejemplo que me inspiro a luchar por mis ideales, y defender mis convicciones y sobre todo a nunca bajar los brazos.

A mi hermana mayor Laly, quien me trajo a la Argentina, motivada para que pueda expresar mi identidad de género, ingresar a la universidad y embarcarme en un proyecto de vida en igualdad de condiciones. A ella y a mi hermana Jesica, por esa complicidad sorora fundada en un lazo de amor y afectos incondicionales.

A mi padre Segundo Vásquez Baca y hermanos: Lucho, Pepe y Carlitos, quienes a pesar de la distancia, me hacen llegar su amor infinito acompañándome en cada paso que doy.

A Matías David Rodríguez, por su amistad incondicional, por estar conmigo en los momentos más difíciles y felices de mi vida. Porque seguimos eligiéndonos y porque el lazo que construimos ambes, se fortalece cada vez más y permanece indemne.

A Tania Alejandra Páez, por su sinceridad, frontalidad y por su ser maravilloso.

A mis hijes, Morena, Mestizo, Néstor y Tobías, quienes en el calor de nuestro hogar, conocen mis sentimientos más íntimos y me acompañan día a día.

"Y a les que luchan por hacer de la sociedad un mundo más justo, desafiando la norma y transgrediendo los límites impuestos por el patriarcado, el capitalismo y la heteronorma...a Néstor Kirchner y Cristina Fernández, por la voluntad política en pos de generar las mejores condiciones de reconocimiento para nuestro colectivo... y a los que estamos convocades a reescribir la historia, nuestra historia", Claudia Vásquez Haro.

Ciudad de La Plata - Argentina, 12 julio del año 2020. 
Indíce

Introducción

Capítulo 1. Estado del Arte

Las Adelantadas

Migrantes transgénero en México: éxodo de violencia y discriminación 24

Triplemente Vulnerabilizadas: Prostitutas, inmigrantes y transexuales 33

La migración en números 39

La comunicación, como elemento constitutivo de la identidad

\section{Capítulo 2. Marco Metodológico}

2.1. Planteamiento del problema 46

2.2. Posicionamiento metodológico 47

2.3. La Informante clave 49

2.4. Estudio de Caso 50

2.4.1. Las técnicas de recolección de información 52

\section{Capítulo 3. Marco Teórico Conceptual}

La perspectiva comunicacional: prácticas político-comunicacionales

La identidad como primer elemento de sociabilidad 60

Alteridad y Nostredad como componentes de la Identidad 62

Identidad travesti y trans de las charapas: algunas

conceptualizaciones claves

Diversidad sexual. Consideración de las charapas como parte

del colectivo TLGBI.

Performatividad y vidas precarias. Aportes de la teoría queer desde

la perspectiva butleriana.

Exilio socio-corporal

Nociones de agencia y biopoder. 
Cultura ético-política como concepto antropológico

Estigma social.

Fundamentalismo cultural, Epistemicidio y Transepistemicidio

La heteronormatividad como régimen disciplinador

Feminidades travestis y trans migrantes: las charapas.

Una comunidad cruzada por el mestizaje, la etnicidad y

los pueblos originarios.

Colonialismo como forma de gobernabilidad.

80

Migración

Migración y globalización.

82

Migración transnacional.

Redes migratorias.

Pueblos originarios. Las charapas como comunidad

pluriétnica proveniente de la selva peruana.

Interseccionalidad

Capítulo 4. Contexto histórico del movimiento

4.1 Construcción y problematización del movimiento

travesti y trans en Argentina.

Primera generación. Los 90: Resistencia y negociación.

Surgimiento de las primeras organizaciones

Segunda generación en los 2000. Crisis social, económica,

política y cultural: Las travestis

y trans también se apropian de las cacerolas.

Tercera generación. Del 2010 en adelante: Avances y retrocesos en la conquista de derechos del colectivo travesti y trans en Argentina. 
Capítulo 5. Identidades golondrinas.

Primeras etapas en la vida de las charapas.

5.1.- Nacer y vivir en territorio enemigo: Infancias travestis y trans

Cuerpo, sentido y lenguaje: la potencia del nombre propio

5.2 Tiranía social y heterosexual.

5.3 Educar para la vergüenza

5.4 Abandonar el Nido

5.5 Vuelan, migran, buscan hacerse en otra costa

Alzar el vuelo

Mito del Progreso

Relación entre madres e hijas putativas

Las charapas y su relación con el espacio físico:

Condiciones habitacionales

Cuerpo, identidad y sentido

Capítulo 6. Arraigarse en la Argentina:

estrategias comunitarias territoriales de organización y construcción colectiva.

6.1. Prácticas político-comunicacionales informales de subsistencia.

Tejido territorial en comunidad: prostitución, vóley, comida, entierro.

El mapa, la fiola y el territorio

Jugar con sus propias reglas

Diversidad Gastronómica

Gestión de la muerte

6.2 Prácticas político- comunicacionales formales institucionales.

Ser desde identidades golondrinas y construir bandadas:

modos y estrategias de organización colectiva plurales y subjetivizantes.

OTRANS ARGENTINA como sujeto político: Los primeros pasos 
Disputa por el espacio público: intentos de traslado de la "zona roja"

al bosque platense

Rechazo al traslado de la "zona roja" al bosque platense.

Núcleos de asociatividad

Capítulo 7. Coalicionar con otres: la construcción de alianzas y estratégicas colectivas 182

La primera gran aliada 183

Plan Patria Grande: Hacia el proceso de regularización migratoria 184

La migración como derecho humano 187

Hacerse visibles: el feminismo, ese lugar incómodo. 188

Reconfiguración del movimiento: Somos Plurinacional 191

Cambio de Identidad en La Plata: XXXIV Encuentro Plurinacional de Mujeres

Lesbianas Travestis Trans Bisexuales y No bineries 192

No estamos todas, faltan las travestis y trans presas 196

Por una comunicación transfeminista, interseccional desde una perspectiva de Derechos Humanos 198

Diversidad cultural e interseccionalidades del movimiento travesti y

trans en Argentina: Otra forma de concebir el Sur 199

Desafíos del movimiento travesti y trans en Argentina 202

La academia como desafío: hacer de lo ajeno un espacio propio. 204

Identidades golondrinas desde una epistemología del despojo:

Conclusiones Finales 213

Bibliografía 225 Anexos digitales 238 
La presente investigación propone una lectura de las prácticas político- comunicacionales en el proceso de constitución de las feminidades travestis y trans migrantes peruanas en La Plata: las Charapas, que en tanto sujetas con capacidad de agencia, habilitan estrategias colectivas, plurales y subjetivizantes, para disputarle al Estado y a otros sujetos políticos la aparición, apropiación y visibilización en el espacio público, una esfera que les había sido sistemáticamente negada.

Así, identificamos en el arraigo en Argentina, un conjunto de prácticas político-comunicacionales informales de subsistencia y prácticas político-comunicacionales formales institucionales, que generan desde el hacer, modos diversos de enunciarse. Este nosotros colectivo, se consolidó a través de un proceso performativo en el que, a la vez que genera el encuentro y la comun-unidad con otras; en el mismo acto, rompe con aquellas hetero-significaciones con las que se des-identifican.

Demostramos cómo aquella cadena de despojos que lleva a las charapas a migrar, encontró en la figura de OTRANS ARGENTINA, la constitución de un sujeto político, que teje alianzas estratégicas con o tres actorxs institucionales para demandar al Estado su reconocimiento como sujetas políticas y de derecho. Allí se inscribe la contribución política del colectivo travesti y trans migrante en la Argentina. Un aporte a la construcción histórica de los movimientos políticos, gestada desde los bordes, resultado de la hibridación de culturas y mestizajes.

La colonialidad y la interseccionalidad que atraviesa las prácticas de las charapas, es una de las características constitutivas y fundantes de lo que denominaremos, a partir de esta investigación, como una epistemología del despojo. Reconocer, que el otre de la relación de conocimiento o gnoseológica es un sujeto igual a mí, permite producir otro tipo de conocimiento y gestar teoría. Apostamos a una agencia performativa y plural que, en definitiva, inaugure una práctica política insurreccional y de resignificación positiva de aquellos despojos. Lo que implicará el reconocimiento de lo que nos constituye, la oportunidad de hablar desde y para nosotras mismas, y generar, a su vez, fecundos espacios transfeministas. 


\section{ABSTRACT}

This research proposes a reading of the politico-communicational strategies of trans and travesti migrant Peruvian femininities in La Plata, focusing on Las Charapas. As subjects with agency, the members of the Charapas enact collective, pluralistic, and subject-affirming strategies that challenge the State-and other political actors-by reclaiming public space (a sphere systematically denied to trans and travesti individual) as a site of trans and travesti resurgence, appropriation and visibility.

I have identified a set of politico-communicational practices at both the informal level (which are primarily geared toward survival), and the institutional level, which emergence in the process of establishing roots in Argentina. By being enacted, not merely enunciated, these practices produce new and diverse ways of enunciating oneself. This collective we/ us was consolidated through a performative process in which, on the very act of generating an encounter, a common-unity with others; there is a rupture with, and a des-identification from, hetero-signification.

In this context, OTRANS ARGENTINA (a non-profit organization based in La Plata) turns into a political subject that resignifies the chain of disenfranchisement that forces las charapas to migrate. It does so by weaving strategic alliances with other political subjects in different institutions to demand from the Statethe recognition of la charapas as political subjects and of rights. This is the space where the political contribution of travesti, trans and migrant collective happens. It is a contribution to the historic construction of political movements created from the borderlands, which is the result of cultural hibridity and mestizajes.

The coloniality and intersectionality, which cut through the everyday practice of las charapas, are foundational and constitutive aspects of what we will name, in this research, an epistemology of dispossession. Recognizing that the other in agnoseological relationship, or a relationship of knowledge is my equal, allows for the production of other types of knowledges and the engendering of theory. We strive for a performative and pluralistic agency that begets and insurgent political practice capable of resignifying those dispossessions in an affirming manner. This will imply the recognition of what constitutes us, the opportunity to speak from and for ourselves; and to generate fertile transfeminist spaces. 


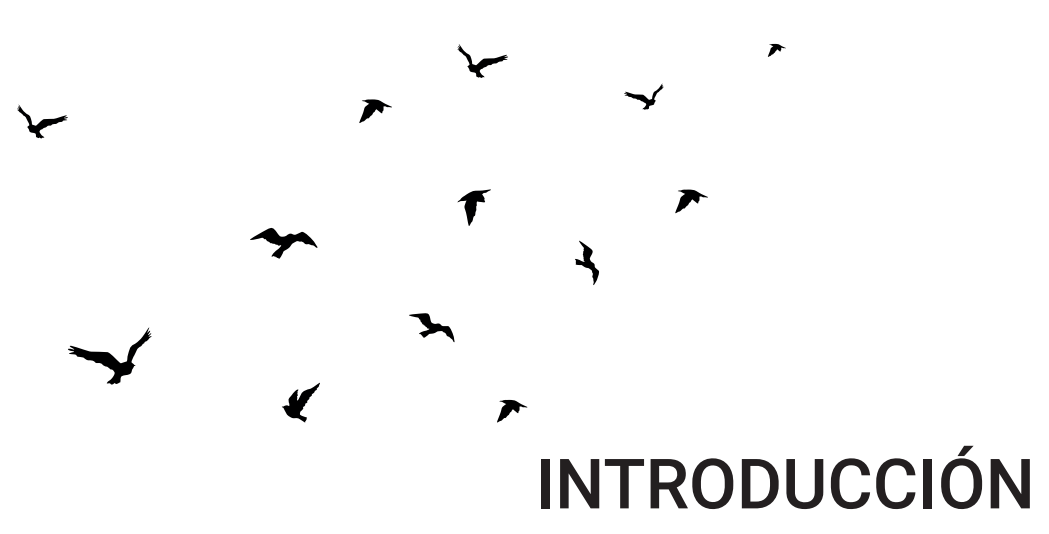


Introducción

La situación histórica de vulnerabilidad que atraviesa el colectivo travesti y trans migrante en Argentina, nos permite problematizar los condicionamientos que sujetan a los cuerpos a ciertos marcos de visibilización y reconocimiento. Así, quienes quedan por fuera de estos marcos normativos quedan desposeídas, lo que implicará una exposición inducida a la violencia del Estado, por acción u omisión.

De esta forma, la presente investigación formula una lectura a las prácticas político- comunicacionales en el proceso de constitución de las feminidades travestis y trans migrantes peruanas en La Plata: las Charapas, que, en tanto sujetas con capacidad de agencia, habilitan modos plurales y colectivos de organización, para disputarle al Estado y a otros sujetos políticos la aparición y apropiación del espacio público.

En este sentido, este trabajo está estructurado en siete capítulos. El primer capítulo está destinado al Estado del Arte, basado en el recorrido bibliográfico de investigaciones precedentes que permitieron la creación del constructo para la investigación realizada. A partir de una aproximación a las múltiples disciplinas que intersectaron el análisis, asumimos, la relación entre género y migración, desde una interpretación crítica resultó necesario problematizar la experiencia a partir de la consideración de: la etnia como un proceso de (des)identificación, la clase como factor determinante, y la prostitución como práctica de común vulnerabilidad entre las entrevistadas, producto de los múltiples condicionamientos que las atraviesan.

En el segundo capítulo, se presenta el diseño metodológico de la investigación, donde dimos cuenta de la perspectiva, técnicas e instrumentos de recolección de información que se utilizaron. La investigación se enmarca dentro de la perspectiva crítica interseccional que parte del reconocimiento a las trayectorias migrantes y a las prácticas de arraigo de las sujetas que forman parte activa de la experiencia, a fin de dar cuenta de los modos agenciales que se construyen desde el colectivo travesti y trans migrante: las charapas.

A tales propósitos, realizamos un recorte en el análisis, circunscribiéndonos a la ciudad de La Plata en el período 2012 al 2019. Para llevar a cabo la recolección de datos se elaboraron entrevistas en profundidad y semiestructuradas a feminidades travestis y trans migrantes peruanas que viven en La Plata. El trabajo de campo estuvo regido a partir de informantes claves con la intención de recuperar las estrategias que se construyeron en el período analizado. Se combinaron técnicas de recolección de información provenientes de 
los estudios de caso y de las biografías. También, se revisaron documentos y materiales provistos por la organización OTRANS ARGENTINA.

La investigación llevada a cabo pretendió hacer una renuncia al monismo metodológico y de método, que procura su abordaje desde una perspectiva única para dar cuenta de toda la realidad, como tendencia estabilizante que instituye un patrón normativo para la investigación social. Este análisis reflexivo, no comprende a las travestis y trans migrantes: las charapas, como objetos de estudio, sino como interlocutoras válidas en una relación de sujeta a sujeta de investigación.

En tanto, en el tercer capítulo presentamos el marco teórico conceptual, enmarcado desde una perspectiva interseccional crítica, a fin de hacer una contribución al campo de la comunicación, y de los estudios de género y la disidencia sexual. En tal intención, nos circunscribimos en una teoría post-fundamento, inscripta en la necesidad de concebir la noción de sujeto y agente político lejos de un centro autónomo de soberanía y conocimiento, como una posición inestable, y como el efecto de constantes re-negociaciones estratégicas de la identidad.

Concebimos para ello, nociones de identidad que hacen hincapié en el aspecto relacional, construido y no estático de las identidades, teniendo en cuenta las transculturaciones que suceden durante el proceso migratorio, tanto para los migrantes como para los habitantes oriundos del lugar de destino.

Asimismo, recurrimos a la noción de identidad de género autopercibida, como un concepto clave para abordar el modo como se identifican y nombran las sujetas de nuestra investigación. También rescatamos el concepto de pertenencia que aporta Ángel Aguirre Baztán, en relación al movimiento de identificación/desintificación que propone Castells. La interdependencia de los conceptos de identidad y alteridad se comprueba en las reflexiones de López Aranguren.

Por otra parte, recuperamos los postulados de Rosana Guber, respecto a que somos sujetos cognoscentes y que todo sujeto cognoscente parte del desconocimiento al reconocimiento. En esta misma línea, serán clave los diálogos establecidos con los trabajos de Cantelli, Pereira, Oliveira, Tozo, \& Nogueira, respecto al concepto de transepistemicidio. Abordar, en este sentido, la identidad en tanto constructo no esencialista, ni reificado nos conduce a dimensionar el concepto de núcleos de asociatividad de Adriana Archenti, para entender las formas de organización/actuación/intervención que desde los "intersticios" posibilitan formas de filiación/pertenencia/participación. 
En esta línea, recuperamos el concepto de precariedad de Judith Butler, el cual designa una condición impuesta políticamente que maximiza la vulnerabilidad. Así mismo, sus aportes sobre la performatividad del género, nos permite analizar las posibilidades que tiene el género de abrir fronteras culturales que pudieran confrontar las hegemonías de los regímenes institucionales.

En este sentido, los conceptos de precariedad y performatividad del género se constituyen en constructos interdependientes para comprender las estrategias que tejen colectivamente las sujetas de nuestra investigación "las charapas" con el objetivo de hacerse visibles en el espacio público, en tanto ámbito privilegiado de disputa.

En continuidad con esta lectura, retomamos el concepto de exilio socio-corporal de Verónica González, entendido como un gesto simbólico, mediante el cual se garantiza la "pureza" de ciertos tipos ideales y del imaginario de "lo público". Para cuestionar qué es una vida, qué valor tiene, cómo ha de reproducirse y en qué condiciones.

Siguiendo esta ruta, recuperamos los aportes de Michel Foucault, sobre su teoría de la bio-política, en relación con las técnicas de biopoder y anatomopolítica. En función de la sexualidad como mecanismo de producción disciplinar del cuerpo y las regulaciones poblacionales. En este sentido, es importante rescatar los conceptos de táctica -como recurso del débil para contrarrestar la estrategia del fuerte-, y estrategia -como la "manipulación" por parte del sujeto con poder-, desarrollados Michel de Certeau.

Asimismo, recuperamos el término epistemicidio acuñado por Boaventura de Sousa Santos para reflejar la influencia de la colonización europea y del imperialismo capitalista. Entendido como el aniquilamiento de conocimientos, de saberes y de culturas no asimiladas por la cultura blanca/ occidental. Siguiendo las pautas de Gloria Anzaldúa, resulta valioso destacar su manera de concebir la hibridación de razas o mestizaje. Las cuales involucran espacios de existencia y conectividad a estratos identitarios e interpersonales para las personas migrantes en el marco de una realidad socio-económica dada. Cuando se juntan dos marcos de referencia, coherentes en sí mismos, pero normalmente incompatibles el uno con el otro, se produce un choque, una colisión cultural. 
La colonialidad es también una realidad que atraviesa transversalmente la grupalidad de las charapas. En figuras como Franz Fanon y Aimé Cesaire, encontramos grandes precedentes significativos a la hora de abordar la problemática del colonialismo para América Latina. Este concepto relacionado al criterio de gobernabilidad de Michel Foucault, dan cuenta de cómo las colonias fueron un ámbito de ejercicio por excelencia de esta forma de gobernar. A su vez, recuperamos el concepto de Douglas Massey, sobre redes migratorias, las que sirven para entender las relaciones interpersonales que conectan a les migrantes en las áreas de origen y destino mediante lazos de parentesco, amistad y de compartir un origen común.

Por otro lado, retomamos la perspectiva de la Investigación-Acción- Participativa, como un modo de producción alternativo, la cual tiene relevancia para la práctica social y política. En esta misma línea recuperamos los aportes de Abatedaga y Siragusa, respecto a la praxis comunicativa, que permite pensar los procesos de auto reconocimiento y auto constitución identitaria que serán fundamentales a la hora de comprender las prácticas político/comunicacionales, siguiendo a Sergio Caletti, no solo desde su dimensión política sino comunicativa.

En el capítulo cuatro, se reconstruye una historización del movimiento travesti y trans en la Argentina, a partir del cual dimos cuenta de la articulación de este movimiento y la inscripción de las feminidades travestis y trans migrantes peruanas, las charapas. Además, nos permitió dimensionar las acciones colectivizantes que potenciaron las dinámicas político-comunicacionales en el contexto de las luchas y reclamos por la exigibilidad del cumplimiento pleno de sus derechos y el ejercicio de la ciudadanía.

El movimiento travesti y trans, implicó la consideración de ciertas especificidades para su análisis, como así también para la construcción de una historia propia, narrada y escrita por quienes la han protagonizado. Es el resultado de las luchas emancipatorias de los últimos 30 años. Esto, permitió configurar un colectivo con agenda propia, y con una lectura clara sobre la responsabilidad del Estado y sus instituciones. Asimismo, ha generado alianzas estratégicas para visibilizar sus reclamos, entendiendo a sus integrantes como sujetas políticas e interlocutoras válidas.

De esta forma, se estableció una primera generación de feminidades travestis y trans: la primera en la década de los ' 90 , la segunda en el ' 00 y, la tercera, del ' 10 en adelante. En este contexto las charapas, comienzan a pensarse en términos de colectivo organizado, en la ciudad de La Plata. Así nace el 12 de julio del 2012 OTRANS ARGENTINA, con el objetivo de ser una organización de la sociedad civil sin fines de lucro, al calor de la sanción de la Ley de Identidad de Género. 
En el capítulo cinco, damos cuenta de las primeras etapas de vida de las sujetas de nuestra investigación, donde comienzan a expresar su identidad de género desde niñas, lo cual da lugar al origen del "conflicto", en torno a sus relaciones en el seno familiar. Allí, experimentaron violencia verbal, psicológica, simbólica y física. Las cuales se van a reproducir con mayor crudeza en el barrio, la escuela, la comisaría, y las calles de las ciudades donde transitan.

Estas violencias asentaron sus bases en el dogma vinculado a las creencias y los fundamentalismos religiosos; y en el discurso biologicista relacionado a la reproducción de la especie humana. Mientras que sus experiencias en las instituciones educativas, también estuvieron marcadas por prácticas violentas, donde aparece el discurso militar y religioso en su formación, disciplinamiento y control de sus cuerpos.

Las charapas abandonan sus hogares desde muy chicas, en busca de lugares menos hostiles: la totalidad de ellas transitan un mecanismo de desarraigo inducido. En ese marco, comienzan sus primeras experiencias laborales, en condiciones de precarización, situaciones de violencia y discriminación por parte de sus empleadores y de los clientes a quienes les brindaban sus servicios; una etapa donde la prostitución se presenta como "destino" petrificado.

Tanto la migración interna como externa se da en la búsqueda de nuevas oportunidades y la necesidad de reafirmar su identidad de género. A partir de la experiencia común del desarraigo, estas configuraciones se construyen en lo que denominamos como identidades golondrinas, que habilitan el tejido de nuevas prácticas, desplazan los vínculos de consanguinidad e inscriben nuevos lazos de sociabilidad; lo que les permite, a su vez, disputar y apropiarse del territorio, en el trazado de esa cartografía, durante el viaje y su arribo, permanentemente.

A tales propósitos, en el capítulo seis, identificamos en el arraigo a la Argentina y, más específicamente, en la ciudad de La Plata, un conjunto de prácticas informales de subsistencia como la prostitución, el vóley, la gastronomía y el entierro; que sedimentaron en la praxis, en su vinculación y disputa con otros interlocutores.

Demostramos cómo aquella cadena de despojos que lleva a las charapas a migrar al país, construyó privilegiadamente, a través de la figura de OTRANS ARGENTINA, un sujeto político que se consolidó, también, mediante otras prácticas político-comunicacionales formales institucionales. Desde allí, se constituyen y crean en coalición con otres; la organización de demandas al Estado por su reconocimiento como sujetas políticas y de derecho; y por tanto, generan las condiciones para disputar su visibilidad, es decir, una esfera de aparición que les había sido sistemáticamente negada. 
Por último, en el capítulo siete, hacemos una lectura sobre estas prácticas que se cimentaron en modalidades y estrategias que definimos en términos colectivos, plurales y subjetivizantes. A partir de acciones institucionales específicas, y desde un espacio de militancia y trabajo territorial formal, analizamos cómo las charapas planificaron y tejieron tales estrategias de resistencia y visibilización, demandas de derechos y políticas públicas, y memorias de la resistencia.

Allí inscribimos el aporte político del colectivo travesti y trans migrante en la Argentina, en general y, particularmente, de OTRANS ARGENTINA, que fue imprescindible en la disputa, apropiación y consolidación desde adentro de los espacios feministas, que históricamente habían sido orquestados colectivamente por mujeres, lesbianas y otras identidades. Esto permitió revisar en la historia de los movimientos políticos, una gesta construida desde los bordes, una historia subversiva y alejada del mainstream.

Con todo, concluimos que esta construcción desde los bordes o fronteras, fue resultado de la hibridación de culturas y mestizajes. Las charapas, al provenir del Perú y de la región selvática con mayoría poblacional de pueblos originarios, donde las imposiciones del hombre blanco condicionan sus historias de vida, y deja huellas indelebles en la cosmogonía de su comunidad. Por lo tanto, diremos que la colonialidad que atravesaron, transversalmente, las prácticas de las charapas, es una de las características constitutivas y fundantes de lo que denominamos una epistemología del despojo.

Pensar la epistemología del despojo implica, no olvidarse de eso que las constituye desde los primeros años de vida. Un despojo que les permitió ser charapa como una subjetividad de trinchera. $Y$ en tanto tal, organizarse y coalicionar con otres para ser tenidas en cuenta como sujetas parlantes; y desde ese lugar común, potenciar la agencia. Para fundar una epistemología del despojo, es clave partir de algunos pilares comunicacionales; por eso, apostamos a un trabajo sobre un ejercicio crítico a la interdependencia que nos une, de la memoria activa de les otres, del autoconocimiento o cuidado de sí, y un profundo sentido de interrelación o corresponsabilidad. 


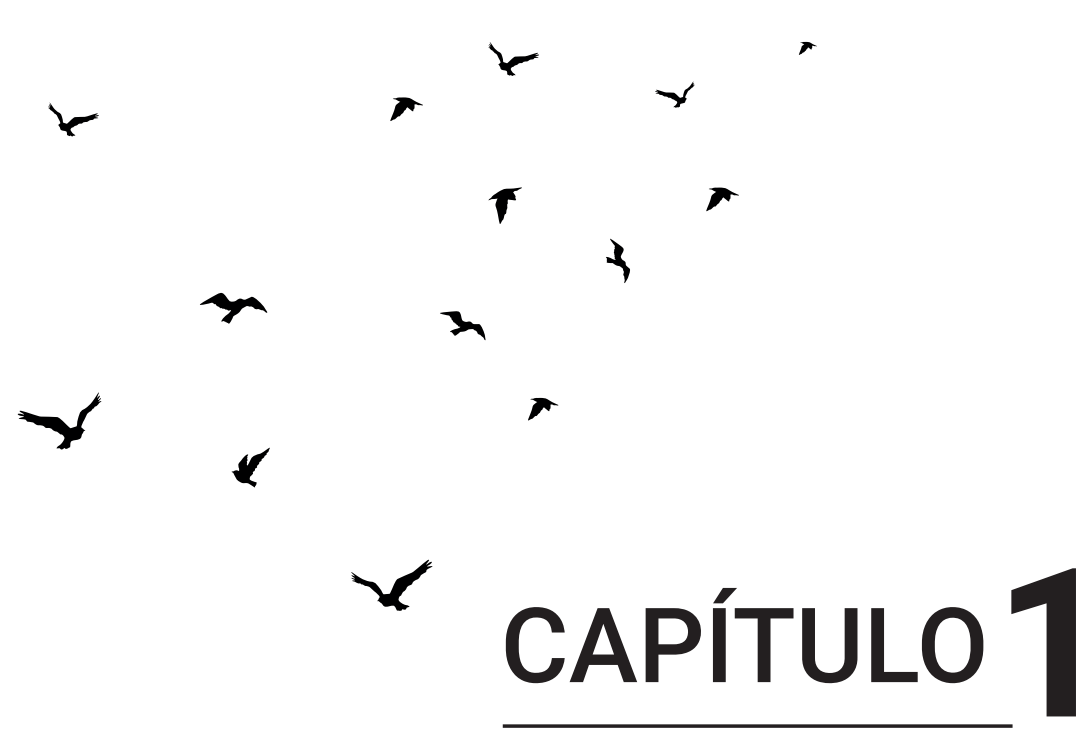

Estado del Arte. 
Capítulo 1.- Estado del Arte.

La interseccionalidad con la que se aborda la presente investigación, permite un acercamiento interdisciplinario a la problemática que se plantea, lo que resulta un aporte a los estudios académicos de las ciencias sociales en general, y al campo de la comunicación social, en particular. Al mismo tiempo, pretende contribuir a la construcción de una memoria viva del movimiento travesti y trans en Argentina, a través de la compleja articulación que supone hacer una lectura sobre las identidades de género, y los procesos de participación y consolidación de diversos espacios políticos-formativos que habilitan en su constitución, en clave de la migración, la clase, la raza y la etnia.

En este sentido, asumimos primeramente, la relación entre género y migración. No obstante, a partir de la interpretación crítica, resultó necesario problematizar la experiencia a partir de la consideración de: la etnia como un proceso de (des)identificación, la clase como factor determinante, y la prostitución como práctica de común vulnerabilidad entre las entrevistadas, producto de los múltiples condicionamientos que las atraviesan.

De esta manera, iniciamos el recorrido por las investigaciones precedentes a través de la consideración de todas aquellas que se constituyeron interlocutores a la hora de abordar el estudio de caso sobre las feminidades travestis y trans migrantes peruanas: las charapas. 


\section{Las Adelantadas:}

En el trabajo de tesis de grado de Claudia Vásquez Haro: “Configuraciones de identidades trans en medios gráficos argentinos: nociones identitarias en disputa. Buenos Aires 1998-2005", recuperamos aportes sustanciales que sirven como antescendentes para la presente tesis doctoral.

Dicha publicación, da cuenta de una historia del movimiento de diversidad sexual en Argentina. Ya en 1967, activistas comunistas del Sindicato de Correos conforman en Gerli el núcleo de una agrupación: Nuestro Mundo. Un año después aparecen otras organizaciones: Bandera Negra (homosexuales anarquistas), Grupo Safo (lesbianas), Grupos de Cristianos Gays y el famoso Grupo Eros, en el cual militaba Néstor Perlongher. En 1972, los grupos deciden confederarse en el Frente de Liberación Homosexual (FLH), que rápidamente será conducido por Néstor Perlongher. La estrategia política del FLH fue acercarse a la izquierda peronista y trotskista para intentar articular consignas. Sin embargo, esta estrategia tendrá sus inconvenientes debido a la fuerte discriminación hacia mujeres y varones homosexuales en la época. Finalmente, el Frente se une a sectores de la izquierda en el FAS (Frente Antiimperialista y Socialista), donde militaba el mítico dirigente sindical Agustín Tosco. Sin embargo, sus integrantes no eran valorados como pares, más bien escondidos en marchas y actos públicos, por lo que en 1974 se decidió comenzar un camino de autonomía junto con activistas feministas con quienes se formó el Grupo Política Sexual que realizó un acto público cuando el gobierno de Isabel Perón prohibió los métodos anticonceptivos en el sistema público de salud. En 1975, el FLH decide pasar a la clandestinidad frente a la situación represiva de la Triple A y se convierte en un grupo cuasi secreto que se dedica a la concientización de homosexuales y a la lectura de material llegado al país desde Estados Unidos y Europa. En 1976, el FLH se auto-disuelve, muchxs de sus activistas desaparecen o se van al exilio, mientras otros/as se pliegan a una "retirada" interna hacia ciudades menos cuadriculadas del Gran Buenos Aires, especialmente las islas del Tigre.

Llegado el año 1982 y con la dictadura cívico-militar en picada, muchos homosexuales, sobre todo varones, comienzan a formar grupos de autoconciencia: Grupo de Acción Gay, Grupo San Telmo, entre otros que forman parte del nuevo clima de época democrática que se va gestando. El flamante presidente Raúl Alfonsín contó con la simpatía de la comunidad gay porteña, que festejó en la avenida Santa Fe el día 10 de diciembre con un baile en la calle. Pero la alegría se terminaría pronto con las razzias policiales que se incrementaron en 1984, cuando Antonio Tróccoli asume como ministro del Interior. En ese marco, las 
agrupaciones deciden federarse y conformar la $\mathrm{CHA}$ (Comunidad Homosexual Argentina), que al igual que el FLH fue, en sus inicios, una confederación de grupos. En 1985 emiten un documento denominado "Política en sexualidad en un Estado de Derecho" donde articulan el libre ejercicio de la sexualidad con la agenda de derechos humanos que en la Argentina cobró vigencia a partir del informe Nunca Más de la Comisión Nacional sobre la Desaparición de Personas (CONADEP) y los juicios a las Juntas Militares. Alrededor de 1988 comienzan a surgir grupos independientes de lesbianas, sobre todo "separatistas" (no trabajan con varones), que tienen contactos con la CHA: Convocatoria Lesbiana, Las Lunas y las Otras.

Recién en el año 1991 aparecen las travestis y trans en la escena de la militancia y en la escena pública y de los medios. Por primera vez aparece una travesti, Keny de Micheli, integrante de la organización Travestis Unidas (TU) en el programa Almorzando con Mirtha Legrand, donde se presenta como activista y candidata a diputada por el Frente Democracia Avanzada. Esta aparición fue un hito si tenemos en cuenta que cinco años antes el periodista José de Zer y el Canal 9 afrontaban juicios por mostrar y denunciar, con recursos testimoniales, las muertes de travestis que trabajaban en Panamericana. El recibimiento de Kenny de Micheli implica una primera ruptura en el ocultamiento e invisibilidad que existía hasta entonces sobre el colectivo trans. Claro que esta aparición fue rápidamente banalizada, presentando a Kenny como un personaje pintoresco. En este primer momento se ve al travestismo como una expresión exagerada de la feminidad, pero disponible para el consumo de la masculinidad.

La primera reunión como ATA (Asociación de Travestis Argentinas) estaba integrada por quince compañeras, y se llevó a cabo el 25 de junio de 1993 para denunciar el maltrato policial e institucional. Marcela Romero, una activista fundadora de esta asociación, señalaba que "por ese tiempo no podíamos salir a tomar un café o ir al cine, tomar un subte o el micro, por ser detenidas constantemente por la policía amparada en edictos. Cosas tan sencillas y cotidianas para otros, para nosotras eran un lujo. Sabíamos que estábamos cansadas de vivir así, pero no sabíamos para dónde arrancar, pero no obstante el grupo se mantenía muy unido, nos mandábamos comida y frazadas para la estadía en los fríos calabozos. Tengo que aclarar que en Capital Federal eran 24 horas, pero en las provincias eran 5,10 y hasta 30 días".

La primera reunión fue para presentar a ATA en la reunión organizadora de la segunda marcha gay, como se denominaba en ese tiempo y que para el colectivo travestis y trans fue la primera. De acuerdo con los testimonios, la integración fue compleja. Sin embargo, se pudo articular trabajo en conjunto. En el año 1993, el primer contacto fue con Carlos Jáuregui, integrante de Gays por los Derechos Civiles, que invita a las travestis y trans a organizarse. Las lesbianas discutían el género de las trans y alentaban a que estos grupos se alinearan con los gays, por considerarlas unas de las tantas versiones de esta orientación 
sexual. Los gays oscilaban entre el maravillarse por el glamour travesti y el rechazo a éste. Aquí se dio lo que podemos considerar la primera lucha por la visibilización y producción de sentido.

Por esa misma época, la revista gay NX organiza encuentros para debatir la problemática de las "minorías sexuales" y las asociaciones de travestis y trans son invitadas. Allí se testimonió y se fue generando cierta sensibilización de los/as activistas. Allí se convoca al Primer Encuentro Nacional Gay, Lésbico, Travesti, Transexual y Bisexual, que organiza el Colectivo Arco Iris en Rosario. Las organizaciones trans presentan la obra de teatro Una noche en la comisaría. Fue en ese marco que las organizaciones gays y las lesbianas allí presentes pidieron disculpas por los prejuicios que habían marcado la relación con el colectivo trans. Rosario marca un antes y un después. Conocer a las mujeres feministas ubica al colectivo frente a una serie de preguntas vinculadas con la identidad: ¿Qué somos las travestis? ¿Somos varones? ¿Somos mujeres? En la búsqueda de respuestas a estos interrogantes, se crean dos organizaciones más: Asociación Lucha por la Identidad Travesti y Organización de Travestis Argentinas. Transcurre por entonces el año 1995. En la acotada binariedad masculino/femenino, las travestis comienzan a usar el femenino.

El primer espacio universitario que se articuló con el movimiento fue el Área de Estudios Queer y Multiculturalismo de la Universidad de Buenos Aires, que desarrollaba sus actividades en el Centro Cultural Ricardo Rojas. Desde su fundación, organiza reuniones semanales, cada vez más numerosas, en las cuales cada une de les presentes plantea sus necesidades y se implementa una política conjunta para hacer frente a las agresiones y detenciones policiales, específicamente. Ese proceso implica la concientización de las integrantes del grupo, el cual surge de la necesidad de denunciar cada una de las violaciones a sus derechos. En este marco de trabajo conjunto, distintos tribunales comienzan a recibir diariamente dichas denuncias. Como resultado se logra que las detenciones sean menos frecuentes. Antes de fundar la organización, las trans eran detenidas de tres a cuatro veces por semana. Este índice se redujo a una o dos detenciones cada diez días. En palabras de Claudia Pía Baudracco, "pusimos a prueba nuestro ingenio para realizar acciones diferentes en cada detención, que despertó la reacción policial, quienes implementan nuevas formas de persecución. Como utilizamos otros domicilios particulares para las reuniones, volvemos a tener allanamientos, en donde se nos acusa de ejercer la prostitución".

En el año 1994, a raíz de un allanamiento, surgió la necesidad de darle una forma más concreta a la asociación. Distintas organizaciones no gubernamentales dieron su apoyo, especialmente la organización Gays por los Derechos Civiles y la Iglesia Metropolitana, que comenzaron a trabajar en distintos objetivos de manera conjunta con ATA. 
En ese momento, y desde hacía casi cincuenta años, en la ciudad de Buenos Aires existían los Ilamados edictos policiales. Estos edictos eran una especie de "pequeño código penal” por el cual se regía la Policía Federal, que a su vez era, de modo inconstitucional, el organismo de aplicación. Estos edictos permitían detener a una persona hasta 21 días. El artículo que aplicaban a las personas trans era el de “Escándalo”, que rezaba: “Art. 2) Serán reprimidos con multa de 600 a 2100 pesos o con arresto de 6 a 21 días... Los que se exhibieren en la vía pública o lugares públicos vestidos o disfrazados con ropas del sexo contrario".

Para luchar contra esta represión policial, se organizaron charlas semanales en donde se les aclaraba a las trans qué podían hacer y cuáles eran los derechos que tenían como ciudadanas. En ese momento, las trans pasaban un promedio de cinco días por semana detenidas.

Entre los objetivos que se propuso ATA y que logró, estuvo visibilizar a las trans como sujetos de derechos. Se utilizaron distintas estrategias, como cambiar la vestimenta, adoptando en las diferentes marchas y manifestaciones una remera fucsia con el logo de la organización, un triángulo turquesa, que las identificó ante los medios de prensa lejos de la típica imagen de prostitución. A pesar del crecimiento de la organización, se producían amenazas constantes a la vida de muchas militantes, acoso reiterado por parte de la fuerza policial, acusaciones falsas que implicaban gastos innecesarios de dinero para defenderse.

En año 2001, el grupo decide nacionalizar el movimiento y aumentar la presencia de "T" en su sigla, para representar al grupo trans. La agrupación pasa a llamarse ATTTA: Asociación de Travestis Transexuales Transgéneros Argentinas. Por un lado, se incluye a las autodenominadas transgéneros y, por el otro, se federaliza la comisión directiva al formar una comisión con activistas trans de las distintas provincias de la Argentina, creando sedes en todo el territorio. Frente al conflicto surgen distintas estrategias, lo que también implicó la segmentación de las organizaciones de travestis y trans: de ATTTA surgirá ALITT (Asociación de Lucha por la Identidad Travesti y Transexual) y OTTRA (Organización de Travestis y Transexuales de la República Argentina). Esta división no sólo fue estratégica, sino también ideológica, en tanto ATTTA y OTTRA sostendrán el discurso del "trabajo sexual”, al cual ALITT se opuso desde una concepción abolicionista de la prostitución. Las tres organizaciones desarrollaron "unidad en la acción" a partir de sus diferencias, y compartían articulaciones con los movimientos de gays y lesbianas, mientras ALITT privilegió una alianza con el feminismo. Entre el año 1995 y 2005 las organizaciones trans se fortalecen trabajando con otras organizaciones, la relación con la academia y distintas articulaciones con partidos políticos. De grupo de reflexión y presión, las travestis y trans comienzan a producir agendas que van desde la lucha contra el VIH y sida, la violencia policial, la prostitución y los derechos sociales. Las trans porteñas operan políticamente desde 1991 a la fecha y constituyen uno de los colectivos más dinámicos entre los movimientos sociales. La noción de "identidad de género" fue incorporada, alrededor de los años '90, por una segunda generación de ac- 
tivistas. Leemos en el trabajo "Transgeneridad: la construcción/deconstrucción de nuestra identidad" elaborado por Lohana Berkins, activista del grupo Asociación de Lucha por la Identidad Travesti y Transexual: "Elijo la palabra travesti porque es importante resignificar el término con el cual se refieren a nosotras. Acepto que hemos sido criadas con toda una carga patriarcal, pero somos, como las mujeres, traidoras del patriarcado, y eso es algo que muchas tenemos que pagar con nuestras vidas... El género que queremos construir no es el femenino, pero no podemos negar que algunas de las características que asumimos se encuentran en las mujeres". La historia que sigue, ya es presente.

\section{Migrantes transgénero en México: éxodo de violencia y discriminación}

En esta investigación periodística publicada en el 2017 por Ana Luisa Guerrero, para el portal Cienciamx Noticias, la cual analiza la migración en la frontera sur de México en los últimos años, y cómo ha experimentado un ascenso en el número de personas que se identifican como LGBTI, en particular feminidades trans-travestis provenientes de los países del Ilamado Triángulo Norte, conformado por Guatemala, Honduras y El Salvador.

Este fenómeno se observa principalmente en los albergues para migrantes localizados en los municipios fronterizos de Tenosique, Tabasco, Tapachula y Chiapas, donde esta población busca pasar desapercibida entre los cientos de niños, mujeres y varones que hacen paradas en busca de alimentos, servicios de salud y un sitio donde dormir.

Aunque a la fecha no existen datos oficiales sobre el flujo migratorio en el sureste mexicano, organizaciones de la sociedad civil estiman que 400 mil personas en situación irregular cruzan anualmente la frontera con Guatemala.

En 2015 se inició el proyecto exploratorio "Diversidad sexual y movilidad forzada en la frontera sur de México", con el propósito de conocer y documentar las experiencias que tuvieron en su lugar de origen, cómo vivían y qué impulsaba su huida a las personas LGBTI; además de saber cómo es el proceso de cruzar la frontera, así como los proyectos que tienen a futuro.

Los resultados apuntaron a que la mayoría huye de la violencia de género por no cumplir los roles asociados a un hombre o a una mujer. Derivado de ello, el abuso sexual, la tortura y el homicidio son una constante para esta población, por lo que se desplazan buscando condiciones más seguras y dignas para vivir. 
En las más de 50 entrevistas en profundidad que fueron aplicadas, se observó que el rechazo familiar por cuestiones de la identidad de género es la primera confrontación que vi, debido a que no son aceptados por transgredir las normas sociales que son regidas por el patriarcado y condicionadas por la religión.

A ello se suma el rechazo social. En el caso de las mujeres trans, salir a la calle significa estar expuestas a burlas, insultos y agresiones; por lo que se mueven en condiciones clandestinas -tanto en sus países de origen como en su ruta de desplazamiento- para evitar ser víctimas de violencia.

Marginación social:

Culturalmente se define el género a partir de la diferencia sexual, basándose en los atributos, roles y comportamientos de acuerdo con el sexo: una concepción binaria hombre-mujer. Así, las expresiones diferentes a la heterosexualidad transgreden los parámetros sociales, por lo que son objeto de marginación. El nivel de distrés que presentan las personas trans es explicado por el rechazo familiar -comenta Ana Fresán Orellana, investigadora del INPRFM-, pues aquellos que experimentaron marginación en su hogar tenían cinco veces más probabilidad de padecerlo; en tanto que el deterioro social se explica por la exclusión de sus compañeros y la violencia física que vivieron.

Concluyeron que no es la condición transgénero por sí misma la que conlleva al distrés y al deterioro funcional, sino la violencia y discriminación que constantemente padecen, impactando, además, en su funcionalidad y calidad de vida.

Búsqueda de oportunidades:

Una vez instaladas en México, las mujeres transgénero centroamericanas deben sortear múltiples obstáculos. El primero es la discriminación, pues el imaginario social las señala como trabajadoras sexuales o portadoras de $\mathrm{VIH}$, a pesar de que en los últimos años ha habido un intenso trabajo gubernamental y de asociaciones civiles en temáticas de diversidad sexual, apunta Miguel Lucero, doctorando de El Colegio de la Frontera Norte (Colef) y quien realiza una investigación desde un enfoque sociológico sobre el desplazamiento forzado de las mujeres trans migrantes de Honduras y El Salvador. 
Refiere que esta población demanda oportunidades laborales, pero es segregada del ámbito formal por prejuicios sociales, y para subsistir terminan ejerciendo el trabajo sexual, con los riesgos que implica esta actividad para su salud y seguridad.

Muchas de las mujeres transgénero que se establecen en la Ciudad de México terminan laborando en Puente de Alvarado - una zona de tolerancia para el comercio sexual de personas LGBTI- donde deben pagar unas cuotas semanales de 300 pesos, expuestas a redes de trata y al tráfico y consumo de drogas. Salir de este círculo, les resulta muy difícil.

Aquellas con mayor suerte son contratadas de ayudantes en restaurantes o cocinas económicas, como personal de limpieza o asistentes en comercios; en Tijuana, una de las ciudades mexicanas a donde más se desplazan, las contratan para la fabricación de artesanías y manualidades.

En su intento por sobrevivir, las migrantes trans se desplazan a urbes grandes y diversas como Guadalajara, Ciudad de México y Tijuana, donde es más fácil invisibilizarse y moverse con mayor libertad. Sin embargo, ahí también deben desafiar problemas severos, como conseguir un sitio donde vivir, pues pocas logran que les sea rentada una casa.

Como si lo anterior fuera un desafío menor, ser reconocidas legalmente con el género en que se identifican es una gran dificultad. Y es que muchas de ellas pierden sus papeles de identidad en el camino y recuperarlos suele ser complicado.

Nakay Flotte, estudiante de doctorado en antropología en la Universidad de Harvard, describe el sinuoso procedimiento al que se enfrentan las migrantes transgénero cuando se acercan al consulado de su país en busca de sus documentos. $Y$ es que se les expiden con su género de nacimiento, además que para otorgarlos las obligan a presentarse como hombres: quitarse el maquillaje, recogerse el cabello y vestirse de varón; es decir, no las reconocen como son.

La también organizadora de Diversidad sin Fronteras, un colectivo de investigación etnográfica que acompaña a migrantes LGBTI en México, señala que a la misma situación se enfrentan cuando solicitan el refugio ante la COMAR. El procedimiento es engorroso y tardado. Les lleva aproximadamente tres meses y durante ese tiempo no pueden salir de la ciudad en que lo tramitaron. Muchas recurren a los albergues, o bien al apoyo económico (alrededor de mil 300 pesos mensuales) que les brinda la ACNUR para alimentación y pago de renta. 
Ante el acoso de los grupos criminales (sobre todo en la frontera sur) o porque se desesperan de no poder resolver su situación, muchas piden que se transfiera su caso a otra ciudad, o bien desisten del proceso emprendiendo su camino rumbo a Estados Unidos en busca de oportunidades.

A quienes se les otorga el refugio u obtienen la visa que avala su estancia regular en México, los documentos no reconocen su expresión de género, señala Irazú Gómez Vargas, responsable de la Coordinación de Incidencia y Vinculación de Sin Fronteras, IAP, organización civil que brinda asesoría jurídica y psicológica a refugiados en nuestro país.

El que su documento contenga nombre e identidad de hombre es un factor de rechazo sistemático para acceder a los servicios de salud, a oportunidades laborales, conseguir el alquiler de una vivienda o continuar sus estudios.

Ello incluso en la capital del país, donde a pesar de que existe un procedimiento administrativo para simplificar el trámite de cambio de sexo en el acta de nacimiento, es inaccesible para personas refugiadas o con estancia regular, al estar destinado sólo a aquellas con nacionalidad mexicana.

El diagnóstico «iLo que no tenemos y necesitamos se llama inclusión!», elaborado por Sin Fronteras, detectó que las reglas de operación de los programas sociales en la Ciudad de México no son totalmente inclusivas, pues solo tres por ciento de ellos acepta documentos migratorios como papeles de identidad, impidiéndoles el acceso.

Por otra parte, la tesis de grado de Bárbara Cornelli Colombatto de la Facultad de Periodismo y Comunicación Social-UNLP “Mi cuerpo... i¿qué no ha dado?! El cuerpo travesti como espacio de comunicación", da cuenta de las experiencias y relatos de vida de diez entrevistadas trans que habitan la ciudad de La Plata, haciendo visible lo que la presencia de sus cuerpos sexuados, migrantes y diversos comunican. Las palabras de las entrevistadas muestran cómo los parámetros de normalidad en torno a la sexualidad se sostuvieron en el tiempo despojando de sus derechos a las personas trans. A su vez observa que la mayoría de ellas ha relegado ocupar ciertos lugares, cumplir ciertos deseos o reclamar sus derechos. A pesar que en los últimos años se ha convertido en un tema con resonancia en los medios de comunicación, el lenguaje utilizado continúa siendo sexista. Aun habiendo alcanzado cierta visibilidad y generado ciertos debates respecto a la legislación vigente, en la mayoría de los casos ese universo resulta a la vez ajeno y desconocido. 
El lugar de la comunicación en su investigación cobra importancia, como lo destaca Jesús Martín Barbero (1988), para rescatar la memoria popular que adquiere su sentido no desde la búsqueda de una recuperación nostálgica, sino en la oposición a ese otro discurso que la niega y frente al que se afirma una lucha desigual. La intención de abarcar esa memoria de lo popular apunta a poder dar cuenta de una totalidad de circunstancias que configuran la cultura, entendiendo que "la noción de totalidad" que utiliza, recupera una visión comprensiva, abierta y dinámica que cuestione las interpretaciones parcializadas y permita incluir lo excluido, es decir señala los silencios (Argumedo, 1996).

Así mismo toma una mirada desde la antropología para sostener que la interdisciplinariedad contribuye a una visión integradora que fortalece las aristas desde las cuales se observa y se estudia el objeto seleccionado. “...el antropólogo social como elaborador de conocimiento científico se ha ocupado fundamentalmente de distancias culturales -que son también sociales (...) (para) dar cuenta de la alteridad que le permita superar los límites tanto del sentido común como de los siempre perfectibles paradigmas teóricos. El antropólogo social se ocupa de producir la diversidad, gracias al descentramiento de sus propios parámetros" (Guber, 2014. p. 72). Es así que se plantea la actitud antropológica de extrañarse frente a la propia experiencia y los propios juicios aprendidos, sin considerarlo necesariamente aprehendidos. Se mira entonces al entramado social como una red que busca parecer siempre conectada, aparentar completamente inclusiva, pero que se consolida en dejar varios cabos sueltos y encuentra argumento para dejarlos aislados y desprotegidos.

También resulta interesante retomar de su trabajo de investigación la teoría semiótica de Charles Sanders Peirce (1974), y en Juan A. Magariños de Morentin (1991) quienes sostienen que nuestro modo de acceder al mundo es a través de los discursos que circulan y se nos representan a través de los otros. Así el lenguaje y la comunicación entre las personas, se interpreta como una relación de sustitución. Se sustituye, al nombrar, al objeto por la palabra. Es decir, la comunicación, en su investigación fue mirada desde el mismo lugar sustitutivo. Teniendo la conciencia de que la palabra conforma una idea que es arbitraria sobre el objeto/sujeto que representa, así accedió a las representaciones individuales que tienen ciertas personas sobre sí mismas y particularmente sobre sus cuerpos.

El cuerpo es el objeto material que presenta a los sujetos frente al mundo y sobre el cual se establecen juicios al utilizar palabras que ya cuentan con una carga de sentido. Según Peirce nada queda por fuera de la significación, pero qué ocurre cuando esa significación es siempre interpretada por fuera del sujeto y lo fija de algún modo en ciertos lugares marginales de la sociedad. Entonces, Cornelli Colombatto se pregunta ¿qué mirada tienen de estas significaciones las sujetas que las portan? Por otro lado, cobra importancia el camino que recorrió desde un marco feminista, por el logro que este tuvo de transformar en 
políticas ciertas discusiones que no eran tomadas como tales. Shulamith Firestone (1976), en Dialéctica del sexo formula al feminismo como un proyecto radical. Tomando herramientas del marxismo y del psicoanálisis. Además, parte de un principio del materialismo histórico según el cual la humanidad sólo se plantea los problemas que puede resolver. Este principio resulta interesante para mirar las posibilidades de cambio y de acción sobre las problemáticas en estudio.

En este sentido, desde el feminismo la noción de cuerpo ha sido mirada y evaluada con nuevos ojos. Según Scheper-Hughes y Lock (1987) plantean que, desde la época clásica y el cristianismo, el cuerpo es visto como un fenómeno peligroso y amenazante si no se lo controla y regula por un proceso cultural. Es un vehículo o recipiente de lo ingobernable, las pasiones irracionales, los deseos y las emociones. Resaltan el hecho de que, si bien el cuerpo se presenta dentro de la antropología médica en constante relación con la enfermedad, puede también expresar un sentido de pertenencia y autoafirmación, porque la forma de sentir nuestro cuerpo está culturalmente contextuada y abierta al cambio. ¿Qué ocurre entonces cuando ese cuerpo plantea un cambio que irrumpe en ese contexto cultural generando una fricción? ¿Cómo explica esa cultura las experiencias y decisiones de esos cuerpos intransitivos ${ }^{1}$, inabarcables?

En ese marco, nuestra investigación, se perfila desde las contradicciones discursivas y epistemológicas que han marcado la reflexión sobre la política de la sexualidad y el género, y en las teorías más contemporáneas del cuerpo y la performance. Autores como Preciado, Butler, Sedgwick, Moraga, Haraway, entre otras, insisten en una crítica feminista a la tradición teórica y metafísica occidental, inspirada en las lecturas, bajo el prisma de la modernidad, de pensadores como Foucault, Lacan, Derrida Lyotard, Deluze, entre otros. El post-feminismo, de esta forma reclama la urgencia de concebir el sujeto y el agente político lejos de un centro autónomo de soberanía y conocimiento, como una posición inestable, y como el efecto de constantes re-negociaciones estratégicas de la identidad.

Por un lado, Paul Preciado hace hincapié en la concepción del cuerpo como espacio de construcción bio-política, de opresión, pero también de resistencia. Las nuevas tecnologías de la sexualidad que este autor nos propone ponen de manifiesto que el cuerpo es a su vez el lugar político de mayor intensidad donde realizar operaciones de contra-producción de placer. Es el cuerpo en mutación, reclamando formas de hipersexualización y de hiperconstructivismo del cuerpo y de sus órganos sexuales en total ruptura con las soluciones filosóficas y políticas del feminismo tradicional. Lo que aporta Preciado, siguiendo este orden viene a ser la certeza de que todxs estamos más o menos mutiladxs por las tecno-

1 Ana Amado utiliza la categoría de cuerpos intransitivos y considera al travestismo como un modo atinado de denuncia sobre "la mentira de las identidades" basándose en considerar lo masculino y lo femenino como una mascarada que puede deconstruirse en un repertorio de gestos, de apariencia, de atuendos. 
logías sociales, y que se precisan ciertas formas de resistencia contra-sexuales frente a las anteriores maneras de concebir determinadas disposiciones del género y la sexualidad como propios de la normalidad y la naturaleza.

De esta forma, es posible recurrir a los planteamientos de Donna Haraway (1984) en su ensayo “Un manifiesto ciborg” y su crítica al feminismo radical, que entendía a las mujeres de manera esencialista, siguiendo una teoría que declara identificar una causa o constitución de identidad de género -según las pautas del patriarcado universal- transhistórica y necesaria. Tales proposiciones, argumenta Haraway, excluyen a las mujeres que no se conforman a la teoría y las segregan de las "mujeres reales" o las representan como inferiores.

Las prácticas culturales que ponen de manifiesto pueden ser controversiales si tenemos en cuenta el normativismo que subyace en gran parte de la teoría política actual y la reificación demasiado expeditiva de identidades grupales, como es el caso de las charapas, el fracaso para cuestionar el significado de la identidad cultural y el abandono de estas temáticas por parte de la literatura sociológica e histórica, dominadas por el constructivismo metodológico. En este sentido, Seyla Benhabib (2006) en su texto "Las reivindicaciones de la cultura" propone un modelo democrático deliberativo que permita la máxima controversia cultural dentro de la esfera pública, en las instituciones y asociaciones de la sociedad civil, y a través de ellas. Concebimos al igual que la autora que, estas las sujetas, han construido cierta complejidad interna, y en sus luchas por alcanzar reconocimiento, de manera latente, pasan por buscar un diálogo democrático que denuncie la exclusividad y la jerarquía de los arreglos culturales existentes, es decir, encontrar un espacio donde ser y existir a través de sus instancias culturales y de sabidurías propias.

La autora propone, además, que los inmigrantes pueden ser incorporados en la cultura mayoritaria a través de procesos de cruces de fronteras, borramientos de fronteras o modificación de fronteras entre culturas dominantes y minoritarias. Es decir, la inclusión democrática y la continuidad y conservación de las culturas no tienen por qué ser mutuamente excluyentes, respetando las diferencias.

Siguiendo esta ruta, se han valorado los abordajes de autores y teorías que marcan las pautas históricas para los estudios del género y la sexualidad. De esta forma, uno de los referentes fundamentales es el filósofo, investigador, escritor y pionero en los estudios de géneros y sexualidades Michel Foucault y particularmente su teoría de la bio-política.

Foucault (1979) explica ampliamente en varios de sus textos, y en particular en $\mathrm{Na-}$ cimiento de la biopolítica, curso dictado en el College de France, el concepto de biopolítica como elemento fundamental abocado a comprender la conformación del estado y la sociedad modernos. Para Foucault, el desarrollo del biopoder y sus técnicas constituyen una verdadera revolución en la historia de la especie humana. Ello porque la vida está completamente invadida y gestionada por el poder, lo que fue fundamental para la expansión del capitalismo al crear los instrumentos para la inserción controlada de los cuerpos en el 
aparato de producción y mediante un ajuste de los fenómenos de población a los procesos económicos que generó una expansión inaudita de la acumulación de capital.

Sin embargo, Giuseppe Campuzano (2007) en su trabajo el Museo Travesti del Perú da cuenta que el control del cuerpo no es una característica de la sociedad moderna. El travestismo en el Perú es historia antigua, su primera prohibición data del año 1566 desde el incanato, la república, hasta la actualidad.

Con lo dicho hasta aquí ambos trabajos serán fundamentales en esta investigación. De Foucault retomaremos la distinción que realiza sobre las dos técnicas de biopoder surgidas en los siglos XVII y XVIII; la primera es la anatomopolítica que se caracteriza por ser una tecnología individualizante del poder, basada en el escrutar en los individuos sus comportamientos y su cuerpo con el fin de anatomizarlos, es decir, producir cuerpos dóciles y fragmentados a través de mecanismos de vigilancia, control, intensificación del rendimiento, multiplicación de capacidades, emplazamiento, utilidad, entre otras categorías. El segundo grupo de técnicas de poder es la biopolítica que tiene como objeto a poblaciones humanas, grupos de seres vivos regidos por procesos y leyes biológicas. Esta entidad biológica posee tasas conmensurables de natalidad, mortalidad, morbilidad, movilidad en los territorios, que pueden usarse en la dirección que se desee. Así, según la perspectiva foucaultiana, el poder se torna materialista y menos jurídico, ya que ahora debe tratar respectivamente -a través de las técnicas señaladas- con el cuerpo y la vida, el individuo y la especie. Cabe agregar que el punto de articulación entre ambas técnicas radica en el control de la sexualidad como mecanismo de producción disciplinar del cuerpo y las regulaciones de poblaciones.

Lo inédito es que lo biológico se refleja en lo político, produciendo que la existencia vital entre de lleno en la modernidad, ya que los humanos, en función del poder que los rige, se juegan la vida en la política. Los efectos del biopoder hicieron que las sociedades se volvieran normalizadoras usando como instrumento la ley. Por otra parte, las resistencias entraron al campo de batalla que las estrategias basadas en el biopoder crearon, por lo que se centraron en el derecho a la vida y al cuerpo desplazando a otros objetos de luchas.

Mientras que la mirada del filósofo peruano, nos aporta una condición vital: su compromiso con la praxis del travestismo. A partir de su obra podemos vislumbrar el contexto histórico peruano, pero también una reflexión filosófica de lo que es el travestismo, que parte desde las travestis de carne y hueso, hasta los múltiples significados de puedan tener, tanto en el Perú como en la Argentina.

Otra de las autoras que se consideraron para la investigación es le filósofe y profesore Judith Butler, une de les primeres referentes que encontramos en la teoría queer y los estudios feministas. A través de su obra escrita y su desempeño como docente de varias de las más prestigiosas Universidades de Estados Unidos y otras partes del mundo, desarrolla lo que hoy conocemos como la performatividad del género, categoría en la que se ha ba- 
sado gran parte de su obra y su propuesta investigativa. Una de las fuerzas ético-estéticas de la filosofía de Butler radica en que deconstruye el valor productivo del poder ligándolo a la administración del género por parte de la norma social, por lo que esta producción del género crea la apariencia de una naturaleza identificable del sujeto.

Deshacer el género es la obra que inaugura su giro ético, en la que Butler estudia los cambios sociales y los nuevos movimientos que la norma falocéntrica toma como neonormativas de género productora de quimeras. La nueva política del género se representa en nuevas formas de vida, siendo estas afines a la transexualidad, al intersexo y al trans-género. Las relaciones que tienen estos movimientos con la teoría feminista y la práctica queer son dependientes del modo de producción de la identidad. Para le autore, el travestismo, al ser ajena a la norma y mutada desde ésta, es una auto confección. Esta idea es tomada por Butler y al modo paródico del drag, el género se vuelve una disputa, donde la producción de sujetos e identidades se expresa como estrategia de subversión que demuestra la contingencia de la norma. Es la expresión de un deseo, de transgresión por transgredir, usado como estrategia.

El fundamento teórico que le autore brinda, crea la posibilidad de superar los éxitos del feminismo ilustrado, allanando el camino y la expansión de los movimientos queer, y también trans e intersex. Estas corrientes, gracias a Butler, pueden, por fin y por primera vez en el occidente heteropatriarcal, deshacerse del tabú. Derrocada la prohibición del nombrar, nace la performance del género fluido.

Por otro lado, retomamos los antecedentes, de la tesis de grado de Andrea Butler y Lucas Bertulo, de la Facultad de Periodismo y Comunicación Social-UNLP “Voces trans...... Solo ellas". La cual está conformada por narraciones que describen la construcción compleja en la formación de la subjetividad trans femenina. Los discursos que atravesaron todo el recorrido de su investigación, interpelan las categorías fijas de sexo y género, a la vez que cuestionan la manera de "estar" en el mundo. Las voces trans, en este sentido, son las protagonistas. Voces que son escuchadas, respetadas y valoradas en un espacio de reflexión teórica. El arribo a estos relatos es posible gracias a la capacidad individual de cada una de las colaboradoras de expresar sus emociones, vivencias y expectativas de vida. La expresión Trans no clasifica, no determina ni condiciona. Enuncia diversidad y transformación. El término es abarcador adrede, ya que cada persona aludida por esa denominación es libre de entrar y salir del "etiquetado", mutando, reconociéndose o no en locuciones que de otra manera no le serían propias, sino impuestas. El subtítulo "Solo ellas" alude a personas que se expresan en cuerpos femeninos solamente. Se hace referencia a su universo simbólico a través de sus transformaciones físicas, prácticas culturales y problemáticas sociales. 
De este trabajo retomo los aportes teóricos como: La identidad como concepto relacional, la mirada filosófica en torno a la identidad, la categoría Identidad de Género y la relación entre género y cuerpo.

\section{Triplemente Vulnerabilizadas: Prostitutas, inmigrantes y transexuales}

Es un Informe que surge del interés por el día a día de las prostitutas transexuales latinas migrantes en la ciudad de Alicante, España. Voces que se hacen visibles mediante las sinergias entre el Instituto de Desarrollo Social y Paz de la Universidad de Alicante y las ONG's.

Experiencias, objetivos y expectativas se dan cita en este Informe. Se trata de una aproximación cualitativa financiada con la convocatoria de becas del Vicerrectorado de Investigación de la Universidad de Alicante (Beca de Iniciación a la Investigación, 2009) dentro de un proyecto sobre vulnerabilidad y salud dirigido por el profesor Titular de Sociología Daniel La Parra Casado (Grupo de Investigación OBETS, Observatorio Europeo de Tendencias Sociales). La intencionalidad es humanizar y visibilizar, comprender y entrelazar las condiciones socioeconómicas, los contextos y las vivencias de sujetos de cambio, que no son objetos de estudio. Ser capaces de tener una visión conjunta sin generar teorías causales, sino hechos y trayectorias vitales que debemos traducir en autovaloraciones, cambios sanitarios, académicos y sociales. Mediante la técnica de la entrevista, el grupo de discusión y la etnografía se configura un abanico de biografías y realidades distintas pero homogéneas al mismo tiempo. Crear vínculo y ubicarse como un investigador cualitativo en un campo de trabajo democrático da lugar a poder conocer realidades socio-sanitarias, vivencias con la salud y contextos compartidos.

Transfobia, machismo y racismo se hacen visibles en estos cuerpos triplemente estigmatizados y vulnerabilizados.

Las prostitutas denominan coloquialmente la zona al espacio físico habitado por las noches para el ejercicio de la prostitución en la ciudad de Alicante (enfrente de la antigua estación de Murcia, Puerto de Alicante). Es percibido como un elemento socializador en el que se ofrece un servicio sexual, al igual que se relacionan entre sí, conscientes en todo momento de su situación espacial y social, reflejada en las constantes agresiones verbales y físicas sufridas en la zona. Como consecuencia de la indefinición al respecto del servicio sexual ofrecido por las prostitutas, es inexistente la posibilidad de crear sindicatos y organizaciones de trabajadoras. Plataformas sociales de las que ellas carecen, pero no acontece lo mismo con las reivindicaciones existentes. Aparece la jefa de zona como un elemento vertebrador entre las prostitutas transexual, no definida como proxeneta sino 
como portavoz, portadora del jefazo. Ser veterana y experimentada en la zona la convierte en un sujeto imprescindible dentro de la socialización endogrupal de las prostitutas transexuales. Conseguir material preventivo, defender la zona de agresiones transfóbicas, evitar intrusismo de proxenetas y prostitutas, parcelar los horarios de puteo con el fin de que todas puedan trabajar, etc. Las participantes en los grupos de discusión y la visita a la zona valoran positivamente el jefazo y el papel otorgado a la jefa de zona, formando parte de su socialización y fortaleciendo la idea de la especialización y funcionalidad de la zona como espacio compartido y referencial. Esta categoría del jefazo será puesta en tensión a partir del estudio realizado, atendiendo a las particularidades que el caso analizado reviste para nuestras sujetas de investigación.

Los procesos migratorios que protagonizan las prostitutas transexuales son complejos y permanentes, inacabados en la mayoría de los casos. España no suele ser el primer país de destino, siendo el tercero o el cuarto, habiendo estado en varios países como Alemania, Reino Unido e Italia, preferentemente; lo que las convierte en conocedoras de múltiples culturas, legislaciones y sociedades. El flujo migratorio dependerá de la demanda de servicios sexuales existentes en una zona y las condiciones socioeconómicas, políticas y culturales con las que se cuente para poder desplazarse, en caso de ausencia de trabajo. La vulnerabilidad en el caso de la socialización se origina por la ausencia o existencia de contactos y conocimientos previos que favorezcan el empoderamiento y procesos migratorios en condiciones óptimas (la migración en este caso se ve favorecida). Consejos y apoyo de compañeras son piezas claves para crear una identidad en el país de destino, desplazarse y comenzar una nueva vida. Esto será tenido en cuenta a la hora de abordar los lazos sociales que tejen las personas trans durante su migración.

Socialización y empoderamiento:

Las vivencias compartidas y habitar espacios comunes genera una conciencia colectiva por encima de cada individuo particular. Es por eso que la jefa de zona, generalmente, encabeza la crítica del colectivo y sintetiza los procesos migratorios, sociales y sexuales. La socialización no se ve limitada exclusivamente a la zona, puesto que comparten ocio, problemas personales e inquietudes que las une más allá del compartir un espacio físico donde ofrecer servicios sexuales. Se muestran preocupadas por la situación legal de su compañera, la agresión sufrida por su amiga, la muerte de un familiar en el país de origen, los problemas económicos o las alegrías de una compañera que se desplaza a Latinoamérica para ir al quirófano y culminar su proceso de reasignación sexual. El componente transexual (identidad de género) y latino (identidad nacional) articula junto el componente "prostituta" (condición socioeconómica), un triple escenario compartido que entrelaza trayectorias personales y pautas de conducta semejantes, dando lugar a una cultura endogrupal compartida. 
Los procesos migratorios percibidos y definidos como inmigración derivan en xenofobia, los procesos identitarios definidos como transexualidad derivan en transfobia y ejercen la prostitución como forma de vida deriva en machismo y ostracismo. Triplemente vulnerabilizadas y agredidas por la condición de inmigrante, transexual y prostituta. La violencia estructural justifica y favorece un contexto culturalmente violento con las prostitutas transexuales inmigrantes, siendo el objetivo de todas las miradas. Justificadas están, generalmente, las agresiones sufridas. Vistas como personas molestas, entrometidas y socialmente marginadas, cualquier ataque verbal o físico se justifica con su condición de pluri-estigma. La violencia entendida como mecanismo de control y estigmatización es efectiva con las prostitutas transexuales inmigrantes porque define su espacio físico-social que deben ocupar y habitar, tanto de noche como de día. Siendo críticas con la violencia padecida en numerosas ocasiones lejos de justificar tales actos, en ocasiones suelen mantener una actitud derrotista al asumirse como "estorbo para la sociedad", sujetos molestos tanto por sus prácticas como por sus modalidades de vida.

Siendo conocedoras de tal contexto vulnerabilizador que las desampara negándoles la posibilidad de no ser violentadas, son fuertes y actúan en grupo frente a los posibles agresores externos, como medida de supervivencia. Puesto que se sienten desamparadas por la legislación y el conjunto de agentes sociales en general divagan entre el coraje y la apatía ante la violencia, dependiendo del día se sienten con ganas de reivindicar sus derechos o ceder ante la pluriestigmatización (machismo, transfobia, racismo).

De esta investigación recuperaré las ideas y el sentido que le dan a la zona, a la espacialización y la funcionalidad. La zona es percibida como un elemento socializador en el que se ofrece un servicio sexual, al igual que se relacionan entre sí, conscientes en todo momento de su situación espacial y social, reflejada en las constantes agresiones verbales y físicas sufridas en ella.

En el trabajo de Laura $\mathrm{M}^{\mathrm{a}}$ Agustín "Olvidar la victimización: los migrantes como protagonistas" Publicado en Development, (2003). Sostiene que hay una tendencia creciente de victimizar a los pobres, a los débiles, a los no formalmente educados y a los migrantes. Esta tendencia, que empezó como modo de llamar la atención sobre formas específicas de violencia cometidas contra mujeres, se ha convertido en el modo de describir a todos los de abajo. Rutinariamente, quienes se solidarizan con ellos los posicionan como víctimas para poder reclamar sus derechos, pero esta táctica también los convierteen víctimas, y las víctimas necesitan ayuda, rescate-lo cual otorga un papel principal a los solidarios. Mucha retórica sobre la migración ha tomado esta forma: resulta que los migrantes no sólo son vulnerables a la explotación, una verdad evidente, sino que también son víctimas. 
Ya que se piensa que los migrantes siempre vienen de países pobres, la ubicación de tantos de ellos como víctimas de la reestructuración económica, sino de agentes criminales recuerda de manera perturbadora la antigua categoría del 'nativo', un ser humano 'atrasado' en comparación con los ciudadanos de los países ricos. Se nota esta tendencia más en los discursos sobre las mujeres 'traficadas' por ejemplo en Barry (1979), pero también se nota cada vez más en discursos sobre los migrantes 'ilegales'.

La categoría 'migrante', incómoda y ambigua desde el comienzo, se vuelve peor cuando se añade la victimización. En este artículo, examina lo que se quiere decir cuando se llama a alguien migrante, y después sugiere un análisis poscolonial y de clase sobre esta identidad pasiva que se ha construido. Para lograr esto, se refirió a sus investigaciones con personas en proceso de migrar en varias partes del mundo. Sostiene que lo que aborda es bien conocido, pero no siempre está incluido en los estudios formales de la migración.

Sostiene que la dicotomía viajero-que-trabaja/viajero-sin-trabajar engaña, ya que varias formas de viajar incluyen aspectos de los dos. Entonces, se pregunta ¿qué es lo que hace a un 'migrante' distinto? Según esta distinción, los migrantes se mudan de su hogar para fundar otro en el país de otra gente. No están posicionados como viajeros o turistas, ya que están buscando no sólo gastar dinero sino ganarlo. La palabra migrantes se utiliza casi siempre para referirse a personas de la clase obrera, no a los profesionales de la clase media. Tampoco se utiliza para personas de los países ricos, incluso si los últimos también se han mudado a trabajar en otro país. Al contrario, la palabra migrante implica un estado subalterno.

Las teorías de migración han tendido a concentrarse en las causas de las mudanzas a países nuevos, enfocándose en las condiciones estructurales tales como la recomposición del capital o la globalización de los mercados, las políticas nacionales y las decisiones racionales de las 'unidades familiares'. Los discursos 'push-pull' sobre el punto de origen y el punto de recepción se centran en causas tales como diferencias de sueldos entre países, la pérdida de tierras o cosechas, reclutamiento por empleadores en el extranjero, proyectos de reagrupación familiar, políticas favorables de inmigración, la huida de violencia, la persecución y el conflicto armado y la 'feminización de la pobreza'. Ninguna de estas condiciones excluye las demás, y es evidente que pensar en las migraciones como producto de múltiples causas es lo más recomendado, ya que ninguna condición sola garantiza que una migración se produzca.

Estos factores existen, sí, pero consideran a los seres humanos como objetos de acciones ajenas, dejando poco espacio para los temas más sutiles de deseo, aspiración, frustración, angustia o un sinnúmero de otros estados del alma. Los factores push-pull, 
que parecen ser algo que ocurre a personas que son menos que 'civilizadas', no se mencionan cuando gente de los países ricos son los migrantes; hay más posibilidad de que estos últimos se describan como individuos modernos que están activamente buscando mejores situaciones en las que puedan realizarse. Se sabe que la elección siempre forma parte, incluso con los migrantes más pobres, porque no todos migran de sitios difíciles.

Si fuera verdad que el flujo de inmigrantes y refugiados es simplemente un tema de individuos en busca de mejores oportunidades en un país más rico, entonces la creciente población y pobreza en todos lados del mundo habría creado números auténticamente masivos de pobres que estarían invadiendo los países más desarrollados, un gran flujo indiscriminado de seres humanos de la miseria a la riqueza. Tal cosa no ha pasado. Las migraciones son procesos altamente selectivos; sólo ciertas personas salen, y viajan por rutas altamente estructuradas a sus destinos, en vez de gravitar ciegamente hacia cualquier país rico en el que puedan entrar, Sassen (1999).

Los medios de comunicación, muchos gobiernos y numerosas personas que apoyan a los migrantes tienden a hablar como si las 'avalanchas' proverbiales estuvieran ocurriendo de verdad, parece importante destacar este punto. Incluso en las situaciones más difíciles, hay personas que prefieren quedarse en casa, mientras otras personas prefieren salir. Todas las personas son influenciadas por las fuerzas mundiales, sí, pero no pierden la capacidad de meditar sobre sus opciones. Sus personalidades individuales juegan un papel: el grado de auto-confianza, la voluntad de correr riesgos y la adaptabilidad frente al cambio. Ocupar una posición menos poderosa en términos estructurales no significa que no se pueda tomar decisiones, y estas decisiones están influenciadas por una multitud vasta de circunstancias, incluyendo el deseo individual. Ser económicamente pobre no te hace pobre espiritualmente.

De la misma manera, no es cierto que las personas que han decidido salir de sus casas, viajar al extranjero y buscar trabajo, incluso en las condiciones más arduas, jamás tengan tiempo de ocio, hagan turismo o busquen placer. Combinar negocios con diversión es un concepto tan disponible para los pobres como para los ricos, para los que se mueven con un pasaporte falso como para los que lo hacen con un pasaporte auténtico, y tanto para los que trabajan en ocupaciones estigmatizadas como el trabajo sexual como para los que hacen lo que la sociedad denomina 'trabajo digno'. Hablar de los migrantes como personas exclusivamente dedicadas al trabajo tiene tan poco sentido como hablar de los viajeros de negocios de esa manera: significaría convertirlos en seres unidimensionales, menos que humanos. El enfoque actual sobre cómo la gente migra es responsable de este reduccionismo. 
Laura Ma Agustín, en su trabajo "Cuestionar el concepto del 'lugar': La migración es algo más que una pérdida" Publicado primero en Development, Society for International Development, Rome, 2002. Utiliza el caso de las migraciones de mujeres para trabajar en la industria del sexo para cuestionar un concepto siempre positivo del 'lugar'. Sostiene que hay una discontinuidad entre las imágenes esencialistas que las ONGs, los funcionarios gubernamentales y otros que difunden de estas trabajadoras como despojadas de su casa y sometidas a experiencias traumáticas como personas traficadas, por un lado, y las experiencias, expectativas y narrativas de las propias migrantes, por otro. Las trabajadoras sexuales migrantes no son siempre desplazadas a la fuerza, y cuando lo son, sus trayectorias posteriores pueden tener, y muchas veces tienen, desenlaces tan positivos como la vida de cualquier persona. Agustín ofrece una descripción de los ambientes en los que viven estas migrantes, tanto mujeres como transexuales.

Mitos sobre las migraciones

Cuando la gente emigra, hay una tendencia a idealizar la casa (el hogar). Se evocan cálidas imágenes de familias unidas, objetos domésticos simples, rituales, canciones, comidas. ${ }^{2}$ Muchas fiestas religiosas y nacionales, en diversas culturas, materializan conceptos como el 'hogar' y la 'familia', usualmente a través de imágenes de un pasado folclórico. En este contexto, la emigración se ve como un último recurso o un acto desesperado y los migrantes como despojados del lugar al que 'pertenecen'. Pero para millones de personas del mundo, el lugar donde nacieron y crecieron no es un lugar viable o deseable para desarrollar proyectos más adultos o ambiciosos, y mudarse a otro lugar constituye una solución convencional -no traumática.

¿Cómo se produce está decisión de mudarse? Terremotos, conflictos armados, enfermedades o la falta de alimento arroja a alguna gente a situaciones que no parecen dejarles demasiada libertad de elección o tiempo para 'procesar' las opciones: a veces se le llama a esta gente refugiados. La decisión de un hombre soltero de viajar se entiende generalmente como algo que evoluciona con el tiempo y como producto normal de su ambición masculina de progresar mediante el trabajo: se les llama migrantes. Y luego están las mujeres que intentan hacer lo mismo.

2 La palabra home en inglés (hogar, casa) connota mucho de esto por sí sola, pero no tiene esa omnipresencia en otros idiomas. 
Aunque hace casi 20 años que investigadores y personal de ONGs trabajan con prostitutas migrantes en Europa, la publicación de sus conclusiones se mantiene fuera de las revistas y la prensa de las corrientes generales. La mayoría de quienes se han reunido y han hablado con prostitutas migrantes no son ni académicos ni escritores. El trabajo de "acercamiento" se conceptualiza de manera distinta a la "investigación" y se financia generalmente como prevención de VIH/SIDA. Esto significa que los productos publicados por sus investigaciones se reducen en general a información sobre salud y prácticas sexuales; el resto de la información recolectada, de muy diversa índole, permanece inédita. Algunos de los que trabajan en estos proyectos tienen la oportunidad de encontrarse e intercambiar la información reunida, pero no son la mayoría. Recientemente, se incorporó un nuevo tipo de investigador, en su mayoría mujeres académicas jóvenes que estudian la sociología o la antropología y trabajan temas migratorios.

Estas investigadoras quieren hacer justicia a la realidad migrante que las rodea, la cual ellas ven como compuesta tanto de trabajadoras sexuales como de empleadas domésticas y del cuidado. La mayoría de estas investigadoras utilizan historias de vida, y algunas han empezado a publicarse, pero todavía este tipo de trabajo no está reconocido. La estigmatización opera de múltiples maneras, entre otras el silenciar los resultados que no encajen en los discursos hegemónicos. ${ }^{3}$ La crítica de las corrientes dominantes sostiene que "la información no está sistematizada" o que "no hay datos fácticos". En nuestra investigación, buscamos esos resultados "marginados", ofreciendo una lectura analítica crítica desde la interseccionalidad de factores que inciden en el caso de las charapas, las feminidades travestis trans migrantes peruanas.

\section{La migración en números}

El informe, "Personas, papeles, políticas y derechos: las migraciones contemporáneas en Argentina desde la perspectiva de la Comisión Argentina para Refugiados y migrantes (CAREF), señala que Argentina:

Surge también como un caso singular: se trata del país de la región que históricamente recibió la mayor cantidad de migrantes regionales (1.400.000 en 2010) y cuya Ley de Migraciones ( $N^{\circ} 25.871$ ) aprobada en 2003 , incorporó, bajo el criterio de nacionalidad (art. 23 inc. I) las facilidades establecidas en el Acuerdo del Mercosur (Pacecca, 2019, p. 9).

3 David Sibley ha contribuido invalorables datos al respecto en su capítulo sobre las rigurosas investigaciones sociológicas de W.E.B. DuBois en 'Los negros de Filadelfia', que nunca fue aceptado por la academia (1995). 
De la lectura de los datos arrojados, se observa que en el período que comprende nuestra investigación, cuando las feminidades travestis y trans peruanas inician el viaje en los albores del nuevo siglo, en el país se censaron un 1.000 .000 de extranjeros y 1.400 .000 en 2010 , lo que representa en la población total entre el $2 \%$ y el 3,5\%.

De los flujos migratorios provenientes de los países como el Perú, de donde son originarias las sujetas de nuestra investigación, puede observarse que crecieron significativamente, pasando de 90.000 personas censadas en 2001 a 160.000 en 2010, lo que constituye un crecimiento del $77 \%$ en la primer década, lo que demuestra su dinamismo y relevancia en la conformación de la población extranjera contemporánea (Pacecca, 2019, p. 17).

Resulta interesante observar la variable definida en términos de trámite de residencias, que en el caso de la población peruana en la Argentina, en el período comprendido entre 2004 y 2015, en términos absolutos, indica que 172.000 personas, tramitaron sus residencias permanentes, mientras que 150.000 su residencia temporarias. Sin embargo, sabemos que este dato no es representativo a la población específica analizada puesto que uno de los indicadores más notables entre las travestis y trans migrantes es la escasa regularidad de sus trámites migratorios. Cuestión que será abordada oportunamente en el análisis.

Un dato de consideración es que la variable sexo-genérica no aparece desagregada en el informe de referencia. Sin embargo, podemos observar la presencia de indicadores establecidos en torno a las categorías varones - mujeres - niños y niñas. Atendiendo a que las feminidades migrantes del Perú señalan como una de las causales del viaje la falta de políticas públicas en materia de respeto a sus identidades de género y, que en la Argentina, la ley 26.743 se sancionó en 2012, queda un margen de menos de tres años considerando el período comprendido por el presente informe elaborado por el Servicio Social de CAREF (2004-2015). Con lo cual, no hay datos oficiales construidos, específicamente, en torno a la intersección migración-identidad de género.

En el trabajo titulado Comunicación y Migración: El caso de Ecuador (2006), Lucía Benítez Eyzaguirre de la Universidad de Cádiz, España, analiza el papel de la comunicación en el desarrollo, como uno de los elementos que lo convierten en codesarrollo. Se defiende que en un mundo en que el valor social se renegocia al instante a través de los bienes simbólicos, el desafío está en lograrlo de forma intercultural con la inclusión de la totalidad de los individuos sin renuncia a su diferencia y sin alentar nuevas desigualdades que ahora operan desde la desconexión, la desinformación y la incomunicación. Tras exponer el panorama de las políticas comunicativas actuales a nivel mundial, expone los nexos existentes entre globalización y migración, para luego hacer lo mismo con los casos de la comunicación y migración. Estudia el Plan “Migración, Comunicación y Desarrollo Ecuador-España”, descri- 
biendo sus bases conceptuales y organizativas, así como sus potencialidades. Finalmente, se presentan una comparativa entre inmigrantes ecuatorianos y marroquíes en España sobre el papel de la comunicación en el desarrollo y una serie de propuestas de impulso para la comunicación y el desarrollo.

Allí, Benítez Eyzaguirre, propone unos apuntes para la investigación sobre este tema, cuando el contexto es de confusión entre lo real y lo mediado, en el que se superpone la forma en que los medios designan los hechos y su capacidad para moldear las sociedades. Ahora que la comunicación y la información son claves para la productividad de un determinado tipo de economía, cuyo molde se expande también con la globalización; la política se mezcla con la comunicación, la cultura audiovisual se impone a los modelos tradicionales y la transmisión de valores que nos llegaban de la religión se ha trasladado al escenario mediático.

Carolina Stefoni en su trabajo de investigación denominado Inmigración y Ciudadanía: La formación de comunidades peruanas en Santiago de Chile y la emergencia de nuevos ciudadanos. Analiza cómo el mundo popular vinculado a la inmigración peruana en Chile ha logrado crear un tipo particular de comunidad en Santiago centro, que se caracteriza por un elemento de transnacionalidad, en cuanto logra constituirse más allá del territorio local, incorporando e integrando elementos del mundo peruano y del chileno. El artículo considera a su vez la emergencia de nuevos ciudadanos vinculados a estas comunidades transnacionales y plantea que existe una distancia objetiva entre los derechos consagrados por la ley y el cumplimiento real de los mismos. En este sentido, el desconocimiento y las actitudes de discriminación por parte de la sociedad chilena merman la adecuada protección de los derechos que poseen los inmigrantes en el país.

El interés de este artículo busca identificar y comprender el proceso que ha dado origen a la emergencia de una comunidad peruana popular en el corazón de Santiago. ¿Cómo se ha ido conformando alrededor de la Plaza de Armas una comunidad de inmigrantes peruanos? ¿Cómo se han negociado los espacios y cómo se ha transformado el territorio? ¿Cuál es la relación de esta comunidad con las autoridades políticas, tanto a nivel municipal como con las instituciones estatales? ¿En qué medida quienes conforman estas comunidades logran transformarse en ciudadanos?

Para Stefoni, si bien muchas de estas preguntas no encuentran aún una respuesta definitiva, constituyen una invitación a reflexionar sobre algunos aspectos de la migración en Chile. Ello supone asumir una actitud crítica sobre algunos conceptos tradicionales de las ciencias sociales. Identidad y territorio, nuevas ciudadanías y comunidades transnacionales, son elementos que nos permiten abordar las múltiples dimensiones de un fenómeno que 
introduce interesantes transformaciones en el mundo social y político chileno. En este sentido, una de las ideas centrales que desarrollaré en este artículo es que el mundo popular vinculado a la migración peruana asume en Chile un carácter transnacional en cuanto logra constituirse más allá de un territorio local, estableciendo vínculos con Perú y con Chile tanto en un plano objetivo como en uno simbólico.

\section{La comunicación, como elemento constitutivo de la identidad}

El equipo de investigación dirigido por la Dra. Nidia Abatedaga en la Facultad de Ciencias de la Comunicación indaga acerca de los emergentes laborales en la provincia de Córdoba y sobre la potencialidad que adquiere la práctica comunicativa al momento de crear estrategias de resistencias y redes de autogestión laboral. Para eso les autores estudian las estrategias de comunicación de los bordes que los colectivos laborales articulan para disputar sentidos en el espacio público, frente a los sentidos predominantes con los medios de comunicación, organizaciones de la sociedad civil y el Estado. Tomaremos de este trabajo la noción de estrategias para analizar la manera en que el colectivo estudiado, combina luchas por el reconocimiento identitario. No será objeto de la presente investigación las estrategias de resistencias por la redistribución de recursos, otra de las categorías que se desprenden del análisis sobre los emergentes laborales de la provincia de Córdoba.

En este sentido, será necesario recuperar la noción de práctica comunicativa de Abatedaga y Ordoñez (2017). A partir de la cual, será posible empatizar con la necesidad de reconocer las articulaciones comunicativas internas que permiten a los sujetos apropiarse de una historia narrada conforme a la identificación deseada por el grupo, para posteriormente poner en acto estas elecciones, en una praxis comunicativa capaz de construir un relato destinado al espacio público que construya una identidad acorde a su funcionamiento no lucrativo y solidario.

Esta lectura a las identidades guarda correlación con el trabajo de Tesis de Facundo Abalo, "Lecturas insurgentes: práctica y significación en trayectos biográficos de sujetos trans”, realizada en el año 2015 para la obtención del título de Doctor en Comunicación Social por la Universidad Nacional de La Plata. Asentado en el método biográfico, fundamentalmente a través de las historias de vida, el trabajo indaga sobre tres ejes temáticos que serán puestos en diálogo con nuestra investigación. La escuela, la familia, entre otros ámbitos estudiados para analizar los trayectos biográficos y, en el caso de referencia, nodales para señalar las experiencias de las entrevistadas, serán un punto de partida común al momento de establecer los condicionamientos que inciden en las etapas primarias de la conformación 
de la identidad trans. Sin embargo, nuestro trabajo adquiere relevancia, además, puesto que al abordarse desde una lectura interseccional, permite además considerar la cuestión de la migración como elemento sustancial constitutivo.

A propósitos de las primeras etapas de vida, dos trabajos resultaron una referencia a la investigación que se pretendió abordar. Por un lado, Pablo Vain (2018) entiende a la educación como una práctica social, situando una articulación entre sujeto, sociedad y cultura. Con la intención de dar cuenta del rol que cumplen los rituales escolares, en tanto instancias esencialmente dramáticas a partir de las cuales una sociedad comunica algo importante acerca de sí misma, pero al mismo tiempo, construyen nuevas prácticas. Imaginar la fuerza de los rituales culturales, más no educativos, en la investigación sobre las feminidades travestis y trans, permitirá comprender las prácticas que se sedimentan en los lugares a los que migran y que refuerzan sus tradiciones, al tiempo, que permiten inaugurar nuevas y novedosas prácticas político-comunicacionales en el espacio público.

Atendiendo a lo anterior, y en segundo lugar, el trabajo de María Belén Rosales y Lucas Ledesma "Procesos de Comunicación, Educación y Género: desde una perspectiva de la diversidad", el cual permite dialogar con una lectura analítica desde los estudios culturales, las teorías de género y la perspectiva de la comunicación para la transformación social. Les autores, desde esta perspectiva problematizan la reproducción mediática de estereotipos que existen en la cultura y que a la vez se van remodelando y reconstruyendo en los medios de comunicación. Desde este lugar, se preguntan por los trayectos formativos de les profesionales de la comunicación con el foco puesto en las múltiples dimensiones que adquiere el debate sobre la articulación universidad y políticas públicas/educativas.

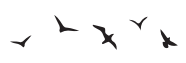

Este primer recorrido bibliográfico basado de investigaciones precedentes permite la creación del estado del arte, es decir crear el constructo para la investigación a realizar, a partir de una aproximación a las múltiples disciplinas que intersectan el análisis. Entendemos que, el relevamiento de trabajos similares brinda aportes teóricos, conceptuales y metodológicos útiles para la construcción del objeto de estudio. No obstante, a la luz de los trabajos explorados, el tema que investigo pretende brindar nuevos aportes al campo de las ciencias sociales, debido a que mi referente empírico es lo novedoso -inédito- en este trabajo: migración de feminidades travestis y trans de la selva peruana y su arraigo en la ciudad de La Plata, Buenos Aires, Argentina; desde una perspectiva interseccional. 


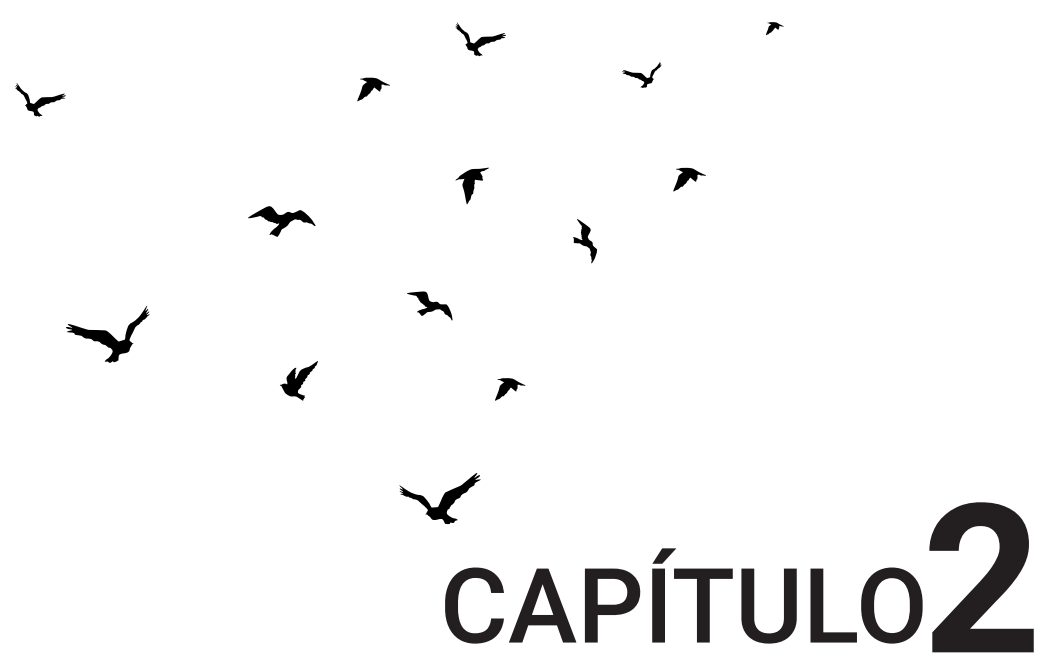

Marco metodológico 


\section{Capítulo 2. Marco Metodológico}

La presente investigación se enmarca dentro de la perspectiva crítica interseccional a fin de contribuir, en el campo de la comunicación, y de los estudios de género y disidencia sexual, mediante la sistematización, identificación y descripción sobre los modos agenciales que se construyen desde el colectivo travesti y trans migrante: Las charapas.

Definimos un alcance correlacional para la investigación, alternando, de una primera instancia exploratoria, a fin de examinar un problema de investigación poco profundizado a partir de la interseccionalidad de los condicionamientos que constituyen la especificidad del caso analizado; a una segunda etapa descriptiva, con el objeto de dimensionar las características desde las primeras etapas de vida de las sujetas de la investigación.

A tales propósitos, realizamos un recorte en el análisis, circunscribiéndonos a la ciudad de La Plata en el período 2012 al 2019. La elección diacrónica del tiempo se sustenta en la posibilidad de hallar antecedentes -no sistemáticos- de los modos de agenciamiento que el colectivo travesti y trans migrante construyó para organizar y visibilizar su resistencia en el espacio público desde su arraigo en la Argentina.

Para llevar a cabo la recolección de datos primarios, elaboramos entrevistas en profundidad a feminidades travestis y trans migrantes peruanas que viven en La Plata para la elaboración de los registros previstos, a partir del establecimiento de variables, como lo establece Hernández Sampieri (2010).

El trabajo de campo estuvo regido de un criterio de selección de la muestra a partir de informantes claves del colectivo travesti trans de La Plata migrantes, que están o no nucleadas en organizaciones políticas, con la intención de recuperar las estrategias que se construyeron en el período analizado. Combinamos técnicas de recolección de información provenientes de los estudios de caso y de las biografías, a saber:

. Entrevistas en profundidad que permitieron narrar sus experiencias de vida y su relación del colectivo estudiado;

. Entrevistas personales cualitativas semiestructuradas a través de cuestionarios;

. Revisión de documentos y materiales provistos por las organizaciones;

. Análisis de contenido cualitativo del registro documental dispuesto en el Archivo de la organización OTRANS ARGENTINA (2012-2019) 
Finalmente, con la finalidad de converger los datos objetivos y subjetivos obtenidos se realizó un análisis convergente o anidado Hernández Sampieri (2010) a la luz de los supuestos que guían la presente investigación y los lineamientos teóricos que la enmarcan.

\subsection{Planteamiento del problema}

El presente trabajo, se formula en la intención de hacer una lectura a las prácticas político- comunicacionales en el proceso de constitución de las feminidades travestis y trans migrantes peruanas en La Plata: las Charapas, que, en tanto sujetas con capacidad de agencia, habilitan modos plurales y colectivos de organización, para disputarle al Estado y a otros sujetos políticos la apropiación del espacio público.

El desafío implicará reconstruir esas trayectorias que parten de sujetos individuales en El Perú, desplazándose en la búsqueda de asumir o visibilizar su identidad de género en el viaje, desafiando los límites no solo de la subjetividad individual, sino también intersubjetiva, en la generación del lazo con otras. Se pretende abordar, de esta manera, la dimensión comunicacional en la construcción de la intersubjetividad, a fin de comprender cómo esas prácticas político-comunicacionales colectivizantes, logran constituir acciones plurales, que devienen en la formación de OTRANS ARGENTINA, un sujeto político que asume diferentes modalidades organizativas en el espacio público.

Con lo anterior, planteamos los siguientes objetivos:

\section{Objetivos Generales}

- Reconocer y analizar la relación entre las prácticas político-comunicacionales y la constitución de identidades de las feminidades trans y travestis migrantes peruanas en La Plata.

- Reflexionar sobre los modos en que esta agencia política plural configura estrategias subjetivas y colectivizantes: El caso de las charapas. 


\section{Objetivos Específicos}

- Historizar y contextualizar las formas que asumen las prácticas político-comunicacionales de las feminidades trans migrantes en La Plata: las Charapas.

- Problematizar el proceso de constitución, redefinición, consolidación y fortalecimiento de las identidades políticas.

- Sistematizar y analizar críticamente las modalidades organizativas que asume la agencia política de las Charapas en términos subjetivos y colectivizantes.

\subsection{Posicionamiento metodológico.}

La investigación llevada a cabo pretendió hacer una renuncia al monismo metodológico y de método, que procura su abordaje desde una perspectiva única para dar cuenta de toda la realidad, como tendencia estabilizante que instituye un patrón normativo para la investigación social. No se pretendió, por tanto, encorsetar las prácticas y saberes de las sujetas implicadas en esta investigación, en categorías estancas, sino evitar las tipificaciones de metodología y métodos que establecen para cada investigador, según su disciplina, consideramos que, de ese modo, si se encuadra en los cánones normativos, se anula la experiencia de la investigación.

Preferimos abandonar la comodidad del mapa y sus coordenadas, para animarnos a rastrear aquello que se escapa a los etiquetamientos, del significado. Aquello que no se puede tomar sino en el movimiento mismo, establecen Deleuze y Guattari (2002). Asimismo, no renunciamos a tener como horizonte de posibilidad una epistemología que se ubique a contrapelo del dogma, que desestime cualquier principio rector o vía maestra a seguir. Este análisis reflexivo, no comprende a las travestis y trans migrantes: las charapas, como objetos de estudio, sino como interlocutoras válidas en una relación de sujeta y sujeta de investigación.

Como lo sostiene Rosana Guber (2014) debemos entender que les investigadores debemos partir de "una sabia ignorancia metodológica", (p.20) y de métodos, a la hora de acercarse a "la realidad", que estudiamos para conocerla, construir conocimiento. Para ello, en tanto sujetas cognoscentes, establecemos un recorrido del desconocimiento al reconocimiento de las prácticas y saberes socialmente producidas y compartidas. De allí que consideremos que lo importante de un aporte universitario como el aquí esbozado no es qué camino ha seguido, o dónde se publica, sino qué saberes y prácticas aporta al campo de las ciencias sociales, cuáles legítima y para qué.

En este sentido metodológicamente el acceso al trabajo de campo fue consistente y sistemático, en tanto el rol asumido dentro del campo, adquirió sentido en el marco de un modo de comunicación preciso de la coyuntura social, como lo plantea Althabe (2005). Es decir, las integrantes de este colectivo no están habituadas a relacionarse con investigado- 
res y al vincularse mi acceso con gente de dicho colectivo quedé homologada a este grupo, dentro del contexto/coyuntura específica.

Debido a que las personas que fueron entrevistadas asocian la investigación al periodismo de denuncia, fue necesario tejer una estrategia metodológica con algunas integrantes del colectivo. Para ello se logró un ambiente ameno para la elaboración de los cuestionarios de la mano de una de las entrevistadas, quien adujo ser parte del "equipo de investigación" ante sus demás compañeras. Esta situación adquiere relevancia puesto que podrían haberse negado a mi presencia en sus casas y esto podría haber llegado a causar un problema, ante una eventual sensación de amenaza. Según Berreman (1962), el acceso al campo fue de la mano de la confianza generada entre las sujetas. Esto fue posible, por una conocida, como da cuenta en una de sus investigaciones, Abeles (2002).

Asimismo, diseñar una investigación en torno a las feminidades travestis y trans migrantes implicó pensar en situaciones no lineales, comprendidas en dimensiones y tiempos distintos, según Bourdieu (2007). Su estudio, entonces, requirió dejar de lado versiones estáticas y homogéneas de una cultura unitaria, teniendo en cuenta que la composición poblacional de estos bordes se caracteriza por su diversidad y dinámica compleja, fragmentada, creadora de entrecruzamientos varios.

Por ello, nuestra propuesta consistió en sistematizar, desde la experiencia, las particularidades de estas feminidades travestis y trans, entendidas en un doble sentido. Por un lado, como una tecnología de inteligibilidad, es decir, una serie de operaciones que nos permiten hacer inteligible y accesible la experiencia. Y, por otro, como un hecho político de gran importancia, como apunta Haraway (1994).

Por tanto, realizar una investigación con sujetas sociales que pertenecen a una comunidad que constantemente se percibe en peligro por el miedo y resquemor a les otres lo que, en ocasiones, se tradujo en reiterados pedidos de postergación a las entrevistas pautadas para realizar la presente investigación. Lo anterior, motivó a modificar y suprimir los nombres de las entrevistadas, optando en todos los casos por el uso de iniciales cuando así se lo requiera, las cuales no necesariamente responden al mismo, a los efectos de resguardar su identidad. A tales efectos, se puso a disposición de las entrevistadas los objetivos de la investigación académica llevada a cabo y se firmó, de común acuerdo, un consentimiento informado. Allí nos comprometimos a guardar la información por el grado de sensibilidad que reviste el tema e implicancia en algunas problemáticas que se describen en las entrevistas, como la droga, el fiolaje, y la relación intrínseca con la policía, entre otras. En la necesidad de priorizar el relato en primera persona, se conserva las formas propias de enunciar sus palabras. 


\subsection{La Informante clave}

Tal como esbozamos en el apartado anterior, es trascendental destacar el rol que ocupa la informante clave en esta investigación. Dado que este tipo de comunidades establecen barreras, como un modo de autoprotección con el afuera y, en algunas ocasiones también, entre sus mismos pares; estas personas fueron quienes posibilitaron el acercamiento, ingreso y permanencia en este colectivo de personas travestis y trans migrantes.

De esta manera, fue posible conocer la cotidianeidad que atraviesa a las feminidades travestis y trans migrantes peruanas, las charapas: sus modos de organización colectiva, así como los problemas internos, la existencia de la transfiola, la violencia institucional por parte de la policía, la justicia, la disputa con los medios de comunicación y algunos sectores de la sociedad civil.

A las primeras feminidades travestis y trans migrantes las conocimos en la parada $O$ la plaza en el año 2008. Allí estaba C, en el 2008, en la intersección de 1 y 58, -en la esquina de la Escuela Técnica Albert Thomas-. Ante la pregunta de quién era la referente para empezar a trabajar sobre el cese de la violencia policial y de los motoqueros ${ }^{4}$, que las golpeaban cuando estaban en las paradas, nos dijo que preguntáramos por $\mathrm{K}$ en 1 y 55 . Nos contó que estaba por viajar a Francia.

Durante este tiempo hemos podido entablar confianza con $\mathrm{K}$-nuestra primera informante clave-, para después conseguir una relación más fluida con la mayoría de las charapas. En el 2013 realizamos la primera entrevista sobre la historia de vida de K de manera exploratoria. Ahí pudimos advertir y corregir cuestiones respecto a la formulación de las preguntas, como también establecer el modo y los criterios en la selección de nuestras entrevistadas.

Asimismo, $\mathrm{K}$ se han constituido como referentes dentro del grupo de las charapas en La Plata. Ello nos facilitó adentrarnos a este círculo de feminidades travestis y trans migrantes, las cuales no permiten a menudo el ingreso de otras personas travestis y trans, tanto del mismo país, como de otro. El primer requisito para formar parte de este colectivo es "ser una charapa".

Previo a la realización de esta investigación, nos interrogamos acerca de cuáles aspectos íbamos a observar en relación con nuestro referente empírico - las charapas como feminidades travestis y trans peruanas migrantes en La Plata-, teniendo en cuenta que las personas implicadas no sólo comparten la identidad de género y la migración, sino también la prostitución como una práctica que les permite generar ingresos económicos de subsistencia, y para ayudar a sus familias en sus países de origen.

4 Según el testimonio de las entrevistadas, definen como "motoqueros" a un grupo de vándalos juveniles, quienes salían los días jueves y domingos por la noche en motos, con el fin de atacar violentamente con palos y botellas a las travestis y trans que se encontraban en sus paradas en situación de prostitución. 
Con este propósito nos adentramos, desde la observación participante para conocer su vida cotidiana y tener un acercamiento a sus experiencias en un espacio perteneciente al ámbito privado.

\subsection{Estudio de Caso}

Los estudios de caso son considerados como una respuesta al positivismo imperante del siglo XIX, el cual era el paradigma predominante en la investigación científica de las ciencias sociales, específicamente en la sociología y la antropología, las cuales adoptaron un criterio basado en el análisis y observación de situaciones específicas con mucha profundidad, como por ejemplo biografías de personajes, historia de instituciones, etcétera.

La utilización del estudio de caso como metodología será uno de los desafíos que la investigación enfrente, debido a su diseño complejo, las herramientas de recolección de informaciones requeridas, así como el ejercicio de análisis, interpretación y sistematización de los datos, fundamentalmente, por la multidimensionalidad que el fenómeno en estudio reviste. Para Robert Stake (1991) una de las ventajas de este método es que permite un estudio correlacional de la particularidad mediante la interacción de los contextos. En este sentido, la presente investigación aportará desde el abordaje del caso de las feminidades travestis y trans migrantes: las charapas, la oportunidad de comprender un fenómeno social complejo, a través de las características representativas que adquieren relevancia a la hora de analizar los modos organizativos que habilitan las prácticas político- comunicacionales colectivas.

A tales propósitos, algunos interrogantes que guiaron la investigación se construyeron en torno a indagar: ¿Cómo inciden las prácticas político-comunicacionales en la construcción y consolidación de las feminidades travestis y trans migrantes? ¿Las estrategias definidas de modo plural facilitaron u obstaculizaron nuevas configuraciones de la agencia política? ¿Qué modalidades asume en términos colectivos y subjetivizantes la constitución de la identidad charapa en el espacio público y qué desafíos enfrenta?

A partir de este momento, se diseñaron algunas herramientas de recolección de información, las cuales serán complementarias unas de otras, y así producir un análisis convergente de datos que permita contrastar los mismas con los supuestos que guían la presente investigación, en la intención de realizar un proceso interpretativo crítico a través de la sistematización de esta experiencia particular, y de ese modo, se constituya en un aporte sustancial al campo de la comunicación y los estudios de géneros, a la hora de abordar casos similares. 
Ana Lía Kornblit (2007) señala que este procedimiento interpretativo consiste en identificar en la vida de una persona un hecho clave, en este caso la migración, la cual adquiere un lugar central, en los sentidos y significados que los sujetos le otorgan. Por lo anterior, la metodología propuesta permitirá partir desde dicha perspectiva a fin de analizar las representaciones que construyen en torno a los acontecimientos estudiados en cada una de las etapas de su vida: antes del viaje, durante la migración y una vez arraigadas en la Argentina. Para eso privilegiamos un proceso inductivo, no a instancias de generalizar conclusiones, sino permitir el diálogo con casos similares y entretejer experiencias. El análisis consiste en trabajar en la interpretación de la experiencia a través de un movimiento constante para adelante y para atrás en el tiempo, en lo que se denomina un análisis progresivo-regresivo.

En este sentido, Sautu (1999) privilegia un enfoque biográfico basado en la indagación no estructurada de las historias de vida descritas en el relato de los propios sujetos a partir de un conjunto de técnicas metodológicas propias de los estudios cualitativos:

Kornblit (2007), plantea que las experiencias particulares de las personas recogidas a través de las historias de vida representan la posibilidad de recuperar los sentidos, vinculados con las experiencias vividas, que se ocultan tras la homogeneidad de los datos que se recogen con las técnicas cuantitativas. Pero, a la vez que permiten vislumbrar un mundo de significaciones, en ocasiones en torno de la intimidad, plantean también el desafío de volver a insertar los sentidos individuales atribuidos a la experiencia en el contexto social en el que ellos surgen, única vía de trascender lo particular y construir un saber más denso sobre lo social.

Este grupo tiene características particulares como, por ejemplo, el modo en que llegan a La Plata a través de redes migratorias internas, es decir, una trae a la otra. En su mayoría comparten la vivienda, costumbres, comidas, deporte, idiomas autóctonos de sus lugares de origen, fiestas de cumpleaños, la enfermedad, el encierro en las cárceles debido a la criminalización de sus identidades, el entierro en el caso del fallecimiento de alguna de ellas y, por último, la militancia. Estas prácticas plantean un modelo comunicacional que performó las prácticas de las charapas, específicamente, y consolidó ciertas modalidades organizativas colectivas que disputarán los sentidos predominantes que otros actores institucionales y no institucionales ponen a circular en el espacio público. 


\subsubsection{Las técnicas de recolección de información}

Para la definición de las herramientas seguiremos los lineamientos de Hernández Sampieri, (2010) quien considera que es "un proceso no lineal ni secuenciado, más sino como un conjunto de acciones en terreno que efectuamos para el logro de los objetivos de la investigación y las preguntas que guían el estudio, las cuáles, desde la perspectiva del autor, se yuxtaponen, son iterativas o recurrentes" (p. 408).

\section{La observación participante}

Esta herramienta cualitativa se distingue por la potencialidad de permitir explorar y describir los procesos, vinculaciones entre personas y sus situaciones o circunstancias, los eventos que suceden a través del tiempo, los patrones que se desarrollan, así como los contextos sociales y culturales en los cuales ocurren las experiencias humanas.

A estos propósitos construimos un diario de campo sin la pretensión de crear unidades o categorías de análisis estancas, sino para diseñar un esquema en el cual volcar las notas obtenidas de primera mano, y que al mismo tiempo, permiten dar cuenta de las primeras impresiones sensibles que se captan de la observación, por ejemplo, del ambiente (dimensionamiento témporo-espacial), las relaciones que se establecen entre las sujetas de la investigación (comportamientos verbales y corporales), y los procesos que constituyen (individuales y colectivos).

\begin{tabular}{|c|c|}
\hline Nota de Campo \#: & Convenciones: \\
\hline $\begin{array}{l}\text { Investigadora: } \\
\text { Lugar: } \\
\text { Día: } \\
\text { Hora y Duración: }\end{array}$ & $\begin{array}{l}\text { “....” Fragmentos Textuales de la Conver- } \\
\text { sación. } \\
\text { ( ) Aclaraciones. } \\
\text {---- Cuando se pierde información de lo } \\
\text { dicho. } \\
\text { //Descripción del Contexto } \\
\text { [ ]Interpretaciones - Impresiones }\end{array}$ \\
\hline Situación Observada: & \\
\hline
\end{tabular}

La técnica de la observación participante fue utilizada a la hora de describir las situaciones comunicacionales abordadas durante el trabajo de campo. Privilegiamos la construcción para registrar las condiciones habitacionales, los campeonatos de vóley, la elaboración y venta de comidas típicas, los velorios y entierros, entre otras prácticas político comunicacionales que desarrollan las charapas. 


\section{Entrevistas}

La entrevista cualitativa se caracteriza por ser una técnica basada en la conversación estructurada, semiestructurada o inestructurada entre una persona que realiza el relevamiento (investigadora) y les sujetes que forman parte de la experiencia, pudiendo ser por tanto, individual o grupal, lo que se denomina, generalmente, grupo de enfoque, pero que tiene características particulares.

Hernández Sampieri (2010) señala que, regularmente en la investigación cualitativa, las primeras entrevistas son abiertas y de tipo de prueba o piloto, para ello es imprescindible el rol de la informante clave, conforme éstas van estructurándose a medida que avanza el trabajo de campo. 


\section{ENTREVISTA ESTRUCTURADA.}

\section{Procedencia.}

¿Cuál es tu procedencia?

¿Cómo llegaste a la Argentina?

¿Cómo fue tu proceso migratorio?

¿A través de qué medios te trasladaste a la Argentina?

¿En qué punto se encuentra tu documento migratorio?

\section{Identidad de género.}

¿Cómo te identificas en relación a tu identidad de género?

¿Cómo fue tu proceso de reconocimiento de tu identidad de género

internamente y cuándo comenzaste a expresarla socialmente?

¿Enfrentaste algún conflicto durante el proceso?

¿Sufriste discriminación en algún espacio social?

¿Tuviste algún referente?

¿Utilizaste la ley de identidad de género para cambiar tu identidad?

\section{Origen étnico/ pueblos originarios.}

¿Cuál es tu origen?

¿Qué características tiene la comunidad de la que provienes?

¿Qué costumbres/prácticas conservas de tu lugar de origen?

4. Desarrollo laboral y educacional.

¿Cuál es tu nivel educacional alcanzado?

¿Cómo fue tu desarrollo escolar?

¿Cuál es tu vocación laboral?

¿En qué actividades te has desempeñado laboralmente?

¿En qué trabajas actualmente?

5. Formas de organización. OTRANS-ARGENTINA.

¿Cómo llegas a OTRANS?

¿Conoces el recorrido histórico de la organización?

¿Cómo son los modos de organización para visibilizar tus reclamos al Estado a través de OTRANS-ARGENTINA?

¿Cuál es tu forma de participación dentro de la organización?

¿Qué ha significado para ti la pertenencia a Otrans? 
De la población travesti y trans migrante peruana residente en la ciudad de la Plata, al momento del trabajo de campo, se relevaron 50 casos de una totalidad de 79 charapas. El criterio establecido no fue definido con anterioridad, más sino en oportunidad de contar con la predisposición de las entrevistadas (siguiendo la voluntad expresada por cada una de ellas). El propósito de realizar las entrevistas estructuradas radicó en la necesidad de explorar las características más generales de los casos abordados. De esta manera, pudo abarcarse una muestra representativa de la población estudiada.

Las entrevistas en profundidad, por su parte, permitieron ahondar en dos momentos que serán comprendidos como fundamentales para la constitución de la identidad charapa: las primeras etapas de vida y la migración/ arraigo. Esta técnica se llevó a cabo para el relevamiento de 40 casos, teniendo en cuenta el criterio de saturación y pertinencia de las variables analizadas. 


\section{ENTREVISTA EN PROFUNDIDAD}

\section{A. Primera etapa de vida:}

1. ¿Cómo fue tu infancia? ¿Cómo está conformada tu familia?

2. ¿Cómo era la relación con tus padres y familiares?

3. ¿Cómo era tu relación con las personas de tu entorno/barrio?

4. ¿Cuándo comenzaste a expresar tu identidad de género?

5. ¿Sufriste algún tipo de violencia o discriminación por expresar tu identidad de género durante tu infancia y adolescencia? Familia, barrio, contexto religioso e instituciones estatales (hospitales y centros de salud, comisarías, espacios públicos). ¿Cuáles?

6. ¿Cómo fue tu experiencia en las instituciones educativas?

7. ¿Cómo fue el trato recibido por tus profesores?

8. ¿Cómo fue el trato recibido por tus compañeres?

9. ¿Sufriste algún tipo de violencia o discriminación en la escuela?

10. ¿Cuándo empezaste a trabajar?

11. ¿Cómo eran tus condiciones de trabajo?

12. ¿Pudiste expresar tu identidad de género en tu ámbito laboral?

13. ¿Sufriste algún tipo de violencia o discriminación en tu espacio de trabajo?

\section{B. Segunda etapa de vida. Migración:}

1. ¿Cuándo decidiste venir a la Argentina?

2. ¿Cómo conociste la posibilidad de venir a Argentina?

3. ¿Por qué decidiste emigrar a la Argentina?

4. ¿Quiénes te apoyaron para que pudieras llegar a la Argentina?

5. ¿Pudiste tramitar tu documento de identidad?

6. ¿Cómo has construido tus vínculos sociales en Argentina? (amistades, relaciones de pareja, lugares que frecuentas)

7. ¿Cuál es tu relación con tus familiares en Perú?

8. Narra un día completo de tu vida cotidiana, desde que despiertas hasta que te

vas a dormir.

9. ¿Qué sueños/aspiraciones tienes para el presente y el futuro?

Análisis de Documentos, Materiales y Registros

Los materiales audiovisuales, los documentos escritos organizacionales y los registros de archivos públicos, son para Hernández Sampieri y Fernández Collado (2010), fuentes muy valiosas de datos cualitativos, que nos ayudan a comprender y dimensionar el fenómeno o caso estudiado. De hecho, reconocen que prácticamente, la mayoría de las personas, grupos y organizaciones los producen y narran, con el fin de delinear sus histo- 
rias y estatus actuales. Esto, en palabras de los autores, sirve a la investigación a la hora de conocer antecedentes de un ambiente, las experiencias, vivencias o situaciones y su funcionamiento cotidiano.

Algunas de las fuentes documentales que se privilegiaron para analizar en la presente investigación de estudio de caso fueron:

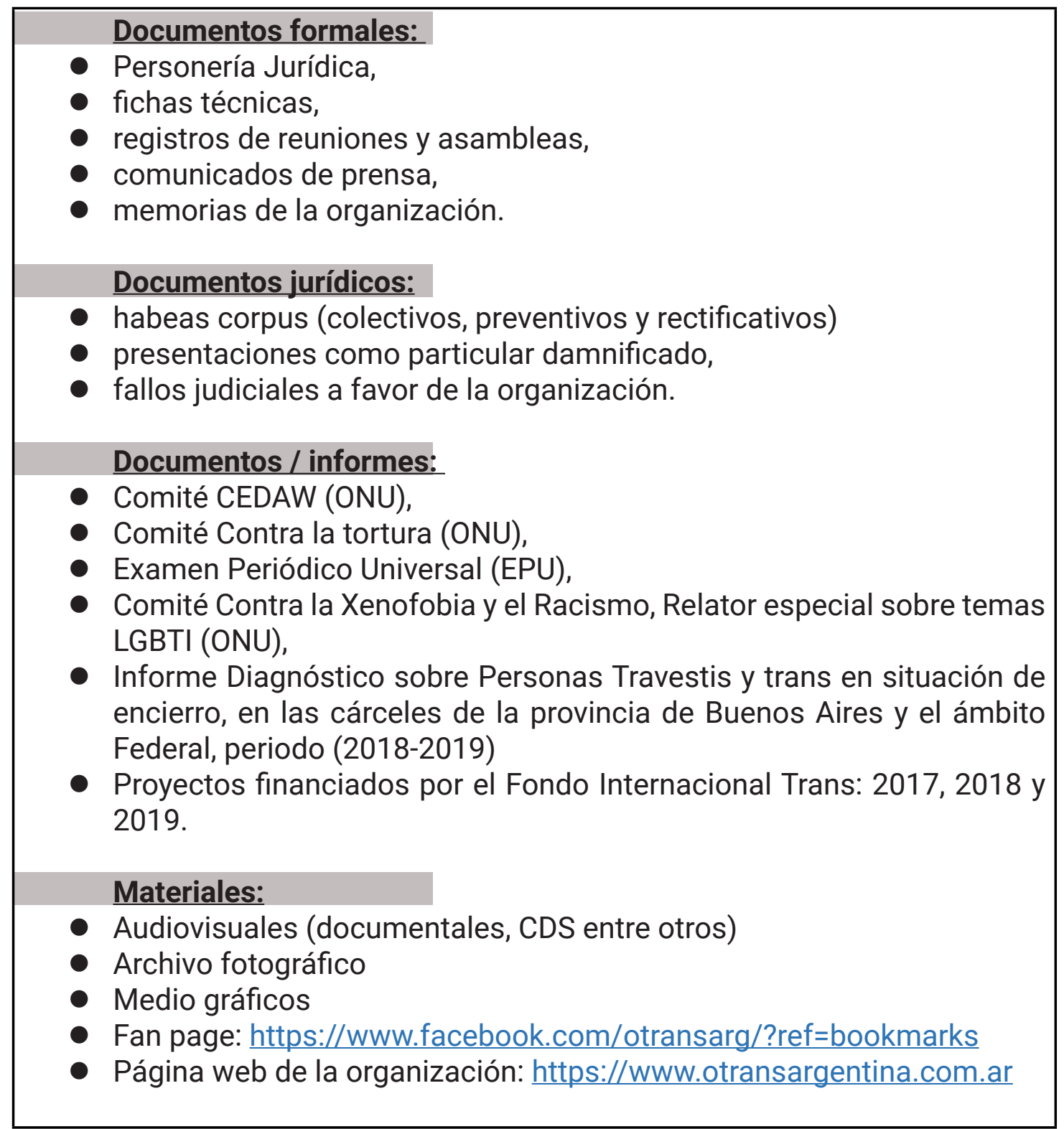




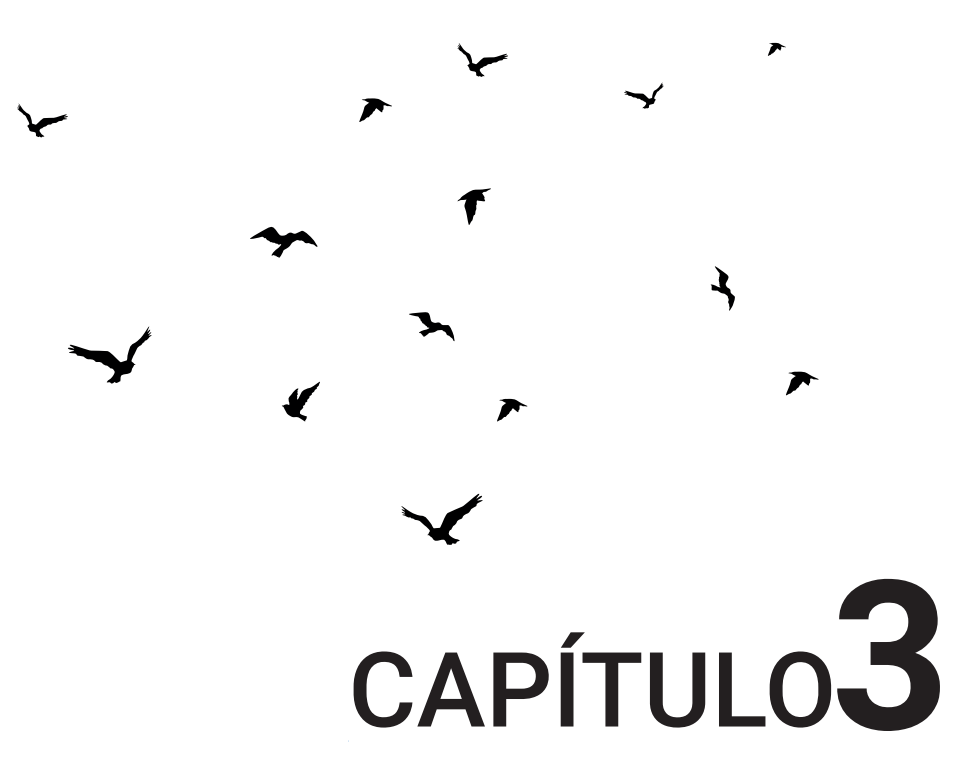

Marco Teórico Conceptual 


\section{La perspectiva comunicacional: prácticas político-comunicacionales}

Cuando pensamos hacer una lectura de las prácticas político-comunicacionales, nos propusimos indagamos el modo cómo estas inciden en la constitución del sujeto colectivo: las Charapas. Para ello, retomamos los aportes de Nidia Abatedaga y otres, según la cual, la comunicación facilita la asunción de lo que denomina formas de conciencia práctica, condición necesaria para elaborar modos de intervención colectiva con el objetivo de transformar aspectos de su propia realidad.

En este sentido, es que inscribimos este estudio, por un lado, considerando que las prácticas de este sujeto colectivo son políticas, porque están orientadas a la acción, y surgen a partir de las necesidades y prioridades definidas por quienes están involucrados. A la vez son comunicacionales, en tanto la comunicación posibilita el proceso dialógico y participativo a través del cual los sujetos reflexionan colectivamente sobre sus problemáticas.

De esta manera, la autora recurre a dimensionar el proceso que ocurre, de un lado, en el plano de la toma de conciencia de los sujetos, y del otro, en el que los sujetos actúan de modo colectivo, generando un cambio de actitud, tendiente al hacer práctico y comunicativo. La comunicación como práctica e intercambio de significados se incorpora facilitando la asunción de formas de conciencia práctica, posibilitando la configuración de intereses definidos y la apertura de posibilidades para intervenir sobre su propia realidad (Abatedaga, 2012; Abatedaga y Siragusa, 2014).

Con lo cual, atender a la praxis comunicativa, en estos términos, permitirá pensar los procesos de auto reconocimiento y auto constitución identitaria que surgen de las prácticas concretas y cotidianas que se da entre las charapas, y su relación con otros institucionales con los cuales articulan o confrontan. "Desde donde parten para la elaboración teórica y comprensiva del hacer en un proceso inductivo de construcción colectiva y de conceptualización, para posteriormente volver a la práctica enriquecida", (Abatedaga y Siragusa, 2014, pág. 24-25). 
Las prácticas político-comunicacionales, en definitiva, serán entendidas desde las interacciones que los sujetos establecen en el marco de la propia organización para desarrollar proyectos colectivos con el objetivo de la transformación social. Siguiendo a le investigadore Sergio Caletti (2001), no se puede pensar la política al margen de la comunicación, porque la comunicación está atravesada por la acción política.

En suma, entendemos la relevancia comunicacional de nuestra investigación, que pretende explorar estos sentidos construidos por los sujetos y las identidades atribuidas, para dar cuenta del proceso de construcción identitaria en el colectivo de las charapas. Identidades que se conforman dentro de ciertas condiciones socio-históricas y políticas, entre sujetos que experimentan la organización colectiva y la posibilidad de reaccionar ante determinadas situaciones como grupo.

Para ello, junto a Abatedaga y Siragusa, (2014) comprendimos que la perspectiva de la Investigación-Acción- Participativa, (IAP) aporta a un estudio centrado en el campo de la comunicación, la transversalización para intervenir en tipos de organizaciones que tiene novedosas modalidades de gestión horizontal y colectiva. Por cuanto consiste en "un proceso de investigación, producción de conocimiento e intervención, que parte de problemas sociales específicos buscando transformarlos y concretar un proceso colectivo de producción de saber" (p. 20).

Es decir, parten de asumir un modo de producción alternativo, que plante un desafío en la producción de conocimiento con les otres, para pensar juntes cuáles son sus problemáticas, y los posibles modos como mejorar su situación. Así, la importancia de la participación en un proceso de investigación-acción como el aquí esbozado, anida en contribuir a la producción de conocimiento "que tenga relevancia para la práctica social y política" (Fals Borda, 1985, p.279). Allí, la dimensión comunicacional se entiende siempre en relación a otros procesos sociales, procesos culturales, políticos, económicos, entre otros.

Desde este enfoque, la comunicación será transversal a los objetivos de transformación social que protagonizan las charapas, posibilitando una lectura crítica a los procesos dialógicos y participativos que tienen lugar, para la elaboración de significados compartidos a partir de los cuales reconocerse y diferenciarse como colectivo.

\section{La identidad como primer elemento de sociabilidad}

La presente tesis doctoral consiste en una investigación sobre las prácticas político-comunicacionales de las feminidades travestis y trans migrantes en La Plata: El caso de la comunidad trans migrantes peruanas las charapas. La investigación se enmarca desde 
una perspectiva interseccional crítica, a fin de contribuir en el campo de la comunicación, y de los estudios de género y la disidencia sexual a la sistematización de conocimientos sobre los modos agenciales que se construyen desde el colectivo travesti y trans, lo que se constituye en uno de los aportes sustanciales para el movimiento travestis y trans de la Argentina.

Asumimos esta investigación desde una teoría post-fundamento, inscripta en la necesidad de concebir la noción de sujeto y agente político lejos de un centro autónomo de soberanía y conocimiento, como una posición inestable, y como el efecto de constantes re-negociaciones estratégicas de la identidad. De esta forma, la identidad de género autopercibida alude a la percepción subjetiva que un individuo adopta sobre sí mismo en relación, en este particular, a su género, el cual podría o no coincidir con su sexo asignado al momento de nacer.

En cada sociedad y civilización, observamos un grupo de categorías de género construidas culturalmente, que pueden abonar la formación de la identidad social para une sujete en particular, en relación con otros miembros. En la mayoría de ellas, existe una división básica entre los atributos de género asignados a hombres y mujeres, lo cual conocemos como binarismo de género que responde a los ideales de la masculinidad y la feminidad en todos los aspectos del sexo y el género: el sexo biológico, la identidad de género y la expresión de género. Sin embargo, también hay algunas personas que no se identifican con algunos -o todos- los aspectos de género que están asignados a su sexo biológico. Así, damos en llamar a dichos individuos como personas transgéneros. Igualmente, en esta línea concebimos a las personas de género no-binario Chávez (2004).

En referencia al concepto de identidad existen múltiples aproximaciones desde la Psicología, la Antropología, la Sociología, la Filosofía, los Estudios de Género, entre otras ciencias sociales. Para los objetivos y el tema central de este trabajo, se decidió considerar nociones de identidad que hicieran hincapié en el aspecto relacional, construido y no estático de las identidades, teniendo en cuenta las transculturaciones que suceden durante el proceso migratorio, tanto para los migrantes como para los habitantes oriundos del lugar de destino.

En este sentido, Ángel Aguirre (1997) sostiene que las identidades implican a la vez, el conocimiento de pertenencia a uno o varios grupos sociales, la valoración de esa pertenencia y el significado emocional de la misma. Desde esta construcción de la identidad social, el individuo se afiliará a los grupos que afirmen los aspectos positivos de su identidad (individual y social) y abandonará la pertenencia a los grupos que pongan en conflicto su identidad. Desde un enfoque análogo, Manuel Castells plantea que todas las identidades son construidas: "Lo esencial es cómo, desde qué, por quién y para qué. La construcción de las identidades utiliza materiales de la historia, la geografía, la biología, las instituciones productivas y reproductivas, la memoria colectiva y las fantasías personales, los aparatos 
de poder y las revelaciones religiosas" (Castells, 1999, p. 26).

En este sentido, es interesante rescatar el concepto de pertenencia que aporta Ángel Aguirre Baztán. Según este autor, la pertenencia a un grupo se da como resultado de un proceso de categorización en el que los individuos van ordenando su entorno a través de categorías o estereotipos que son creencias compartidas por un grupo, respecto a otro; aluden a rasgos de personalidad como simpáticos, huraños, sinceros, características físicas -altos, fuertes, rechonchos-, conducta social como; trabajadores, vagos, responsables, al género; los hombres, las mujeres y sobre todo, a los grupos étnicos; gitanos, judíos, polacos y a los grupos nacionales; alemanes, franceses, italianos (Aguirre, 1999, p. 65).

Así, la identidad en tanto elemento en permanente construcción y reconstrucción, ya no como algo estanco o reificado implica, al decir de Castells un movimiento de identificación/desidentificación. Por tanto, la pertenencia a varios grupos provoca que los sujetos lleven a cabo un proceso de selección; esto es, del conjunto de rasgos culturales que caracterizan a los grupos de los que van seleccionando los valores, creencias, informaciones, opiniones, actitudes, prácticas y símbolos, con los cuales se definen a sí mismos, explican la realidad y guían sus acciones. De ahí que la identidad implica un proceso de construcción del sentido atendiendo a un atributo cultural, o un conjunto relacionado de atributos culturales, al que se da prioridad sobre el resto de las fuentes de sentido (Castells, 1999, p. 28).

La interdependencia de los conceptos de identidad y alteridad se comprueba en las reflexiones de López Aranguren (1993) quien, al abordar la dualidad entre el yo y el otro, relaciona la construcción de la identidad con el establecimiento de la personalidad de los seres humanos. Al yo, en tanto que uno por antonomasia, se opone el otro. Pero el otro, los otros me han precedido, me he hecho con ellos y, en mayor o menor grado, por ellos. La dualidad yo-tu, el aprender a ser a partir de los demás, de cómo me miran, me sienten me ven, genera mi capacidad de verme a mí mismo como si fuera otro, y en esta dualidad entre mi yo y mi alter-ego consiste la personalidad.

\section{Alteridad y Nostredad como componentes de la Identidad}

En tanto no es posible comprender la identidad sin la alteridad, también conocida como otredad, diremos que el individuo la desarrolla en la diferenciación que establece entre sí mismo y otras subjetividades, lo cual le propicia desarrollar un nivel de conciencia donde la noción de lo propio pasa por la comprensión de la individualidad de le otre.

La alteridad es entonces la definición del otre, por contraposición de la identidad, que es la definición de uno mismo. Existen distintos grados de alteridad y diversos modos de construirla. La alteridad es también multidimensional y, por ende, es posible relacionarla con los puntos de convergencia de las distintas categorías que manejamos en el presente estudio, si tenemos en cuenta que nos interesa abordar las problemáticas que se producen 
en este grupo, las charapas, desde la interseccionalidad.

La nostredad, en este sentido, se constituye en un lugar desde donde interpelar a les otres. A partir de esta idea, aparece la noción de saber qué no somos, más que lo que sí somos. Marlene Wayar, (2019), considera que la misma es una construcción, imaginaria, política, y nuestra. Clave en dónde se sintetiza la "otredad" de la que no nos podemos desentender y la "nostredad" travesti, donde una cuestión nodal es el aprendizaje surgido del ejercicio prostitutivo: praxis necesaria, no hay un libro que enseñe a ejercer la prostitución. Tampoco uno que enseñe a ser hombre o mujer o no ser estas opciones, solo violencias. Hemos aprendido a ciencia cierta que no somos lo hombre y no somos lo mujer que se nos ofrece desde lo pre-existente, como únicas alternativas legítimas y legales del ser. Somos una otra posibilidad de mismidad con densidad propia: somos travestis.

Las corporalidades travestis, en este sentido, y podemos a los fines de esta investigación afirmar, también, que la corporalidad trans, entre otras, han sufrido no solo violencia física, sino también discursiva. Han sido marcadas y signadas por la violencia interpretativa. Por eso el identicidio se constituye en el genocidio travesti por parte de la estructura social y jurídica normativa.

Las puertas que nos quieran cerrar nos habilitan para declararlas cómplices del ataque sistemático y generalizado que se comete en base a nuestro ligamen en común, la identidad (identicidio), que se traduce en asesinato, esclavitud, traslado forzoso y deportaciones, encarcelamiento y privación grave de libertad, tortura, violación, esclavitud sexual, prostitución forzada, violencia sexual, persecución, desaparición forzada de personas, el crimen de apartheid, y otros actos deshumanos de carácter similar que devienen en el no acceso a educación, salud, trabajo, vivienda. Es una trama que nos asola desde niñas, al menos entre los 8 y los 13 años. Un exitoso plan de exterminio con algunas fallas, como quien suscribe, que ha superado la media de mortandad de 32 años. Y además, continuamos naciendo (M. Wayar, comunicación personal, 10 de octubre 2018).

El Apartheid es, entonces, un ejemplo de esta violencia interpretativa que venimos enunciando. Cuando el ordenamiento jurídico habla del Apartheid o de los guetos -sean crímenes de lesa humanidad o genocidio- para fundamentarlo, lo hace teniendo en cuenta no sólo lo territorial, sino también lo temporal. Si tenemos en cuenta que a las travestis y trans, históricamente se les asignó un horario, que era el nocturno, y un lugar para poder transitar la ciudad (zona roja), y volver de día a esconderse en un hotel, no se les daba la libertad de poder ir al supermercado, al cine, a un parque a tomar mate, porque eran perseguidas, y objeto de pánico social.

En este sentido, podemos recordar los postulados de Rosana Guber (2014) quien plantea que somos sujetos cognoscentes y que todo sujeto cognoscente parte del desconocimiento al reconocimiento. Por eso, aquella violencia simbólico-interpretativa se traduce en una invisibilidad, una recusa a la producción trans de conocimiento. Les autores 
hablarán en términos de un transepistemicidio, en tanto representación del transodio en la producción intelectual, por recusar la capacidad de personas travestis y trans de producir saberes, y la ausencia de ellas en los espacios académicos, en tanto creadoras de conocimiento (Cantelli, Pereira, Oliveira, Tozo, \& Nogueira, 2019).

Si apelamos a la hermenéutica, encontramos que las travestis y trans se identifican como grupo. Hay toda una fenomenología que nace a partir de ese encuentro. Las distintas formas en que se da la convivencia y el lazo socio-afectivo, los modos en que reconfiguran nuevas familias-tipo, y no tipos de familia, que rompen con los estereotipos preconcebidos, se desarrollan a través de las maneras de alquilar una vivienda en común, de compartir alimentos y gastos, y experiencias conjuntas en las calles estando en situación de prostitución. El encuentro se replica también en las comisarías, en las visitas a los mismos hoteles, y los similares recorridos migratorios.

En esta línea, nos interesa recuperar la propuesta teórica de Héctor Schmucler (1984) cimiento en los estudios de la Comunicación. A través de su obra, “Un proyecto de comunicación/cultura", planteó el reemplazo de la Y por la barra, donde seguía existiendo una especificidad para cada uno de los conceptos, aunque también avizoraba el impedimento de abordar las problemáticas planteadas por ambos campos de estudio de forma individual. Una forma novedosa de interpretar y abordar las prácticas sociales, colectivas o individuales. Esta propuesta nos permite reflexionar acerca de las prácticas particulares de las charapas, cuando asumen modos colectivizantes a partir de la comunicación, pensada desde la cultura.

Tal como expresa Rosana Reguillo (1998), abordar la comunicación y derechos humanos alude a entender una relación cultural, se trata fundamentalmente del debate entre la inclusión y la exclusión, por lo que se impone un trabajo para el desmontaje crítico de los dispositivos, de aquellos discursos y mecanismos que, al decir de la autora, naturalizan la exclusión y expropian la posibilidad de la palabra a ciertos colectivos. Para analizar el modo en que estos discursos son construidos y representados en el espacio público, recurre a tres estrategias: el desmontaje de una expresión popular, la crítica a un pensamiento legitimado y el uso del relato etnográfico.

Abordar, en este sentido, la identidad en tanto constructo no esencialista ni reificado nos conduce a dimensionar el concepto de núcleos de asociatividad de Adriana Archenti (2016), el cual nos da herramientas para entender las formas de organización/actuación/ intervención que, desde los "intersticios"; -los cuales responden a relaciones no formalizadas, coexistentes con las formales, insertadas en ellas o colaborantes con su operación (tales como parentesco, amistad, patronazgo, redes, cuasi-grupos, mediaciones, etc; y a su vez a las maneras en que, habida cuenta de su peso constituyente junto a variables 
de pertenencia étnico nacional, regional, de clase, de género, de grupo etáreo, de matrices culturales, se producen -o se dificultan- que habilitan formas de filiación/pertenencia/ participación en iniciativas de organizaciones gubernamentales o no gubernamentales que intervienen o procuran intervenir sobre la incorporación, la promoción de derechos o la condición ciudadana, por ejemplo, de las personas migrantes.

\section{Identidad travesti y trans de las charapas: algunas conceptualizaciones claves}

El grupo social que estamos estudiando en la presente tesis doctoral, está contenido en el concepto de lo que las propias sujetas dan en llamar travesti, chica o mujer trans -transgénero-es por ello que consideramos necesario identificar que dicho constructo se define como una persona a la que se le ha asignado el sexo masculino al nacer, pero percibe su identidad de género como femenina.

Si se someten a tratamientos con el objetivo de adecuar su apariencia a la de su identidad autopercibida. Estas intervenciones pueden ser hormonales o quirúrgicas, como la mamoplastia de aumento y la cirugía de reasignación de sexo. En el caso de las charapas, la mayoría de sus miembras ha recurrido a tratamientos como los anteriormente referidos, que tienen que ver con la producción del cuerpo o montarse, en sus palabras: maquillaje, silicona, aceite de avión o silicona líquida, y la reafirmación de su identidad de género. No obstante, su autopercepción se haya más atravesada por la transgeneridad que por la transexualidad, viendo ambos criterios de una forma estricta, como lo plantea Martínez (2014).

En este sentido, la noción de la identidad o las identidades adquiere una mayor preponderancia, puesto que es este el elemento aglutinador por excelencia que propicia el motivo del encuentro, la participación y las diferentes dinámicas que tienen lugar durante el accionar cotidiano de la población estudiada, desde la socialización y el compartir de múltiples interacciones espacio-temporales. Todo ello a partir de la identificación como feminidades travestis y trans, y la condición de personas migrantes como ejes primordiales.

Para abordar el término transgeneridad, podemos seguir los criterios de la investigadora Anahí Farji Neer (2017). La autora entiende que la publicación de El género en disputa de Judith Butler en 1990, repercutió tanto en el ámbito académico como el militante. A partir de entonces comenzó a delinearse la teoría queer: una corriente de pensamiento que condensa el feminismo y los estudios gay-lésbicos con las corrientes teóricas del posestructuralismo y los estudios culturales. La teoría queer se erigió fuertemente contra aquel punto de vista sobre la sexualidad humana que concibe que los sexos son sólo dos: masculino y femenino. Radicalizando su propuesta frente a los desarrollos clásicos del feminismo, bregó por una desencialización de los sexos, los géneros y las identidades. El surgimiento de nuevas representaciones en torno al género y la sexualidad significó un cambio de epis- 
teme y generó las condiciones para que “las imágenes anticonvencionales, consecuencia de experiencias diversas, de biografías intransferibles, de variedad de espacios y ámbitos culturales, en lugar de considerarse 'desviadas' prefieran ser consideradas generadores de pluralidad". Es en dicho marco que surgió la categoría "transgénero".

A fin de dar cuenta del proceso de emergencia de esta categoría y sus distintas formas de apropiación y circulación, la autora retoma la genealogía del concepto elaborada por el antropólogo estadounidense David Valentine. Se remite a las primeras formulaciones identificadas por el autor: los desarrollos de Sandy Stone (1991), Susan Stryker (1994) y Kate Bornstein (1994). Según Valentine, la primera utilización del término transgenderist vino de la mano de Virginia Prince en la década de 1970. Esta activista estadounidense formuló el término para referirse a aquellas personas que, al igual que ella, vivían de forma íntegra en un género distinto al asignado al nacer sin el deseo de intervenir su genitalidad quirúrgicamente. Prince buscaba un término que visibilizara aquellas experiencias distintas a la transexualidad quirúrgica y al cross-dressing y que discutiera también con las categorías médicas del transexualismo y el travestismo. Un hito importante en el recorrido del concepto fue la publicación de The Empire Strikes Back: A Post transsexual Manifesto, por Sandy Stone en 1987.

Esta autora inscribió su escrito en el posmodernismo, el postfeminismo y el post transexualismo. Allí, confrontó el modo en el cual tanto el discurso médico como el feminismo fueron utilizados como herramientas de regulación del sexo y el género en general y de los cuerpos trans en particular. El título de su escrito emula al de la escritora feminista Janice Raymond titulado The Transexual Empire: The Making of the she-male escrito en 1979, que entendía la existencia de personas transexuales como parte de la estrategia del imperio falocrático para invadir los espacios femeninos. Stone se abocó a analizar la trama de lo que ella misma denominó "paradoja trans", que puede ser expresada de la siguiente manera: si por un lado el deseo de ser en el sexo/género elegido sustenta los marcos binarios existentes, por otro cuestiona el mantenimiento mismo de ese sistema. En este mismo sentido, para Stone el cuerpo transexual abre potencialidades intertextuales: desestabiliza el sistema sexo-género a través de la yuxtaposición de fragmentos y la reconstrucción de elementos de ambos géneros en nuevas e inesperadas geometrías.

La militante transgénero Susan Stryker, escribió My Words to Victor Frankenstein. Above the Village of Chamounix: Performing Transgender Rage (1994). Se trató de la adaptación textual de una performance desarrollada en el marco de una protesta frente a la reunión anual de la American Psychological Association (APA) en San Francisco. 
Según Stryker (1994) el cuerpo transexual es un cuerpo no natural. Es el producto de la ciencia médica. Es una construcción tecnológica. Su carne es desgarrada y cosida nuevamente, en una forma diferente de aquella en la que nació. En estas circunstancias, encuentro una profunda afinidad entre yo misma como mujer transexual y el monstruo de Frankenstein de Mary Shelley. Como el monstruo, soy percibida con demasiada frecuencia como menos que humana del todo, debido a los medios de mi corporización; como también le ocurre al monstruo, mi exclusión de la comunidad enciende en mí una profunda y sostenida ira que, como el monstruo, dirijo contra las condiciones en las que debo luchar para existir.

Stryker reivindicó la ira transexual como motor para la acción política y la definió como una experiencia subjetiva originada por la transgresión involuntaria de las normas de género. Para Stryker, el activismo transgénero debía oponerse a las intervenciones de la medicina sobre los cuerpos y subjetividades transexuales, reivindicando, por el contrario, las nociones de criatura, monstruo, y artificialidad. Debía denunciar que toda identidad sexo-genérica es una fabricación artificial y ficcional.

La activista Kate Bornstein (1994), en su escrito Gender Outlaw: On Men, Women, and the Rest of Us, desde el relato de su propia experiencia criticaba la gramática de la identidad transexual impuesta por el discurso médico. Puso en práctica un estilo transgénero de escritura y auto escritura: una idea de collage y de unión de fragmentos sin solución de continuidad. Para Bornstein, el estilo transgénero sería un gender outlaw por encontrarse fuera de las leyes del género. Como parte de una acción política sobre el propio cuerpo y la identidad, su relato describe y brega por la experiencia de desidentificación tanto de las categorías de hombre y mujer como de las de gay y heterosexual.

En ese marco, y en el contexto argentino, el activista y académico, Mauro Cabral (2003), define a la transgeneridad como un espacio por definición heterogéneo, en el cual conviven un conjunto de narrativas de la carne, el cuerpo y la prótesis, el deseo y las prácticas sexuales, el viaje y el estar en casa, la identidad y la expresión de sí, la autenticidad y lo ficticio, el reconocimiento y la subversión, la diferencia sexual y el sentido, la autonomía decisional y la biotecnología como instrumento que es, a la vez, campo de batalla. Es, por lo tanto, un espacio atravesado por una multitud de sujetos en dispersión y por todes aquelles que encarnan formas de vida no reducibles ni al binario genérico ni a los imperativos de la hetero o la homonormatividad. 
Diversidad sexual: consideración de las charapas como parte del colectivo TLGBI.

Por otro lado, nuestro grupo de estudio se encuentra siendo parte también de la categoría diversidad sexual, el cual es un concepto utilizado para referirse de manera inclusiva a toda la variedad de sexos, orientaciones sexuales e identidades de género, sin necesidad de especificar cada una de ellas, como tampoco los comportamientos y características que conforman esta pluralidad.

Usualmente, se emplean clasificaciones simples y herméticas en torno al sexo (hombres, mujeres e intersexuales), a la orientación sexual (homosexuales, heterosexuales y bisexuales) y a la identidad de género (transgéneros y cisgéneros), reunidas bajo las siglas LGBTI (Lesbianas, Gays, Bisexuales,Transgéneros e Intersexuales). Sin embargo, otras culturas poseen maneras diferentes de entender el sistema sexual. Es necesario conocer que, en las últimas décadas, diversas teorías filosóficas de la sexología, como la teoría queer, ofrecen nuevas perspectivas desde las que asimilar este constructo teórico nombrado diversidad sexual. Dicha clasificación resulta insuficiente para describir la complejidad de la sexualidad desde lo humano, e incluso también en otras especies animales.

Por ejemplo, puede que las personas experimenten una orientación sexual intermedia entre heterosexual y bisexual (heteroflexible) o entre homosexual y bisexual (homoflexible) o que ésta varíe a lo largo del tiempo, o que incluya atracción independientemente del sexo o género (pansexual).

La diversidad sexual también incluye a las personas intersexuales, que nacen con una variedad de características intermedias entre lo que biológicamente se concibe como hombres y mujeres. Además, también incluye todas las identidades transgénero y transexuales que no se encuadran dentro del sistema de género binario y que, al igual que la orientación sexual, pueden experimentarse en distintos grados más allá del cisgénero y la transgeneridad, como es el caso de las personas de género fluido.

Por último, la diversidad sexual también engloba a las personas asexuales, quienes experimentan desinterés en la actividad sexual. También se inscriben aquellas personas que consideran que su identidad no se puede definir, incluida en el ámbito anglosajón bajo el término paraguas "queer".

Sin embargo, y en palabras de Mary Nash (2001) no podemos hablar solo de un tipo de alteridad, puesto que "La percepción binaria de la alteridad oculta, sin duda la complejidad de las relaciones de poder y el complejo entramado de relaciones de género, raza, etnia y clase que juega en el complejo reconocimientos de sujetos históricos. 
Por ello, un abordaje como el aquí esbozado adquiere valor como antecedente para futuras investigaciones; alcanza vigencia tanto en el orden de las categorías propuestas como por la contemporaneidad de la problemática analizada, y contribuye a generar un aporte sustancial para las organizaciones o movimientos reconocidos en la diversidad sexual.

\section{butleriana. \\ Performatividad y vidas precarias. Aportes de la teoría queer desde la perspectiva}

Otra de les autores que se consideraron para la investigación es le filósofe y profesore Judith Butler, une de les primeros referentes que encontramos en la teoría queer y los estudios desde una perspectiva de género post-fundamento. La primera parte de su obra se desarrolla en torno a la teoría de la performatividad. Una de las fortalezas de la propuesta radica en que deconstruye el valor productivo del poder, ligándolo a la administración del género por parte de la norma social, por lo que esta producción del género crea la apariencia de una naturaleza identificable del sujeto.

Deshacer el género es una obra bisagra, en la que le autore estudia los cambios sociales y los nuevos movimientos que la norma falocéntrica toma como neonormativas de género productora de quimeras, donde la nueva política del género se representa en nuevas formas de vida, siendo estas afines a la transexualidad, al intersexo y al transgénero. Las relaciones que tienen estos movimientos con la teoría feminista y la práctica queer son dependientes del modo de producción de la identidad.

Hablamos de una identidad ya no presentada como un yo o entidad, sino como práctica de significación iterada, un producto de discursos reglados, siendo los sujetos capaces de establecer sus propios límites. Los discursos producen identidades y por consecuencia el género, pero su dominio dependerá del amor a la sujeción y el miedo a la exclusión. En esta línea, retomaremos las categorías de Butler a la hora de analizar cómo el colectivo de feminidades que se constituyen es el caso en estudio, las charapas, encuentran en la grupalidad un espacio de contención ante las realidades adversas que experimentan durante el viaje migratorio, las vicisitudes de arribar a la Argentina -territorio aún desconocido y ajeno- $y$, más tarde, la lucha por ocupar el espacio público, la cual comienza por obtener un lugar o "parada" en la calle donde ejercer la prostitución. Este mecanismo se da a través de dinámicas de socialización que posibilitan la viabilidad del trayecto.

Por otro lado, Butler se apropia de la "acción ética" del desdoblamiento presente en Foucault, donde la pretensión ética es el sujeto, que se "dobla sobre sí mismo", a modo de autoconsciencia y así, como un pliegue, puede hallar la resistencia al discurso heteronormativo. La conciencia de que el género es producido por repetición ritual de convenciones sociales, puede ser entendida como "la actuación" de una consternación interna nunca re- 
suelta. En el travestismo, la constitución "normal" del género representado está compuesta por un juego de apegos rechazados; de identidades que constituyen la potestad de lo "no representable”, del tabú. Es la expresión de un deseo, de transgresión por transgredir, usado como estrategia.

Pero no podemos malinterpretar la subversión al poder como estrategia de la pura transgresión. No toda violación de la norma es buena y deseable. Sin embargo, la confección de la identidad siempre nace desde un individuo o conjunto de individuos producidos en y por la matriz heteronormativa y, por tanto, toda mutación que parta de esta siempre guardará cierto parentesco. El caso de las charapas es posible entenderlo a partir de la insubordinación al binarismo de género.

El concepto de vida precaria, Butler lo introduce a partir de la dimensión ex-tática del sujete, una originaria desposesión fundado en la relación con otres:

La estructura de la demanda es importante para entender cómo se introduce y se sostiene la autoridad moral si aceptamos que cuando hablamos no sólo nos dirigimos a otros, sino que de algún modo ingresamos a la existencia, por así decirlo, a partir de la demanda, y algo acerca de nuestra existencia prueba ser precario cuando dicha demanda fracasa (Butler, 2006, p. 154).

Desde aquí, Butler se interesa por conocer las redes de relaciones dinámicas que se tejen entre las personas, y cómo activan el apoyo, la disputa, la ruptura, la alegría y la solidaridad. En sus palabras,

Las alianzas que pueden establecerse entre ciertas minorías o entre poblaciones consideradas desechables; o para ser más concretos, lo que me interesa es averiguar cómo la precariedad -ese término generalizado y, en cierto sentido, mediador- podría operar, o está operando ya, como un campo en donde se pueden establecer alianzas entre ciertos grupos

(...) considerados desechables (Butler, 2017).

Al describir la performatividad del género, el pensamiento de Judith Butler se inclina hacia el análisis de las posibilidades del género de abrir fronteras culturales que pudieran confrontar las hegemonías de los regímenes institucionales, incluyendo a la familia, que intentan "normalizarlo" para preservar un determinado orden de cosas.

Para Butler (2017), el género es performativo, porque incide en una puesta en acto: el género sería una clase determinada de práctica, y además destacamos que la "aparición" del género suele interpretarse erróneamente, como si fuera una señal de su verdad interna o inherente. El género sale a la luz a raíz de normas obligatorias que nos exigen convertirnos en un género o en el otro (generalmente en un marco de carácter estrictamente binario); la reproducción del género conlleva siempre una negociación con el poder y, por último, cabe destacar que todo género reproduce unas normas, y que cuando el género se pone repetidamente en acto, se arriesga a deshacer o modificar las normas en formas no previstas, de modo que la realidad del género puede quedar abierta a nuevas estructuraciones. 
Por eso, al hablar de precariedad, Butler presenta una perspectiva imbricada en los procesos de construcción de la performatividad, no exclusivamente ligados al género, sino también a la raza y a la clase, entre otras categorías sociales. En este sentido, la precariedad y la performatividad del género se constituyen en constructos interdependiente en las experiencias de vida que tienen les sujetes, fundamentalmente, en les que encarnan las disidencias sexuales. Con lo anterior, es menester atender cómo en el caso de las charapas, dicha conexión se pone de manifiesto a partir de la experiencia, es decir, en las estrategias que tejen colectivamente con el objetivo de hacerse visibles en el espacio público, en tanto ámbito privilegiado de disputa.

\begin{abstract}
(...) la performatividad del género es una teoría y una práctica que se ha enfrentado a las condiciones insostenibles en que las minorías sexuales y de género viven ( $y$ a veces también a esas mayorías de género que pasan por normativas a costa de graves consecuencias psíquicas y somáticas). Desde mi punto de vista, el término precariedad designa una condición impuesta políticamente, merced a la cual ciertos grupos de la población sufren la quiebra de las redes sociales y económicas de apoyo mucho más que otros, y en consecuencia están más expuestos a los daños, la violencia y la muerte (Butler, 2010, p.46).
\end{abstract}

En este sentido Butler (2017) plantea que los grupos más expuestos son los que más riesgo tienen de caer en la pobreza y el hambre, de sufrir enfermedades, desplazamientos y violencia, por cuanto no cuentan con formas adecuadas de protección o restitución. Esa condición impuesta políticamente maximiza la vulnerabilidad y la exposición de las poblaciones, de manera que quedan expuestas a la violencia estatal, a la violencia callejera o doméstica, así como a otras formas de vioIencia no aprobadas por los Estados, pero frente a las cuales sus instrumentos judiciales no ofrecen una suficiente protección y restitución.

\title{
Exilio socio-corporal
}

Siguiendo las pautas marcadas por la investigación Precaridad, (in)visibilización y exilio. Una lectura crítica sobre las ontologías sociocorporales trans desde la perspectiva de Judith Butler, definimos junto a su autora, Verónica Andrea González a la categoría de exilio, como un gesto simbólico mediante el cual garantizar la "pureza" de los ciertos tipos ideales y del imaginario de "lo público".

Seguimos así pues a la autora cuando se pregunta:

¿Qué es lo que amenaza, disturba o desestabiliza la "pureza" del paisaje urbano que la ciudad imagina para sus ciudadanos?, ¿es el exilio corporal el medio a través del cual se garantiza "el buen uso" del espacio público, y al mismo tiempo, condición de posibilidad de un sitio donde se realizarán los "ideales" de comunidad, en términos jurídicos? (González, 2015, p. 38).

González (2015) se apoya en diversas autoridades académicas y, a partir de ese reconocimiento aborda el concepto como una producción performativa que -producto de la delimitación y articulación espacial del imaginario- distribuye diferencialmente la legitimidad no sólo de las cuáles serán las 'sexualidades' posibles, sino también cuáles serán 
pasibles de visibilizar en el espacio urbano. Lo cual, no sólo pone de manifiesto la 'reacción' violenta que se esfuerza por mantener este tipo de imaginarios en torno a definir el 'otro amenazante' del que es necesario protegerse; sino fundamentalmente, del 'miedo' que produce la posibilidad de que ese imaginario sea desestabilizado.

Este razonamiento sirve a la autora al momento de analizar en qué medida la ciudadanía ideal se sigue sosteniendo en torno a argumentos tales como la preservación del 'bien común' o 'tranquilidad pública'. De esta manera, concibe dependerá la exclusión, la inclusión o el reconocimiento de ciertos cuerpos y prácticas dentro del imaginario normativo, en tanto sitio simbólico donde se realizarán los ideales de la comunidad.

Este acto de desplazamiento o 'reclusión' como lo llama oportunamente Lohana Berkins, le conduce a (re)pensar en el exilio socio-corporal que se pone de manifiesto producto del ejercicio de violencia arbitraria, que se produce y perpetúa a través de ciertas estructuras institucionales legales, maximizando políticamente las condiciones de ciertos sujetes:

\begin{abstract}
Estas vidas deshumanizadas, privadas de peso ontológico al implicar ciertos modos normativos de ser sujetos; como vimos desde la particular lectura arendtiana que realiza Butler, no entran en el dominio de la inteligibilidad social para ser reconocidas por el Estado y en tanto tal, no solo descalifican para la ciudadanía, sino que califican 'activamente' para convertirse en sin-estado. Esto, por un lado, puede leerse producto de la expansión que tuvo el accionar estatal más allá de la esfera de lo público -que antaño se entendía como campo privilegiado, relegado de lo privado o doméstico-; pero, por otro lado, por la privatización de dichos espacios públicos (González, 2015, p.40).
\end{abstract}

Es así como, con el fin de impugnar y anular aquellas formas de legitimidad política, González afirma se redistribuye el espacio, (re)significando la asignación espacial desigual a otros cuerpos con derecho a aparecer. Todo lo cual condujo, en consonancia con los planteos de Judith Butler, a cuestionar qué es una vida, qué valor tiene, cómo ha de reproducirse y en qué condiciones. En este sentido, la investigadora argentina concibe que el desplazamiento de tales cuerpos del campo ontológico deriva fundamentalmente de la proliferación de actos de violencia física y simbólica en tanto se manifiestan en el 'borramiento sistemático' de tales seres del campo de la inteligibilidad, en manos de la pretendida normatividad y perpetuidad de los argumentos morales que le dan forma (González, 2015).

\title{
Nociones de agencia y biopoder.
}

Siguiendo esta ruta, se han valorado los abordajes de autores y teorías que marcan las pautas históricas para los estudios del género y la sexualidad. De esta forma, uno de los 
referentes fundamentales es el filósofo, investigador, escritor y pionero en los estudios de géneros y las sexualidades Michel Foucault y, particularmente, su teoría de la bio-política.

Foucault explica ampliamente en varios de sus textos, y en particular en Nacimiento de la biopolítica, curso dictado en 1979 en el College de France, el concepto de biopolítica como elemento fundamental abocado a comprender la conformación del Estado y la sociedad modernos. Para Foucault, el desarrollo del biopoder y sus técnicas constituyen una verdadera revolución en la historia de la especie humana. Ello porque la vida está completamente invadida y gestionada por el poder, lo que fue fundamental para la expansión del capitalismo al crear los instrumentos para la inserción controlada de los cuerpos en el aparato de producción y mediante un ajuste de los fenómenos de población a los procesos económicos que generó una expansión inaudita de la acumulación de capital.

En este sentido, Foucault (2007) distingue dos técnicas de biopoder surgidas en los siglos XVII y XVIII; la primera es la anatomopolítica que se caracteriza por ser una tecnología individualizante del poder, basada en el escrutar en los individuos sus comportamientos y su cuerpo con el fin de anatomizarlos, es decir, producir cuerpos dóciles y fragmentados a través de mecanismos de vigilancia, control, intensificación del rendimiento, multiplicación de capacidades, emplazamiento, utilidad, entre otras categorías. El segundo grupo de técnicas de poder es la biopolítica que tiene como objeto a poblaciones humanas, grupos de seres vivos regidos por procesos y leyes biológicas. Esta entidad biológica posee tasas conmensurables de natalidad, mortalidad, morbilidad, movilidad en los territorios, que pueden usarse en la dirección que se desee. Así, según la perspectiva foucaultiana, el poder se torna materialista y menos jurídico, ya que ahora debe tratar respectivamente -a través de las técnicas señaladas- con el cuerpo y la vida, el individuo y la especie. Cabe agregar que el punto de articulación entre ambas técnicas radica en el control de la sexualidad como mecanismo de producción disciplinar del cuerpo y las regulaciones de poblaciones.

Lo inédito es que lo biológico se refleja en lo político, produciendo que la existencia vital entre de lleno en la modernidad, ya que los humanos, en función del poder que los rige, se juegan la vida en la política. Los efectos del biopoder hicieron que las sociedades se volvieran normalizadoras usando como instrumento la ley. Por otra parte, las resistencias entraron al campo de batalla que las estrategias basadas en el biopoder crearon, por lo que se centraron en el derecho a la vida y al cuerpo desplazando a otros objetos de luchas.

\section{Cultura ético-política como concepto antropológico}

El concepto de cultura, desde una perspectiva antropológica como lo propone Grimson (2011), se asocia a una cierta intervención ético-política, además de tener fuertes con- 
secuencias epistemológicas y metodológicas. El primer concepto antropológico de cultura se opuso a la idea de que hay gente "con cultura" y gente "sin cultura", de que el mundo se divide entre personas "cultas" e "incultas". En 1871 Tylor había planteado un concepto de cultura asociado a los conocimientos, creencias y hábitos que el ser humano adquiere como miembro de la sociedad. Todas las actividades y pensamientos humanos son aspectos de la cultura. Hay diferentes culturas, pero todos los seres humanos tienen en común el hecho de ser seres culturales.

Para Grimson, las ideas expresadas por Franz Boas introdujeron la noción de pluralidad cultural, según la cual no sólo era importante "la cultura" en singular sino también el estudio de "culturas" específicas. En su perspectiva, una cultura particular sólo es comprensible a partir de su historia. Una creencia o un hábito cultural sólo pueden ser comprendidos en el marco de un universo específico de sentido. Durante mucho tiempo el etnocentrismo "científico" fue contemporáneo del colonialismo.

La suposición de que los pueblos no occidentales eran inferiores constituía un argumento que legitimaba el poder colonial. En ese sentido, antropólogos como Malinowski promovieron una crítica de la concepción racionalista del "hombre" dominante en Occidente. Sostuvieron que, lejos de ser "salvajes" e "ilógicos", los pueblos no occidentales tenían un estilo de vida distintivo, racional y legítimo que debía ser valorado. Esta tesis entra en tensión con la proclamada misión civilizadora del proyecto colonial europeo.

Después del Holocausto, explica Grimson en su análisis, las concepciones racialistas quedaron desacreditadas. A medida que se deslegitimaban los criterios biológicos, comenzaron a explorarse otros modos de clasificación. Después de 1945, con el abandono del concepto de raza para legitimar legislaciones o políticas públicas, aumentó sostenidamente el uso social y político del concepto de cultura.

Para pensar cómo el significado de cultura, visto como un conjunto de elementos simbólicos o bien como costumbres y valores de una comunidad asentada en un territorio es problemático en términos teóricos y ético-políticos, Grimson habilita el criterio de entender el mundo como archipiélago de culturas. Las principales dificultades teóricas que presenta surgen de que tiende a considerar a los grupos humanos como unidades discretas clasificables en función de su cultura, como en otras épocas lo eran en función de la raza, sustenta la clasificación en el supuesto de que esas unidades tienen similitudes internas y diferencias con su exterior, y diseña un mapa de culturas o áreas culturales con fronteras claras.

Al hablar de la cultura como recurso político, nos conduce el autor a encontrarnos ante situaciones muy diferentes: desde la defensa del "ser nacional" como parte de las retóricas de la discriminación culturalista en Europa, hasta los fundamentalismos culturales 
cada vez más presentes en la geopolítica internacional. También es necesario considerar la culturalización de los movimientos y los reclamos de grupos subalternos, como asimismo los logros legales de sectores históricamente discriminados en América Latina. Se verá, entonces, que el recurso político de la cultura no tiene un signo único, sino que diferentes sectores pugnan por apropiarse de él. Se verá, también, que ineludiblemente esa generalización de la cultura tiene efectos políticos específicos y delimitables.

Otro criterio interesante para enriquecer el análisis de los modos en que se configuran las charapas como grupalidad y se insertan en el escenario socio-político argentino, es el constructo entendido como lazo social. Siguiendo esta línea, pensamos la cultura, en tanto formación social, como un fundamento esencial humano que requiere del lazo social para determinar cómo se conforma la sociedad y, de esta manera proponer un tipo de subjetividad que responda a esa manera de hacer lazo social. Asimismo, concebimos al lazo social según lo plantea Ignacio Lewkowicz (2004), en tanto una ficción eficaz de discurso que hace que un conjunto de individuos constituya una sociedad, y a la vez, instituye los individuos como miembros de esa sociedad.

\section{Estigma social.}

El término estigma es frecuentemente empleado con el fin de designar a aquellas señales que marcan a una persona de distintas maneras. La palabra tiene origen griego, y hacía referencia a un tipo de marca que consistía en un corte o una quemadura en la piel. Esta marca identificaba a criminales, esclavos o traidores, que eran rechazados por la sociedad.

El término estigma social fue acuñado por Erving Goffman (2006) y se define como el rechazo social por características o creencias que van en contra de las normas culturales establecidas. En este punto, Goffman, establece 3 categorías que causan el estigma social: tribales (etnia, religión); diferencias físicas (obesidad, enfermedad mental, etc.) y; estigmas asociados al comportamiento o a la personalidad (delincuencia, homosexualidad, etc.).

El estigma social hace referencia a las actitudes y creencias que conducen a las personas a rechazar, evitar y temer a aquellos a quienes perciben como diferentes. Es un atributo que "convierte" a una persona en distinta de las demás, en alguien "menos apetecible" y hasta inferior con respecto a la figura de una "persona normal y corriente". En realidad, aclara Goffman, el concepto de estigma no debe entenderse de un modo esencial, sino relacional. Por ejemplo, en el caso de la diversidad funcional, podría decirse que ésta no es necesariamente un atributo desacreditador. El atributo que en apariencia identifica a una persona como discapacitada lo que hace en realidad es contraponerla a una idea de normalidad atribuida a otras personas. 
La elaboración, construcción y reproducción de argumentos estigmatizadores no es algo propio de sociedades y épocas concretas. Estos procesos se deben considerar como un fenómeno universal y consustancial a la propia esencia humana, ya que se dan allí donde existan relaciones humanas; su manejo, así pues, es un rasgo general de la sociedad, un proceso que se produce dondequiera que existan normas de identidad.

La construcción de un estigma suele realizarse para poner en contraposición la existencia de un grupo ajeno al considerado como verdadero; por lo tanto, debe hacer referencia a elementos diferentes, elementos propios de ese grupo objeto de estigma que lo hacen profundamente distinto; es por ello que el estigma es utilizado para hacer referencia a un atributo profundamente desacreditador.

En este sentido, podemos analizar los conceptos de táctica y estrategia desarrollados por el historiador y filósofo francés Michel de Certeau (1996). La táctica es el recurso del débil para contrarrestar la estrategia del fuerte. La estrategia es puesta como la "manipulación" por parte del sujeto con poder, que es aislable, es colocada como ese lugar que va a buscar lo que es propio (voluntad propia), ésta va primero que nada a reconocer su ambiente, visualizar el espacio para luego imponerse sobre el mismo. Un ejemplo de ello es el ejército con sus estrategias militares, que se inicia primero que nada con la construcción y el control mediante la vista, de los espacios propios. Las estrategias son acciones con finalidades de poder y totalidad, se interesan por las relaciones espaciales (un ejemplo es el panóptico), pues los lugares ofrecen una victoria sobre el tiempo.

Por otra parte, la táctica debe actuar a partir de la imposición de una fuerza (ley, dominación) externa, ésta se presenta audaz y muy astuta frente al poder. La táctica actúa en el momento preciso, transformando la situación de manera beneficiosa para el que carece de poder (precisamente porque carece de lugares y espacios propios, ha de valerse de los espacios del poder, pero actuando rápidamente, audazmente.). Las estrategias ponen sus esperanzas en la resistencia que el establecimiento de un lugar ofrece al deterioro del tiempo; las tácticas ponen sus esperanzas en una hábil utilización del tiempo. Una táctica muy utilizada es la parodia: provocar la risa en el espacio mismo del poder.

\section{Fundamentalismo cultural, Epistemicidio y Transepistemicidio}

El término epistemicidio fue acuñado por Boaventura de Sousa Santos en la obra "Pela Mão de Alice", y posteriormente utilizado por otres autores para reflejar la influencia de la colonización europea y del imperialismo capitalista sobre los procesos de producción y reproducción de la vida. El epistemicidio puede ser entendido como el aniquilamiento de conocimientos, de saberes y de culturas no asimiladas por la cultura blanca/ occidental. Es 
un subproducto del colonialismo instaurado por el imperialismo europeo sobre los pueblos asiáticos, africanos y de las Américas.

En este sentido, hablar de transepistemicidio, apuntan (Cantelli, Pereira, Oliveira, Tozo, \& Nogueira, 2019), es hablar sobre una invisibilidad, una recusa a la producción trans de conocimiento. Sería la representación de la transfobia en la producción intelectual, por recusar la capacidad de personas trans de producir saberes, y la ausencia de personas trans en los espacios académicos en tanto productoras de conocimiento.

Siguiendo el análisis de Alejandro Grimson (2011), el fundamentalismo cultural, al igual que el racismo, consiste en una estructura conceptual y en acciones que distinguen y jerarquizan a los seres y grupos humanos según condiciones supuestamente inherentes a ellos, naturales. El racismo clásico implica ideas y prácticas de menosprecio y odio hacia personas de rasgos fenotípicos diferentes. Se basa en una ideología que presupone que la humanidad se divide en razas, que hay una continuidad entre lo físico y lo moral, que los grupos humanos son homogéneos, que existe una jerarquía única de valores y que es necesaria una política fundada en el saber. En cambio, el fundamentalismo cultural implica ideas y prácticas de menosprecio y odio hacia personas presuntamente portadoras de una cultura diferente.

Las nociones racistas se sustituyen por otras equivalentes: la humanidad se divide en culturas; hay continuidad entre el territorio, la cultura y lo moral; las culturas son homogéneas y mutuamente inconmensurables; existe una jerarquía única de valores y es necesaria una política basada en la propia cultura. En síntesis, el racismo justifica el sometimiento de la alteridad por su supuesta inferioridad, mientras que el fundamentalismo cultural justifica la segregación del otro en función de las diferencias culturales y de su manera de conceptualizarlas. El racismo se elogia a sí mismo como civilizador; el fundamentalismo cultural se auto-exalta como preservador de la diversidad, y especialmente de "nuestra pureza".

La noción de fundamentalismo cultural fue utilizada por la antropóloga Verena Stolcke, (1999) para conceptualizar una retórica de exclusión que exalta la identidad nacional fundada en el exclusivismo cultural. Stolcke analizó la "nueva retórica de la exclusión en Europa" basándose en su propio estudio de las formas de discriminación hacia los inmigrantes en las décadas de 1980 y 1990. Cabe señalar que el fundamentalismo cultural es un procedimiento de diferenciación "genuinamente distinto del racismo tradicional". La especificidad del fundamentalismo cultural es su cosificación de la cultura, a la que concibe como un todo compacto y territorializado. A su vez, la xenofobia (como odio y hostilidad hacia los extranjeros) se postula como una actitud inherente a la naturaleza humana. Al considerar la nacionalidad como cultura, las culturas como inconmensurables y la nacionalidad como un prerrequisito de ciudadanía, este fundamentalismo construye una barrera infranqueable para los inmigrantes. 
Según Stolcke, desde fines de la década de 1970 ha surgido una retórica de la inclusión y de la exclusión que subraya las diferencias de identidad cultural, tradiciones y herencia entre los grupos, y acepta la delimitación cultural basada en el territorio. En esos años los conservadores británicos sostenían que los seres humanos, por naturaleza, prefieren vivir entre sus semejantes antes que en una sociedad heterogénea. La llegada de grandes cantidades de inmigrantes destruiría la "homogeneidad de la nación", haría peligrar los valores y la cultura de la mayoría, y desataría un conflicto social.

Grimson (2011), argumenta que el concepto de fundamentalismo cultural puede aplicarse hoy a muchos otros fenómenos sociales y políticos. Actualmente, la inmigración es escenario y capítulo clave del fundamentalismo, aunque éste se exprese en, y domine, muchos otros terrenos. Constituye un argumento clave para la reorganización de la geopolítica internacional y para la codificación de diversos conflictos sociales y bélicos.

\section{La heteronormatividad como régimen disciplinador}

La heteronorma o heteronormatividad podemos entenderla como el régimen impuesto socialmente, tanto en el ámbito político, económico, epistemológico, entre otras áreas de incidencia, que asigna las relaciones sexual-afectivas heterosexuales mediante diversos mecanismos médicos, artísticos, educativos, religiosos, jurídicos, etc. y mediante diversas instituciones que presentan la heterosexualidad como necesaria para el funcionamiento de la sociedad y como el único modelo válido de relación sexo-afectiva y de parentesco. El régimen se retroalimenta con mecanismos sociales como la marginalización, la invisibilización o la persecución, considera Adrienne Rich (1980).

Su basamento consiste en un sistema dicotómico y jerarquizado, lo cual encierra la teoría de que todos los seres humanos se enmarcan en dos categorías distintas y complementarias: varón y mujer. A partir de este postulado, dictamina que las relaciones sexuales y maritales son normales solamente entre personas de sexos diferentes y que, además, cada sexo tiene ciertos papeles naturales en el desarrollo evolutivo de la humanidad, lo cual ubica a dicha categoría bajo criterios biologicistas y patriarcales. De esta forma, el sexo biológico asignado al nacer, la identidad de género y el papel social del género deberían encuadrar a cualquier persona dentro de normas íntegramente masculinas o femeninas. Por ende, la heterosexualidad es calificada como la única orientación sexual normal y aceptada.

Las normas que este término describe o crítica pueden ser abiertas, encubiertas o implícitas. Quienes adoptan posturas críticas a la heteronormatividad, desde los estudios de género y las nuevas tendencias de la antropología, sostienen que deforma el discurso al 
estigmatizar conceptos diferentes, tanto los relacionados con la sexualidad, el género, y las expresiones de género.

Por otro lado, las problemáticas sexo-genéricas, tanto en su interacción mutua como en el terreno de la disputa por el uso del espacio público, también pueden ser abordadas a partir de las interpretaciones sobre los baños públicos como espacio por excelencia que han desarrollado autores como Paul Preciado y Jack Halberstam. Ambos estudiosos han ahondado profundamente en estas cuestiones, donde se configuran los roles de género y se visibilizan las fronteras que determinan la pertenencia a uno u otro género, siempre desde el binarismo.

Estas identidades, que podemos entender como expresiones del sujete humano en términos socioculturales y antropológicos, están permanentemente signadas por el binarismo y atravesadas, además, por otras cuestiones culturales que tienen que ver con los efectos de la globalización de la información y los nuevos modos socio-políticos de asociatividad, los cuales abordaremos más adelante en el marco del presente capítulo. Es la ruptura con esa normatividad la que problematiza la indagación sociológica y comunicacional que intentamos desempeñar en el desarrollo de nuestro estudio.

Feminidades travestis y trans migrantes: las charapas. Una comunidad cruzada por el mestizaje, la etnicidad y los pueblos originarios.

El travestismo como categoría paradigmática aparece descrito desde la Real Academia Española como una alteración o adaptación hispana de la palabra «transvestite». Este concepto fue acuñado por el médico, sexólogo y activista alemán Magnus Hirschfeld (2018), quien la incluyó por primera vez en su obra de 1910, en castellano, "Los travestidos: una investigación del deseo erótico por disfrazarse”. Etimológicamente, la palabra proviene del latín «trans», 'cruzar' o 'sobrepasar', y «vestite», «vestire» o «vestitus», 'vestir'. El término sirvió para describir a personas que voluntariamente utilizaban vestimentas socialmente ordenadas al sexo opuesto asignado al nacer.

La palabra ya existía en inglés (travesty) antes de su establecimiento para referirse a este tipo de comportamiento, pero se utilizaba para referirse al subgénero dramático del burlesque victoriano, el travesty (posible origen etimológico italiano o francés). El travesty es un tipo de burlesque que ridiculiza de manera trivial o cruda los temas socialmente dignificados. En las representaciones dramáticas del travesty era común la ridiculización de los preceptos de la etiqueta social y el comportamiento de la aristocracia, por lo que frecuentemente se recurría al cross-dressing y al drag para lograr una completa sátira de dicha alocución.

Antes del establecimiento del término se utilizaban otros similares para referirse a lo cis-género discordante presente en las personas. Entre los más comunes se encontraban los términos utilizados como peyorativos que referían al afeminamiento o la masculiniza- 
ción y otros términos como: ginomanía, andromanía, fetichismo de afeminamiento/fetichismo de masculinización y hermafroditismo físico.

Siguiendo las pautas de Gloria Anzaldúa en su texto Borderlands/La Frontera. The New Mestiza, resulta valioso para la presente investigación destacar su manera de concebir la hibridación de razas o mestizaje. La autora plantea este concepto como un maridaje complejo entre un conjunto de variables socioculturales, más allá del componente biológico visible, que lo conforma como un elemento de distinción entre diversos registros humanos, sujeto igualmente a formas de discriminación y segregación social, las cuales involucran espacios de existencia y conectividad a estratos identitarios e interpersonales para las personas migrantes en el marco de una realidad socio-económica dada. En este sentido, Anzaldúa argumenta que,

(...) La ambivalencia por el choque de voces da lugar a estados mentales y emocionales de perplejidad. La lucha interior genera inseguridad e indecisión. La personalidad dual o múltiple de la mestiza está acosada por el desasosiego. (...) la mestiza es un producto de la transferencia de los valores culturales y espirituales de un grupo a otro. (...) la mestiza se enfrenta al dilema de la raza mezclada. (...) la mestiza sufre una lucha de carnes, una lucha de fronteras, una lucha interior. Como todas las personas, percibimos la versión de la realidad que nos comunica nuestra cultura. Como otras personas que poseen más de una cultura o viven en varias, recibimos mensajes múltiples, a veces contradictorios. Cuando se juntan dos marcos de referencia, coherentes en sí mismos, pero normalmente incompatibles el uno con el otro, se produce un choque, una colisión cultural (Gloria, Anzaldúa, 1999, p. 134).

\section{Colonialismo como forma de gobernabilidad}

La colonialidad es también una realidad que atraviesa transversalmente la grupalidad de las charapas. Al provenir de Perú y de regiones con mayoría poblacional de pueblos originarios, el encuentro con la colonialidad impuesta por el hombre blanco condiciona sus historias de vida y deja huellas indelebles en su cosmogonía como comunidad. En figuras como Franz Fanon y Aimé Cesaire, encontramos grandes precedentes significativos a la hora de abordar la problemática del colonialismo para América Latina. Este concepto relacionado al criterio de gobernabilidad de Michel Foucault, se distingue como el modo de gobierno moderno desde el siglo XVI, sin embargo, está limitado al entorno europeo, que no tuvo en cuenta que las colonias fueron un ámbito de ejercicio por excelencia de esta forma de gobernar.

En el texto Descolonizando el Feminismo: Teorías y Prácticas desde los márgenes, editado por Liliana Suárez Navaz y Rosalva Aída Hernández Castillo se expone la hipótesis de que la gobernabilidad colonial instituyó como lógica de gobierno (como su legitimación) la inferioridad del "otro" colonizado. Uno de los rasgos fundamentales que caracteriza el colonialismo en tierras latinoamericanas, frente a otras formas de dominación es la centralidad de la "diferencia colonial". La técnica de categorización asociada con esta forma 
de gobernabilidad consiste en definir la "normalidad dominante" con base en la creación de alteridades radicales encarnadas en colectivos sociales naturalizados como esencial e insoslayablemente diferentes. Ambos conceptos - colonialismo y gobernabilidad- se encuentran imbricados con el concepto de identidad, ya que inciden en la configuración de la esencia humana y de sus prácticas políticas. En este sentido, la cosificación del subalterno colonizado es una problemática compleja que se suscita al interior de los procesos de la colonialidad que padecen las personas migrantes. Césaire lo expresa de la siguiente manera:

"Me toca ahora plantear una ecuación: colonización=cosificación. Oigo la tempestad. Me hablan de progreso, de "realizaciones", de enfermedades curadas, de niveles de vida por encima de ellos mismos. Yo, yo hablo de sociedades vaciadas de ellas mismas, de culturas pisoteadas, de posibilidades suprimidas" (Aimé Césaire, 2006, p. 20).

\section{Migración}

Según la perspectiva de Abdelmalek Sayad (1984),las personas "no-nacionales" (i.e. extranjeros, "nacionales" de otra nación y de otra nacionalidad, de otro orden nacional) ubican por simetría a la emigración como la ausencia fuera del orden nacional (i.e. fuera de la nación, primero, y segundo, tarde o temprano, fuera de la nacionalidad) de los "nacionales", lo que implica que ella es la presencia de los "nacionales" en otro orden nacional (en una nación y en el seno de una nacionalidad extranjeras); el inmigrante es el "no-nacional" (el extranjero, por lo tanto el "nacional" de otro orden nacional, de una nación y, hasta nuevo aviso, de una nacionalidad extranjera). Igualmente, la inmigración es la ocasión de realizar prácticamente, en el modo de la experiencia, la confrontación entre "nacional" y "no nacional", es decir, es al mismo tiempo un extranjero -en el sentido jurídico o "nacional" del término-, es decir de otra nacionalidad. No ignoramos que, más allá de esta definición relativamente abrupta que solo retiene la nacionalidad o el estatus jurídico como único principio diacrítico, la realidad es más compleja: ser inmigrante en un país diferente del propio terruño. Por otro lado, para desaparecer como inmigrante, esta vez en el sentido social del término (inmigrante definido, aquí, tomando en cuenta los efectos de la sola consideración social, que duplican los efectos de la condición o del origen étnico y hasta racial y de origen nacional). Inmigrante designa cada vez con mayor frecuencia una condición social, mientras que extranjero corresponde a un estatus jurídico-político; este último puede cambiar sin que nada cambie en la primera o sin que cambie nada en absoluto.

El inmigrante, expresa Sayad, es un no-nacional que sólo es a título provisorio y que sólo tiene como razón de ser la razón que le da el trabajo que cumple y en tanto que lo cumple; al mismo tiempo, esta misma exclusión emana de las mismas características: el inmigrante, que únicamente ha de ser a título provisorio y solamente por razones de trabajo, 
no puede más que estar excluido de lo político. Son inmigrantes de ese orden (y, correlativamente, una cosa lleva a la otra, los inmigrantes se excluyen de ese mismo orden), y la emigración fuera de un orden político del cual los emigrantes son por ese mismo hecho excluidos y del cual ellos se excluyen.

Por tanto, el inmigrante pone en "peligro" el orden nacional forzando a pensar aquello que es impensable, lo que no ha de ser o lo que no debe ser pensado para poder ser; fuerza a develar su carácter arbitrario (en el sentido en que la lingüística entiende la palabra: no necesario), a desenmascarar los presupuestos; fuerza a revelar la verdad de su institución y a actualizar las reglas de su funcionamiento.

El orden de la inmigración, continúa Sayad, y de la emigración es tan tributario del orden nacional, es decir de las categorías o de los esquemas de pensamiento que han constituido este orden, que conduce a la herejía a todos los discursos, todas las prácticas que no están conformes o que no adhieren inmediatamente a la representación espontánea, ordinaria, casi natural que se tiene de uno o de otro orden. Entonces, si es posible considerar la "nacionalidad", es decir la pertenencia (nacional) o la no-pertenencia a la nación, como la objetivación de la nación, y el código de la nacionalidad que rige esta pertenencia.

\section{Migración y globalización.}

Los efectos de la globalización en las migraciones son uno de los campos de estímulo del imaginario colectivo, ya que la expansión de los modelos culturales de los países más poderosos tiene una gran incidencia sobre las poblaciones periféricas debido a la redundancia de los mensajes hegemónicos, la espectacularidad de los medios de comunicación de masas, y el desarrollo de una comunicación que construye ideas míticas sobre las ventajas de emigrar a otras tierras. La globalización para Benítez Eyzaguirre (2006) desarrolla su eficacia en la lógica del beneficio directo, tangible e inmediato, para el que es imprescindible el acompañamiento de un sistema de exclusión social que lo justifica y acelera. El acceso a la tecnología, a la propiedad y a los recursos han provocado, entre otros factores, el reparto desigual y la permanencia de este estado de cosas que sigue una pauta cada vez más restrictiva para los perjudicados, conforme los dispositivos de exclusión son más complejos y escapan del alcance de ellos, puesto que esta dominación está apoyada también en el acceso desigual a la educación y el conocimiento.

Si consideramos la migración como una decisión de racionalidad económica, habrá que estudiar los mecanismos de inestabilidad que se desarrollan a partir de percepciones sobre las que actúa la lógica del beneficio para el caso particular que nos ocupa, las charapas de la selva peruana en su viaje migratorio hacia la Argentina.

Obtenemos que, en los elementos de la dinámica especulativa, el dominio de la comunicación es la que garantiza la capacidad de manipulación de las percepciones. Se trata 
de corroborar que la decisión de emigrar en los seres humanos está guiada por la información y la comunicación, y al fin por la producción de significados que las orienta, sean estos económicos o no. El papel de las nuevas tecnologías y la madeja de relaciones sociales que genera a su alrededor son fundamentales a la hora de configurar estas decisiones.

La globalización, en este sentido, tiende a desarraigar a las personas, las cosas y las ideas, considera Octavio lanni (1998). En palabras de Jérôme Monnet (1999), sin perjudicar sus orígenes algo se les desprende o resulta indiferente. Todo tiende a desarraigarse, así se desarrolla el sorprendente proceso de desterritorialización, una característica de la sociedad global en formación.

De lo anterior, se desprenden tres conceptos diferentes y complementarios que resultan fundamentales a la hora de concebir los procesos migratorios en la era de la globalización:

Territorialización: proceso de identificación, definición y producción de un espacio como territorio, realizado por un actor geográfico sea individual o colectivo, Monnet (1999);

Desterritorialización: desarraigo de costumbres, identidades, ideas, sistemas de valores o, también, pérdida de poder y control sobre un determinado espacio, lanni (1998). A este último nos referiremos cuando hablemos de desterritorialización de los grupos sociales vinculados a la prostitución y a las invasiones;

Reterritorialización: proceso de la posesión del espacio por un nuevo grupo social que impone sus reglas sobre otros, o por la recuperación del control por un grupo social anteriormente establecido. Siempre referido al cambio y adopción de un nuevo control sobre el espacio.

\section{Migración transnacional.}

Los autores, (Portes \& Guarnizo, 1991; Portes \& Landolt, 1996), definen y delimitan el concepto de transnacionalismo a ocupaciones y actividades que requieren de contactos sociales habituales y sostenidos a través de las fronteras nacionales para su ejecución. El transnacionalismo supone la presencia de vínculos entre el inmigrante, la comunidad de origen y la de llegada. Estos vínculos se activan en un determinado momento, permitiendo el desarrollo de iniciativas tanto económicas, como sociales y culturales, que generan un fuerte impacto en las sociedades de salida y destino.

Por otro lado, Thomas Faist y Christian Ulbricht (2013) señalan la importancia de diferenciar los distintos tipos de espacios transnacionales. Plantea que la sola presencia de un grupo de inmigrantes provenientes de un mismo país no implica la configuración de un espacio transnacional. A su vez, señala que existen diferencias sustanciales entre distintos espacios transnacionales. Estas especificaciones nos permitirán entender, en el caso de Chile, por ejemplo, la dinámica de las comunidades de inmigrantes peruanos y las diferencias con respecto a las comunidades de inmigrantes ecuatorianos o argentinos. 
En virtud del tipo de vínculos, los autores distinguen los espacios transnacionales siguientes: grupos de parentesco transnacional, circuitos trasnacionales, y comunidades transnacionales.

a) Los grupos de parentesco transnacional corresponden al caso de muchos inmigrantes de primera generación y refugiados. Los lazos que los unen con las comunidades de origen son recíprocos, por lo que es frecuente el envío sistemático de remesas a quienes se quedaron atrás. Este mecanismo opera hasta la reunificación familiar y difícilmente subsiste a la muerte de la primera generación.

b) Los circuitos transnacionales se caracterizan por un flujo constante de bienes, personas e información entre los países emisores y receptores de inmigración. Los lazos que mantienen unidos a los inmigrantes de uno y otro lado de las fronteras son de carácter de intercambio, donde los recursos disponibles en ambas sociedades son aprovechados por los inmigrantes para establecer actividades económicas, negocios, etc.

c) Las comunidades transnacionales son propias de situaciones en las cuales quienes se mueven y quienes se quedan en determinados lugares están conectados por una densa red de relaciones sociales y simbólicas que se mantienen a través del espacio y del tiempo. El tipo de relaciones en estas comunidades está basado en la solidaridad. Para ello, se requiere que las relaciones que dan vida a los sistemas de parentesco queden superadas. Casos típicos de comunidades transnacionales son las diásporas.

\section{Redes migratorias.}

Según, (Douglas Massey \& otros, 2000, p.27) “Las redes de migrantes son conjuntos de lazos interpersonales que conectan a los migrantes, primeros migrantes y no migrantes, en las áreas de origen y destino mediante lazos de parentesco, amistad y de compartir un origen común".

Esta teoría ratifica que la migración puede ser tanto una decisión individual como familiar y que genera cierta facilidad para que otros integrantes del hogar o de la comunidad puedan migrar, lo cual no interfiere con algunas teorías antes mencionadas; sin embargo, aun cuando las redes sociales facilitan estos movimientos, en algún momento el mercado laboral llega a saturarse, lo que hace necesario pensar en nuevos destinos de desplazamiento; por lo tanto, no se puede hablar de una perpetuación de la migración.

Esta saturación a la que se hace referencia, es un aspecto que debe analizarse con prudencia en el estudio de las redes migratorias, ya que el objetivo de estas es facilitar todo 
el proceso migratorio. Sin embargo, si el mercado salarial y las tasas de empleo disminuyen, los flujos migratorios también; por consiguiente, aunque se trate de una teoría que explica los beneficios que tiene para el desplazamiento hacia otros lugares el tener contacto con personas que ya hayan pasado por un proceso similar, es importante destacar que éste no es un mecanismo único que pueda explicar este complejo fenómeno.

\section{Pueblos originarios. Las charapas como comunidad pluriétnica proveniente de la selva peruana.}

Denominación colectiva aplicada a las comunidades originarias de América, que corresponde a los grupos humanos descendientes de culturas precolombinas que han mantenido sus características culturales y sociales, la mayoría de ellos con su lengua propia.

El uso del término se ha difundido por su empleo en los Estudios Culturales, las cátedras universitarias y la prensa, en los cuales se lo considera una manera políticamente correcta de referirse a las comunidades previamente denominadas «indígenas».

Héctor Hugo Trinchero (2009), considera que uno de los criterios, consiste en definir a las poblaciones a partir de la negación de rasgos y atributos generados por la sociedad occidental. Son sociedades sin Estado, sin economía, sin escritura, sin religión, etc. En este caso se los define a partir de la carencia, de aquello que no poseen culturalmente. Este planteo remite a cierto etnocentrismo ya que se supone que se trata de poblaciones en un estadio evolutivo inferior al occidental por lo que aún no desarrollaron las instituciones propias de la modernidad.

En contraposión a la ecuación de una "raza = cultura", propia de los enfoques culturalistas, Barth (1976) enfatizó "(...) el hecho que los grupos étnicos son categorías de adscripción e identificación que son utilizadas por los actores mismos y tienen la característica de organizar la interacción entre los individuos" (pag., 10 y11). Por esto a partir de la influencia de la obra de Barth, los antropólogos van a resaltar el carácter relacional de las identidades sociales.

El otro elemento que surge a partir de los 70' es la premisa respecto a las identidades como producto de un sistema de relaciones nos permite comprender el concepto mismo de "indio" o "indígena". En este sentido, Bonfil Batalla (1992), va a advertir que la categoría supraétnica de "indio" constituía una forma de designar al colonizado dentro de una estructura colonial que incluía al colonizador.

Es decir, según Batalla, la definición de "indio" no se basa en el análisis de las particularidades propias de cada grupo ya que el espectro de variaciones es amplio que ninguna definición a partir de sus características internas puede incorporarlas a todas. Entonces, la categoría de indígena no denota ningún contenido específico de los grupos que abarca, 
sino una relación en el sistema social global del que los mismos forman parte. Así, el "indio” como categoría genérica e indiferenciada que abarca la totalidad de pueblos originarios, solo tiene sentido en el contexto del orden colonial, cuya característica es identificar a los pueblos colonizados en oposición a los colonizadores (Bonfil Batalla, 1992, págs., 25 y26).

\section{Interseccionalidad:}

El concepto de interseccionalidad de Kimberlé Crenshaw (1995) en este trabajo será clave, por cuanto le autore consideró que había categorías como la raza y el género que interseccionaban e influían en la vida de las personas. Según esta perspectiva de abordaje, el racismo no tenía los mismos efectos sobre los hombres que sobre las mujeres negras, y tampoco vivían el sexismo como las mujeres blancas. En este sentido, el análisis partía de una estructura primaria donde interseccionaban, al tiempo que la raza y el género, la clase social, a la que se añadían otras desigualdades como la condición de mujeres inmigrantes. Es decir no se trata de una suma de desigualdades, sino que cada una de éstas interseccionaban de forma diferente en cada situación personal y grupo social, mostrando estructuras de poder existentes en el seno de la sociedad.

De esta manera, Crenshaw diferenció entre la interseccionalidad estructural en relación a las consecuencias de la intersección de varias desigualdades en la vida de las personas; y la interseccionalidad política que afecta a la forma en que se contemplan estas desigualdades y cómo se abordan. Todo lo cual, le permitía denunciar que las estrategias antirracistas del gobierno americano estaban diseñadas considerando sólo a los hombres negros como categoría general, y desconsiderando la perspectiva de las mujeres. Más allá de los aportes teóricos que ofrece esta perspectiva, el término de interseccionalidad ha sido formulado desde el feminismo como respuesta a un feminismo occidental exclusivo que no consideraba a las mujeres de otras razas y clases sociales. 
2

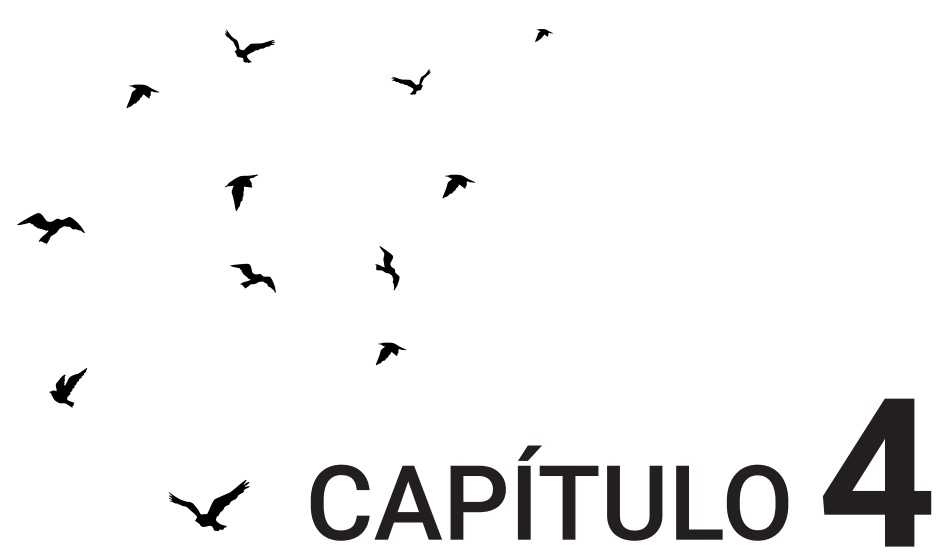

Contexto histórico del movimiento travesti y tras en Argentina. 
Capítulo 4.- Contexto histórico del movimiento travesti y trans en Argentina. Inscripción y articulación socio-histórica de las feminidades travestis y trans migrantes peruanas, las charapas.

En este capítulo proponemos una historización del movimiento travesti y trans en la Argentina. Nos interesa recuperar la memoria del colectivo en cuestión para conocer el pasado más reciente. Asimismo, daremos cuenta de la articulación de este movimiento y la incursión de las feminidades travestis y trans migrantes peruanas, las charapas, en acciones colectivizantes que permiten potenciar estas dinámicas político-comunicacionales en el contexto de las luchas y reclamos por la exigibilidad del cumplimiento pleno de sus derechos y el ejercicio de la ciudadanía.

\subsection{Construcción y problematización del movimiento travesti y trans en Argentina.}

Cuando se piensan de manera individual, comunicación y derechos humanos en Argentina nos conducen a revisar la historia. Una historia que encuentra en la década de los 70 momentos claves a partir de los cuales esbozar un contexto histórico. Los derechos humanos en Argentina tienen la característica de transpolar normativas estructurales. Son, además, el resultado de una historia marcada por el terror instaurado desde el Estado, la persecución y la desaparición de personas, por un lado; pero también la lucha, la organización y la resistencia, por el otro.

Este legado histórico, los modos en que se encuentra anclado en el pasado y las recurrentes formas de emerger en el presente, constituyen una de las piedras angulares de la reflexión en torno a los derechos humanos en Argentina.

Es decir, no podemos hablar de derechos humanos sin estudiar, conocer y resignificar las experiencias traumáticas de la más reciente dictadura. En tal sentido, la matriz de la que nace el discurso de los derechos humanos está estrechamente vinculada a las dinámicas y estrategias de configuración del pasado. $Y$ el modo en el que se han articulado y articulan las múltiples memorias, ofrece igualmente una plataforma sobre la que inscribir el devenir de los derechos humanos.

El movimiento travesti y trans, al ser muy joven, posee especificidades para su análisis, como así también para la construcción de una historia propia, narrada y escrita por quienes la han protagonizado. Es el resultado de las luchas emancipatorias de los últimos 30 años, y se ha nutrido de esos reclamos sociales y políticos en relación a las luchas de las Madres y Abuelas de Plaza de Mayo, H.I.J.O.S, de los organismos de derechos humanos, del movimiento feminista, de mujeres originarias, del movimiento piquetero, la lucha de Ixs migrantes en la Argentina, las luchas del movimiento lésbico-gay, entre otros. Todo ello 
permitió configurar un colectivo con agenda propia, y con una lectura clara sobre la responsabilidad del Estado y sus instituciones. Asimismo, ha generado alianzas estratégicas para visibilizar sus reclamos, entendiendo a sus integrantes como sujetas políticas e interlocutoras válidas.

En este apartado intentamos reconstruir momentos claves de la historia reciente del movimiento travesti y trans en Argentina, en términos de organización social y política, identificando la década del '90 como el período fundacional en las luchas del colectivo por el reconocimiento de sus derechos y el ejercicio de la plena ciudadanía. Al mismo tiempo, si bien es cierto que esta es una década donde se produjo una fuerte impronta migratoria de países del cono sur ${ }^{5}$, la llegada de las charapas será posterior.

La contracara de la represión, es el surgimiento de la organización. La idea en este trabajo es pensar que hay acontecimientos claves, determinantes, que reconfiguran "nuevos" modos de organización. Un ejercicio de la memoria que parte de las experiencias y procesos subjetivos, pero que también son, al mismo tiempo, el resultado de prácticas y experiencias colectivizantes. Apelamos a la razón anamnética ${ }^{6}$, en términos de Kaufman (2011). Una forma de memoria aquella que no consiste en el pasado recordado sino en el pasado olvidado, en la rememoración. Lo olvidado es aquello que es olvidado por causas que se encuentran en el presente y refieren a las condiciones de injusticia. La razón anamnética, en tanto que rememoración actualiza una significación que contribuye a la comprensión del presente. Es decir todo relato histórico del pasado de los oprimidos invoca las compadecencia de la razón anamnética, sin ella se convierte en ideología. Es por esto que debemos dar cuenta de estos hechos en forma cronológica, de los procesos y debates político-comunicacionales del colectivo travesti y trans en Argentina, en particular para el caso de las charapas.

En este momento histórico, podemos advertir el surgimiento y la conformación de las primeras organizaciones de feminidades travestis y trans, junto a los nombres de las compañeras protagonistas: Lohana Berkins, Nadia Echazú, Claudia Pía Baudracco y Marlene Wayar, entre otras, lo cual nos permite situar el contexto histórico.

Si pensamos en términos generacionales, se complejiza la utilización de parámetros y estadísticas creados por la sociología, como por ejemplo la Estadística Descriptiva y la

\footnotetext{
5 En realidad la migración latinoamericana hacia la Argentina es histórica -sobre todo de bolivianes y paraguayes, les peruanes arribaron un poco más tarde-, pero es a partir de los años 90 cuando se hace más visible, porque hubo un cese de la inmigración blanca europea hacia el país (Revista Migraciones Internacionales. Reflexiones desde Argentina. Organización Internacional para las Migraciones. Buenos Aires. 2002).

6 Se plantea la pregunta por la memoria en el sentido benjaminiano de la razón anamnética. Es una pregunta que se interroga sobre el pasado como tránsito para el interrogante radical sobre el presente como acontecer y sobre la condición de la justicia en la actualidad. Es entonces la pregunta que se compromete como una inclinación ética y política tanto con la actualidad como con el futuro del "nunca más", el advenimiento del horror.
} 
Estadística Inferencial, para dar cuenta del común de la sociedad. ${ }^{7}$ En este sentido, es válido enfatizar que la demarcación etaria que establece la Sociología no aplica a la presente investigación, debido a que el universo involucrado posee características particulares, como la baja expectativa de vida, que no supera los 35 años de edad ${ }^{8}$. Asimismo, los modos de ingreso a la participación política ocurren a través de un devenir que responde más a la coyuntura política, social, económica y cultural; y no está anclado a la edad biológica, lo cual permitió el empoderamiento político de sujetas travestis y trans en el contexto de la Argentina.

De esta forma, podemos establecer una primera generación de feminidades travestis y trans en los '90, la segunda en el 2000 y, la tercera, del 2010 en adelante. A interés de este capítulo, nos preocupa indagar sobre algunos momentos específicos de la historia. El desafío es narrarse, pasar de la cultura oral a poner en palabras escritas lo que podríamos denominar una contextualización del movimiento travesti y trans en Argentina.

En este contexto, podemos ubicar al menemismo, movimiento que surgió en ciertas condiciones culturales y políticas que lo hicieron posible. Marcó una época y, al igual que el período, que comenzó en 1945 o el breve lapso en 1973-1974, dejó huellas culturales.

Como lo comenta A. Grimson (2019), Menem no solo fue electo en 1989, ganó también las elecciones legislativas de 1991 y de 1993, y fue reelecto en 1995. Menem expresó un fenómeno social y cultural de la Argentina de esa época. Y por eso, comprender al menemismo es necesario para conocer una de las facetas del peronismo en Argentina.

El menemismo produjo un daño estructural a la economía y la sociedad argentina. No obstante, en su época consiguió un gran sostén y consenso social. Menem redujo la

7 Estadística Descriptiva consiste en el recuento, ordenación y clasificación de los datos obtenidos por las observaciones. Con esos datos se elaboran tablas y se representan gráficas que permiten simplificar los datos que aparecen distribuidos. Con esta información es posible calcular parámetros estadísticos tales como la frecuencia, moda, mediana, media y desviación estándar. No se hace uso del cálculo de probabilidades y únicamente se realizan deducciones directamente a partir de los datos y parámetros resultantes. El conjunto de observaciones se llama población o universo. Cada elemento de la población se denomina individuo o unidad estadística. Por ejemplo, un jefe de familia, las familias o viviendas de una localidad. Se denomina muestra a un subconjunto limitado obtenido o extraído de la población con el propósito de facilitar o reducir el número de experiencias. Las características observables de una población pueden ser cualitativas (sexo, Estado Civil, preferencia política, etcétera) y cuantitativas (peso, edad, estatura, número de hijos vivos o muertos, etcétera). https://sites.google.com/site/sociologiayestadisticas/repaso-de-los-conceptos-de-estadistica

Estadística inferencial consiste en lograr con confianza conclusiones respecto a la forma de proceder del fenómeno que se estudia. La estadística inferencial plantea problemas de previsiones y conclusiones generales de una población considerando los resultados obtenidos de una muestra. Los modelos estadísticos utilizan el resultado observado (muestra) y el resultado desconocido (población). En este caso la construcción y estudio se sustentan en el cálculo de probabilidades. https://sites.google.com/site/sociologiayestadisticas/repaso-de-los-conceptos-de-estadistica

La importancia de la estadística inferencial consiste en realizar descripciones, predicciones, comparaciones y generalizaciones de una determinada población estadística obtenida de una muestra. Por lo regular se trata de muestras grandes para poder utilizar la estadística inferencial. Además, utiliza la estadística descriptiva y se apoya, sobre todo, en el cálculo de probabilidades.

8 Las organizaciones de América Latina informan que el promedio de la expectativa de vida de las mujeres trans en la región es de 35 años de edad o menos. En este sentido, la CIDH ha observado que, si bien parece que los hombres gay de todas las edades son objeto de violencia, en el caso de las mujeres trans, son mayormente las mujeres trans jóvenes quienes son víctimas de violencia. 
tasa de pobreza durante una parte de su gobierno. Alcanzó, además, a construir mayorías en la Argentina durante varios años.

Sería un grave error no dar cuenta de los beneficios coyunturales que la convertibilidad llevó a sectores amplios de la población. Podemos comprender la especificidad de la década del 90 al conectar esos beneficios con el relato que el gobierno proponía sobre la inserción en el primer mundo, por un lado, y con la destrucción del horizonte de imaginación política a partir del cual el menemismo hizo su viraje fundacional por el otro (...) Los 10 años de gobierno de Menem deben separarse en 2 etapas. Desde su asunción en 1989 hay una fase crítica y conflictiva, hasta el establecimiento de la convertibilidad en 1991. Menem asumió el 9 de julio de 1989 en un país convulsionado. Luego de su triunfo electoral en mayo, "hizo pública su decisión de no reproducir las orientaciones de anteriores gobiernos peronistas, aun cuando era notorio que desconocía todavía cuáles serían sus nuevas políticas" (Sidicaro, en Grimson, Alejandro, 2019, p.15).

\section{Primera generación. Los 90: Resistencia y negociación.}

La democracia retorna a la Argentina en 1983. Sin embargo, para el colectivo travesti y trans, los años 90 significaron la continuidad de un latente estado de sitio. Las prácticas de persecución, hostigamiento, vejaciones, tratos crueles e inhumanos, torturas y muertes por parte de la policía, se agudizaron. Para el colectivo travesti y trans, el estatus de democracia alcanzado socialmente en este período, era una ficcionalidad. El derecho a una identidad reconocida por el Estado, será un logro posterior, del que daremos cuenta más adelante en la presente investigación.

\footnotetext{
Vale ahora plantear una diferencia: para las travestis, el estado de sitio es a diario. La rutinaria persecución policial, las acostumbradas restricciones a circular libremente por las calles portando una identidad subversiva, los permanentes obstáculos para acceder a derechos consagrados para todos/as los/as ciudadanos/as del país, entre otros, hacen de la vida travesti una vida en estado de sitio" (Berkins en Mafía; 2003, págs. 127-137).
}

Una de las primeras prácticas en pos de la visibilización de las identidades travesti/ transexual -la identidad trans va a ser posterior en el tiempo histórico- en el espacio público, va a estar mediada por la resistencia y la negociación constante con los agentes de la seguridad y con una trama de sujetos, con quienes la policía comparte el poder y el dominio de las calles. Pero estos grupos presentan algunas fisuras al interior de sus organizaciones, es decir algunos de sus integrantes, son quienes van a recibir dinero, a cambio de poder transitar algunos espacios prohibidos para las travestis.

Estas prácticas incipientes van a desembocar en la organización, principalmente en Ciudad Autónoma de Buenos Aires, luego en La Plata, capital de la Provincia de Buenos Aires, y en las ciudades cabeceras de otras provincias de la Argentina. Mientras que, al "in- 
terior" de las provincias, los modos de organización en ciudades chicas, pueblos y zonas rurales, también contaron con un proceso de construcción importante.

Allí, podemos observar una protohistoria, gestada en paralelo, del movimiento travesti y trans con características particulares (eran pocas, porque la mayoría migraba a las grandes ciudades, sobre todo a la Ciudad Autónoma de Buenos Aires. Igualmente, la situación de prostitución no estaba tan generalizada y visible), pero que comparte los mismos procedimientos discriminatorios y excluyentes que incidían en las prácticas anteriormente mencionadas.

Podemos observar, por un lado, cómo operaba sistemáticamente la criminalización de las identidades travestis y trans por parte de la policía en particular, y fuerzas de seguridad, en general. Por el otro, el estigma social, el pánico moral y sexual actuaban como resultado de cierto sector de la sociedad civil con ideas conservadoras y herteronormativas. Todo ello, en su conjunto, funciona como un aparato para perpetuar el status quo, el disciplinamiento de las corporalidades travestis y trans, y la invisibilización de la existencia de sus identidades al entrar en disputa por el espacio público. Esto se traduce en una práctica que prohíbe el tránsito por el mismo.

\begin{abstract}
Las travestis llevamos a la calle lo que en realidad es nuestra lucha diaria. Para hacer sólo un breve repaso: lucha contra nuestras familias, que nos expulsan a temprana edad con la firme decisión de desterrar de sus livings el pecado; lucha contra las instituciones escolares, que nos cierran las puertas para que no manchemos a sus blancas palomitas; lucha contra el sistema médico, que nos considera una execrable patología que hay que reconducir a la normalidad heterosexual; lucha contra los empleadores, que se desmayan cuando el DNI contraviene la imagen que tienen ante los ojos pero no sienten pudor de la explotación que ejercen, de la contratación en negro, etcétera; lucha contra los poderosos medios de comunicación, que lucran con nuestra apariencia fortaleciendo un estereotipo cada vez más alejado de lo que somos (Berkins en Mafía; 2003, pág. 127-137).
\end{abstract}

En esa época no se hablaba de lo trans, como palabra sombrilla usualmente empleada para identificar el mundo travesti, transexual, transgénero. Pero sí se hablaba de travestis. Generalmente se aludía a la persona como "el travesti", como una forma inadecuada de reconocimiento, más aún, "el puto que se trasviste", como si fuera una versión ampliada e hiperfeminizada de la masculinidad gay.

\title{
Surgimiento de las primeras organizaciones:
}

Una de las principales activistas que emergen en la escena pública es Nadia Echazú. Nacida en Salta, muere el 18 de julio de 2004. Desarrolla su militancia en Córdoba. Luego, emigra para la capital -Ciudad Autónoma de Buenos Aires (CABA)-, lugar donde se afianza junto a sus compañeras de Salta en Palermo. Militó en la Asociación de Travestis de Argentina (ATA) y fundó la Organización de Travestis y Transexuales de Argentina (OTTRA). Fue una de las primeras en convocar a sus compañeras, con el fin de organizarse y hacer un 
reclamo concreto al Estado por el cese de la represión policial y la posibilidad de transitar la vía pública sin ser vejadas.

Paralelamente, en Constitución, estaba Lohana Berkins, quien nace el 15 de junio de 1965 en Pocitos, Provincia de Salta, y muere el 5 de febrero de 2016 en la Ciudad Autónoma de Buenos Aires. En 1994, Berkins fundó la Asociación de Lucha por la Identidad Travesti y Transexual (ALITT), que presidió hasta su muerte. En el 2002, encabezó una reivindicación fundamental de la visibilización de las personas travestis y trans al inscribirse en la Escuela Normal $\mathrm{N}^{\circ} 3$ para ser maestra. Frente a la imposibilidad de hacerlo con su nombre, radicó una denuncia en la Defensoría del Pueblo de la Ciudad de Buenos Aires que, mediante una resolución ejemplar, ordenó a las autoridades de la escuela que respetaran su identidad de género. En esa medida en el año 2009, impulsó la Ley N3060 de respeto a la identidad adoptada por travestis y transexuales, que fue aprobada por la legislatura porteña.

Una de las primeras organizaciones de travestis y transexuales y transgéneros en conformarse va a ser ATTTA. Su figura más representativa, Claudia Pía Baudracco, nacida el 22 de octubre de 1970 en La Carlota, Provincia de Córdoba, muere el 18 de marzo del 2012. Afianzó su labor como activista en Buenos Aires. Mantendrá un perfil bajo por un corto periodo, debido a que tenía problemas puntuales con la ley. Hay otras compañeras, como María Belén Correa, pero claramente era Claudia la referente principal. Aun desde la sombra mantenía su liderazgo.

El grupo de las norteñas, en general de Salta, Jujuy y Tucumán es el más numeroso de todas las organizaciones, quienes inmediatamente se van a separar. Territorialmente, Lohana y las compañeras de Flores y Constitución, militaban en la zona de Palermo.

A pesar de las diferencias políticas entre ALITT, OTTRA y ATTTA, había acuerdos muy claros de no beligerancia interna. Sabían que el enemigo era el Estado, la policía y, a partir de ahí, las diferentes responsabilidades institucionales y sociales.

En ese periodo va a existir una confrontación permanente con la policía. Carlos Jáuregui, activista y primer presidente de la Comunidad Homosexual Argentina entre 1984 y 1987; en palabras de Lohana Berkins, fue un visionario, puesto que "instó a la organización de las travestis". Luego de esto, las compañeras participarán en reuniones de gays y lesbianas, sumando la letra T al movimiento en Argentina.

Por su parte, Marlene Wayar nace en Córdoba el 14 de octubre de 1968. Estudió en la escuela de cerámica, el profesorado técnico-artístico. Emigra hacia la Ciudad Autónoma de Buenos Aires, y comienza a dar sus primeros pasos en la militancia política al lado de Nadia Echazú y Lohana Berkins. Siendo alta y delgada, caía presa mucho más que el resto por su estatura y complexión física visibles, mientras se encontraba en situación de prosti- 
tución. Su rol va a ser el poder explicarles a sus compañeras en los espacios de encuentro establecidos, en muchos momentos, qué está pasando en el universo gay-lésbico, o en el mundo académico, mediante su participación en las actividades y reuniones organizadas. Llegado el día de la reunión, si la persona designada estaba presa, se imponía la asistencia de otra en su lugar, la cual debía comprender y aprender sobre las temáticas discutidas en los encuentros. Después, claramente las lideresas, como Lohana y Nadia lograban, por fin, sostener la presencia en esos espacios.

La diferencia entre el movimiento lésbico-gay y la comunidad travesti radicaba en que esta última partía de la base de que el Estado reconociera la identidad de género como un derecho humano, como ciudadanas plenas y, en ese marco, el acceso a derechos básicos como la educación, la salud, el trabajo, la vivienda, entre otros. Mientras que el reclamo principal de la comunidad lésbico-gay va a ser el acceso a derechos civiles como el matrimonio igualitario, la adopción, entre otros.

Era una cuestión en ciernes, había problemáticas identitarias en disputa, a través de las cuales Lohana Berkins va a poder dar el salto cualitativo y expresar a las travestis como identidades específicas, teniendo en cuenta que ellas no hablaban de relaciones sexuales y de la relación con el otro, o con la otra, ni con el objeto de deseo. A las travestis no las definían determinadas prácticas sexuales, sino que se tenían como objeto a ellas mismas. Es decir, si nadie se relacionaba con ellas, de todas maneras, serían travestis.

\section{Segunda generación en los 2000. Crisis social, económica, política y cultural: Las traves- tis y trans también se apropian de las cacerolas.}

Al hacer un breve recuento de la década que va del 2000 al 2010, podemos conocer que a fines de 2001, después de más de 3 años de recesión, con una gran pérdida de reservas del Banco Central y sin respaldo internacional, el ministro de economía Domingo F. Cavallo ejecutó el "corralito" que impedía extraer en efectivo más de 250 pesos o dólares de los bancos por semana. Cuando esa estrategia no marchó, el mercado aplicó una devaluación. Tras la renuncia del presidente Fernando De la Rúa, del gobierno de la Alianza, y la sucesión de otros 3 presidentes en once días, el gobierno interino de Eduardo Duhalde instituyó en 2002 la "pesificación asimétrica", que tenía como objetivo sortear o atenuar el impacto de esa situación y, teóricamente, favorecía a deudores y acreedores.

En palabras de A. Grimson (2019), ante cada uno de los desastres sociales provocados por esas políticas neoliberales, los economistas encontraban una solución: profundizar esas políticas. Y gran parte de la sociedad, en un marco de inédita exclusión social, mantuvo la ilusión de encontrar una salida que no destruyera el contrato convertible. 
Los inicios de la década, estará marcado por la crisis económica, política, cultural y social; no obstante, se reconoce un avance en términos de organización. Las bases resisten, y al mismo tiempo van generando nuevas demandas y van posicionando una agenda.

En ese contexto de profunda crisis, las travestis y trans también salen a las calles para manifestarse y unirse a los reclamos sociales. Este colectivo, históricamente ha estado en las calles, a través de su presencia poniendo el cuerpo, disputando el espacio público. Pero el escenario es otro, por lo que la dinámica habitué nocturna, se transpola hacia otra franja horaria y con otres actores sociales. Las travestis se irán visibilizando en relación a reclamos concretos del colectivo, y también irán involucrándose en demandas transversales, participando de los cacerolazos y piquetes en esos años. Esta crisis atravesaría a todos los sectores sociales para demostrar luego el poder coalicional que surgiría en este contexto.

Junto a Lohana Berkins y Marlene Wayar, emergen las figuras de Diana Sacayán y Maite Amaya como referentas de esta segunda generación, al encarnar dichos reclamos y alzar sus voces en nombre del movimiento travesti y trans en Argentina.

Lohana Berkins, mientras tanto, se vincula con las Madres de Plaza de Mayo ${ }^{9}$, quienes abrazan los reclamos a las travestis, puntualmente, respecto al trabajo. Hebe de Bonafini, en 2008, fue madrina de la primera cooperativa textil travesti y trans, en el mundo, "Nadia Echazú"10 un proyecto motorizado por la propia Lohana. Luego, los reclamos de Abuelas de Plaza de Mayo ${ }^{11}$ por el derecho a la identidad en relación a la apropiación de bebés nacidos en cautiverio durante la última dictadura cívico-militar, fueron retomados por el movimiento travesti y trans para exigir con más fuerza el derecho al nombre propio. Se entendía la identidad de género auto-percibida como un derecho humano, es decir, al reclamo desde el punto de vista biológico de la apropiación de niñes, se le suma la identidad construida entre la autopercepción y su relación con la cultura y las prácticas de les sujetes en determinado contexto y momento histórico.

Otras luchas también atravesaron las problemáticas del momento, como la lucha de clase, que condujo a la participación de las compañeras en los piquetes, las demandas por

\footnotetext{
$9 \quad$ Las Madres de Plaza de Mayo es una Asociación Argentina formada durante la dictadura de Jorge Rafael Videla con el fin de recuperar con vida a los detenidos_desaparecidos, inicialmente, y luego establecer quiénes fueron los responsables de los crímenes de lesa humanidad y promover su enjuiciamiento. La Asociación tiene una radio, la Universidad popular Madres de Plaza de Mayo, un programa de televisión, un café literario, un plan de viviendas sociales y una guardería infantil. http://madres.org/

10 Primer emprendimiento laboral a nivel mundial, gestionado y administrado por personas travestis y transexuales http://coopnadiaechazu.blogspot.com/

11 Abuelas de Plaza de Mayo es una organización no gubernamental creada en 1977 cuyo objetivo es localizar y restituir a sus legítimas familias todos los niños desaparecidos por la última dictadura argentina

https://www.abuelas.org.ar/abuelas/historia-9
} 
el aborto legal, seguro y gratuito, que contaba con Lohana Berkins en la Campaña Nacional por el Derecho al Aborto, rompiendo con los estereotipos y el modelo biologicista. Porque lo que, en este momento histórico, unifica estas voluntades políticas es la lucha de clase y un mismo opresor, el patriarcado, y la clandestinidad compartida.

Las nuevas organizaciones que aparecen en la escena pública en este período son el resultado de procesos de aprendizaje, debates y demandas coyunturales de la época. Una de ellas es el Movimiento Antidiscriminatorio de Liberación (MAL), liderado por Amancay Diana Sacayán, quien nace en Tucumán el 31 de diciembre de 1975, y es asesinada el 11 de octubre de 2015. Era descendiente del pueblo Diaguita, y desde muy chica se mudó junto a su familia a Gregorio de La Ferrerre, Partido de La Matanza, Provincia de Buenos Aires, lugar donde devino como líder y referente política y social; y como defensora de los derechos humanos en ese territorio, lo cual le permitió trascender, a nivel nacional e internacional, con la impronta del movimiento piquetero, al que también estuvo vinculada. Se hace conocida por la lucha contra la contaminación del CEAMSE $^{12}$ en González Catán.

Sacayán no se separará de ese movimiento sociopolítico ni de ese territorio particular que es Gregorio de La Ferrere. Una de las primeras exigencias que trae es la búsqueda de aparición con vida de Luciano Arruga ${ }^{13}$, lo cual constituye un elemento fundamental para la comunidad travesti y trans en su conformación como movimiento en términos de alianzas estratégicas y articulación con otras luchas sociales. Es decir, pensar nuevos modos de participación - para las travestis y trans- en continuidad con la línea que venía trazando Lohana Berkins en consonancia con los organismos de derechos humanos -como Madres y Abuelas de Plaza de Mayo-; en espacios de reclamos de justicia ante el gatillo fácil, las marchas del 24 de marzo por el Día de la Memoria, entre otros momentos de participación e incidencia.

Surge entonces el desafío por sensibilizar y exigir que sean tenidos en cuenta los reclamos del colectivo travesti y trans, por parte de las organizaciones de derechos humanos no trans.

12 CEAMSE es una empresa creada por los estados de la Provincia de Buenos Aires y la Ciudad de Buenos Aires para realizar la gestión integral de los Residuos sólidos urbanos del área metropolitana.

Desde su creación hace más de cuatro décadas, desarrollan tareas mediante los procesos más modernos de gestión ambiental, lo que implica un compromiso con la innovación y la permanente incorporación de tecnología. Esta implementación de las mejores soluciones para los desafíos ambientales del siglo XXI, está avalada por las certificaciones internacionales obtenidas (ISO 9001 y 14001), así como por el trabajo realizado en forma conjunta con instituciones nacionales como el Consejo Nacional de Investigaciones Científicas y Tecnológicas (CONICET), el Instituto Nacional del Agua, el Instituto Nacional de Tecnología Industrial (INTI) y la Universidad de Buenos Aires https://www.ceamse.gov.ar/quienes-somos/

13 Nacido en Lomas del Mirador, Buenos Aires, el 29 de febrero de 1992, fue un adolescente argentino que estuvo desaparecido desde el 31 de enero de 2009, tras haber sido detenido por la policía bonaerense en su localidad natal, hasta el 17 de octubre de 2014 cuando apareció su cuerpo, enterrado como NN en el_Cementerio de la Chacarita, donde fue enviado desde el hospital Santojanni, al que había sido ingresado por ser atropellado por un auto y operado el 1 de febrero de 2009. Al momento de su desaparición, Luciano tenía dieciséis años. 
Otra de las activistas más importantes de esta segunda generación es Maite Amaya, quien nace en Córdoba en 1981, y muere en el mismo lugar el 13 de junio de 2017. Se destacó por su activa participación en el movimiento feminista cordobés y otras luchas populares. Sus ideas anarquistas se materializaron también en la lucha dentro del movimiento piquetero, en contra del capitalismo y el patriarcado. Radicaba en la Casa Carakol del barrio General Paz, sede de la Federación de Organizaciones de Base (FOB), uno de los principales espacios de la militancia popular y libertaria en Córdoba.

Por esos años, emerge también la figura de Casandra Sandoval, quien nace el 22 de octubre de 1976 en Tartagal, Provincia de Salta. A partir del año 2009, se erige como una de las creadoras de la Asociación de Diversidad Sexual Tartagal, (ADISTAR) una asociación civil fundada en esa ciudad salteña, para convocar a las personas de la diversidad sexo-genérica en ese territorio y ofrecerles un espacio de contención. La primera actividad realizada por la organización fue una mateada por la igualdad en la plaza central de la ciudad de Tartagal. Ello significó la posibilidad de visibilizar las identidades disidentes en su disputa por el espacio público.

Mientras tanto, la ley de matrimonio igualitario estaba en las discusiones sociales y familiares, y también en los medios. El trabajo en grupo cobró una importancia fundamental en los primeros tiempos de ADISTAR. Más tarde, esta organización se sumará a la lucha por la aprobación de la Ley de Identidad de Género. La organización no solamente era de travestis y trans, también de gays, maricas, tortas, entre otras identidades sexo-genéricas. Sin embargo, las que se expresaban públicamente a través de los medios de prensa eran las feminidades travestis y trans. El surgimiento y desempeño de ADISTAR marcó un antes y un después para el norte de Salta, porque fue la primera organización del interior de la provincia, que se constituye con personería jurídica.

Advertimos que, por entonces, los medios de comunicación se verán cada vez más implicados en los acontecimientos. Pero las travestis y trans encontraron una manera más directa de hablar con la sociedad a través de las asambleas de ciudadanes que compartían experiencias de vulneración a sus derechos, y que también eran silenciades por esos medios de comunicación que replicaban prácticas y discursos del Estado y los sectores más conservadores de la sociedad. Por eso, las asambleas radiales fueron otro recurso valioso donde denunciar y plantear dichas exigencias, donde era posible explicar la situación del movimiento de personas Trans, Lesbianas, Gays, Bisexuales e Intersexuales (TLGBI), y del movimiento travesti y trans en particular en Tartagal, Provincia de Salta.

Cuando asume Néstor Kirchner en el 2003, entra en agenda, la reparación política hacia el colectivo. Las organizaciones travestis y trans comienzan a ser vistas como actores sociales. Ocurre un Ilamado al movimiento TLGBI, con un aprendizaje realizado. Un Estado que escucha la realidad de las diversidades sexo-genéricas y que tiene el registro previo 
de saber que hay una problemática concreta que requiere generar políticas públicas para resolverla. Es un tiempo simbólico importante desde todos puntos de vista: políticos, económicos, pero, sobre todo, de nuevas relaciones que repercuten en el subconsciente social y la psiquis de las pequeñas comunidades.

En el 2005, Lohana Berkins, junto a Marlene Wayar, participa en la presentación del libro compilado junto a Josefina Fernández La gesta del nombre propio, en la Facultad de Periodismo y Comunicación Social de la Universidad de La Plata. Ese texto se convertiría en la biblia "trava"14, travesti, y trans, que echaba luz en un primer momento acerca de cuál era la realidad que atravesaba el movimiento en Argentina, particularmente en Ciudad Autónoma de Buenos Aires (CABA). Invitaba a repensar también y a replicar esos saberes en una Facultad donde eran formados futuros comunicadores. El libro contaba con datos estadísticos y encuestas diseñadas junto al Instituto Gino Germani. Fue un trabajo que permitió la posibilidad de demostrar gestión.

A partir del año 1998, Josefina Fernández (2005) considera, que el impacto organizativo comienza a verse. Se registra un total de 300 denuncias anuales y ya no es solo la policía la acusada. Se suman, entre otras, la discriminación en la escuela, en el hospital, la situación de desempleo, etc. Todo esto indica que las travestis empiezan a representarse como sujetas de derecho, de derecho al trabajo, a la salud, a la educación, en fin, a una vida digna

Las personas travestis y trans, en general, se construyen a partir de "la nada". Es una gestación constante en la que se continúa constituyendo una existencia determinada porque, en la mayoría de los casos, el primer lugar de violencia es la institución familiar. Es decir, también en el relato de las protagonistas, es la familia heterosexual el primer espacio de donde son expulsadas. Osvaldo Bazán (2006), señala "Aprendimos a (...) escondernos, a desvalorizarnos, a despreciarnos. A no confiar en nuestra familia más cercana, [ya que] el primer lugar en donde un nene homosexual es ofendido es en su propia casa" (p.403). De allí que retomamos la idea de Carlos Jáuregui de nacer en el "territorio enemigo".

De allí que una de las frases célebres de Carlos Jáuregui que «definió el estado de las luchas por orientación sexual» de la pos dictadura fue: «los gays nacemos en territorio enemigo» En primer lugar, se advierte que cuando en Diferentes aparece el término familia, su sentido explícito o implícito se refiere a ella como una institución exclusivamente heterosexual. Su dimensión antagónica deviene del hecho de ser representada como «un problema» para quienes pretendieran «destaparse», sostiene Vespucci Guido (2015).

En esta etapa podemos advertir una agenda política que contempla al menos dos posicionamientos del colectivo travesti y trans, desde los 90 , con las organizaciones vinculadas a la regulación/ abolición de la prostitución. Mientras que ATTTA defiende la primera vertiente, por su parte, ALITT asume una postura abolicionista, y continúa en su lucha por

14 La palabra "trava" es la reapropiación y resignificación, por parte de las identidades travestis, de un término peyorativo utilizado con el fin de ofender, ridiculizar y discriminar. 
el derecho a la identidad travesti y trans. Futuro Transgenérico establece sus prioridades vinculadas a la educación y la producción de conocimientos, en lazo con la academia y la comunicación. Mientras que el M.A.L suma al movimiento travesti y trans la impronta del movimiento piquetero y la lucha contra el gatillo fácil.

Por su parte, ADISTAR en el norte de Salta realiza un trabajo importante con las travestis y trans de pueblos originarios. Luego, vamos a ver cómo esta segunda generación va a estar signada aún por la lucha contra la violencia policial.

\section{Tercera generación. Del 2010 en adelante: Avances y retrocesos en la conquista de dere- chos del colectivo travesti y trans en Argentina.}

Al fallecer el ex-presidente Néstor Kirchner, las travestis hacen presencia en el velorio, porque van a despedirse de él, quien simbolizaba para ellas un padre social y político, que por primera vez las reconoce como identidades legítimas. Posteriormente, Cristina Fernández va a cristalizar este ideario político, que nace en el 2003 y llega hasta el 9 de diciembre de 2015, asumiendo los derechos humanos como políticas de Estado.

En este período, la militancia de las organizaciones travestis y trans en Argentina se irá afianzando. El año 2012, con la sanción de la Ley de Identidad de Género, va a significar un hito histórico, puesto que por primera vez el colectivo va a adquirir la plena ciudadanía. Por un lado, el Estado reconoce la identidad de género autopercibida, al solo efecto y requerimiento de la persona interesada, sin mediar estudios previos de expertos que decidan sobre un derecho personalísimo, tirando por tierra el discurso médico de la patologización y la criminalización judicial de las identidades sexo-genéricas. Y, por el otro, el acceso a la salud integral, en relación a los procesos de hormonización y las cirugías parciales o totales.

Al proyecto original de Augsburger se habían sumado, en el 2010, los de las diputadas Silvana Giudice, Vilma Ibarra, Juliana Di Tulio, Diana Conti, acompañadas por un importante número de representantes de diversos partidos políticos. Los debates, en ambas Cámaras, recogieron el imperativo de las convenciones, los pactos, los Principios de Yogyakarta, la necesidad de incluir y el cumplimiento de los derechos humanos fundamentales. El amparo de las garantías constitucionales en materia de derechos personalísimos animó inclusive a los espíritus conservadores -y no pocos parlamentarios cambiaron de opinión-, frente a la contundencia de los argumentos vertidos por quienes deseaban la igualdad civil. Las oposiciones a la iniciativa fueron menores que en el caso del matrimonio facultado a las personas del mismo sexo. En mayo de 2012 se sancionó la Ley 26.743 de Igualdad de Género, (Dora Barrancos, 2014, p. 39)

En este contexto se arraigan a la Argentina las charapas, el grupo de feminidades travestis y trans migrantes de la selva peruana que estudiamos en la presente investigación, país donde comienzan a pensarse en términos de colectivo organizado, en un escenario 
particular, la ciudad de La Plata. Así nace OTRANS ARGENTINA, en términos generales, con la idea de ser una organización de la sociedad civil sin fines de lucro, el 12 de julio del 2012, al calor de la sanción de la Ley de Identidad de Género. Este hecho será el resultado de determinados procesos, tales como, la nueva ley migratoria 25871 sancionada en 2004, que algunas de sus integrantes militarán. En el apartado correspondiente al estudio de caso, nos adentraremos a las prácticas político- comunicacionales a partir de las cuales se constituyen como sujetos políticos en alianza y disputa permanente con otros actores institucionales y de la sociedad civil.

En esta tercera generación, destacamos las lideresas Florencia Guimaraes (La Matanza, Provincia de Buenos Aires y CABA), Alma Fernández (Tucumán y CABA), Dalex GaIlozo (Resistencia, Chaco), Úrsula Ximena Sabarece (Resistencia, Chaco), Victoria Ramírez Cavilla (Luján, Provincia de Buenos Aires), Vicky Izquierdo (Uruguay, Malvinas Argentinas, Provincia de Buenos Aires), Dana Valiente (Misiones, Garupá), Yanina Chávez (Vicente López, Provincia de Buenos Aires),Ivanna Aguilera (Provincia de Córdoba), Noelia Luna (Provincia de Buenos Aires), María Eugenia González (Provincia de Corrientes), Ángeles Zuñiga (Provincia de La Pampa), Alba Rueda (CABA), Ornella Infante (Río Negro y CABA), Toni Domínguez (La Plata, Provincia de Buenos Aires), Aradia García Mujica (La Plata, Provincia de Buenos Aires); entre otras referentas que desarrollan un valioso trabajo de militancia y territorialidad en diferentes provincias de la Argentina, realizando aportaciones, tanto individuales como desde sus organizaciones construyendo articulaciones y alianzas estratégicas, que dan cuenta de una lucha en común; y que serán fundamentales a la hora de repensar los desafíos que, en adelante, enfrenta el colectivo travesti y trans en Argentina. 


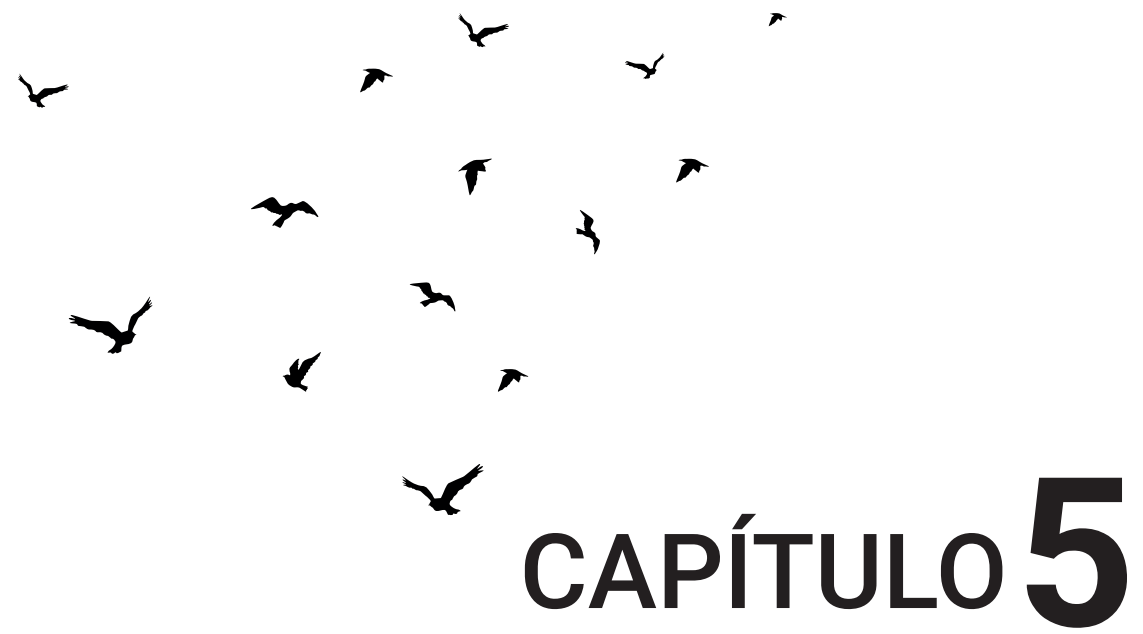

Identidades golondrinas:

primeras etapas en la vida de las charapas. 
Capítulo 5. - Identidades golondrinas: primeras etapas en la vida de las charapas.

En el presente capítulo describimos y analizamos las prácticas de las travestis y trans migrantes, tomando en cuenta diferentes etapas de sus vidas y su relación con su entorno afectivo y los lugares transitados en el Perú. A fin de rastrear y analizar prácticas y sentidos socialmente producidos y compartidos, proponemos un abordaje de forma cronológica, no obstante, advertimos los saltos en el tiempo.

Daremos cuenta de las primeras etapas de vida -infancia y adolescencia-, y su relación con la familia, el barrio, las instituciones educativas y el trabajo en su país de origen; a fin de comprender cómo el modo de enunciarse, con un nombre propio da cuenta de una sólida convicción y reafirmación de su auto percepción en relación al género. En otras palabras y, "en el marco del paradigma de la identidad de género, (...) el género es una convicción subjetiva -fija y estable- que justifica las modificaciones tecnológicas del cuerpo sexuado - mayormente maleable”, (Mattio, 2012, p. 85). Todo lo cual, permitirá describir la larga lucha que tuvieron que transitar para ser reconocidas social y jurídicamente en el país receptor, la Argentina.

Al iniciar las entrevistas con la pregunta ¿Cómo te llamas y de dónde eres?, establecemos un punto de partida, abrimos una ventana desde donde empezar a entablar el diálogo, observar y analizar la realidad en la cual nos involucramos para, luego, emprender el viaje y la aventura.

Estas interrogantes nos ubican en un plano de tiempo y espacio determinado:

En mi pueblo cuentan que nuestra historia surge cuando los chancas junto a los incas huyeron a la selva cuando los españoles invadieron el imperio incaico en el Cusco, algunas personas que vivían ahí se refugiaron escapando, algunos a las sierras, otros al Amazonas y un grupo se quedó en el Cerro de Lamas (M).

Las sujetas de nuestra investigación, en su totalidad, se reconocen como las charapas: feminidades travestis y trans migrantes de la región selvática del Perú ${ }^{15}$, un término que no tiene género, un gentilicio que se les acuña a les lugareñes de esa zona por un tipo de tortuga que habita en la selva.

Desandar esta trama compleja supone a la investigación un trabajo reflexivo, nos sitúa en una matriz de pensamiento crítica que nos invita a revisar y (re)preguntarnos ¿Cuáles han sido los mecanismos que históricamente condicionaron la existencia de las travestis y trans migrantes? ¿Qué prácticas y discursos se construyeron sobre estas identidades?

15 En el Perú hay tres regiones naturales: costa, sierra y selva. A las de la costa se les dice costeñas, a las de la sierra, serranas, y a las de la selva se les dice selváticas. 


\section{1.- Nacer y vivir en territorio enemigo: Infancias travestis y trans:}

“Una vez el profesor le dijo a mi papá, por qué me junto con las niñas, no juego fútbol, no me gusta la educación física, que a la mayoría de los chicos les gusta. Cuando llegó a casa me comenzó a gritar por mi comportamiento. Mi mamá y mi abuelita me defendieron. Yo Iloraba, recuerdo que mi abuelita me decía - tenía 7 años- Ilora hijito, Ilora todo lo que quieras, tú no tienes la culpa de ser así, o de ser lo que vas a ser. Eso es algo que se me quedó grabado por siempre" $(T)$.

Las charapas expresan su identidad de género desde edades tempranas entre los cinco o seis años, empiezan como algo lúdico a través del uso de la ropa, juguetes, accesorios, asociados a la figura femenina. Asumir la identidad de género y expresarla socialmente trae aparejados conflictos dentro del ámbito familiar, sobre todo con la figura masculina encarnada en el padre, hermanos, primos y tíos. Y en algunos casos, los menos frecuentes, en madres, hermanas y tías. Estas últimas, en la mayoría de los casos son aliadas estratégicas, quienes van a acompañar los diferentes procesos que transitan en relación a asumir y expresar su identidad de género autopercibida.

En este apartado, advertimos el origen respecto a cómo se construye y surge "el conflicto" en torno a relaciones de poder en el seno familiar, y las características propias que lo revisten. Allí podemos observar que en la mayoría de los casos las charapas, experimentaron, por un lado, violencia verbal, psicológica, con prácticas que iban desde el aislamiento o hasta el silencio, en cuanto a no hablar del tema en su entorno familiar:

(...) Solo con uno de mis hermanos era un poco conflictivo por mi identidad, y con uno de ellos todo bien. Sabía sobre mí por así decirlo, sobre mi futuro, sobre quién yo quería ser, y uno de mis hermanos no lo aceptaba. Nunca se hablaba del tema en casa. (...) (K).

Por el otro, la violencia física va convertirse en un factor preponderante en la mayor parte de las entrevistadas de la presente investigación:

Sí, mi papá, cuándo se daba cuenta de mi forma de amanerarme. Retrocediendo a mi infancia esto es algo que no cuento, lo conté solo dos veces no más. Esto fue algo traumático para mí y para mi hermano también. Mi papá se daba cuenta mucho de mi amaneramiento- tenía ocho o nueve años- recuerdo que me puse una faldita, jugando porque para mí era un juego en aquel tiempo, no pensaba en vestirme de 
mujer. Entonces mis vecinitas le contaron a mi mamá, ella le contó a mi papá y tuvo una reacción muy fea. Me llamo la atención, me hizo sacar la ropa- mi tía estaba ahí la que se había ido de Lima a visitarnos a Tabatinga-, y me hizo correr "calata"16toda la calle, comencé a correr, tenía vergüenza porque era una humillación. Y no solo a mí, sino a mi hermano también, era en pleno día, los vecinos miraban [...] (T).

La niñez es una etapa crucial de todo ser humano, en los relatos de T, podemos advertir cómo opera la hegemonía patriarcal y machista, a través de la violencia intrafamiliar, que consiste en cualquier tipo de abuso de poder por parte de cualquier miembro de la familia sobre otre.

Como siempre en las relaciones de poder, se encuentra uno ante fenómenos complejos que no obedecen a la forma hegeliana de dialéctica. El dominio, la conciencia de su cuerpo no han podido ser adquiridos más que por el efecto de la ocupación del cuerpo por el poder: la gimnasia, los ejercicios, el desarrollo muscular, la desnudez, la exaltación del cuerpo bello... todo está en la línea que conduce al deseo del propio cuerpo mediante un trabajo insistente, obstinado, meticuloso que el poder ha ejercido sobre el cuerpo de los niños, de los soldados, sobre el cuerpo sano (Foucault, 1979 p, 104).

¿Pero qué implica esta puesta en escena al exhibir los cuerpos desnudos ante los ojos de los vecinos en plena luz del día? ¿Por qué el castigo no solo fue para T, sino también para su hermano? ¿Cuál es el significado de estos actos? ¿Qué sentidos producen las vejaciones y el escarnio público?

Mostrar los cuerpos desnudos ante el público no sólo tiene por finalidad reafirmar que la anatomía de ambos cuerpos son iguales, sino también exponer a la genitalidad como elemento incuestionable y constitutivo de la masculinidad heterosexual, y todos los sentidos que giran en torno a la virilidad y lo que simboliza el pene.

Me pongo a pensar, mi papá en su machismo, en su ignorancia quizás pensó que estaba haciendo bien. Pensaba que así, quizás, me iba a arreglar, pensaba que yo tenía una enfermedad, hacía eso para poder arreglarme, esa era parte de su ignorancia. A mi hermano también lo humilló, nos hizo correr a los dos alrededores de la casa, desnudos, yo llorando, y cuando pasaba me daba unos que otros correazos. Hace poco, antes de venirme a la Argentina, cuando estábamos celebrando el cumpleaños de mi sobrino, comenzamos a hablar de esos momentos con mi hermano, él comenzó a llorar. Me imagino porque me veía así realizada como siempre quise estar, y ahora poniéndome a recordar con él, yo no tuve la culpa, nadie tiene la culpa de ser así. Pude expresar lo que sentía a mi hermano, él comenzó a llorar recordando ese episodio que mi papá nos hizo correr, haciéndonos humillar, dando vueltas y vueltas 
alrededor de la casa totalmente desnuda. Eso fue algo muy feo, muy traumático. Cuando mi papá murió, le perdone todo eso, pero siempre quedan huellas y cosas que te duelen, eso fue algo muy fuerte que me pasó, después de eso gracias a Dios nada $(T)$.

El castigo público ante los ojos de los vecinos tiene por lo menos dos enunciados claros, que se dirigen a diferentes interlocutores, uno de forma horizontal y otro vertical. El primero va dirigido a los mismos pares del sujeto perpetrador, a través de una práctica ritualizada que invoca y convoca a ejecutarlo. Para poder ser parte de ese séquito hay que deshumanizar al otro: el único método para corregir al "desviado" o "arreglarlo"-porque hay algo que está mal- es mediante prácticas violentas usando la fuerza física, el maltrato verbal, y psicológico. Hay que humillar, vejar e incluso aniquilar. Este sector comparte el mismo sistema de pensamiento e imaginario negativo sobre la identidad y/o expresión de género, las mismas prácticas, los mismos códigos, es decir, hablan el mismo lenguaje, se entienden y comprenden.

Mientras que el segundo, es el sujeto perpetrador quien le habla a la víctima, su discurso adquiere un aspecto punitivo y su práctica un efecto moralizador. Se convierte, en ese imaginario que comparten todos los actores de esa misma escena, en el defensor de la moral y las buenas costumbres. Es quien debe disciplinar, corregir y arreglar todo aquello que se desvié de la norma, a través de la violencia que le confiere y ejerce el poder soberano, porque no se puede ser travesti o trans.

En ese mismo acto se conjuga la dominación física, pero también moral. Porque no existe poder soberano que sea sólo físico, sin el sometimiento psicológico y moral del otro, allí lo único que existiría es poder de muerte y este por sí solo, no ejerce soberanía. La soberanía plena consiste en "hacer vivir o dejar morir", plantea Foucault (1976). Es decir, sin el dominio de la propia vida, la dominación no puede completarse.

Así estas prácticas "correctivas" heteronormativas, tienen como objetivo normar "conductas", y disciplinar los cuerpos. Montan una puesta en escena, la del espectáculo para producir pudor e infundir vergüenza ante el espectador que observa el despojo del ropaje, y la exhibición del cuerpo desnudo sin consentimiento: estos actos por excelencia son considerados prácticas vejatorias en grado sumo. El escarmiento, genera un impacto psicosocial: introyecta en la subjetividad de la víctima y les otres el miedo, produce pánico moral y sexual; tiene como finalidad última, aniquilar cualquier intento de asumir y expresar la identidad de género autopercibida.

En las entrevistas existen algunas respuestas que se contraponen con las respuestas de otras preguntas. Algunas entrevistadas, manifestaron que nunca fueron discriminadas en sus hogares. Sin embargo, cuando las analizamos en su totalidad, observamos que, 
en la pregunta sobre ¿Cuándo comenzaste a expresar tu identidad de género? dijeron que se fueron a temprana edad, y otras las echaron de sus casas porque sus familias no les permitieron expresar su identidad de género. En varios casos, previo a la partida de sus casas, experimentaron dichas situaciones de violencia, física, verbal y psicológica.

El discurso determina prácticas y modos de ser en los individuos. Bajo los discursos o paradigmas es que se va a organizar la comprensión del mundo y las relaciones sociales de los sujetos. El discurso será una serie de procedimientos que establecerá líneas divisorias entre lo admitido y lo prohibido.

Supongo que en toda sociedad la producción del discurso está a la vez controlada, seleccionada y redistribuida por cierto número de procedimientos que tienen por función conjurar poderes y peligros, dominar el conocimiento aleatorio y esquivar su terrible y pesada materialidad. En una sociedad como la nuestra son bien conocidos los procedimientos de exclusión. El más evidente, y el más familiar también, es lo prohibido (Foucault, 2008, p. 14).

Hemos advertido sobre la violencia física que se ejerce sobre las charapas, como también respecto a la prohibición del uso de cualquier indumentaria o accesorios culturalmente designados para el género femenino. Asimismo, observamos en los relatos de las entrevistadas el uso recurrente de términos tales como: respeto y aceptación. Estas palabras en el universo vocabular del colectivo estudiado, producen un sentido determinante: advertimos que, a través de ellas, se ocultan relaciones de poder y dominación.

Mi infancia fue muy triste. No viví una vida que uno debería haber llevado, yo sufrí mucho, no fui aceptada por mi familia. Por ser un homosexual, o una chica trans. En Perú le decimos homosexual, y acá en Argentina, somos una chica trans. Con mi papá no llevaba una buena relación porque no me aceptaba como soy, él quería que fuera varón, no una mujer. (...). Mi papá falleció hace 12 años y nunca me quiso así. Por mi barrio algunos me querían, otros me insultaban. Recibía desprecio, vivía marginada. (...) volví a mi casa cuando mi papá falleció. Yo le iba a contar todo lo que soy, de mi propia boca, pero no tuve oportunidad, murió sin pedirle perdón. Yo no hice nada que yo sepa, yo soy así. Él me ignoraba, decía que yo no soy su hijo. Una tía me dijo que le pida perdón, la hermana de mi papá. Decía que yo le faltaba el respeto a la familia, por ser así. Mi papá decía que éramos mal vistos para la familia. "Yo no tengo un hijo maricón" decía mi padre, él a mi me negaba (D).

En este relato, observamos que quien expresa su identidad de género autopercibida, socialmente, trasciende las normas establecidas, por lo tanto, se convierte en una persona irrespetuosa: no respeta los hábitos, prácticas y costumbres impuestos por el sistema heteronormativo. El modo en cómo opera este sistema, no solo es a través de la violencia física, como ya vimos antes, sino también psicológica, y se manifiesta en el plano discursivo. La 
reprimenda genera una carga emocional donde la culpa se contrapone al deseo, y va a ubicar a las charapas en un lugar de inferioridad, y desventaja por no reproducir los mandatos establecidos por la cultura hegemónica.

Otro elemento que aparece de forma recurrente en los relatos de las entrevistadas es la expulsión familiar.

En mi infancia, sufrí demasiado, con mi familia. La familia de parte de mi papá no me quería, me maltrataban, por mi sexualidad me echaban de mi casa y yo ahí mucho sufría y mi mamá siempre sacaba pecho por mí. Luego tuve una violación, a los 11 años tenía yo, el que me violó fue mi tío, porque en realidad no es mi verdadero tío es el hermano de mi padrastro. Le conté a mi mamá y no me creyó. Cuando les dije esas cosas me botaron los dos de la casa, mi mamá y mi padrastro, me dijeron que me fuera de casa que yo hablaba cosas que ellos no creían (M).

Así la expulsión de sus hogares o irse de ellos por no ser un terreno saludable se convierte en un patrón sistemático en este grupo estudiado. Un destino del que, salvo raras excepciones, han podido escapar. Respecto a la violación en el caso de $\mathrm{M}$, la palabra de ella es considerada nula, por su edad e identidad de género. Allí empieza un largo camino en la búsqueda del perdón, y la "aceptación”, por parte de la familia. Entonces nos preguntamos, con toda la violencia que transitaron en su ámbito familiar: ¿Qué implica la búsqueda de aceptación? ¿Aceptación de quién y para qué? ¿Y cómo la obtienen? Reflexionaremos, luego, sobre el lugar preponderante que dicha aceptación juega a la hora del envío de remesas. También en los testimonios de las charapas aparece con nitidez la idea de recibir este castigo por la desobediencia a la norma, por haber traicionado al patriarcado, renunciar a sus privilegios y negarse a ser parte de esa cofradía viril.

Somos ocho hermanos, mamá, papá, cinco hombres y tres mujeres. Somos 3 chicas trans, una de ellas se llamaba $F$, la hermana que falleció. Cuando yo tenía 25 años murió mi hermana, ahora tengo 30. Nací en el 89'. Y mi hermana la mayor, que también era trans, falleció en Tarapoto a los 29. Ella empezó a drogarse con un novio, se alejó de la casa. Conoció un novio con el que se drogaba y se emborrachaba, mamá y nosotras sufrimos mucho verla así. Murió de una enfermedad crónica. Mi padre nunca la perdonó por ser trans, nosotras con mi otra hermana trans nos tuvimos que ir a vivir con mi tía a Lima, porque mi padre y mis hermanos los varones nos maltrataban mucho, no solo con golpes sino con insultos, nos decían palabras feas $(R)$. 
La totalidad de las entrevistadas son hijas de padres y madres heterosexuales cisgenero ${ }^{17}$. Sus familias están compuestas o conformadas por hermanos y hermanas, primos y primas también heterosexuales. A excepción de un único caso, el de R, quien tenía dos hermanas trans F y S.

Mis padres sabían que era diferente a mis hermanos, porque siempre me gustó andar con shorcitos chiquitos. Cuando mi papá murió, tenía 10 años, me fui a vivir con mi tía, la hermana de mi papa. Los comentarios de los vecinos, que tu sobrino es gay, homosexual, chivo, todos los adjetivos que se dicen allá. Un día estando en el colegio, era para que reciba las calificaciones, recuerdo que había una moda de unos aretes que se pegan en la oreja, estoy saliendo de la escuela y me cruzo a mi tía. Me dice que haces con esos aretes, tú eres hombre, llegue a la casa me dio una brutal paliza, me pegó. Totalmente, no aceptaba que fuese homosexual se puede decir, y me empezó a poner más hormonas masculinas" (VN).

Observamos como las charapas fueron llevadas por sus padres y la familia al psicólogo a "terapias de reorientación sexual" o, como advertimos, a otro tipo de prácticas "correctivas", como la descrita anteriormente, a través del uso de fármacos y hormonas masculinas -aplicación de testosterona-, terapias psiquiátricas o psicológicas, en función de convertir a la travesti o trans en alguien "normal", es decir heterosexual.

\section{Cuerpo, sentido y lenguaje: la potencia del nombre propio}

Las charapas, utilizan diferentes conceptos para nombrarse y los ubican, en orden cronológico, respecto al modo como se pensaron y fueron identificándose en determinados momentos de sus vidas, aun cuando muchas de estas formas fueran heredadas e impuestas:

Mi homosexualidad se manifestó desde muy pequeña, desde que tengo uso de razón de tres, cuatro años, a lo máximo que yo me recuerde. Mi papá nos llevaba de vacaciones a lquitos y era ahí donde yo me daba cuenta de mi gran diferencia entre mis primos y mi hermano. Me daba cuenta que era un poquito diferentes a ellos, me refiero a mi comportamiento, mi forma de ser, era como más inclinada a la feminidad. Mis primos eran un poco más toscos, un poco más brutos en el momento de jugar, y yo no, era como más femenina, más delicada $(T)$.

17 Quien no es transgenero, es cisgenero. Cisgénero hace referencia a quien se asume dentro del género que le fue asignado al nacer. 
Podemos observar cómo, en las primeras etapas, en la mayoría de los casos, se nombran como homosexuales, gays, amaneradas y mariconas, a la luz de las incipientes manifestaciones de su identidad, su relación con el objeto del deseo y con las modificaciones del cuerpo. Es decir, la identidad de género autopercibida, en este primer tramo, no es utilizada y expresada en esos términos por nuestras interlocutoras. Aparece, más bien, difusa y en muchos casos queda asociada a la orientación sexual, es utilizada como un sinónimo.

Como todas creo yo, a veces empezamos siendo gaysitos, luego somos transformistas y hasta llegar al sueño que siempre queríamos ser. Como una chica trans. Cuando salía a la noche me ponía aros largos, me vestía de mujer, tacos, ya no usaba nada masculino, y empecé. $Y$ de ahí me fui a Lima, me regrese pero yo ya era declarada, ya era $E(E)$.

Seguidamente, aparece el término transformista relacionado al uso de ropa, maquillaje y accesorios femeninos solo en determinados días y momentos, mayormente por la noche. La identidad y expresión de género es entendida, tiempo después, como tal. No utilizan el concepto de identidad de género, como la vivencia interna y subjetiva del género que se puede corresponder o no con el sexo asignado al nacer, debido a que no solo es un término académico, sino relativamente nuevo. Aquí la materialidad del cuerpo para nuestras entrevistadas adquiere un valor preponderante. La mayoría de ellas se identifica con el término chica trans.

\subsection{Tiranía social y heterosexual.}

La violencia física, psicológica y simbólica que reciben las charapas en el seno de la familia heterosexual, se va a reproducir con mayor crudeza en el barrio, la escuela, el colegio, la comisaría, y las calles de las ciudades donde transitan, entre otros. Aunque algunas de las entrevistadas reconocen que en el lugar donde sufrieron más violencia fue en su propio entorno familiar.

Yo me crié con mi papá, con mi mama, yo hace 10 años que me fui de mi casa, decidí hacer mi vida, ahora no la estoy pasando tan bien, porque mi familia como ahora ven que yo hice mi vida, y como mi mamá es creyente y mi papá también es un poco ignorante, porque a un padre siempre le va a doler aceptar a un hijo por más que sea tu padre pero siempre te va a negar, y mi mamá he conversado el otro día, se puso triste se puso mal porque al saber que hice mi vida y a veces mi mamá se siente mal, porque ella me dice: hijo yo te he parido hombre y a veces verte así me da pena. Yo sufrí más cuando estaba en mi casa, con mis primos, con mis vecinos. Después cuando ya salí no sufría mucho (E). 
En el relato de $\mathrm{E}$ encontramos dos elementos claves que refuerzan y retroalimentan el discurso y la exigencias de la reproducción de prácticas heteronormativas, por un lado el dogma vinculado a las creencias y los fundamentalismos religiosos, y por el otro, el discurso biologicista relacionado a la reproducción de la especie humana. Ambos se erigen como verdades absolutas, quienes van a contrapelo de esas leyes y normas son plausibles de tenerles lástima, pero no cualquier tipo lástima, sino una con carácter de redención. Es decir, le hacen sentir a la charapa que por expresar su identidad de género ha cometido un pecado, y que tiene que redimirse para ser perdonada, pero el perdón implica no asumir su identidad de género autopercibida. Las entrevistadas manifiestan que fueron y siguen siendo acechadas por estos discursos, cuyos argumentos se basan en sus lógicas y sistemas de pensamiento, mientras que el discurso y las prácticas de las charapas, no alcanza el mismo estatuto de valor o validez. Este argumento es utilizado con la intención de anular la discusión de fondo: se trata de las relaciones de poder en el plano de la cultura.

El mayor grado de exposición y violencia que van a experimentar las charapas va a ocurrir en la medida que asuman y expresen su identidad de género socialmente, mediante cambios en el cuerpo a través de intervenciones quirúrgicas o uso de ropa asignada culturalmente al género femenino. Las que lo hicieron en el Perú, aun viviendo con sus familias, sostienen que fue algo traumático debido a que no solo fueron expulsadas de sus casas, cuando tenían once y doce años, sino que se vieron obligadas a subsistir a través del ejercicio de la prostitución, porque nadie les daba trabajo. Eran menores de edad, y tenían que intercambiar con hombres adultos sexo a cambio de dinero:

Mi infancia para mí fue un poco dura, porque no pude expresar mi identidad. Tuve que cumplir los mandatos culturales y los estereotipos que nos atraviesan de la cultura machista en la que vivimos. No pude contemplar mi infancia en divertirme o en vivirla como yo hubiese querido vivirla $(K)$.

Ahí podemos observar cómo se coarta su derecho a vivir una niñez en igualdad de condición y trato, como cualquier otro niñe, de poder ir a la escuela, jugar y proyectar una vida común. Todas las entrevistadas, en mayor o menor medida, son parte de una generación diezmada a quienes se las despojó de su infancia y adolescencia. Esta es una etapa de la cual no se habla, no se piensa a las infancias travestis y trans como una condición de posibilidad a la cual la familia y el Estado deben atender, proteger y resguardar.

Comencé a expresar mi identidad de género, cuando yo tenía 17, 18 años, cuando empecé a salir a las discotecas allá en Perú. Y al 100\% cuando llegué acá a la Argentina (...) Vuelvo a recalcar que vengo de Perú, es un país machista, patriarcal, heteronormativo, y romper con todos esos mandatos culturales con los que nos crían allá era algo raro al momento de expresar mi identidad de género (K). 
Sin embargo, el retorno a casa de la charapa, ya adulta, tiene una condición sine qua non, respecto al envió recurrente de remesas, proveniente en todos los casos del ejercicio de la prostitución. Es decir, aquella familia heterosexual que, en muchos casos, primero la expulsó siendo una niña, luego acepta su reincorporación, en la medida que aporte dinero. Tal es así, que algunas de las entrevistadas, reconocen que son sostén de hogar. Lo que a las claras, resulta evidente una doble moral, por un lado la familia heterosexual, que despreciaba la identidad de género de la charapa, no se cuestiona el origen del dinero que recibe de su parte.

\begin{abstract}
“semanal reúno para comprar 100 dólares. Juego una junta cada tres meses de 20 mil pesos, con eso pude comprar alrededor de 1500 dorares. Este dinero es para cubrir los medicamentos de mi mamá, que tiene problemas de glucosa y el corazón, también para pagar los estudios de mi hermano,-mecánica aeronáutica- sale 1000 soles mensuales ${ }^{18 "}(\mathrm{VN})$.
\end{abstract}

Yo volví a Perú después de 3 años, les dije que ya estaba transformada, que hice mi procedimiento hormonal, me operé. Me aceptaron, me trataron muy bien mis padres. Se alegraron de verme bien, y de que vaya a mi país. Siempre tuve rencor de mis hermanos, de mis padres no. Ayudaba económicamente a mi familia, mandaba dinero seguido pero desde que Mauricio Macri está de presidente no pude irme más a Perú, esta todo caro, no hay dinero en la calle, tampoco puedo ni ayudarlos. Antes sí podía. Pero ahora por más que mis padres estén enfermos, no puedo por la cuestión económica. En su momento cuando estaba bien acá pude traer a mi hermana gemela la $S$, que también es trans, estuvo solo medio año acá, pero no se acostumbró y se fue a mi país. No le gustó. Después se aburrió de Perú, y se fue a Europa. Ahora está en Italia $(R)$.

Esta situación del envío de remesas resulta una práctica que las entrevistadas conciben con total naturalidad, puesto que en vez de ser vista como un mero aporte económico, resulta imprescindible a la hora de acumular un capital que es simbólico. La charapa regresa al seno familiar con la idea de recuperar algo del afecto que le fue negado.

Entendemos lo anterior en términos de aceptación ficcionada, la cual se torna ininteligible. La aceptación, significa la subordinación de uno respecto al otro. Podemos afirmar, como plantea Bourdieu, (2000) que de este modo se reproduce una relación entre pares dicotómicos de oposiciones homólogas. 


$\begin{array}{lll}\text { Familia heterosexual / } & \text { charapa } \\ \text { Quien acepta } & / & \text { quien asiente } \\ \text { Poder } & \text { sujeción } \\ \text { Detenta afecto } & / & \text { carente de afecto }\end{array}$

Reproductora de la especie / proveedora de recursos económicos

Lo anterior, encuentra su correlato en algunos pasajes de las entrevistas donde tal aceptación ficcionada se manifiesta con mayor vigor. El fallecimiento de tres charapas lo demuestra con claridad: hablamos de los casos B y V.

B. se muere acá y la familia ni siquiera está preocupada por el cuerpo ni por nada, sino por el certificado de defunción porque hay una casa a su nombre que compró cuando estuvo en Europa. Todas las veces que se comunicó el hermano con nosotras nunca reclamó el cuerpo, lo tuvimos que enterrar nosotras. Se notó que solo su interés era por la casa. Decía: “mi hermano está muerto, pero no se acabó ahí, le dejó a mi mamá algunas deudas. Vienen a cobrarle a ella, por eso queremos que no se olviden el certificado de defunción. Eso es muy importante para mi viejita. Lo necesitamos urgente porque a mi mamá van a cobrarle y encima está con orden de embargo". Lo del certificado nos lo pidió como treinta veces. (T).

El hermano de V era un interesado, ella había construido su casa en el terrero de él. Cuando tenía plata todo era hermanita, hermanita... y cuando no tenía la echó. $V$ se fue enferma a Perú y tuvo que regresar porque esa última vez había llevado poca plata. Y regresó a Argentina, acá murió mi madre, ella me contó que sintió mucho desprecio por parte de su familia. Creo que ella se murió más de tristeza que de la enfermedad que padecía $(H)$. 


\subsection{Educar para la vergüenza}

En este apartado realizamos un análisis de las trayectorias escolares de las charapas: las percepciones dentro de los ámbitos escolares que transitaron, en la relación con sus compañeres, profesores, y el marcaje del que fueron objeto en las instituciones educativas.

En la medida en que el trabajo de campo se fue afianzando, surgió la pregunta respecto a: ¿Cuál era la relación que establecían las charapas con los contenidos de las materias que recibían durante su formación en la primaria y secundaria? ¿Dónde aparece el conflicto o se interrumpe su trayectoria en las instituciones de educación formal? ¿Qué formas adquieren estas violencias, y qué medidas adoptó la institución?

Esa experiencia fue un poco traumática porque a veces sufría burlas, o a veces decían eres así o a veces, decían eres amanerado o eres maricón porque no le gusta jugar el fútbol, quizás por eso sentía vergüenza o discriminación por dentro. Porque no me sentía bien, hasta que yo termine mi primaria, luego no termine mi secundaria porque no quise seguir estudiando, porque cuando estuve más declarada me gustaba más las cosas de mujeres y no tenía ganas de seguir soportando burlas, quería ir al baño de mujeres y no me dejaban, entonces le daba menos importancia al estudio y terminé abandonando $(E)$.

En el Perú los deportes más populares son el fútbol y el vóley, el primero lo juegan los hombres y el segundo las mujeres, ambos de forma obligatoria. Estas disciplinas han sido reglamentadas y tienen un carácter competitivo, recreativo o también se realiza con fines de contribuir a una vida saludable. Sin embargo, históricamente ha servido para reproducir los estereotipos de género, disciplinar los cuerpos, y obturar las sexualidades e identidades de género de las charapas. A pesar que en los últimos años existen algunos avances en relación al fútbol femenino y vóley masculino, en la cultura peruana continúa impregnada esa idea. Es decir, las mujeres que juegan al fútbol son vistas mayormente como lesbianas o "marimachas", y a los hombres que juegan vóley, como gays o maricones.

En el relato de (E) podemos observar que no le gusta jugar al fútbol, como a varias de las entrevistadas porque es una práctica que en la cultura peruana está asignada para los hombres. No solo se niegan a practicarlo, sino que no reproducen los códigos y reglas que impone ese juego. Sin embargo, van a preferir el vóley, por un lado, para apropiarse de un deporte el cual les ha sido vedado o prohibido; por el otro, con el objetivo de reafirmar su identidad de género autopercibida y acumular capital simbólico para correr los límites de 
los mandatos sociales y de las normas institucionales con las cuales se rigen dichos deportes. Correr los límites, implica entrar en ellos, y dar la disputa desde adentro del campo, para transformarlo en nuevos modos de hacer y pensar al deporte.

La Educación Física, y la Educación Religiosa -católica- están contempladas en la educación curricular del Perú. Además, el sistema educativo peruano adopta lógicas de la formación militar: “(...) por Resolución Ministerial, por el gobierno peruano en el 2009 se presenta al área de Educación Religiosa dentro del plan curricular de la educación primaria y secundaria; es decir, está regulado para que se enseñe durante los once (11) años o grados respectivos" (Flores Caldas, 2016, p. 273 y 274).

En el relato de KS, advertimos, además de vivir la prohibición de jugar al vóley por sus profesores, la presencia del discurso de la religión católica durante su formación educativa:

Mi experiencia en la primaria y secundaria no fue buena, por eso no terminé. Me gustaba jugar al vóley pero mis profesores no me dejaban, me lo prohibían decían que ese juego es solo para las mujeres, no lo pase bien. Era una buena alumna, pero cada vez que nos tocaba hacer educación física o religión lo sufría. El vóley porque no me dejaban jugar y en religión porque una vez de chica le confesé sobre mi sexualidad a mi señorita que era catequista y profesora de religión, y ella me aconsejó que fuera al cura de la iglesia de mi ciudad y que me confesara, que eso me iba ayudar. Entonces fui le conté al padre sobre mi homosexualidad y me dijo que eso era un pecado, me mandó a rezar como cuarenta padres nuestros, treinta ave maría, no sé cuántos credos y no me acuerdo que mas. Me re asuste pero rece más por miedo que por otra cosa. Después regrese, le conté a la profesora, le dije que no me había gustado, sentía que para lo único que sirvió es para que desde ahí me empezara a tratar peor. Me di cuenta que le contó a otras profesoras, porque cuando hablaban entre ellas me miraban mal, me hacían burlas. Eso sumado a toda la discriminación de mis compañeros me cansó y no fui mas al colegio, me quedé en tercer año (KS).

En el relato de (KS), junto al de otras entrevistadas podemos observar cómo opera el secreto de confesión. En algunos casos, las charapas a las primeras que les contaron sobre su autopercepción respecto a su identidad de género, fueron a sus madres, esto considerándolo siempre en secrecía. Pero otras, al no encontrar en casa esa "aliada", vieron en la maestra de la escuela, la extensión de la figura materna. Sin embargo, la secrecía deja de serlo cuando se traslada de lo personal, al ámbito religioso. Allí la confesión implica, por un lado, entender a su sexualidad u autopercepción de género como un pecado, el castigo para ser perdonada es el rezo. Acá la redención aparece nuevamente, pero más nítida, porque como vimos anteriormente en el caso de (E), la madre no la mandó a la iglesia, solo le dijo que sentía pena de ella. Sin embargo ante la incertidumbre, el miedo surge como un elemen- 
to constitutivo a la culpa cristiana.

Por otro lado manifestar su disconformidad con la maestra, posibilitó que su "secreto" sea revelado y compartido con otros profesores. Las miradas y burlas entre les otres es el modo como opera el estigma. Goffman (1998) plantea la cuestión de la identidad deteriorada. Define al estigma como el rechazo social por características o creencias que van en contra de las normas culturales establecidas.

Como ya mencionamos anteriormente la Educación Religiosa -solo católica- también es una materia ordinaria que está dentro del plan de enseñanza curricular del Perú, y se imparte en todas las escuelas y colegios públicos y privados.

El diseño curricular Nacional de EBR (DCN) nos explica claramente al referirse que la educación religiosa en la educación inicial, se orienta fundamentalmente al conocimiento del propio niño, sus padres y las personas que lo rodean, como seres que les brindaron amor, cuidado y protección; expresiones todas ellas de los valores cristianos, así como del testimonio de la vida de Cristo y el amor de Dios. También se busca de esa forma, que los niños se inicien en la participación de las actividades propias de la confesión religiosa familiar; uno de los primeros aprendizajes en la formación cristiana, (Flores Caldas, 2016, p. 276).

Según el último censo realizado en el Perú, en 2017, el 76\% de su población es adepta a la religión católica. Es por eso que un alto porcentaje de nuestras entrevistadas manifiesta ser creyente de la religión católica, mas no ser practicante.

En el relato, observamos que sus experiencias en las instituciones educativas, estuvieron marcadas por prácticas violentas. Por parte de sus compañeres, recibieron violencia física y verbal, al igual que de algunos profesores. Sin embargo en un solo relato aparece una profesora como mediadora del conflicto, pero de forma personal, no como una respuesta desde lo institucional. Es decir, algunos docentes procuran defender la diferencia por medio del disimulo, en el mejor de los casos pretenden reducir el daño, y no visibilizar el problema de fondo, bajo un manto de protección, pero nunca se resuelve el conflicto desde el aula, y todas instituciones educativas involucradas que les compete.

En la primaria estaba bien, tenía una profesora que me decidí contarle que me sentía mal cuando mis compañeros me insultaban y me discriminaban y le dije no quiero que me molesten, y así, mi profesora habló con los compañeros y algunos me respetaban y algunos no. Ella me entendía, me cuidaba, sabía sobre mi inclinación, para que no me molestaran mis compañeros no salía al recreo me dejaba que esté con ella en el aula, mientras ella revisaba las tareas que nos había dejado. Yo jugaba con 
una liga, lo ponía en dos sillas y jugaba, es un juego solo para mujeres, que se hace saltando, mi señorita me permitía solo cuando estábamos solas, me decía que no sepan o me vayan a ver los demás porque me iban a molestar, y para que después no me lleven a la dirección, que me podían castigar si me ven saltando liga (M A).

Este posicionamiento de la profesora habilita una práctica subjetiva no normativa, a diferencia de otres profesores, permite transgredir las normas y el orden de género al menos en secreto. Esto se convierte en un capital simbólico importante para el niñe, porque las reglas del juego ocupan un lugar preponderante en la reiteración y el refuerzo de la norma. Si se juega algo en donde no participan los demás, hay que evitar la mirada de les otres. Por un lado, mantenerlo en secreto cumple un rol importante en la (re)construcción subjetiva del niñe, que siente que la maestra la entiende y la cuida a pesar de que sabe que lo que está haciendo está mal, refuerza la idea de lo prohibido e instala la duda moral en el niñe.

\section{M continúa su relato:}

Cuando salía al recreo mis compañeros me esperaban afuera me tiraban cosas, frutas, y en el baño me tiraban agua. Eso en la primaria. Algunos profesores me castigaban, en el recreo varias veces me dejaban dentro del aula. Eso para mí era una discriminación, siempre era yo la culpable de todo, me discriminaban por ser homosexual. Yo era la mejor de mi aula, me castigaban también con las notas, me ponían cero, pero no eran todos mis profesores, eran mi profesor de inglés, de ciencias sociales y mi profesora de educación física. Otros profesores me pegaban con las reglas de madera, con sus manos en la nuca. Mi profesora de educación física me tiró con una piedra, quería que juegue al fútbol y yo no quería, y ella agarró la piedra y me tiró, yo le dije eso a la tutora y no dijo nada, porque en Perú antes no había quién nos respetara a los chicos que somos así, a los gays así de chiquitos (M A).

En los relatos de $\mathrm{M}$, podemos identificar que a pesar de tener una profesora aliada, la mayoría, la violentaba de forma física y verbal. Además, evidenciamos la complicidad de la tutora y el silencio de la institución educativa en relación a la problemática.

Mi experiencia en la escuela fue muy fea, me discriminaban mucho, había cosas que me obligaban a hacer que no me gustaban porque desde chica era femenina. En el colegio nos obligan a todos ir con el pelo cortito estilo militar, nos hacían formarnos haciendo fila, y si nos portábamos mal, nos castigaban haciendo ejercicios, ranas, planchas, canguros, todo eso que hacen los militares. A las mujeres no les hacían hacer eso. Por eso no termine el secundario, me daba cuenta que me lo hacían por mi condición, y no aguante y me fui (M B).

Por otro lado, en los relatos las entrevistadas, aparece el discurso militar en su formación educativa y como este operó en el disciplinamiento de sus cuerpos. En un caso, la 
tutora es cómplice de la violencia física de la cual es víctima; en otros, cuando las obligan a cortarse el pelo y hacer ejercicios físicos. En el grupo estudiado el cabello es un símbolo que reafirma no solo su feminidad, sino que se convierte en un elemento constitutivo en la expresión de su género.

La fuerte influencia militar en la educación peruana es producto de la reforma educativa llevada a cabo por el entonces Gobierno Revolucionario de la Fuerza Armada en el año 1972. La reforma contempló, además, la libertad en la educación, así como otras acciones y servicios de complementación educativa: entre otros, Orientación y Bienestar del Educando $(\text { O.B.E })^{19}$, Investigación, Tecnología Educativa y Perfeccionamiento Magisterial.

La educación constituye una pieza esencial en el proceso de transformación social y es parte integrante de la política global de cambio estructural que está llevando a cabo el Gobierno Revolucionario de la Fuerza Armada. Cabe a la educación la más alta y trascendental tarea de nuestro tiempo: liberar al hombre [...] Esta liberación no es una acción abstracta y evasiva: es una acción concreta y comprometida sobre todo con los más pobres que son también los que sufren todo el peso de la opresión, (Chávez García, 2006, p. 87).

Existe una especie de acallamiento en la sociedad en general y en los espacios educativos en particular, en los relatos de (M) y de otras entrevistadas, observamos la violencia física de les profesores y cómo se naturalizan estas prácticas sin ningún tipo de cuestionamiento.

Según Althuser (1988), así como hay agentes de la explotación en el sistema productivo y agentes de la represión, lo que él llama los aparatos represivos del Estado, hay profesionales de la ideología. Cada vez que negamos y acallamos la politicidad de nuestras prácticas como sujetos de la cultura, estamos actuando como profesionales funcionales a los aparatos ideológicos del Estado. En otras palabras, los llamados profesionales de la ideología nacen y crecen incorporando estas prácticas e ideas que sólo existen hombres y mujeres, en términos de genitalidad. Así, la educación aparece más afines a la normalización del orden de género, que obtener en ellos saberes críticos y capitales culturales. Es decir que la escuela, el colegio y otros espacios formativos aparecen como homogenizadores de ciudadanos.

19 O.B.E, tiene como objetivo el desarrollo integral del educando, a través de acciones que hagan posible promover, crear ejecutar y regular las condiciones y ambientes que aseguren la mejor atención de las necesidades de los educandos, para que éstos puedan aprovechar los recursos y oportunidades educativas, laborales, familiares y sociales. 
Juan Pechín (2013), pone en evidencia la complicidad entre familia y escuela en relación con la trama psicomédica que se instala como sentido común y, de esta manera. Como parámetro único de inteligibilidad para definir lo masculino y lo femenino y trazar una descripción genitalista de los cuerpos que permite la naturalización y la jerarquización de diferentes modos de volverse varones y mujeres en el tránsito de la escolaridad. De esta forma la escuela organiza y enfatiza su rol pedagógico y formativo al moldear ciertas representaciones duraderas sobre las diferencias de género y la sexualidad.

La actitud del profesorado perpetúa los estereotipos de género binarios, por un lado, porque se comporta con les estudiantes de manera diferente en relación a ideas preconcebidas como resultado de la cultura, y por el otro, de lo que se espera y se supone debe ser un niño y una niña.

El pensamiento de Butler (2016) emergió como una forma de replantearse la distinción sexo/género, y problematizar la categorización binaria de la heterosexualidad como natural. Así la teoría performativa del género de Butler sostiene que la reiteración de las prácticas discursivas de sexo/género, performa y materializa los cuerpos e identidades de acuerdo con la norma heterosexual.

Retomando a Bordieu, el profesor Jorge Huergo (2012), reflexiona al respecto:

"Algunos hemos hecho cuerpo el discurso dominante, porque el cuerpo cree en lo que juega. Francisco Gutiérrez sostiene como hipótesis, en su libro La educación como praxis política, que si los docentes tomaran conciencia de que son inculcadores de la ideología dominante sería posible la transformación de una educación popular, inclusiva y diversa".

Observamos, a lo largo de la trayectoria educativa de las charapas, cómo se naturalizaron aquellas cuestiones que reproducen las relaciones, las ideologías y las formas propias de un sistema de dominación, que se perpetúan desde el punto de vista económico, cultural y financiero.

En el relato (KS) analizamos cómo operan las tecnologías de género en el ámbito educativo, puestas al servicio del binarismo sexo/género, puntualmente, los baños escolares: 
Solo por mis compañeros, que eran muy toscos, me pagaban, me empujaban, me hacían llorar. Después empecé a tener problemas para usar el baño. No podía entrar al de varones porque ahí era muy violento todo. Algunos me metían la mano a la cola y esas cosas, entonces no quería más entrar ahí. Un día le pedí a la profesora para entrar al baño de las niñas y no me dejaron, entonces me mee en el pantalón, eso me dio mucha vergüenza, lo recuerdo hasta ahora, fue traumático. Pase mucha vergüenza, eso lo sentí como una humillación grande (KS).

Preciado en su ensayo "Basura y Género" (2006) plantea dos lógicas opuestas que dominan los baños de señoras y caballeros. Mientras el baño de señoras opera como un mini panóptico en el que las mujeres vigilan colectivamente su grado de feminidad heterosexual en el que todo avance sexual resulta una agresión masculina, el baño de caballeros aparece como un terreno propicio para la experimentación sexual. El baño es junto con los clubes automovilísticos, deportivos o de caza, y ciertos burdeles, uno de los reductos públicos en el que los hombres pueden librarse a juegos de complicidad sexual bajo la apariencia de rituales de masculinidad.

En el relato de la entrevistada aparecen dos situaciones que se contraponen, pero comparten el mismo patrón: la violencia. Por un lado, la violencia física vivida en el aula $y$, por el otro, el acoso entendido como una de las formas de violencia sexual ejercida por sus propios compañeres.

En concordancia con Preciado, el baño funciona como espacio donde los hombres se liberan a juegos de complicidad sexual, bajo la apariencia de rituales de masculinidad, donde la charapa es vista como un objeto de deseo. En cambio, en el aula el comportamiento de sus compañeres opera en un sentido contrario: es objeto de pánico moral y sexual.

Los baños además de servir para hacer nuestras necesidades fisiológicas sirven para reafirmar los códigos de la masculinidad y la feminidad en el espacio público. Por eso, escapar al régimen de género de los baños públicos es desafiar la segregación sexual que opera a través de "oposiciones homólogas", entre los masculino y lo femenino, que conducen a clasificar todas las cosas del mundo y todas las prácticas, sostiene Bourdieu (2000).

Asimismo, otro de los elementos que emergen en la mayoría de las entrevistas es la conducta pasiva de las charapas frente a la violencia recibida en sus diferentes modalidades en los ámbitos educativos. La puesta en práctica del rol de género es el resultado de la construcción de la feminidad. 
En primaria me decían mariconcito, en secundaria los alumnos más grandes me decían maricón o chivo, y allí sí ya empezaba a contestar. Un día me canse, agarré el palo que les dan a ellos, le di en la espalda le pegué bien fuerte, porque me discriminó. Golpeé a un alumno de 5to año, el brigadier. Me fui tranquila porque yo había sido la agredida. Nunca más me volvieron a tocar el tema porque ya les daban miedo mis reacciones. Yo igualmente sabía que con golpes no se llega a nada, pero me hice respetar $(L)$.

En la "La tesis de la fuerza masculina y de la debilidad femenina" Lagarde y de los Ríos sostiene que la fuerza de los varones y la debilidad de las mujeres no proviene de su cuerpo, sino de su lugar en la sociedad, de la posición política de fuerza que les corresponde por género tanto a hombres como a mujeres. En algunos casos, hay mujeres que tienen mayor talla que ciertos varones, y aún así, son víctimas de ellos en diferentes modalidades, no se defienden ni presentan resistencia ante la agresión masculina. Las mujeres viven y son educadas en el temor a los hombres y en la creencia de que todos ellos son físicamente más fuertes que cualquiera de ellas.

A través de esta ideología son pensados y aprendidos los hombres y las mujeres concretos, no obstante que sus características a nivel individual o grupal no concuerdan con la representación simbólica por géneros; más aún, a pesar de que sean exactamente lo contrario. El resultado es que más allá de la evidencia se otorga valor de verdad al principio y se aprecia la realidad de manera estereotipada (Lagarde y de los Ríos, 1990, p.266).

Sin embargo, en el relato de (L), observamos que ante el hartazgo de la humillación de los alumnos optó por defenderse. Esta situación contribuyó a reconfigurar las relaciones de fuerza porque el Brigadier ${ }^{20}$ detenta el poder en el aula después del profesor, es quien vela por el orden y hace uso de la fuerza física, si es necesario, para castigar conductas que alteren lo establecido.

Otro de los mecanismos utilizados por las instituciones educativas donde transitaron las charapas fue la expulsión, fundamentada a partir de "la mala conducta", a través de un 20 Brigadier es un rango militar cuyo significado es diferente en los distintos servicios militares del mundo. En los colegios peruanos es un cargo que detenta el alumno con mejor rendimiento intelectual, y preparación física. Para ocupar el cargo se necesita ser el "mejor" alumno en relación a tener las más altas calificaciones, entrando en una competencia meritocratica. 
certificado, donde se daba cuenta de un comportamiento "desviado", el cual no reproduce el orden de género. Este operaba como un mecanismo de extorsión. La familia al saber que el certificado implicaba la interrupción de la trayectoria educativa del hije se veían obligades a realizar el traslado a otra institución:

Donde más he sufrido discriminación fue cuando estaba estudiando en un instituto superior en Tarapoto. Éramos dos gays y nos insultaban. Luego la directora les Ilamó la atención y ahí bajaron. Cuando le conté a mi papá, me cambió de instituto. Estaba estudiando técnica de enfermería. Hice cuatro de seis ciclos $(T)$.

Otra modalidad de expulsión implícita es la violencia física, psicológica y simbólica, ejercida por parte de los estudiantes y profesores, que derivó en la deserción escolar o en el traslado de un colegio a otro, como podemos advertir en el relato de $\mathrm{T}$.

La mayor parte de las entrevistadas narró haber sufrido, más de una vez, discriminación en el ámbito escolar por sus compañeres, es decir, sus propios pares. Mientras que otras experimentaron discriminación y violencia física por parte de sus profesores. También aseguraron que quienes tenían comportamientos más femeninos y expresaron su identidad de género en los espacios educativos, fueron las más violentadas. Mientras quienes dijeron no ser discriminadas sostienen que se debió al ocultamiento de su identidad de género autopercibida, en esos ámbitos.

También observamos que existe en ellas un ocultamiento/silencio de la violencia que se ha ejercido sobre ellas en el ámbito familiar y escolar, producto de la vergüenza que han internalizado, una especie de transferencia sobre el qué dirán los demás. No solo de ser víctimas violentadas, sino que las educan con la idea de que ser travesti o trans es algo malo, denigrante, que debe dar vergüenza. Esta es una práctica arraigada en la cultura peruana.

Del total de las entrevistadas la mayoría logró terminar la primaria, sin embargo la mitad no pudo finalizar la secundaria y solo una tiene un título terciario. Otro dato relevado es que durante este periodo de sus vidas (infancia y adolescencia) la escuela y la familia fueron los lugares donde más vivieron la violencia.

La escuela, como homogeneizadora de ciudadanes, perpetúa el orden instituido, mediante conocimientos y prácticas heteronormativas que reproducen un orden injusto. En estos espacios formativos las voces travestis y trans fueron acalladas, invisibilizadas y excluidas. No se tuvo en cuenta sus prácticas cotidianas, sus ideas como parte de la producción de un conocimiento subjetivo, diferente al orden existente. Se sesgó el intercambio de saberes y el debate como constitutivo de lo público, desconociendo y restringiendo su rol político de sujetes. Ese acallamiento es producto de lo que uno hace cuerpo, según el sociólogo francés Pierre Bourdieu (1986), quien sostiene que "el cuerpo cree en lo que juega" (p. 40). 


\subsection{Abandonar el Nido}

La mayoría de las entrevistadas abandonan sus hogares desde muy chicas, en busca de lugares menos hostiles, sus deseos están plagados de una búsqueda infinita de espacios menos contaminados. La totalidad de las charapas, en mayor o menor medida, han experimentado algún tipo de violencia y discriminación, y transitan un mecanismo de desarraigo inducido, durante esta etapa de sus vidas. En ese marco, comienzan sus primeras experiencias laborales, antes y después de dejar el hogar.

A los 10 años, vendiendo pan en Perú. Nos daban una canastita. Luego lavaba ropa, iba a cortar pasto a los 10, 11 años. Luego empecé en la peluquería a los 12 o 13. En las fiestas de promoción de Perú, era ayudante de peluquería a los 14, 15 años (KS).

Todo en negro, era todo informal. No me pagaban los aportes, no tenía seguro social. A veces no me pagaban, a veces sí. Trabajé solo un mes. Luego trabajé con una señora vendiendo comida, de ayudante, lavando los platos y sirviendo, en puestitos de la calle (D).

Sí, porque nosotras no somos bien vistas, me miraban como si fuera un bicho raro, de los pies a la cabeza. Porque parecía que nunca habían visto una maricona. Me miraban y murmuraban. Yo una vez fui a servirle la comida a un señor, el señor no quiso comer, pagó y se fue. Yo le dije a la señora, ¿El señor pagó y se fue? ella me contestó, de repente le ha dado asco, ¿Asco de qué?, dije yo. No sé de las personas que son como tú. Así me contestó la señora (D).

Pero algunos clientes preguntaban quién era quién cocinaba, y primero no querían decirle el dueño, luego le dijo que hay un mariconcito que cocinaba, y después le dijeron que no iban a comer más porque les daba asco porque dicen que nosotros tenemos VIH todos (M A).

Pero cuando vine al Norte, ahí sí sufrí discriminación, a veces se burlaban, me daba vergüenza salir atender, cuando la señora me decía que salga atender yo no quería porque la gente se reía porque se daban cuenta que era gay, entonces cuando me mandaba a atender yo le decía no señora yo me quedo aquí porque no quería pasar vergüenza $(E)$.

Como se observa estas labores consistían en: limpieza, ayudante de cocina, ayudante de peluquería, vendedoras de productos de cosmética, vendedoras ambulantes entre otras, 
en condiciones de precarización laboral, donde también experimentaron situaciones de violencia y discriminación por parte de las personas que las tenían a su cargo y de los clientes a quienes les brindaban el servicio en relación a la expresión de identidad autopercibida.

Todas las divisiones del trabajo: las genérico-sexuales, las raciales, las ideológicas, las políticas, las de clase, son consesualizadas como naturales o como creaciones divinas. En distintos niveles ideológicos son justificaciones que remiten a la representación simbólica de poderes inalterables. Todas ellas son, sin embargo, históricas y cumplen funciones básicamente económicas: prohíben, obligan y permiten, a la vez que agrupan a los seres humanos en grupos excluyentes y en ocasiones antagónicos, en géneros, clases, castas y razas (Lagarde y de los Ríos, 1990, p .115).

En este sentido, advertimos cuando la charapa no expresa su identidad de género socialmente, lleva adelante otras labores que no son la prostitución como destino. Estas actividades culturalmente han sido asignadas a las mujeres cisgenero y cumplen la función de reproducción del sistema sexo genérico, por lo tanto, son una extensión de las actividades que las mujeres cumplen en el ámbito doméstico reproduciendo el orden social establecido. En el caso de las charapas como su identidad de género cuestiona el sistema de la cisheteronorma, se las excluye relegándolas, casi inexorablemente, a la prostitución.

En los testimonios de las entrevistadas dan cuenta como todas comenzaron a trabajar siendo menores de edad en trabajos informales, y a su vez, fueron víctimas de violencia laboral, verbal y simbólica. A su vez, en esa etapa de sus vidas estaban en proceso de transición de su expresión de género. Momento en el cual, indefectiblemente, se le presenta a la prostitución como "destino" petrificado, en tanto único lugar donde se piensa y ubica a las travestis y trans, en tanto remota posibilidad de ser.

Por lo tanto, las que no lograron expresar socialmente su identidad de género en el Perú, por distintas razones, pero sobre todo como modo de resguardo por el miedo a la violencia física y a la condena social, vivieron su infancia y adolescencia ocultando su identidad.

(...) A nosotras no nos dieron otra opción, solo el ir a pararse en una esquina a vender el cuerpo a cuanto transeúnte pasara. (...) Antes, bah no digo que haya cambiado del todo. Pero no hay aún elección te vas a pedir un trabajo aquí o en Perú, ven tu condición y por más inteligente o más cartón que tengas te van a decir que no, porque eres una chica trans $(\mathrm{VN})$.

Desde los 15 años estuve en la prostitución. Sólo desarrollé la prostitución hasta la actualidad (...) ¿A qué mujer trans no le gustaría trabajar en algo que no sea la prostitución? A mí por ejemplo me gustaría trabajar de otra cosa. (...) Empecé a 
prostituirme por necesidad, por querer ayudar a mi mamá, para tener un ingreso. (...) Estando en la calle en la prostitución sufrí un montón violencia. Los hombres que te maltratan y te llevan y te pegan. Sufrí violación por parte del marido de una compañera trans que era re bagre, el hombre estaba infectado. Entonces, chica que iba nuevita a la zona, él te llevaba engañada y te violaba amenazándote con pico de botella, esa fue mi primera violación en la calle. A los seis meses me voy a hacer los análisis de chequeo y salgo que soy positiva de HIV. Yo tenía allí 16 años. Y fue por ésta violación, porque el chabón era portador y además violaba a las pibitas, a un montón de chicas les hizo eso (MS).

En la búsqueda por conseguir tales ingresos económicos, advertimos la descripción de un mapa, con lugares menos peligrosos por donde transitar para evitar correr menos riesgos. Sin embargo, en diferentes "zonas rojas" de la capital limeña, como la avenida Colón, Arequipa, y el Pantanal, tienen que enfrentar los embates del Serenazgo -la policía Municipal- y la discriminación traducida en agresiones verbales y físicas por parte de algunos sectores de la sociedad civil:

“Mi experiencia en Lima fue muy dura. Me llevó una amiga que ahora está en París. Ella me lleva, me dice a qué voy, fue franca. Me dijo a qué voy, a dónde voy a vivir, todo eso. Yo llego y fue un cambio total, a lo que yo tenía en mi casa. No tenía todas las comodidades en mi casa, pero era mi casa. Al irme así a Lima tenía que preocuparme sí o sí por la comida, por la vivienda, la vestimenta, ya era mejor dicho una persona independiente, porque tenía que cumplir con muchos gastos personales. $Y$ aparte el lugar donde yo llegué era un lugar no habitable para personas. Era una casona vieja del centro de Lima que lo llaman Hong Kong, creo que hacía un año que lo habían cerrado, hacía un año todavía funcionaba, vivían drogadictos, chicas en estado de prostitución, mujeres, chicas trans, delincuentes, de todo. Estaba ubicada en la Avenida La Colmena. En Lima estuve desde el 2004 hasta el 2008 que me viene para Argentina (K).

Sí, la policía, hacían batidas o razzias, como llamamos nosotras. Nos detenían, nos llevaban a la comisaría, dos, tres, o cuatro horas mientras nos buscan si tenemos algún antecedente policial, pero también había una policía municipal que se hace llamar serenazgo, ellos sí nos maltrataban físicamente, venían, nos golpeaban, nos quitaban las ropas, y aparte de eso nos botaban en lugares alejados de la ciudad de Lima. Pero afortunadamente a mí no me sucedió eso. Pero muchas llegaron a donde yo vivía en pelotas, sin nada en el cuerpo, tapadas con alguna bolsa o algunas ropas viejas que encontraron en algún basurero, o alguien que les daba (KS).

A mí solo me agarraron dos veces y me agredieron físicamente, me dieron patadas, puñetes y me quitaron la ropa. También nos golpeaban con un palo, no sé de qué material era como un bastón, de esos que tienen los policías. Algunos policías del 
Serenazgo, de acuerdo con el distrito, tenían perros. Yo trabajaba en el centro de Lima, ahí no había, en Miraflores y Lince, sí. Eso perjudicaba a las chicas de la Arequipa. Ahí, muy pocas veces bajaba, mi lugar de trabajo era por calle Colón mayormente, en la Arequipa algunas veces y en el Pantanal, que es la zona del aeropuerto, en esos tres lugares $(K)$.

En el relato de $(K)$ y de otras charapas entrevistadas observamos un patrón común y sistemático de violencia. La policía utiliza la fuerza física y psicológica. La práctica del desnudo, a las que eran sometidas algunas de ellas en las primeras etapas de su vida por parte de sus progenitores, como en el caso de $(T)$, vuelven a aparecer en el relato de $(K)$, pero esta vez, ejecutado por parte de los funcionarios públicos.

En Lima, además de compartir la situación de prostitución en la calle, las charapas experimentan vínculos de solidaridad. Muy pocas han podido montarse, como se conoce en la jerga de ellas, en referencia a los cambios físicos en el cuerpo (esto no implica necesariamente el cambio de sexo). Es decir, haberse inyectado siliconas industriales (líquidas), operación de mamas y algunas cirugías estéticas de feminización del rostro como: nariz, la bola de bicharra, relleno de frente y mentón. Para conseguir la materialización de ese deseo, como veremos luego, la mayoría de ellas migra a la Argentina.

A partir del relato de las primeras etapas en la vida de las charapas, determinadas por el tránsito en el ámbito familiar, educativo y laboral informal, hemos podido reconocer que el conflicto surge fundamentalmente cuando las travestis y trans no reproducen las mismas prácticas heterosexuales, estereotipos y roles de género asignados para lo que se considera masculino y femenino, desde el momento del nacimiento. Éstas van a contramano de una fenomenología predominante en la cultura heterosexual, anclada en la reproducción de la especie, fundada en el dato biológico.

Determinar el origen del conflicto es clave para entender cómo se produce el exilio socio-corporal:

El exilio, desde esta perspectiva, será entendido de alguna manera como un gesto simbólico mediante el cual garantizar la "pureza" de ciertos tipos ideales y del imaginario de "lo público". (...) Este acto de desplazamiento o 'reclusión' como llama oportunamente Lohana Berkins, conduce a (re)pensar en el exilio socio-corporal que se pone de manifiesto producto del ejercicio de violencia arbitraria, que según lo expues- 
to anteriormente, se produce y perpetúa a través de ciertas estructuras institucionales legales, maximizando políticamente las condiciones de vulnerabilidad (González, 2015, p.38-40).

En otras palabras, podemos decir que dichas condiciones determinan la exclusión y una migración implícitamente forzada de las charapas. De esta manera, en el apartado siguiente, analizaremos las trayectorias migratorias a partir de las cuales las entrevistadas dan cuenta como la mayoría se trasladaron desde sus lugares de origen a las grandes ciudades del Perú, principalmente, la capital Lima y, desde allí, con destino a La Plata-Argentina, por dos motivos principales: por razones económicas, en la búsqueda de nuevas oportunidades; y por la necesidad de reafirmar su identidad de género, en lugares menos hostiles. El viaje, para ellas es entendido como un acto de libertad para expresar y materializar su identidad de género autopercibida, sin mecanismos que determinen o condicionen su deseo, e intenten disciplinar sus cuerpos, identidades y sexualidades no normativas.

\subsection{Vuelan, migran, buscan hacerse en otra costa}

El presente apartado se busca profundizar en cuestiones que atraviesan la realidad del colectivo de feminidades travestis y trans migrantes peruanas, las charapas, en el contexto argentino, concretamente, en la ciudad de La Plata. Para ello, abordaremos el caso a partir de dos dimensiones analíticas: la ruta que delinean por el país para arribar a otras latitudes, fundamentalmente, Europa; y la reconstrucción de lazos de sociabilidad.

A lo largo del proceso investigativo y de la sistematización del trabajo de campo realizado, emergieron los siguientes interrogantes: ¿Por qué y cómo migran? ¿Qué sentidos le dan a la corporalidad y la expresión de sus identidades travestis y trans? ¿Qué incidencia reviste la dimensión comunicacional intersubjetiva en la construcción de los lazos que se tejen en la migración? 


\section{Alzar el vuelo}

Las compañeras que nos conocemos allá principalmente en Lima, somos de diferentes partes del Perú. Entonces en Lima, como es la capital estamos todas las chicas del norte, del centro, del sur, del oriente, de la costa y de la sierra. La primera parada para llegar a Europa, que viene a ser lo máximo $(K)$.

La región de la selva peruana está compuesta por cinco departamentos: Loreto, Amazonas, San Martín, Ucayali y Madre de Dios; densidad territorial que cubre el 60\% del país. A su vez, estos departamentos están conformados por provincias, distritos municipales y centros poblados.

Nuestras entrevistadas pertenecen, en su totalidad, a los distritos de Tarapoto, Chasuta y Lamas (San Martín); Iquitos (Loreto) y Pucallpa (Ucayali). Observamos en los relatos que los desplazamientos trazan dos rutas bien marcadas, que componen procesos migratorios internos y externos.

Respecto de las migraciones internas, las charapas se embarcan hacia las ciudades costeñas del norte peruano, Trujillo y Chiclayo; y, en su mayoría, a Lima capital del Perú:

No me acostumbre en Lima, porque ya me había acostumbrado al norte, Lima es

más movido (...) Entonces volví a Trujillo, pero no a Chasuta, desde los 19 años que me fui de ahí y no volví nunca más. (...) mi meta era ser una mujer, ese era mi sueño, que se me luzca el pelo, hasta que decidí trabajar en la calle. Fue en Trujillo, me decidí trabajar en la avenida Ayacucho, sin conocer a ninguna chica trans, andaba sola en el mundo, en eso conocí una amiguita de lquitos, ella ya era chica trans (...) y comencé a trabajar y trabajar, hasta que un día conocí un señor que trabajaba vendiendo sus dulces, caramelos. Esa noche (...) me dice vamos, porque en Chiclayo vas a trabajar más y me fui con él sin conocerle, me fui con el hombre (E).

Mi primer trabajo fue a los 13 años, luego de la primaria. Porque me quería ir de mi provincia, yo soy del Distrito de San Pablo, en San Martín de Lamas, de Fausa Lamista. Quería trabajar cocinando, pero mi papá no me quería mandar porque era chica, así que trabajé en enero una semana, hui de mi casa, a otra provincia a 12 horas. En Chiclayo. Ahí trabajé en cocina, mi papá me buscó y me encontró y me llevó a casa, porque quería que estudie ( $L$ ).

Después de Pucallpa voy a Lima (...), cuatro años en la zona de Ate Vitarte. Allí trabajé en la calle, en la prostitución, antes nunca había estado en eso. Estando allí me sentía triste, porque no conocía a nadie (M.A). 
Cuando cumplo los 20 años, estoy hablando del 2004, estaba allá estudiando en Tarapoto cosmetología. Yo estaba estudiando, yo ya tenía conocimiento de amigas que estaban en Lima, la capital del Perú, que trabajaban ya en situación de calle o prostitución. Yo me fui con una mentalidad de trabajar en eso (K.)

Por otra parte, dentro de los procesos externos, los destinos posibles de las charapas son, en primer instancia, las ciudades de La Plata, CABA, Monte Grande y Mar de Plata en Argentina y; en segunda instancia, algunas ciudades europeas, como Barcelona, Madrid, París, Roma, Florencia y Venecia.

Al momento de elegir Argentina, lo que nosotras miramos es la experiencia de otra compañera, en lo económico, en lo cultural, que acá la gente está más abierta, no como el Perú que es un país muy, pero muy machista. Acá también hay machismo, pero estamos hablando de otras culturas, son culturas europeas, porque acá hay mucha diversidad de naciones, de migrantes que emigraron acá a la Argentina, o sea, tenemos otra cultura, no la misma que del Perú. Entonces también ese es otro de los motivos porque nos tratan bien acá, no es la misma discriminación que existe en el Perú. Obvio que existe discriminación acá en la Argentina, pero no como en nuestro país. O sea, eso también es uno de los motivos para poder migrar. (...) Entonces, es como un circuito que es como un espiral, que va desde abajo hasta arriba. También lo podemos ver como una pirámide, como que nosotras estamos en nuestro pueblo, de nuestro pueblo vamos a Tarapoto, de Tarapoto a la capital de Perú que es Lima, de Lima a Argentina, y Argentina Europa" (K).

Llego a Retiro, vine en bus, haciendo escalas por diferentes ciudades del Perú, de Bolivia y llegué acá a la Argentina. Primero me fui para Arequipa, de Arequipa me tomé otro colectivo que era para Juliaca, de ahí otro para Puno, de Puno para Desaguadero, de Desaguadero me tomé un colectivo para La Paz, en La Paz me quedé a dormir esa noche porque ya no había carro, no había Bus para Buenos Aires, tuve que salir al siguiente día a la tarde. De ahí para Villazon, que es la frontera con Argentina. Y de ahí ya recién tomé directo para Buenos Aires, que llegué acá un domingo a las 8 de la noche, mi destino final tenía que ser Mar del Plata (K).

El viaje hacia la Argentina, lo hacen en avión o microbús. Mientras que desde Lima hasta la Ciudad Autónoma de Buenos Aires, son tres horas en avión y tres días en ómnibus. Hay que pasar por cuatro controles de frontera: el de Perú y Chile, y el de Chile y Argentina. Este recorrido es el más difícil, corren el riesgo de ser deportadas y perder los pasajes. Hay un tercer recorrido alternativo que es por Bolivia, el cual es el menos inseguro para ingresar. 
(...) vinieron en ómnibus, la mayoría por Bolivia, porque en la Frontera de Chile los carabineros son terribles, te joden mucho y hay veces que no te dejan pasar. Hay chicas que han perdido el pasaje. El pasaje sale de 1500 a 1800 pesos en temporada baja, en fiestas de 2000 a 2500 pesos, en ómnibus ${ }^{21}$ (VM).

\section{Mito del Progreso}

En el relato de nuestras entrevistadas podemos observar que han construido una cadena de valores respecto a los lugares donde migran. Si bien Argentina es el primer lugar elegido, en la mayoría de las charapas está instalada la idea de que viajar a Europa, da estatus.

Si estuvo en mis planes, hasta hace dos años quizás era mi sueño como todas las chicas que vienen acá, irse a Europa. Es el sueño más grande de todas las que trabajan en la calle, pero ahora no pienso en eso.

(...) Ahora solo viven 10 chicas, las demás están en Europa, Chile y Perú. Viajaron porque cambió la plaza, por su familia, y otras en Europa "euros, son euros", para ganar más dinero" (VN).

$Y$ es por ese motivo que emigramos para otros países, por el bienestar y progreso económico. (...) Cuando llegas a Europa ya sos la que puede decir, cumplir tu sueño, de comprarte una casa, ayudar a tu familia económicamente. Para llegar allí el primer paso es Argentina, porque económicamente nos servía para poder ahorrar, para poder llegar a Europa (K).

Esta ficción del estatus alimenta una expectativa por lograr arribar al viejo continente. Por este motivo a las charapas, que logran concretar el ansiado anhelo, las bautizan como las europeas. Observamos como aquí se produce un proceso de (des)identificación del lugar de origen, suplantándolo por un gentilicio que las asocia con el continente receptor, lo cual se puede ver en la valoración positiva que hacen sobre las que migraron a España, Italia, Francia, entre otros países.

Argentina se convierte no solo en un lugar clave y estratégico para vivir y radicarse, sino también para dar el salto hacia Europa. Porque salir desde el Perú es imposible, debido a que muchas veces no tienen cómo acreditar solvencia económica:

21 Estos precios hacen referencia al momento en que fue realizada la entrevista en cuestión, en el año 2013. En la actualidad se han multiplicado estas cifras. 
Supuestamente con la ley que ahora los peruanos pueden entrar a Europa, entre comillas te dicen eso, pero es una gran mentira, te piden muchos requisitos (VN).

En cambio, migrar desde Argentina, aún falsificando documentos es un trayecto casi seguro para llegar a su destino final:

Es totalmente ilegal, todas se van ilegales. Si eres argentina, si podes ir con tu pasaporte nomás, porque Argentina tiene pase libre para Europa, y nosotras las peruanas no. Las peruanas tenemos que falsificar documentos (Z).

En estos relatos podemos observar las relaciones subterráneas que entablan las charapas y cómo se generan los vínculos de confianza entre ellas: arriban a las ciudades de destino a través de redes migratorias. En ese proceso, desplazan los vínculos de consanguinidad e inscriben nuevos lazos de maternaje. En el viaje veremos cómo, a partir de la experiencia común del desarraigo, se reconfiguran también las prácticas de sociabilidad.

\section{Relación entre madres e hijas putativas}

En las redes migratorias que se van construyendo, específicamente, entre las charapas, la que trae asume la categoría de madre y, la que viene, de hija. La madre desempeña un rol clave, puesto que es la que manda el dinero para la compra del pasaje, quien le da los recaudos de cómo manejarse en migraciones, qué responder en caso de algunas preguntas, cómo venirse vestida para no llamar la atención y que eso sea una excusa para no permitirle el ingreso, entre otras orientaciones. Asimismo, en el país receptor, la espera con un lugar donde alojarla, le consigue la parada y la acompaña para montarse o la siliconeen -término que hace referencia a las inyecciones de silicona líquida que se colocan en su cuerpo-.

Las hijas son chicas que son amigas nuestras o alguna chica que compartiste cosas en Perú. Se les llama hijas porque nosotras las traemos acá, lo que gastamos en pasaje y todo, ellas lo devuelven, le damos parada. Así cumplimos la función de una madre, como cuidarla y todas esas cosas. Tengo una sola hija, G, estoy pensando en traer a dos chicas más de allá, de mi tierra, de lquitos $(\mathrm{N})$.

Me ayudó mi madre A, me mandó el pasaje. Ser madre es la que te cuida tiene que darte parada, todo, te da todo, ella responde por cualquier problema. Me envió 300 dólares y el pasaje, aparte. Eso cuando trabajamos lo devolvemos. Cuando Ilegamos, $A$. me recibe en la casa... "tienes que trabajar pensando, me dice porque no viniste al pedo. Y lo primero que trabajes, me devuelves la plata". Cuando estaba hace un año empecé a traer amigas, yo era demasiado buena, yo no les pedía el pasaje, se los regalaba. Yo traje a 6: La T, la B, V, La M, La K y a la K. (L.) 
Mira, estas son las fotos de mis hijas, traje 7 a la Argentina, estoy por traer otra. De las 7 todas se pusieron el cuerpo y lolas, solo la P no se puso las tetas. De todas las que traje, solo una vive conmigo $R$. No quiero tenerlas, porque me gusta mi independencia. $R$ tiene 22 años y hace 6 meses llegó de Perú, empezó a verse con un pibe, no salía a trabajar o volvía temprano. Entonces agarré y le dije tener marido acá es un atraso, vos viniste para progresar. Ella tiene dos hermanas trans, cuando quería que la traiga me dijo, madre yo quiero ser más que mis hermanas, por eso la ayudé. Le dije los chicos de la calle te sacan hasta el último peso. Por suerte me escuchó, me hizo caso y ahora está sola. Una de mis hijas, la primera que traje, a la S, me pagó al otro día que le traje. Hizo un buen "chichis"22, se puso el cuerpo y las tetas (V).

La totalidad de nuestras entrevistadas migraron a través de una propuesta hecha por alguna charapa que tenía la experiencia de migrar. Luego, aquella debe devolver lo prestado, y una vez estabilizada, la hija se convierte en madre trayendo a otras charapas. Así se reproduce la red migratoria.

La experiencia de las charapas, nos permite entender el fenómeno de la migración desde una multidimensionalidad que se inscribe en lo social, sin ignorar los contextos más amplios y las múltiples articulaciones, a partir de las cuales podemos comprender el presente, siempre relacional y necesariamente provisorio.

De esta manera, dirá Grimson (2012), sus hábitos culturales sólo pueden ser entendidos en el marco de un universo específico de sentido. Pretender analizar estas prácticas fuera de sus contextos, mediante diferentes valores, significa por un lado desconocer la diversidad de prácticas socioculturales que las constituyen desde sus lugares de origen, y

por el otro primordialmente, actuar de modo etnocéntrico y nacionalista

Así, en el presente estudio, optamos pensar las experiencias de las feminidades travestis y trans migrantes peruanas en tanto evidencia de un emergente sociocultural que implicó comprender las redes complejas que construyen a su paso, y que pueden ser descriptas a partir de las condiciones en las que viven.

22 Cuando mencionan que hace "chichis," está remplazando esa palabra por la de robo y cuando dice "chichar" tiene que ver con la acción de robar. Pero no se trata de cualquier robo, no es un asalto a mano armada, tampoco con algún elemento punzo cortante. Sino que consiste en sacarle sólo el dinero de la billetera y devolverla a su lugar, para que el "cliente" no advierta la falta de ella, al momento de irse. Esta práctica requiere de un saber artesanal, sobre todo de cierta habilidad con los dedos de la mano. Cabe destacar que no todas se dedican a los chichis, las que lo hacen bien, son reconocidas entre sus pares, a las cuales le otorgan cierto prestigio: "La reina de los chichis o re chichera". No obstante, esta práctica puede ser muy peligrosa para ellas: "En algunas ocasiones casi me matan por chichis, recuerdo dos veces: en Tocache, allá en Perú y otra vez en calle 42, acá en La Plata, me balearon dos chicos con balas de goma. Una amiga lo hizo y cobré yo. Y otra vez que yo hice chichis, cobró ella. Soy gordita, grande, si no meto mano ¿de qué vivo?” (V). 


\section{Las charapas y su relación con el espacio físico: condiciones habitacionales}

Las charapas que viven en La Plata, en su mayoría alquilan habitaciones en pensiones. Durante el trabajo de campo conocimos cuatro de ellas: en calle 45 entre 121 y 122 , calle 43 entre 3 y 4, calle 121 entre 35 y 36, y en la calle 115 entre 65 y 66 . En la primera, vivían veinte charapas y en la segunda, diez. Mientras que, en la tercera, trece y, en la cuarta, quince. Pero tiempo después se trasladaron a otros lugares, en parte debido a los allanamientos de la policía en relación con los problemas vinculados a estupefacientes, y en otros casos, viajaron a Europa o regresaron a Perú.

"Si lo venden no sé a dónde vamos a ir a parar, no es fácil conseguir donde vivir. Te piden muchos requisitos para alquilar, ahí se complica. Antes acá vivíamos alrededor de 20 chicas. Ahora solo somos cinco. La mayoría se fue y otras regresaron a Perú. Esta casa la quemaron, algunas vendían droga hasta en la puerta, me pelee con ellas, pero no hacían caso. La policía vino a allanar la casa, rompieron todo y se Ilevaron a algunas. Nos trataron mal a todas por igual y eso te generaba impotencia porque había chicas que nada que ver con eso. También estamos mal vistas por taxistas. No quieren entrar hasta acá" (V).

En el relato de $\mathrm{V}$ se pone de manifiesto la situación habitacional, una de las constantes preocupaciones de las charapas, esto les genera incertidumbre. Conseguir un lugar para alquilar donde vivir se torna difícil porque la identidad travesti o trans - por prejuicio y estigma social- está asociada con la prostitución, y con la venta y consumo de drogas, entre otras cuestiones. Por otro lado, al ser migrantes y no tener, en su mayoría, el D.N.I argentino, se dificulta rentar alguna vivienda. Y para quién pudo obtenerlo, y no tuvo un trabajo formal, se convierte en un triple obstáculo, cualquier inmobiliaria a la hora de rentar un inmueble dentro de sus requisitos exige acreditar sus ingresos a través de recibos de sueldo.

Estas pensiones eran casas viejas, con pasillos. Las paredes no tenían revoque. Algunas estaban pintadas de colores llamativos que intentan disimular el mal estado del inmueble. Los cables de luz, y de internet se encontraban en mal estado y colgando. Las paredes tenían humedad y hongos. En una de las pensiones, había un solo baño. Solo tenían agua fría. En la de calle 45 hay 13 habitaciones, algunas de $3 \times 3$ y otras de $4 \times 4$; en la de calle 43, sólo seis de $3 \times 3$; en la de 121, cinco de $2 \times 3$ y; en 115, ocho de $3 \times 3$. A pesar del mal estado de las viviendas, las charapas pagan sumas exorbitantes por el alquiler, y han llegado a vivir hacinadas, cada pieza es compartida entre cuatro y cinco personas. 


\section{Cuerpo, identidad y sentido}

En la mayoría de los relatos se reitera la palabra progreso, asociado no solo a las cuestiones económicas, sino también al sentido y al valor que le dan a la construcción de la corporalidad. Ni bien llegan a Argentina, la mayoría de nuestras entrevistadas, comienzan a dar esos cambios.

El primero consiste en ponerse silicona líquida -aceite de avión o industrial- en las caderas y glúteos. Muy pocas se aplican en los pechos. La que lo hace es una chica travesti o trans, con alguna experiencia en inyectar este producto, que en todos los casos, es nocivo para la salud y, en otros tantos, les ha llevado a la muerte. Todo esto es realizado de forma clandestina, constituyéndose como la segunda causa de muerte de las personas travestis $y$ trans en Argentina, sostiene Berkins (2005).

Me puso cadera y glúteos. No me iban a poner al principio porque mi piel era muy dura y, como durante muchos años me hormonié, había subido un poco de peso. Entonces al pincharme para que me pongan el producto, no entraba la aguja. Tengo una piel de cerdo, quizás dura. Me pincharon, salía sangre, no tiene que salir sangre. N. me dijo, si vuelve a salir sangre no te voy a poner. Me pinchó, y ya no salió sangre. Entonces empezaron a bombear el silicón, demoro como tres horas. Algunas demoran como ocho, o un día dependiendo. Pero a mí me entró rápido el silicón y no me dolió. Otras gritan, lloran. Me puse los tres litros, me quería poner cuatro, pero me entraron solo tres porque mi piel es dura y ya no cedía más. El reposo es horrible, las ligas que te amarran te aprietan, te molesta, no quisiera volver a pasar por eso. Estuve como tres días ahí, sin moverme, no tenía que sentarme, no tenía que pararme, pero como me dijeron que mi piel era dura, me pare $(T)$.

Las entrevistadas sostienen que realizan esta práctica, al menos, por dos razones: primero, porque es accesible y, segundo, por una cuestión estética. Explican que en las caderas y la cola queda mejor con la silicona líquida, ya que con las prótesis quedan grumos. No es el mismo procedimiento para las mamas, ya que para esta operación recurren a médicos profesionales quienes realizan las cirugías en quirófano, y con anestesia total.

Así, las chaparas empiezan a jugar las juntas ${ }^{23}$, un tipo de préstamo/ahorro, -práctica que reemplaza a préstamos bancarios y que las exime del pago de intereses y mantenimiento de cuentas-, a la cual recurren para hacerse la cirugía de implantes mamarios en

23 Es una práctica usual en las charapas, de la cual participan un número determinado de personas con la finalidad de beneficiarse en el caso de necesitar con urgencia dinero por enfermedad de algún familiar o ahorrarlo para realizarse alguna cirugía. Se juega por un monto total, por ejemplo por 50 mil pesos, se sortean los números de salida desde el segundo al décimo, el primero entra directamente al juego sin sorteo, es para la que organiza la junta. Cada semana sale un numero, cada una pone 5 mil pesos por semana, entre las diez juntan 50 mil pesos semanal. Así será durante diez semanas hasta que la última pueda recibir sus 50 mil pesos. 
una clínica privada, y también para mandar dinero a sus familias en Perú a través de giros y transferencias de dinero:

Acá me hice las lolas, trabajando en la prostitución pude juntar dinero. Por suerte me fue bien. Las charapas acá vivimos agrupadas, alquilamos una casa con varias piezas, o en las pensiones, siempre nos estamos viendo. Somos unidas, jugamos las juntas de 2.000 pesos por semana, me había agarrado dos números. Uno fue destinado para mis prótesis. En aquel tiempo me costó 12 mil pesos la operación de lolas. La primera que había recibido, siempre pensando en mi familia en mi mamá, fue girada a Perú. La junta que iba a recibir destinada a mi prótesis, esa no la tocaba, era algo que quería hacerme. Me mantuve así y me hice las prótesis. Tengo el silicón en las caderas y en las nalgas y las prótesis en los pechos, no me voy a hacer nada más por el momento" $(T)$.

Si, nosotras, todas las chicas, cuando nos ponemos eso, nos vamos a dos cosas: 0 salimos bien o nos vamos en cajón. Todas son conscientes de que puede pasar eso, porque en una clínica sale muy caro. A veces optamos por lo más barato sabiendo que nos puede llevar a la muerte, que con el tiempo puedes tener cáncer a la piel, al hueso. Es más fuerte la expresión de género, que ver las consecuencias que nos puede acarrear a nosotras. Somos muy conscientes de eso (MV).

En este contexto, el sentido y el valor que las charapas le otorgan a la construcción del cuerpo adquieren vital importancia. Por un lado, les permiten expresar y reafirmar la propia identidad de género autopercibida y, por el otro, plantear qué percepciones tienen les "otres", a partir de las transformaciones del cuerpo.

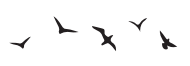

Tras haber rastreado las primeras etapas de la vida de las charapas, donde advertimos las múltiples y complejas situaciones de violencia que atravesaron en sus lugares de origen por parte de sus familias, las instituciones educativas y el ámbito laboral informal; comprendimos los diferentes condicionamientos que las forzaron a abandonar el nido.

De esta manera, abordamos las rutas migratorias que trazan en el viaje, embarcadas en una idea de progreso y bienestar económico, y el anhelo por mejorar las condiciones de vida tanto a nivel individual, como familiar.

Pero este viaje también estará cargado del deseo de materializar y reafirmar la identidad de género autopercibida. Para ello, recurren a prácticas corporales que, en ocasiones, atentan contra su salud, debido al uso de sustancias nocivas como el aceite industrial -sili- 
cona líquida-, para moldear un cuerpo de mujer como el que impone la lógica hegemónica, patriarcal y mercantil como requisito indispensable para el consumo.

Así, las charapas dibujan un mapa subrepticio, basado en la experiencia de otras que las antecedieron, y cuyo trayecto implica sortear peligros y obstáculos durante el proceso migratorio. Las fronteras o ciudades fronterizas se presentan como el límite material de la ficción geográfica de las naciones, en tanto restringen el ingreso y egreso a los territorios. La ilegitimidad de estos flujos tensiona los bordes, haciendo de su práctica cotidiana la reconfiguración constante de los márgenes físicos.

En las fronteras Perú-Chile, Chile-Argentina y Perú-Bolivia, Bolivia-Argentina, las charapas cruzan los controles desafiando a quienes criminalizan sus identidades de género. Así, en los terrenos fronterizos se desenvuelven, retando y resistiendo un orden económico, social y político. Mientras que, para quienes migran al continente europeo desde la Argentina, les implicó la necesidad de comprar a un alto costo documentos falsos, con el riesgo de ser deportadas.

Las dinámicas migratorias se caracterizan, principalmente, por el traslado a grandes ciudades del país, donde La Plata, capital de la Provincia de Buenos Aires y CABA, se destacan, como principales destinos. Decisión fundada por varias de las entrevistadas, por las posibilidades de generar ingresos -sobre todo a través de la prostitución-, y de poder materializar y expresar su identidad de género.

Muchas quedaron en el camino, otras tantas lograron sobrevivir. En esa cartografía, observamos cómo tejen y fortalecen nuevos lazos de sociabilidad, entre los que destacamos el de madres e hijas putativas-, lo que les permite disputar y apropiarse del territorio, permanentemente.

Pero ¿qué implicancias asume la agencia política de las charapas en términos colectivos, plurales y subjetivizantes? En los próximos capítulos, nos adentraremos a describir y analizar estas prácticas, a partir del establecimiento de las siguientes categorías: prácticas político-comunicacionales informales de subsistencia y prácticas político-comunicacionales formales institucionales. 
2

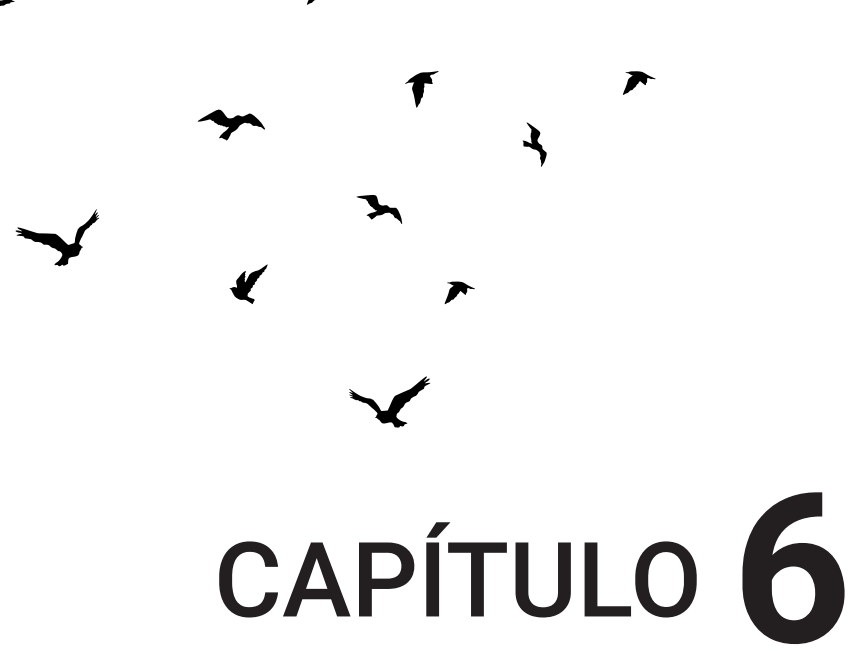

Arraigarse en la Argentina:

estrategias comunitarias

territoriales de organización

y construcción colectiva. 
Capítulo 6.- Arraigarse en la Argentina: estrategias comunitarias territoriales de organización y construcción colectiva.

A partir de esta investigación, nos propusimos realizar un estudio de caso sobre las prácticas político-comunicacionales de las feminidades travestis y trans migrantes peruanas en La Plata: las charapas. A tales efectos, consideramos que es necesario hacer una distinción entre la construcción de las prácticas informales de subsistencia y prácticas formales institucionales. No obstante, estas dos dimensiones, en la praxis concreta se encuentran interrelacionadas, puesto que no las pensamos una separada de la otra, como dos compartimentos estancos, debido a su mutua y compleja implicación.

Con lo anterior, abordamos las prácticas informales de subsistencia como las de la prostitución, el vóley, la elaboración y venta de comidas típicas y el entierro, en tanto prácticas político- comunicacionales que permitieron a estas feminidades recuperar sus tradiciones, costumbres y hábitos culturales, y arraigarse en la Argentina. De esta manera, nos proponemos describir las estrategias que tejieron en alianza y disputa con otres interlocutores: actores institucionales, la sociedad civil; y otras organizaciones de travestis y trans, del colectivo TLGBI y de personas migrantes.

Seguidamente, establecemos una segunda lectura analítica sobre los procesos abordados, a partir de la sistematización de prácticas institucionales formales específicas, que cimentaron en la construcción de OTRANS ARGENTINA, como sujeto político. Desde este espacio de militancia y trabajo territorial, las charapas planifican estrategias de visibilización, demandas de derechos y políticas públicas, y memorias de la resistencia. 


\subsection{Prácticas político-comunicacionales informales de subsistencia. Tejido territorial en comunidad: prostitución, vóley, comida, entierro.}

\section{El mapa, la fiola y el territorio}

Al indagar en la vida de las charapas, observamos y advertimos que todas comparten la misma trayectoria vital, hacen el mismo recorrido, frecuentan espacios comunes y detentan, por antonomasia, el mismo destino. Ser travesti o trans se convierte en sinónimo de prostitución. De esta manera, la mayor parte de las entrevistadas cuando les preguntamos sobre el tema trabajo lo asocian con ésta, pero no como trabajadora prestadora de un servicio, sino como un mecanismo de subsistencia respecto al sostenimiento económico ${ }^{24}$. Es decir casi la totalidad de los casos encuestados expresan que ingresaron en el circuito prostibulario por necesidad económica. Manifiestan que no hubo una elección, sino dar respuesta a una necesidad vital. Este se convirtió en el único modo de poder conseguir recursos básicos para vivir y ayudar a sus familiares y, posteriormente, convertirse en sostén de familia.

Así, este imperativo que adopta la forma de hacer algo por obligación, es una práctica que se ha ido naturalizando en las charapas porque como se dijo antes "el cuerpo cree en lo que juega". En ese contexto, no hay casi lugar para cuestionar el destino asignado, se prioriza las necesidades básicas de subsistencia.

En la escena de la prostitución, hay actores ocultos. Se habla de la policía, la coima, los vecinos, pero casi nunca de los llamados "clientes" o "prostituyentes". Y cuando se habla de prostitución travesti y trans, muchas veces el agente que queda oculto es el cafishio ${ }^{25}$. En este caso particular, se destaca que el rol de proxeneta está desempeñado por

\footnotetext{
24 La discusión sobre la prostitución, en relación a posturas regulacionistas o abolicionistas, no es un tema que las charapas prioricen, o se construya como parte de su agenda. Por el contrario, la pelea diaria y su preocupación está puesta en la violencia que reciben por parte de la policía y algunos sectores de la sociedad civil. La necesidad imperiosa, en este sentido, está en poder acceder a derechos laborales que les permita obtener ingresos económicos que les permita cubrir, entre otras cosas: la comida, el alquiler de la pieza o los servicios que implica, y poder ahorrar para mandar las remesas a las familias en el Perú. Esta demanda la canalizan a través de OTRANS ARGENTINA, asociación civil a la que pertenecen muchas de las entrevistadas. Como veremos oportunamente, desde lugar, cuentan con estrategias y posicionamientos políticos respecto a este tema, militando por la implementación de la inclusión laboral travesti y trans en todo el país.

25 El cafishio es la palabra lunfardo usada en Argentina para referirse al proxeneta.
} 
otra feminidad travesti o trans, lo que denominamos transfiola, la que les cobra la "parada" ${ }^{26}$ a sus pares. Y que, si no le pagan, las agrede físicamente.

"Cuando llegué estuve trabajando en diagonal 73 entre 4 y 5 hasta que me querían cobrar la parada, unas chicas trans argentinas, la $L$ y la D. Mi prima me dijo tú no vas a pagar nada, así que nos vamos de acá. De esa manera dejamos la diagonal, me fui a trabajar en calle 1 y 55. Antes ahí también cobraba la $L$, pero se juntaron todas las charapas, le hicieron correr a ella y sus matones. Desde ahí nadie paga plaza en calle 1" (VN).

Al denunciar estas prácticas en la comisaría, el procedimiento de la policía es derivar hacia el diálogo con la misma proxeneta, que es quien "maneja la zona". Lo que evidencia la connivencia entre ambos actores. Según las entrevistadas, la transfiola opera a través de una dinámica en detrimento de la socialización entre las travestis y trans que se encuentran en situación de prostitución. Es por ello que, el diálogo entre ellas y con otras personas, es clave a la hora de problematizar y desnaturalizar la violencia y la dominación.

Las charapas en La Plata han podido construir a través de sus prácticas mecanismos de subsistencia para desplazar a aquellas proxenetas de algunos lugares. Por testimonios de las entrevistadas conocimos que $C$, fue quien lideró el primer enfrentamiento junto a otras charapas para ganar el territorio y no pagar más la coima por la parada a la transfiola. Liberó la calle 1, de 55 a 60, cuando migró a Europa dejó ahí a sus hijas organizadas para cuidar la parada. Tres años después J, lideraría una disputa similar liberando diagonal 73, desde 1 a calle 6. En el 2015, migró a Europa y dejó a sus hijas al cuidado de la parada.

Yo cuando llegué a La Plata, la zona donde yo estoy laburando ya estaba liberada por las charapas, porque había una argentina que cobraba por parada, por plaza a cada chica. Ya no cobra más, era una tal L, que ahora cobra por calle 66, son pocas las veces que yo bajo por esa zona. Y gracias a C. pues ya no le pagan plaza en todo lo que es calle 1. C se enfrentó con varias chicas con $L$ de ahí para que no les pague, y ella ya nunca más bajó a cobrar. L venia con gente, armados con palos, cadenas. Así me comentaron, yo nunca lo vi. Si se que cobraban 100 o 150 pesos por semana a cada una, y si no pagaban les pegaban o las botan de la parada. Son cosas que suceden en la sociedad, pero porque somos un grupo muy vulnerable y es por eso que es más visible y más potente, y es por eso que a mí esas cosas no me gustan hablarlas $(K)$.

Sin embargo la disputa por el territorio es constante, siempre vuelve a hacerse presente una nueva transfiola que amenaza con el cobro de la parada. La experiencia de las charapas, ha constituido modos de resistencia y apropiación de la "zona roja", dibujando

26 Las charapas denominan parada o plaza al espacio físico permanente donde se paran habitualmente a ejercer la prostitución. 
su propio mapa colectivo. Pero para la charapa sometida, es muy difícil dejar de valorar a la transfiola como su protectora. No puede verla como una captora, naturaliza sus prácticas violentas, se siente siempre en deuda, aunque pague su plaza, debido a que ésta la "protege". La charapa tiene internalizada la idea de que ella es "su amiga", a pesar de que ésta la ve, simplemente, como mercancía, objeto de lucro ${ }^{27}$.

“Cuando llegué mi madre C. me llevó a la parada, me presentó a la que cobra, la L, es muy buena onda, chévere, nunca se enojó conmigo. T, me llamaba así, no me cobraba directamente, si no era como un saludo. Pero yo ya sabía que tenía que pagar mí parada 100 pesos semanales. Con la L. todo bien, ella nos cuida" (T).

Así, las charapas deben estar alerta a la violencia endógena. El poder que el patriarcado le ha conferido históricamente al hombre cis, en el caso estudiado, lo ejerce una feminidad travesti o trans, quien en defensa del dominio de "la parada o plaza" y su usufructo, ocupa el mismo lugar de tutelaje que el cafishio.

A su vez, tienen que enfrentar la violencia exógena que proviene de diversos actores de la sociedad civil, a los que se enfrentan en el ejercicio de la prostitución:

Trabajar en la calle, hay muchos peligros, uno nunca sabe qué cliente te va a tocar o qué tipo de gente $(K C)$.

Ahora, los chicos que se van a cobrar las paradas, te hablo de los cirujas, vienen a pedirte diez o veinte pesos, una se los da de miedo. Decís, eso es nada comparado a lo que te pueden hacer. De sanos vienen tranquilos, pero cuando están ebrios y drogados si tú les das dinero, te piden más, si no les das entre varios comienzan a tirarnos palos, botellas y piedras. No podemos emparejar, ellos no tienen nada que perder, nosotras tenemos silicón, prótesis, algunas son cirujeadas en el rostro, esos palos, piedras pueden caer entre nosotras. Lo que hacemos es correr, tener miedo, hay de todo $(G)$.

Por ejemplo, a mí la semana pasada voy a hacer un servicio, término, es la segunda vez que salgo con él. Era un señor, cuando me quiero bajar del coche, me apunta con un arma -es algo feo que te apunten así- lo primero que pensé fue en mi mamá, es lo primero que vino a mi mente. Le digo ¿qué te pasa? no es la primera vez que estás saliendo conmigo. No, que me des la plata que te he dado, obviamente no le di. Me dijo quieres que te deje tirada ahí, con la pistola queriendo matarme. No le tuve miedo, bueno por fuera no le tuve miedo, por dentro estaba que me moría de miedo. No es la primera vez que me encuentro con un arma, me pasó dos veces este incidente $(R)$.

En la parada también pasan chicos y nos tiran huevos, ese es otro problema.

27 Lo cual no significa que no suceda la misma lógica violenta con otras feminidades travestis y trans nacionales o de otras procedencias. En la presente investigación ponemos énfasis en la dinámica descrita particularmente hacia las charapas, debido a que es nuestro tema de estudio. 
Estamos paradas y nos tiran con lo que sea (...). A veces pasan en los coches y nos tiran con botellas, pero si nosotras fuéramos las que tiramos con las botellas sería distinta la cosa ¿cierto? Son cosas que pasan en la calle, hay que aguantarlas simplemente, no todo es bonito en la calle. Algunos piensan que vas a la calle y haces la plata fácil, no es fácil. Primero porque aguantamos frío, nos podemos enfermar, algunas estamos totalmente descubiertas, nos encontramos con cualquier cliente que puede ser un maniático, un psicópata, que se yo. Entonces no es fácil la vida en la calle $(T)$.

A mí me rompieron el brazo, en el mes de diciembre del año pasado. Vino un "cliente" y me pregunto cuánto está el servicio, le respondí 50 y 100, bueno hagamos por 50 tienes cambio. Respondo que no, le digo será para otra oportunidad. Entonces viene y me golpea la cola y me da una piña, me saque los tacos para defenderme y pelear. Cuando me da una piña me resbalo, me caí en el filo de una vereda, ahí se me rompe el codo. Hace poco que me dieron el alta, el brazo ahora lo tengo bien. Perdí mucho tiempo, nadie me pagó nada, me banque todo sola. Algunas amigas que pasaban a darme algunas monedas. La noche es muy terrible, más en los fines de semana que viene el tema de la falopa y los que te lanzan botellas (VN).

Hasta aquí, en el análisis advertimos dos dimensiones constitutivas de las prácticas de las charapas -endógenas y exógenas- con las que tienen que lidiar por cuanto habilitan estrategias de reterritorialización en el espacio público. 


\section{Jugar con sus propias reglas}

En Perú los deportes más populares son el fútbol y el vóley, el cual se incentiva, sobre todo, como una práctica de formación y socialización desde los ámbitos educativos. Sin embargo, su enseñanza no queda exenta de los imperativos del género, los cuales determinan quiénes son les sujetes que pueden y deben jugarlo. De esta manera, el fútbol para los hombres y el vóley para las mujeres, se torna una práctica performativa privilegiada a la hora de modelar cuerpos, atributos, comportamientos y habilidades válidas y aceptables, conforme a la norma.

Estos imperativos se manifestaron de manera recurrente en las entrevistadas, quienes expresaron con claridad cómo la práctica deportiva del vóley estuvo marcada desde sus infancias:

Existen otros deportes, pero estos dos que te menciono son los que más se juegan. Cuando era chica, mi papá y mis hermanos me prohibían jugar al vóley porque decían que ese deporte es para mujeres, y me decían que los que juegan vóley son maricones, cabros o vengo, como dicen en el lugar de donde soy. Cuando alguien les decía que me habían visto jugando al vóley, llegaba a mi casa y me pegaban con golpes o con el látigo. Me decían te vamos a volver hombre a golpes (V).

En el colegio cuando estaba no me gustaba jugar el deporte, a mí me querían hacer jugar de obligado, en los cursos me gustaba la matemática. Tampoco me gustaba hacer educación religiosa, después no me gustaba el deporte, no casi me llamaba la atención el deporte. (...) No me gustaba el fútbol, me gustaba el vóley, a veces no quería hacer deporte porque no me gustaba (E).

A mi hermano le gustaba el futbol, a mi no me gustaba. Él andaba con amigos varones, y a mí no me gustaba, así que por eso me gustaba más andar con mi hermana. Con mi papá, nos quería hacer como si fuéramos él, nos trataba de que seamos fuertes, muy varoniles, muy machistas como era él. Le gustaba tomar sus tragos. El quería que yo fuera como él. Yo no estaba para esas cosas, no me gustaban. Mi papá estaba en el ejército, siempre trataba con muchachos, hacía muchos ejercicios físicos y violentos, era muy machista. Mi papá siempre tuvo este problema porque yo era un poco delicada, afeminada. Se enojaba mucho, él decía que mi hijo no podía ser un hijo maricón, no podía tener un hijo maricón, como lo dicen en Perú. Así que él siempre trataba de corregirme (...), me tenía con mi hermano, hacía ir hacia donde él iba. No me sentía conforme a los lugares que mi hermano iba, no me gustaba jugar al fútbol (KC). 
Nosotras por ejemplo no nos identificamos con el fútbol porque es muy masculino para nosotras, por eso nada que ver con eso (V).

De esta manera, podemos observar cómo la práctica de este deporte implicó para ellas un modo de poder expresar públicamente su identidad de género, lo que muchas veces solía ser una vivencia interna, o que se relegaba puertas adentro.

Cuando hacíamos deporte, mis padres nos veían femeninas ya. Mis hermanos y mi papá le metían en la cabeza a mi mamá que no debería ser así. Ellos no entendían que se nace trans $(R)$.

Pero mi deseo de jugar al vóley era más grande, porque me gustaba y me hacía sentir mujer. Porque como me decían que era para mujeres entonces no me importaba, era lo que yo sentía y lo hacía, aunque después me daba miedo porque sabía que me iban a castigar, pero después se me pasaba. Entonces lo hacía a escondidas, siempre. Me castigaron muchas veces por jugar al vóley con mis amigas. Hasta que después me fui de mi casa y ahí no tuve que andar escondiendo de nadie, ni tener que pedir permiso para jugar al vóley, ni estar dando cuenta de lo que soy. Es muy feo que te obliguen a hacer lo que no sentís, lo que no sos, por eso me escapé de mi casa desde chica, cuando tenía 14 años" (V).

En la Argentina, desde un principio, el vóley formó parte activa de la vida de las charapas. Significó, para ellas, la posibilidad de arraigar las tradiciones y costumbres que trajeron, con la migración, desde sus lugares de origen:

Este deporte lo traemos desde chicas, por ahí quizás si habría otro deporte lo haríamos pero estamos más familiarizadas con el vóley nosotras. Es una práctica de años $(V)$.

La ciudad de La Plata, resultó un lugar fecundo para conformar y consolidar aquellos espacios de encuentro:

(...) Para nosotras es eso, para nosotras la excusa es el vóley, pero lo importante acá es encontrarnos de mucho tiempo, porque hay compañeras que están hace rato en Argentina y no nos vemos porque están en diferentes provincias. Entonces el desafío de nosotras es encontrarnos.

Esto nosotras lo traemos desde la selva, todas las charapas jugamos al vóley, y la que no puede jugar mira, la idea es formar parte del evento. Hemos crecido jugando este deporte, por eso nos sentimos identificadas con él (V). 
Los domingos, es recurrente la organización de campeonatos de vóley en la zona del bosque platense -sobre todo durante las estaciones de primavera y verano- y, algunos días de altas temperaturas, en el balneario de punta Lara (Ensenada):

[Aquí] organizamos un campeonato de vóley, donde participan 4 equipos, un cuadrangular. Viene un equipo de Mar del Plata, otro de CABA y Monte Grande y nosotras también sacamos nuestro equipo de La Plata, que somos anfitrionas" (V).

La organización de los campeonatos conlleva mucho trabajo entre las compañeras del equipo. Podemos decir con claridad que hay ciertas prácticas que se han ritualizado.

Al inicio de la jornada, comienzan las inscripciones de los equipos, a medida que van llegando al bosque. Con los nombres de todos los que participarán, realizan un sorteo, identificando con cada papelito, cada una de las ciudades de donde vienen las deportistas. Los primeros que salen sorteados, son los que inician el campeonato y, así, sucesivamente, con todos. De esa manera, van diagramando el fixture de partidos.

El espacio físico donde cada domingo juegan al vóley, se emplaza a tres cuadras del colegio Técnico Albert Tomas, en el medio del bosque. El piso es todo de tierra, la red la sostienen de un lado del tronco de un árbol, y del otro un tubo de un poste de luz. No tiene techo alguno, juegan a la intemperie, tampoco posee butacas o sillas para sentarse. La cancha la marcan con harina para delimitar el cuadrilátero donde se desarrolla la disciplina deportiva, al menos hasta que dure la contienda.

Para los campeonatos, reciben donaciones de las compañeras. Un ejemplo claro son los trofeos que se entregan en la premiación:

Los premios son donación que hacen las mismas compañeras, a ellas les gusta esas cosas y luego ser nombradas, por ejemplo, este premio nos regaló $L, M, C$ y $T$, ellas me dieron estas cositas para nosotras poder visibilizar esto y para que las compañeras se vayan conformes. Nosotras, siempre, las charapas nos damos una mano, somos unidas por más que tengamos algún rencor, que esto, que el otro. Pero si estamos unidas por un motivo como este, por ejemplo (V). 
Y encima de la copa y del dinero, van a llevar su medalla dorada para el primer lugar y plateada para el segundo puesto $(K)$.

Como nosotras no tenemos ingresos fijos, y para poder recaudar algo de dinero, convocamos a un grupo de chicas trans charapas, para que nos auspicien con trofeos, copas, medallas y camisetas (V).

Las camisetas que utilizan para los partidos son un elemento clave a analizar. Porque contar con esa distinción, les permite consolidar entre ellas un sentido de unidad. Las identifica con su equipo, las hace ser parte de, al mismo tiempo, las diferencia de las demás. La remera es de color rojo y blanco, a rayas en forma vertical; en la parte delantera dice Movimiento TLGBI La Plata, y en la parte de atrás, el nombre de cada una de las jugadoras.

Las charapas conocen quienes juegan bien, y quienes son amateur -en relación a la falta de experiencia en esta disciplina-. Entonces arman sus equipos teniendo en cuenta las capacidades y destrezas con las que cuentan cada una de ellas. Los domingos comunes, es decir cuando no hay campeonatos, son más permisibles tanto en la composición del armado de los equipos, como también no son tan exigentes en cuanto a las faltas que comenten algunas de sus jugadoras, que ellas identifican en instancias de aprendizajes. De este modo es cómo van preparando el nuevo semillero de jugadoras, a las que van probando en los campeonatos, una instancia que utilizan para que éstas se fogueen, con otras contrincantes.

$\mathrm{K}$ y V, a quienes conocimos como las organizadoras del campeonato, se han convertido en referentes. Son las mismas charapas quienes las legitiman en ese lugar, pero esto se consigue con el tiempo y, lo que más cuesta, reconocen ellas mismas, es sostenerlo en el día a día. Una experiencia que, entendemos, se va capitalizando con los años, de charapa en charapa y, que como pudimos comprobar, va más allá del campo de juego.

La mayor parte de los encuentros deportivos juegan sin árbitro, es muy complejo, establecer las reglas a quienes tienen sus propias lógicas. En la puesta en escena del vóley converge varias dificultades: desde quienes no alcanzan a detectar u observar si la pelota cayó fuera o dentro del campo de juego, como también, si alguien tocó la red o retuvo la pelota. Lo anterior, sumado a la pasión que genera el deporte, produciendo un conflicto que debe ser resuelto tomando las mejores decisiones en el momento que lo amerita.

Al iniciar el partido, se sortea el lugar del campo que cada equipo ocupa. No hay un tiempo o duración estipulado entre ellas, si una cantidad de puntos, que se acuerda en 40 corridos sin cambiar de cancha. Si la pelota toca la rama de algún árbol, durante el saque, 
por ejemplo, el equipo pierde la jugada. Mientras que, si sucede durante el juego, es nuevo servicio. Es decir, no hay punto para ningún equipo, si no hay claridad. 0 si tocan con una mano o con el cuerpo la red, pasa lo mismo.

Tener las reglas claras, permite apaciguar el conflicto siempre. Este rol lo cumplen de manera clave tanto las organizadoras del torneo, como las capitanas del equipo. Por eso $\mathrm{K}$ y $\mathrm{V}$, son quienes en todo momento están pendientes, y aunque también juegan al vóley, los días de campeonato optan por estar atentas a que no haya ninguna pelea por efectos del deporte, o realizar otras actividades que se organizan en paralelo para recaudar fondos.

El rol de la capitana decíamos, también, es muy importante. Quién accede a ocuparlo no sólo es considerada la mejor jugadora, en cuanto a su destreza deportiva, sino es quien sabe y debe negociar de forma pacífica cualquier reclamo que se suscita durante el juego. Es la única interlocutora válida con $\mathrm{K}$ y V, incluso con quien, ocasionalmente pueda estar en el lugar de árbitro. Por tanto, reviste suma responsabilidad en el equipo, porque después, también es cuestionada por las pares que integran cada uno de los cuadros deportivos.

En los campeonatos organizados por las charapas, tampoco hay tarjeta roja, ni amarilla para sancionar a nadie. Solo basta con pasar los límites del reclamo e intentar ir dar golpes de puño o lanzar insultos verbales, para quedar expuesta y ser repudiada por la mayoría de las participantes. Si hay pelea, se corta el partido, se les devuelve su apuesta y juegan otros equipos. Pero quien protagonizó la pelea, automáticamente, sabe que no juega más, durante mucho tiempo. No solo porque sus demás compañeras de equipo la hacen de lado, sino que las demás charapas condenan ese tipo de prácticas: "No queremos que haya problemas y se empañe el campeonato", se escucha decir con total claridad a una de ellas. Al lado de las charapas, se ubican dos personas con conservadoras portátiles llenas de latas de cerveza. En ese momento, $\mathrm{K}$ le dijo a $\mathrm{V}$ "decile que nosotras no les prohibimos que vendan en nuestra actividad, pero que encaleten [esconder con disimulo] las latas, porque no queremos tener problemas con nadie".

Los campeonatos, culminan con el acto de cierre, donde quienes donaron el trofeo, la copa, las medallas y remeras, hacen entrega al equipo ganador del primer puesto:

Este trofeo, el más grande es el premio para el primer puesto, mas el dinero que se recaude ${ }^{28}$. Porque cada inscripción de cada equipo es 6000 pesos, es decir 1000, por jugadora. Y el segundo puesto esta copa más pequeñita, más los bolsitos que ves acá, en cada uno hay una remera con los colores de la bandera Argentina. Es el

28 En el 2019, año en que se hizo el presente relevamiento, cada equipo debía abonar un costo de inscripción de $\$ 6000$ (\$1000 por cada jugadora). Mientras que el $80 \%$ del total de lo recaudado se le entregaba a quien obtenía el primer premio en el campeonato, el $20 \%$ restante quedaba en manos de quienes organizaban el evento. 
recuerdo del campeonato que estamos haciendo.

Entonces, además de los trofeos, se hace entrega del 80\% del monto total recaudado en el momento de la inscripción. Para quienes acceden al segundo lugar, los premios consisten en medallas plateadas y remeras de regalo. Por último, también reconocen a la mejor jugadora de todo el torneo, a quién se le hace entrega de una copa.

La práctica deportiva del vóley resulta, para las charapas, un ritual que propicia, ante todo, el encuentro, un lugar para confraternizar, un espacio propio que todas tienen que cuidar.

Escuchar los relatos y biografías personales, y dimensionar los múltiples condicionamientos que las marcaron desde las primeras etapas de sus vidas, implicó enmarcar las violencias físicas y simbólicas a las que están expuestas y; de este modo, comprender los significados que le imprimen a estos actos disruptivos como la práctica deportiva del vóley, que tantas veces les fue vedada.

En este sentido, es muy importante atender a la apuesta político-comunicacional que generan en el espacio público:

"Ir al bosque platense a jugar al vóley significa visibilizarnos más, que la sociedad sepa que nosotras también existimos, que no solo nos prostituimos, sino que hacemos otras cosas más que eso. Y también para encontrarnos con las compañeras que están lejos de acá, que por una u otra razón, encontraron trabajos por otros lugares. Darnos un abrazo, eso es lo que también significa para nosotras, un encuentro" (V).

Si trazamos una diagonal imaginaria, el espacio físico donde practican vóley, está ubicado en el medio del bosque platense: en uno de los extremos está la cancha de Club Estudiantes y, en el otro extremo, Gimnasia y Esgrima La Plata. Ambos, diametralmente opuestos y rivales históricos en la ciudad.

Pero este espacio cobra vida en la medida que las charapas lo intervienen, al menos, por unas horas todos los domingos, de los meses de primavera y verano. Así, mientras que otras actividades y disciplinas deportivas, como el fútbol, se desarrollan en ámbitos institucionalizados, las travestis y trans migrantes peruanas, producen sentido desde los márgenes.

Por eso decimos que, a través de esta práctica político-comunicacional, las charapas se apropian, disputan y resignifican el espacio público. Lo hacen desde fuera de las murallas 
altas de concreto y cemento que divide, construye, produce y refuerza la idea de un "nosotros", en términos de normatividad, y los "otros", tejiendo una resistencia desde los bordes.

El paisaje que rodea los campeonatos de vóley, está compuesto de familias que van al bosque a tomar sol y mate en sus reposeras, quienes ofician de espectadores asiduos, en algunos casos, y otros que van por primera vez. Todo el que pasa y advierte que se trata de un deporte conformado en su totalidad por jugadoras travestis y trans, se detiene. Un evento deportivo digno de observar, de manera libre y gratuita. 


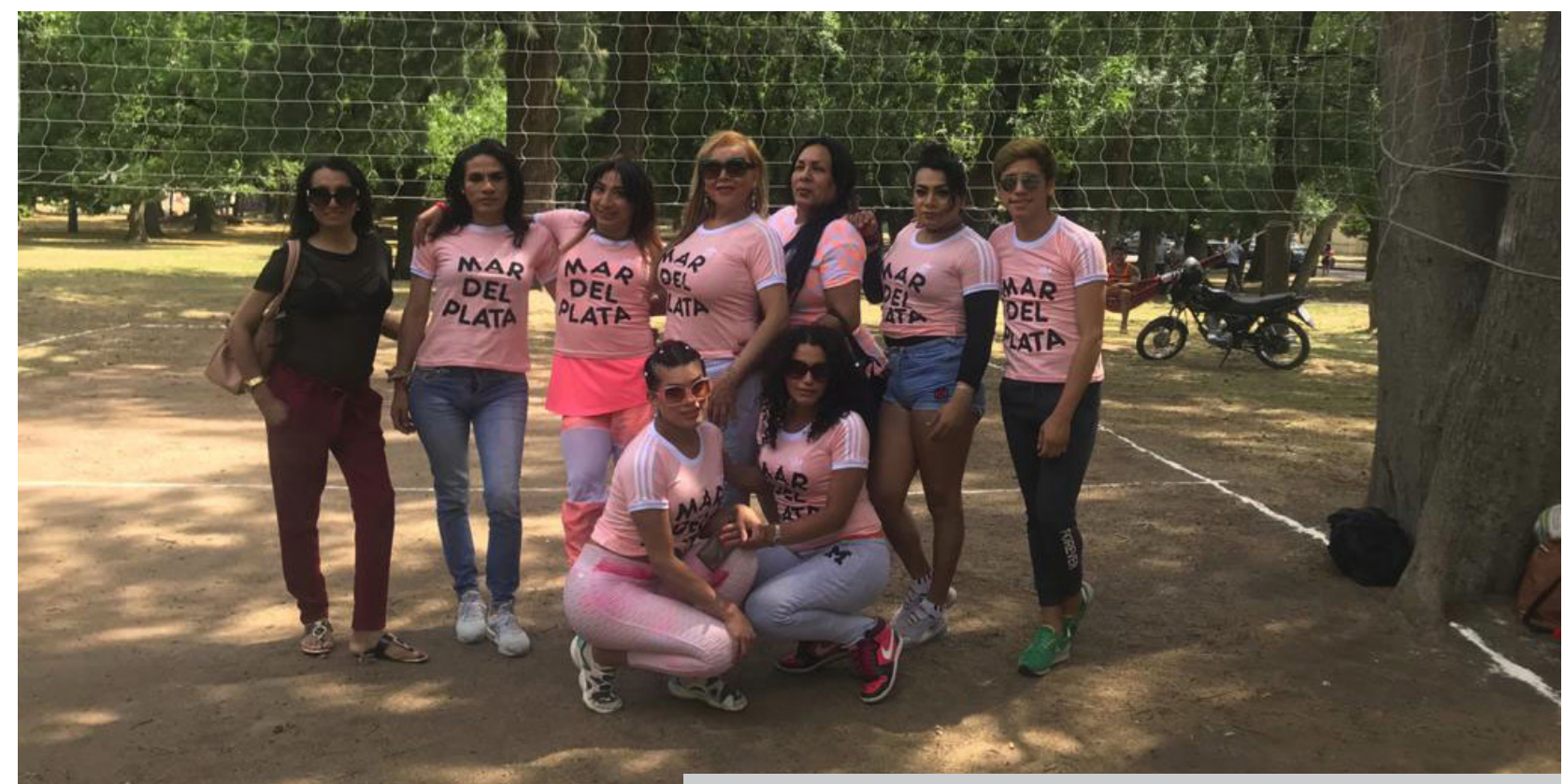

Equipo de voley de Charapas que viven en Mar del Plata

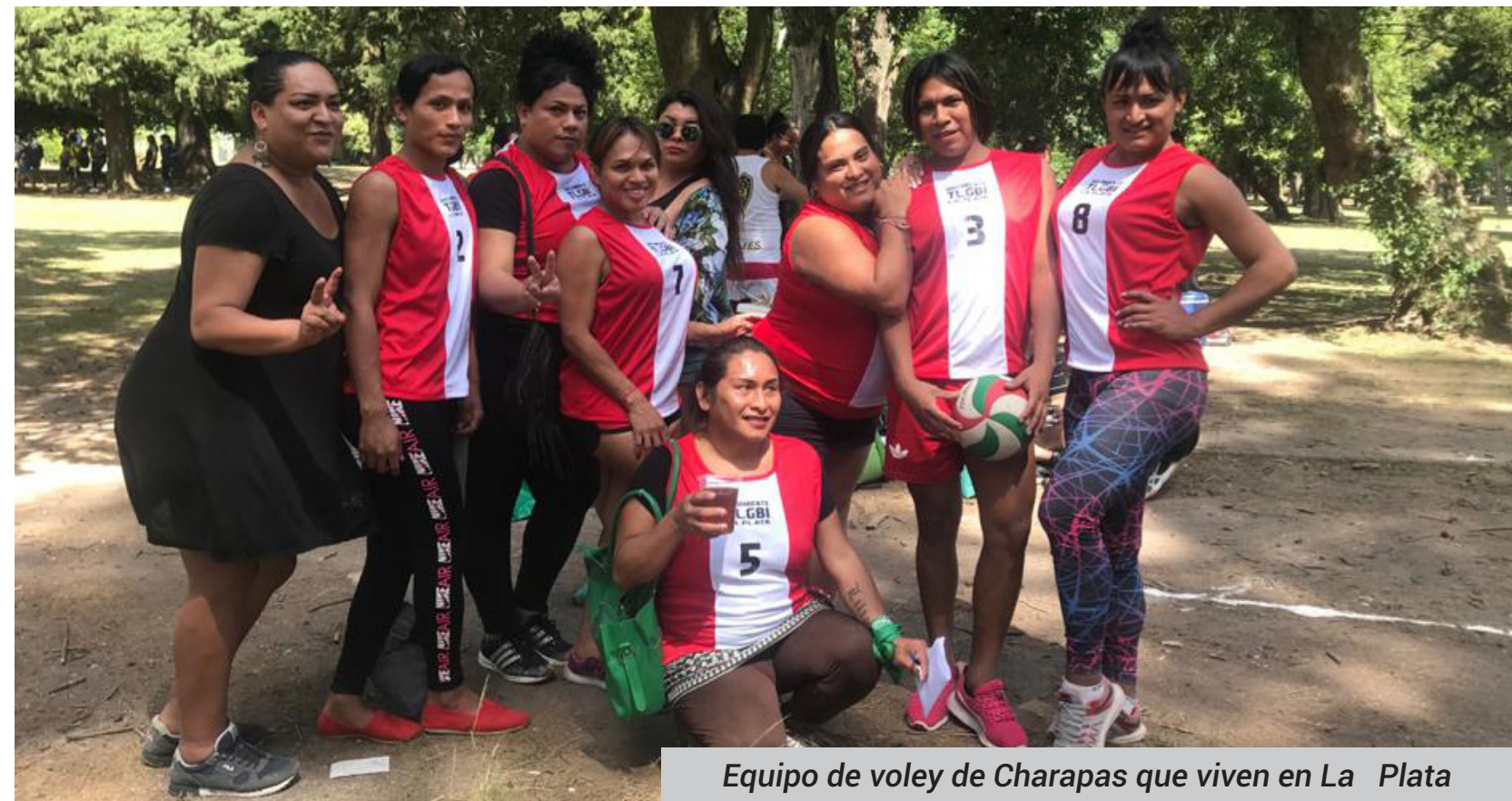

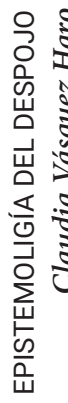



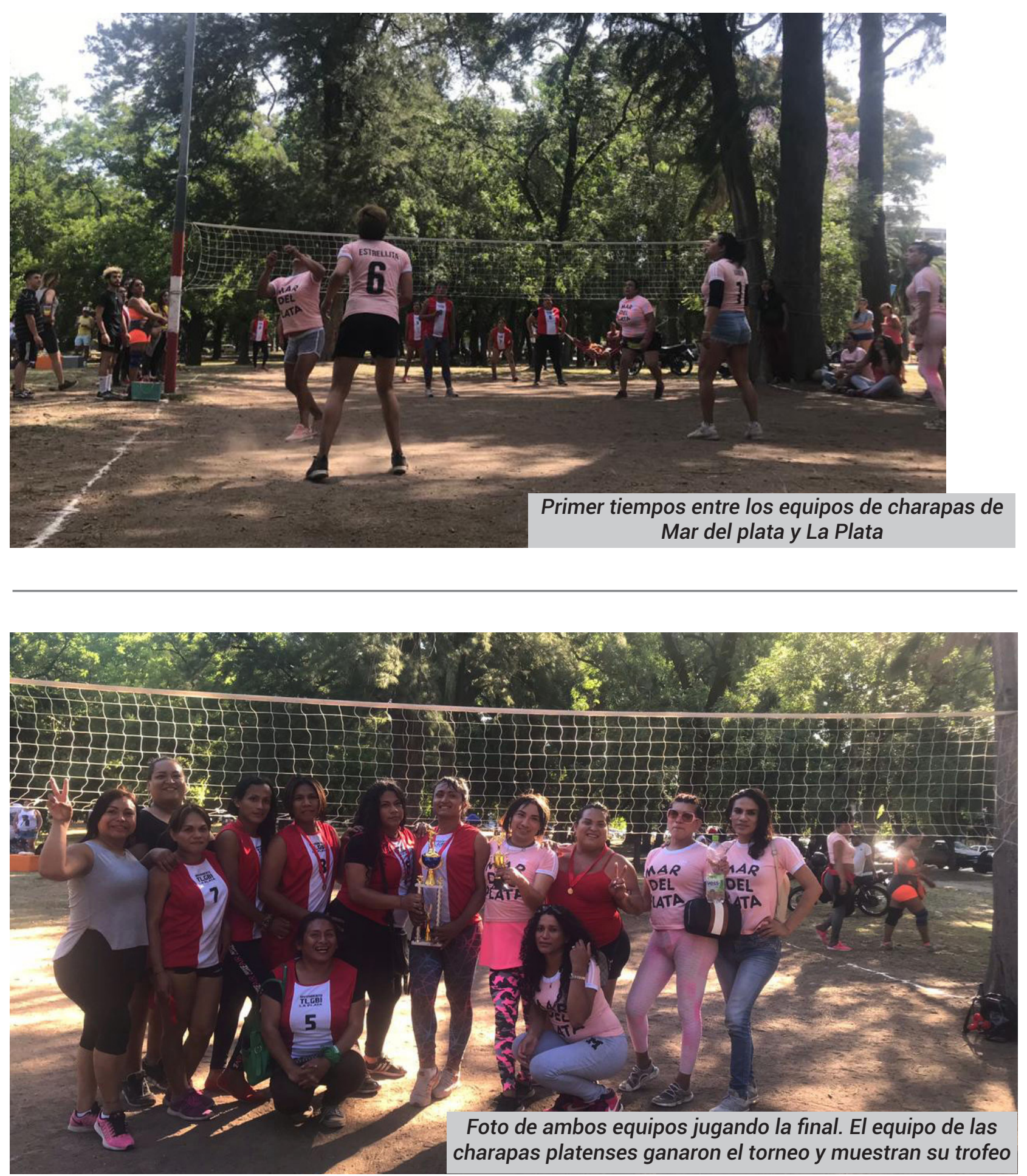


\section{Diversidad Gastronómica}

La comida es un rasgo identitario de la cultura de cada una de las travestis y trans migrantes. En cada una de las recetas, se pone de manifiesto el sentido que le dan a cada uno de sus platos típicos:

La comida me recuerda a mi lugar de origen, uno nunca olvida cómo ha crecido, son raíces de nuestras tierras. Cuando fui a comer la primera vez conocía $K, a$, $A, B F a$ Jl, a M... todas charapas como yo (E).

La cocina peruana es tan diversa, que varía de región en región, dentro del mismo país. Las peruanas de la zona costera del norte priorizan el ceviche, el seco de cordero, la papa a la huancaína, el pollo a la brasa, y la chicha morada. Mientras que las charapas, los juanes, el tacacho con cecina, el inchicapi, la patarashca y refresco de camucamu, aguaje, cocona y carambola.

T: La comida peruana es variada, depende de las regiones. Escabeche peruano, y si hay pescado, un pescado sudado con yuca, tú sabes que los peruanos si no es eso, no es comida para nosotros, nosotros no somos como la gente de aquí, la gente de acá come un fiambre y eso ya es comida, entonces para nosotros eso es como una entrada, nosotros estamos acostumbrados a comer comida pesada. Como los Juanes, el tacaco, hay variedad de comidas $(L)$.

La elaboración y venta de comida se constituyó en una práctica constante entre ellas, que exigió la discusión y puesta en común de estrategias colectivas, así como también, establecer dinámicas de toma de decisiones. En los primeros años, algunas prestaban dinero para comprar las cosas y, luego de la venta, se les devolvía. Después, como la ganancia era escasa, en algunas reuniones se propuso la idea de colaborar con artículos no perecederos, y diferentes carnes. Entonces cada vez que se acordó un día para realizar la actividad de venta de comida, juntaban sus donaciones: pollo, arroz, verduras, fruta, elementos descartables, etc.

En cada reunión, se discute primero qué platos se cocinarán y se tiene en cuenta las destinatarias. En primer lugar, se apunta a las travestis y trans migrantes, quienes no todos los días comen sus comidas tradicionales. Luego, en menor medida, a algún público que desee probar por primera vez. 
Acá hay restaurantes peruanos, pero no hacen comida de la selva. Los platos típicos que comemos las charapas y lo que la mayoría extraña son: el juane, el tacacho, la cecina, el chorizo, el inchicapi, el caldo de gallina, el masato, el plátano, el chapo, esas son las comidas típicas de allá. Acá las chicas hacen la comida típica de nuestra región, compran la gallina, para hacer los Juanes. Es un plato que se elabora con arroz, condimentos y se lo envuelve en hoja de bijao, esta le da un poco más de sabor a la comida. Acá eso no hay. Las chicas lo hacen con el papel platino. Creo que lo más, lo más importante es hacerlo, en esas ocasiones nos reunimos todas las de la selva, es decir las charapas. Hay veces invitamos a las chicas del norte, pero no son muy unidas como nosotras. Por ejemplo, si alguien se enferma o está mal, estamos apoyándole, siempre todas unidas (VN).

El dinero recaudado, se destina para alguna charapa que esté enferma, para llevarles alimentos y ropa de abrigo a las travestis y trans privadas de su libertad, comisarías y alcaldías.

Llegué en 2010 y a los 6 meses de mi llegada tuve un accidente. Estaba en situación de prostitución, me llevo un cliente en la moto y nos chocó una camioneta $4 \times 4$. No pude caminar por 1 año, tuve cinco operaciones. Estuve un año postrada en la cama. Pero todas las charapas que estaban ahí me ayudaron, me bancaron, eran compañeras, nunca faltó un plato de comida, siempre estuve con ellas $(K C)$.

Sin embargo, otras veces lo recaudado sirve a la hora de solventar gastos de subsistencia. En este sentido, es recurrente en el relato de las entrevistadas apelar a la venta de comidas típicas, entre otros productos (maquillajes, objetos de importación) para paliar la falta o escasez de ingresos, fundamentalmente, en contextos de crisis ya que la mayoría vive del ejercicio de la prostitución.

Las charapas son como un círculo especial, en la casa de una cocinan las comidas típicas de la selva, conservan su comida. $\mathrm{V}$ y $\mathrm{K}$ se despertaron a las 5 de la mañana porque tienen que cocinar (...) junto a los juanes (plato elaborado en base a arroz, carne de gallina, aceituna y huevo); para la venta de hoy, cocinaron pollo al carbón; patarashca (pescado envuelto en papel metálico, que reemplaza a la hoja de bijao con la que lo envuelven en Perú); y el tacacho con cecina. Estas son algunas de las comidas tradicionales de la región de la selva de donde son las charapas y que la practican y conservan desde que llegaron a La Argentina. Junto a ellas estaban $\mathrm{H}$ y $\mathrm{M}$, también charapas quienes estaban ayudando a servir la comida en platos descartables, envolviéndolos con film y organizándolo en filas, en cajas de plástico grandes, para poder trasladarlo con mucho cuidado para no volcar el contenido. Asimismo, para tomar hicieron jugo de ananá y agua de cebada con limón, llevaron dos 
baldes -esos donde vienen la pintura para casas-, de 20 litros cada uno (Notas de Campo \#3).

Algunos platos, como los Juanes, nos cuentan, requieren mucha producción previa, lo cual se torna muy cansador. Se hace de un día para el otro, no del momento:

Se empieza haciendo hervir con la gallina con sal y condimentos durante tres horas porque su carne es muy dura. Después se hace el arroz y cuando ya está listo se deja enfriar, porque si no fermenta. Una vez que está frío, se empieza a batir los huevos y se le agrega ajino moto, sal y comino, y se mezcla con el arroz. Después se hace hervir huevo duro. Después se pasa a envolverlo en el papel aluminio: se pone una porción de la masa de arroz ya condimentado, una presa de gallina, un huevo duro entero cortado en dos mitades y aceitunita. Luego se pone a hervir todo eso envuelto dos horas más. Luego para servirlo sacas todo del papel aluminio y va acompañado de frijoles negros, y picante que lleva cebolla, tomate, pepito y rocoto picante, todo cortado a cuadritos, se le agrega sal y limón y listo. Ahora, cada Juane cuesta 300 pesos no podemos venderlo más barato, por la crisis. Antes costaba 30, 40 pesos ( $V)$.

Soy de la selva de lquitos, extraño mucho mi cecina con mi tacacho, mi juane, mi salsa de cocona. Extraño mi camucamu de la selva, es una bebida de una fruta, tiene forma de bolitas que es ácida, es muy buena, nutritivo, es sano. El camucamu es exportado mundialmente. También mi aguajino, que es de aguaje, una fruta de la selva. La otra vez vi en un catálogo que viene en perfume ahora, lo llaman "burichi", así se le dice en portugués, pero de aguaje. Mi masato de yuca, mi masato de pijuayo, mi masato de pandilla. (...) Son cosas de la selva, que extraño mucho, comidas, las bebidas y la gente, todo eso $(T)$.

Como vemos, la venta de comida requiere de mucha organización previa, contar con los ingredientes adecuados que no siempre se consiguen en La Plata, como así también, respetar los tiempos y secretos de preparación del arte culinario peruano.

Se arman diferentes grupos, cada una con una encargada. Está el grupo de quienes van a hacer las compras, quienes cocinan, quienes hacen el jugo, quienes se encargan de de despachar y cobrar por la venta la comida. Así, se acuerda siempre hacer dos o tres platos diferentes, pensado en las peruanas de otras regiones, a un solo precio de $\$ 100$ y el vaso de jugo $\$ 30^{29}$ (Nota de Campo).

Lo que más conservo acá de mis costumbres es mi comida típica de la selva, el juane, tacacho con cecina, o la patarashca. Me reúno con las charapas acá en La Plata a veces a comer nuestras comidas, pero a pesar de eso extraño mucho mis comidas 
como lo cocinan allá, por los condimentos y el pescado fresco varía mucho al que hacemos acá (M).

Además de la adquisición de los insumos específicos con los que deben contar para cada receta; necesitan hacer una convocatoria adecuada para vender. Esta tarea la realizan a través del diseño de algunos productos comunicacionales, como los flyer o folletos, así como también, algunas publicaciones a través de las redes sociales.

La convocatoria estaba prevista para las 13 horas, fue entonces cuando empezaron a llegar algunas charapas que participan asiduamente de estas actividades de camaradería, junto a ellas otras travestis y trans del norte peruano, algunas ecuatorianas, y otras argentinas. Algunas de ellas vinieron acompañadas de sus parejas, amigas, y amigos. Lo primero que hacían al llegar es acercarse primero a saludar y luego a comprar de forma directa la comida típica de la selva peruana. La cual tiene mucha elaboración, es abundante, muy condimentada y deliciosa. Cada une de elles van comprando diferentes platos y para acompañar, piden una bebida a base frutas y semillas. Hubo momentos donde se juntó muchas comensales y mientras atendía $\mathrm{K}$, $\checkmark$ anotaba en un cuaderno el nombre de quién y qué pedían, para después cobrar. Se acercaron dos mujeres que pasaban y observaron que estaba pasando, preguntaron qué había de comida. Cuando les explicaron que había y cuanto costaba, dijeron que iban a regresar, pero al final no lo hicieron (Nota de Campo \#3).

Al igual que la práctica del vóley, la preparación y venta de comidas típicas de la región selvática peruana, significó la posibilidad de reconstruir y fortalecer sus vínculos sociales y culturales en la ciudad de La Plata, uno de los sitios elegido por la comunidad de las charapas para afincarse en Argentina.

Estos rituales les permiten recrear las costumbres y tradiciones de sus pueblos, y rememorar prácticas ancestrales que se van transmitiendo a través de relatos orales, de generación en generación. Las charapas descienden de tribus Chancas, Shipibos Conibos, Lamas, Kichwa, Quechuas, Ashaninkas, entre otras; cuyos modos de subsistencia van desde la caza, la pesca y la recolección.

A las charapas nos dicen indias, como algo malo, pero porque somos descendientes de indígenas u originarias. Yo conservo sus tradiciones en cuanto a la comida, porque son pueblos con mucha riqueza y diversidad cultural; más no sus rituales y creencias, porque a mi parecer siguen siendo machistas $(R)$.

Pero además, la venta de comidas típicas es utilizada para recaudar fondos con los cuales las charapas pueden llevar a cabo otros modos posibles de subsistencia. Y, de este modo, imaginar espacios de trabajo colectivos, autogestionados y sustentables capaces de 

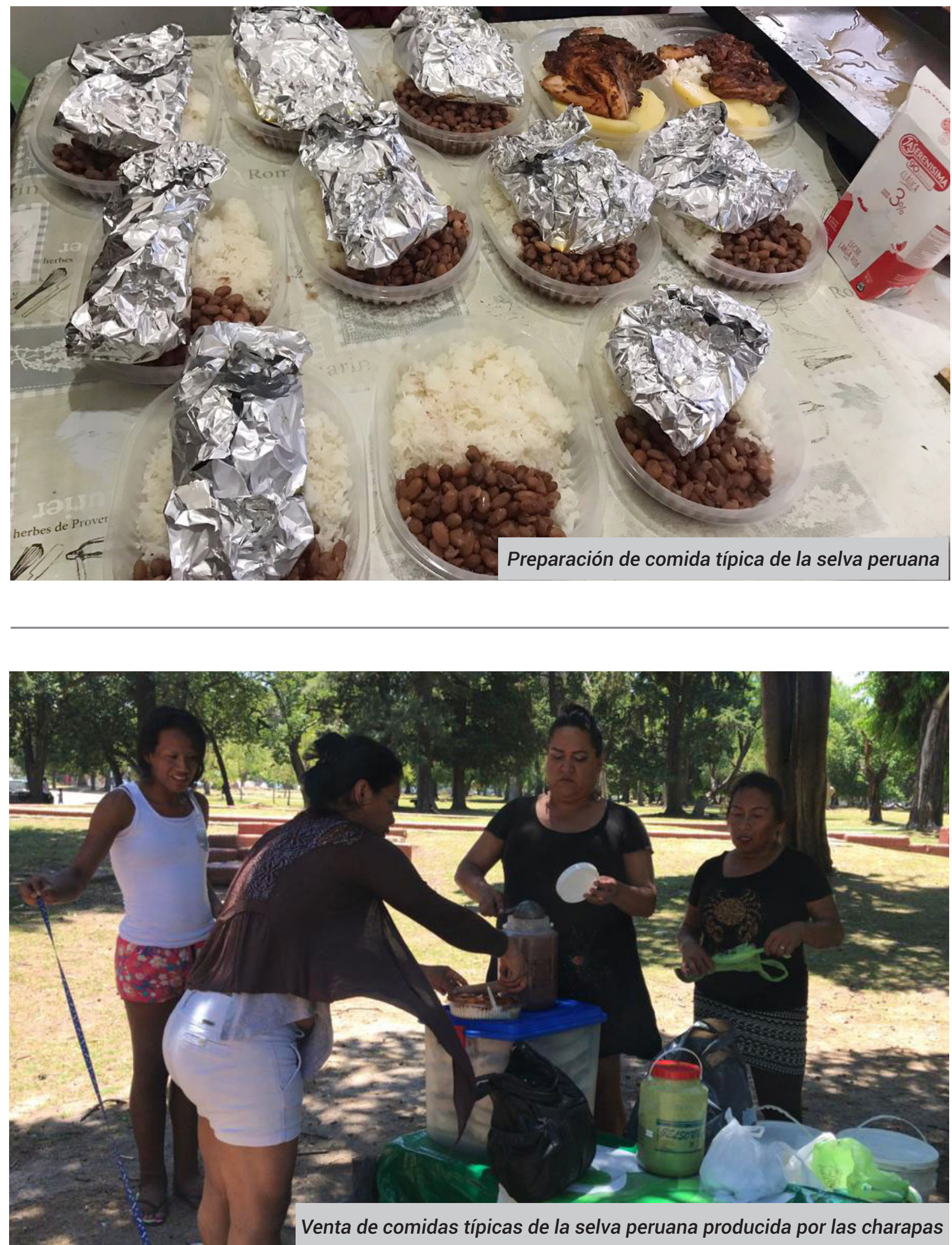

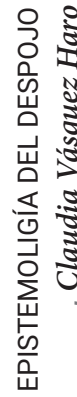


materializar una salida laboral, por fuera del circuito clandestino prostibular.

\section{Gestión de la muerte}

“¿Somos creyentes acá no?"

Preguntó el padre, y volteó a mirar a todes.

"Si, respondieron las charapas en coro".

En la mayoría de las entrevistadas, la muerte no es ajena a su cotidianeidad. En algún punto, existe entre ellas una naturalización de la violencia en un sentido amplio, es decir, que cada vez que salen de sus casas son conscientes que pueden ser la última. Quizás por encontrarse en situación de marginalidad, viviendo siempre en la clandestinidad, existen escasas posibilidades para embarcarse en un proyecto de vida, y pensar la vejez como una de las etapas del ciclo vital humano.

Hijas que yo traje, tuve 2. Una falleció y otra que se regresó a Perú. Aparte, se hicieron hijas mías como muchas que tengo, que yo las acogí cuando no tenían dónde estar, o llegaron y vinieron de otras casas donde no querían estar, y se acostumbraban conmigo, yo ya las agrupaba como hijas mías. Una de ellas también falleció, en total fallecieron 2 hijas mías. $P$ tenía 20 años si no me equivoco, y S este agosto cumple 2 años de haber fallecido, el 28 de agosto, ella tenía 30 años (K).

Los velatorios y entierros de las charapas también conservan parte de sus tradiciones y culturas de su pueblo. Desde la disposición del cuerpo, los adornos que ornamentan las salas, la comida que se sirve para quienes acompañan a les deudes:

En el Perú, sobre todo en los sectores populares durante los velatorios reparten café y comida a quienes acompañan. En el Velatorio, a las 5 de la madrugada, $\mathrm{V}$ y $\mathrm{K}$, llegaron con dos ollas grandes, que contenían caldo de gallina. Repartieron a todas las personas que acompañaron, hasta esa hora (Nota de Campo \#4). 
(...) Cada vez que ingresaba una charapa y se acercaba al ataúd donde se encontraba $V$, se persignaba o santiguaba en silencio y empezaba a rezar, inclinaba la cabeza, ponía las manos juntas y luego entrecruzaba los dedos. Otras acariciaban su rostro, con tristeza y llanto. Después de rezar volvían a persignarse, esto era como un ritual en la mayoría de ellas, quienes tenían ropa oscura, que simboliza el luto, una especie de reverencia y respeto hacia la muerta y los dolientes. Este hábito se acostumbra en la mayoría de los entierros en el Perú (Nota de Campo \#4).

Como observamos y estas ceremonias lo confirman, las charapas sostienen que en el Perú, al menos cuando estudian en la escuela o el colegio, la educación religiosa es una materia obligatoria. Y en alguno de los casos también educación pre militar. Es por eso que existe en ellas una fuerte influencia de la religión católica. Todas saben el ritual de una misa no solo desde saberse la letra de todas las oraciones, sino también los silencios y posturas con el cuerpo frente al rezo y al Padre, a quien demostraron, al menos durante el tiempo que duró la oración, obediencia y respeto.

Luego el padre se persignó y rezó el Ave María, junto a todas las presentes, que repetían al unísono la oración. Todas las charapas participaron con atención del rezo, repetían en coro lo que el padre les había propuesto "yo pongo mi esperanza en ti señor". El sí rotundo cuando el cura preguntó si todas eran creyentes, no dio lugar para ninguna duda (Nota de Campo \#4).

Sin embargo, estos espacios se constituyen, también, en territorios propicios para el tejido de redes comunitarias. Ante la adversidad, de haber perdido una madre, una hija, una compañera de parada, incluso, a una amiga; las charapas fueron construyendo estrategias colectivas:

Mi madre era muy buena, tenía muchas amistades acá, y en Europa. Tenía tres hijas en Argentina, yo fui la última que ella trajo, me quería mucho, siempre me daba consejos, ella y papá $P$, la extraño. Su muerte me chocó mucho, dejó un vacío muy grande en mi vida (...) Murió joven, tenía 35 años, por suerte cuando murió estuvimos todas apoyando para poder darle un entierro digno $(H)$.

Hablar de dignidad en este punto no es menor, sobre todo, en el caso de un colectivo tan criminalizado como el travesti y trans migrante. Para ello utilizan una práctica que tiene una lógica muy similar a la del "juego de juntas”, en términos solidarios:

La casa de sepelios tiene varias salas, algunas pequeñas y otras más amplias. Su alquiler va a depender de la cantidad de personas que asistan. Pero también va a implicar un costo más elevado. Las charapas, que viven en La Plata, hicieron una colecta de dinero para cubrir los gastos, la madre de $V$ que estaba en Europa, y otras 
amigas charapas que viven en el viejo continente, también enviaron su colaboración (Nota de Campo \#4).

Recolectar el dinero, no es tarea sencilla. Sin embargo, parece existir un protocolo muy afinado para estos casos, construido en base a la cercanía y afinidad entre ellas, y facilitado, también por el uso de las nuevas tecnologías, sobre todo para llegar hasta aquellas que ya migraron al viejo continente.

Cuando llego a la casa de sepelios Osacar y me dirijo a la sala velatoria donde estaba $\mathrm{V}$, lo primero que advertí fue un crucifijo grande en la parte de la cabecera de la difunta y en medio una fotografía de ella con su vestido blanco, bouquet de rosas y corona de casamiento, que servía como puente, entre la simbología religiosa y ella. En el lado izquierdo, había una corona de flores de colores blancas y rosas con una inscripción que decía "Los familiares, su pareja, amigas, y amigas europeas" (Nota de Campo \#4).

En las entrevistas accedimos a conocer que la mayoría de las charapas utiliza la red social Facebook para comunicarse y estar al tanto de lo que ocurre en el mundo travesti y trans migrante. Esta práctica que tiene una multiplicidad de efectos en algunos casos, negativos, adversos y peligrosos, en ellas produce sentidos respecto a ir construyendo y consolidando redes colectivas.

La ayuda económica llegó en tiempo real para el velorio de $\mathrm{V}$, lo que permitió cubrir los gastos, también, para el entierro. El sepelio se realizó en un salón grande, que tenía una sala chica donde estaba el féretro y otra contigua más amplia donde las charapas y sus amistades estuvieron toda la noche acompañando (Nota de Campo \#4).

Dos prácticas más no pasan inadvertidas durante los velatorios de las charapas, las cuales aportan rasgos distintivos sobre el caso en estudio:

(...) en la sala contigua a donde se encuentra el féretro, las amigas y compañeras de la difunta juegan al ludo (...), el juego es por apuesta: cada una pone 300 pesos, se juega de a una por ficha o de a dos. Es decir, hay solo cuatro colores de fichas: azul, rojo, amarillo y verde. El color que llega primero a la meta logrando acumular todas las fichas de su mismo color, gana el pozo acumulado. (Nota de Campo \#4).

También es recurrente, sobre todo entre las más jóvenes, el uso de celulares para filmar y tomarse fotos en todos los momentos de sus vidas, incluyendo los velatorios: 
T, R, T, entre otras, le tomaban fotos a la muerta. A V, la velaron a cajón abierto, práctica culturalmente usada en Argentina. En Perú se velan los muertos a cajón cerrado, solo podes ver su rostro a través de un vidrio. También se filmó el funeral y ninguna cuestiono esta práctica. Particularmente, por un momento sentí la invasión que genera la lente de una cámara, sobre todo en un funeral donde desde mi desconocimiento deberían, al menos la mayoría estar tristes. Estaba de espaldas cuando vi la cámara, me produjo esa sensación, pero rápidamente quien filmaba giró la cámara, y con ella, la lente y enfocó a un grupo de charapas donde lejos de sentirse intimidadas posaban para las cámaras, levantaban la mano, y la movían de un lado a otro, en señal de saludo (Nota de Campo \#4).

Lo anterior, despertó la inquietud de conocer y analizar en profundidad qué sentidos se construyen en torno del velatorio de una ellas. A esta cuestión le subyace otro interrogante: ¿existe una valoración diferente sobre la vida y la muerte de las charapas?

Al velatorio de $\mathrm{V}$. asistieron alrededor de 90 personas, durante toda la tarde y noche entraba y salía gente. (...) cuando pregunté a una de sus hijas me dijo que eran charapas que viven en capital y otras localidades del Gran Buenos Aires. A ella pudieron velarla una noche, y a la mañana siguiente, el cortejo fúnebre encabezado por las charapas, trasladaron el cuerpo al cementerio de La ciudad de La Plata (Nota de Campo \#4).

Durante el tiempo que se realizó el relevamiento de campo, participamos del velatorio de varias charapas, las cuales fueron enterradas por sus compañeras, quienes al mismo tiempo se convierten en su familia en Argentina. Ellas son quienes cuidan todos los detalles de las ceremonias, incluso, de honrar sus nombres aun cuando la difunta no haya conseguido realizar su cambio registral en el D.N.I:

(...) su pareja $\mathrm{P}$, sus hijas y las demás charapas cuidaron cada detalle para que se respetara su identidad de género aún muerta. En la pizarra donde ponen los nombres de las personas que se velan, incluyendo la chapa de su responso, decía V., el nombre que ella había elegido y con el cual todas sus amistades la conocieron en vida. Aunque en los trámites institucionales, permaneciera el nombre registral que le habían asignado al momento de su nacimiento (Nota de Campo \#4).

(...) No quedó fisuras, ni dudas respecto a quien se estaba velando. El padre, rodeado de más de una treintena de travestis y trans, mientras oraba, aclaraba sobre el uso del término hombre como el universal en su alocución. Al siguiente día, estando ya todes en el cementerio (...) durante la oración y minutos previos antes de bajar el ataúd a la fosa, empezaron a llorar desconsoladamente sus hijas, Z y H (Nota de Campo \#4). 
Entre tantos relatos, uno de ellos generó una reflexión incómoda. Nos preguntamos, en este sentido, al arbitrio de qué condicionamientos están expuestas quienes no tienen tal reconocimiento por parte de sus pares:

No me gustaría morir en este país, tampoco sola como pasó con varias que murieron estando presas, en soledad. Lejos de sus casas y sus familias $(H)$.

\begin{abstract}
A. era una de mis potenciales entrevistadas, sin embargo, cuando le decía de hacerle la entrevista, siempre me evadía. Se excusaba con el tiempo, o que luego lo haríamos. Entonces espere paciente, porque la idea no era ser invasiva, sabía que íbamos a hablar de temas sensibles, que quizás ella por alguna razón, sentía que no era el momento indicado, por eso escapa siempre. Hasta que la llevaron detenida el 18 de febrero de 2017. Fui a verla cuando la tenían presa en los calabozos de fiscalía; allí la vi enferma, tenía herpes en el cuerpo y el semblante demacrado. De allí la llevaron a la comisaría $N^{\circ} 11$ de Ringuelet y el 9 de marzo, la trasladaron a la Unidad 32 de Florencio Varela (Nota de campo \#4).
\end{abstract}

A días de su detención se comunicó con unas de sus compañeras charapas: “(...) con voz quebrada y afligida, decía que se sentía en mal estado de salud, pero lo que le dolía más era la discriminación que estaba pasando por parte del servicio penitenciario y los doctores. Nos pidió que denunciemos" (C):

Madre no sabes lo mal que estoy, siento que me muero. Pero lo que más me duele es al maltrato por mi enfermedad, los médicos no me quieren ni tocar. Hubo uno que se puso doblemente los guantes, que mal me hace sentir eso, por favor ayúdame a denunciar esto $(A)$.

El caso de A es paradigmático. Implicó que la abogada L.S. solicitara un habeas corpus, donde fue necesario adjuntar copia del certificado de la enfermedad crónica que padecía. Sin embargo, la justicia lo rechazó. No es la primera vez que procede de esta manera: la justicia no falla a favor de las travestis y trans, y es menos probable aún cuando son migrantes. Se ha negado sistemáticamente los pedidos de algún beneficio como la morigeración de las condiciones de detención, o el arresto domiciliario.

El fundamento más recurrente en estos casos se basa en la figura del arraigo. Al respecto, la justicia se ampara en que la falta de familia en Argentina, potencia el peligro de fuga de la detenida. Al mismo tiempo, al no constatar un domicilio donde cumplir la medida, permanecen en la cárcel. En estos casos, la presencia del consulado peruano en La Plata, es nula. La mayoría de las charapas se ayudan entre ellas, dando la dirección de sus vivien- 
das, pero existe el temor a ser involucradas en las causas. Estas limitaciones de la justicia y su brazo ejecutor la policía, en algunas ha generado miedo y traumas, lo que deriva en que prefieran no ir de visita a los penales donde se encuentran privadas de su libertad sus compañeras:

“No voy más a visitar a mi madre la L que está presa en Varela, porque los del servicio penitenciario nos maltratan cuando vamos, nos tratan como hombres, no respetan nuestra identidad de género. Como no cambie mi nombre en el DNI, porque no tengo ni el DNI argentino, entonces, más se ensañan. Pero así lo hayas cambiado te hacen lo mismo, una vez fui con la $\mathrm{N}$, que ella si tiene el documento de mujer, y también la trataron mal. Ella se peleó con los guardias cárceles, hizo que viniera una femenina para que la revisen. Pero a mí me reviso un hombre. Son morbosos, nos llevan a un cuartito chiquito y ahí te hacen que te desvistas toda, te dejan calatita, como viniste al mundo. Eso para mí es humillante, me traumé, por eso no fui más (G).

El 16 de marzo de 2017, A. muere en prisión, donde estuvo menos de un mes. Este hecho alerta a las charapas quienes realizan un reclamo público en la puerta de tribunales en La ciudad de La Plata, en calle 7 entre 56 y 57 :

Las charapas presentan una denuncia penal que consta de:“homicidio por omisión agravado por odio a la identidad de género, en concurso con asociación ilícita y apremios ilegales", en contra del Juez Juan Pablo Massi, y de los fiscales Marcelo Sellier y Rodrigo Granado, como responsables de la muerte de A el 16 de marzo de 2017 (Nota de Campo \#4).

El caso de A. no es aislado. Otras muertes como la de P. D. y B. fueron judicializadas. Esto implicó que sus compañeras nunca pudieron despedirlas. Sus cuerpos estuvieron en la morgue varios meses, hasta que la justicia dictaminó su entierro.

Si bien las charapas se constituyeron como querellantes de estas muertes, para la justicia no tiene el valor legal, hasta tanto sus familiares de Perú -con quienes muchas veces sólo les une un lazo de consanguinidad-, entreguen un poder de actuación. Los casos que investigan las causales de muertes de las charapas en situación de encierro, y más aún, las respectivas repatriaciones luego de culminado la investigación, pueden tardar hasta 12 años. Mientras tanto sus cuerpos no se pueden repatriar ni enterrar fuera del perímetro de la provincia de Buenos Aires quedando, por tanto, a disposición de la justicia.

A. murió estando privada de su libertad en la Unidad 32 de Florencio Varela. La vimos, junto a $\mathrm{A}$ y $\mathrm{M}$ en una camilla muerta en la Unidad Penitencia 22 de Lisandro Olmos. Su familia ni bien se enteró de su deceso comunicó que su padre vendría a la Argen- 
tina con la idea de repatriar el cuerpo. Ella, había contado a sus compañeras que era oriunda de lquitos y desde que vino a este país, nunca más regresó. También relató que su relación con su familia no era buena, sobre todo con su padre, hacía varios años que habían perdido comunicación, ya que él había sido uno de los motivos por el cual decidió migrar: "mi familia nunca va a aceptar lo que soy", habría señalado (Nota de Campo \#4).

Podemos dar cuenta que la migración, en este caso, fue motivada por el desprecio a su identidad de género, el mismo que se vuelve a reafirmar en el entierro:

(...) las charapas al enterarse que el padre viene a la Argentina, le solicitan un encuentro: querían contarle quién era A. y qué significaba para ellas su muerte. Su hermana les solicitó que se le comprendiera a su padre cuando hablaba en masculino en referencia a A, el uso constante de nombrarla como hijo. Ella parecía justificar que le costaba porque era un hombre de 74 años. Tras los constantes intercambios vía mensajes de audio por whatsapp, entre la hermana de A y alguna de sus compañeras, una vez en la Argentina, ningún familiar se dio a conocer. El padre de A, nunca se hizo presente a los encuentros pactados (Nota de Campo \#4).

Sus compañeras habían denunciado su muerte y pedido la intervención de la justicia. No obstante, el poder de la ley que le otorga al padre sacudió a las charapas: el padre de A. habría ido al consulado peruano para asentar la defunción y obtener la partida correspondiente, retirar el cuerpo y enterrarlo. Su familia borró las huellas de la muerte; todas las pruebas de la investigación. Este acto, contribuyó a la injusticia que vivió A. antes de su muerte, y que viven cotidianamente el colectivo trans y travesti migrante. A fue enterrada lejos de sus amigas y compañeras, sin merecerlo, en absoluta soledad, y sin el debido respeto a su identidad de género. Aquella que ella misma autopercibía y su familia había negado desde el inicio. A. no había realizado su cambiq registral en el DNI. Fue enterrada con el nombre asignado al nacer. Algo que sus compañeras, las charapas, no hubieran permitido para honrar su memoria, y su entierro, también fuera digno.

Las muertes de V. primero, y la de A. después, son ejemplos paradigmáticos para analizar cómo los lazos sociales y comunitarios que tejen las charapas a partir de la migración y el arraigo en los nuevos territorios, ponen en tensión las estructuras familiares e institucionales formales. 
La lectura a las prácticas político-comunicacionales informales de subsistencia desarrolladas con antelación permitió analizar cómo las charapas se inscriben en un proceso a partir del cual transforman su pensar y su hacer, reconociéndose y autodeterminándose como sujetas de palabra y de acción. Para ello planifican cuidadosamente la producción de cada uno de dichos eventos, en ciertas dinámicas que les permite recuperar sus saberes, compartir sus experiencias y hacer con otras.

Unas prácticas que, además de comunicacionales también son políticas, porque operan en un terreno de disputa por la aparición y apropiación en el espacio público habilitando, desde la praxis, modos diversos de enunciarse. Este nosotros colectivo, se consolida a través de un proceso performativo en el que, a la vez que genera el encuentro y la común-unidad con otras; en el mismo acto, intenta romper con aquellas hetero-significaciones de las que se desidentifican.

De esta manera, las charapas desafían las lógicas de un sistema patriarcal y heteronormativo que históricamente las oprime. Confrontan y disputan sus sentidos desde los márgenes. Construyen colectivamente prácticas subterráneas, marginales, gestadas en los bordes, visibilizando no solo su existencia, tantas veces negada, tantas confinadas a la clandestinidad; sino reconfigurando los modos posibles de ser y aparecer en el espacio público.

En estas prácticas advertimos el germen de una subjetividad colectiva que adquiere un valor inconmensurable, en términos sociales y culturales, para las charapas. A tales propósitos en el próximo apartado, analizamos cómo éstas, al mismo tiempo, construyen organización: contribuyen a revalorizar el sentido de la migración, y lo que, además, permite dimensionar su aporte político, como veremos al finalizar esta investigación, a través de ciertas estrategias formales institucionales de acción y de resistencia puestas a disposición, fundamentalmente, para la consolidación del movimiento travesti y trans en la Argentina. 

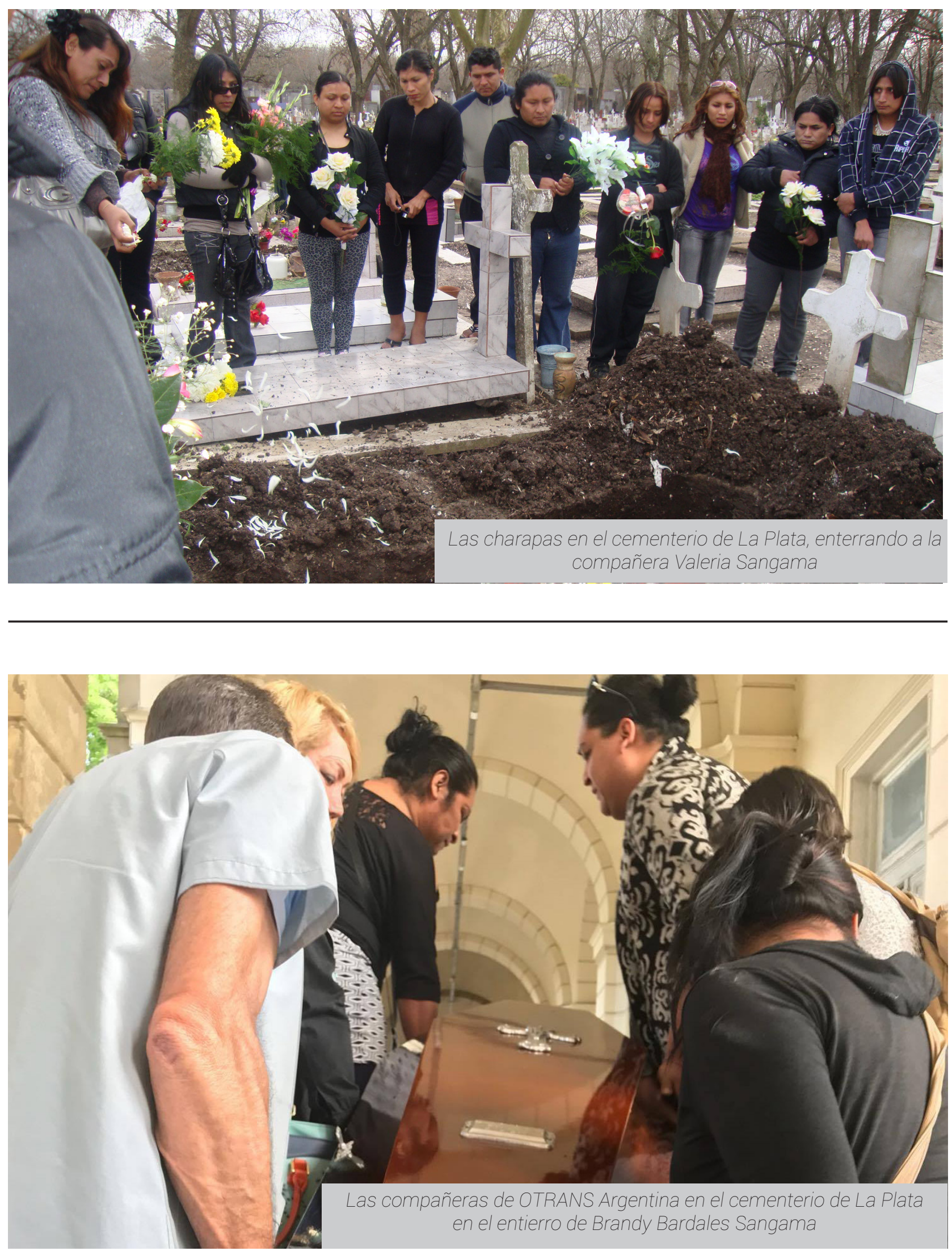
6.2 Prácticas político- comunicacionales formales institucionales. Ser desde identidades golondrinas y construir bandadas: modos y estrategias de organización colectiva plurales y subjetivizantes.

Dar cuenta de los espacios comunicacionales que las charapas han habitado, fundamentalmente, como resultado de la disputa y apropiación de los lugares históricamente vedados, será el segundo eje de análisis que aborda esta investigación, para comprender las implicancias político-comunicacionales que conlleva hacerse inteligible; aparecer, en una escena disruptiva en el ámbito de lo público.

\section{OTRANS ARGENTINA como sujeto político: Los primeros pasos}

El nuevo milenio trajo consigo algunos intentos de armar una organización de travestis y trans con la identidad propia platense; a partir de la cual abogar por la defensa de los derechos del colectivo, atendiendo al contexto sociocultural y político de la época. Sin embargo, estas primeras iniciativas quedaron truncas, al parecer las condiciones no estaban dadas.

El 2008 será testigo de un proceso de despertar político singular: el arribo masivo de las feminidades travestis y trans migrantes peruanas charapas a la ciudad de La Plata. Este proceso, va a ir transformando el mapa político, y reconfigurando las prácticas, hacia adentro del mismo colectivo, y hacia afuera, en la relación con otros actores institucionales.

Al inicio, las reuniones organizativas se hicieron en la casa de algunas de las compañeras, solo eran tres o cuatro las que siempre se reunían. Luego, habrá algunas reuniones en torno a la problemática de la diversidad sexual, pero la participación de feminidades travestis y trans seguía siendo escasa.

La militancia, un poco más organizada, que empieza a dar visibilidad al tema por la defensa del colectivo Lesbianas, Gays, Bisexuales, Trans e Intersex (LGBTI) se dará en los pasillos y aulas de las Facultades de Periodismo y Comunicación Social, Humanidades, Bellas Artes y Trabajo Social, siempre predominando la participación de gays y lesbianas. 
Sin embargo, tiempo después, se produjo un distanciamiento de estos grupos con quienes en un principio militaron, por razones políticas; fundamentalmente, en relación a los modos de organización de la Primera Marcha del Orgullo en La Plata, donde la participación de las compañeras travestis y trans se traducía solo en poner el cuerpo en la marcha, y no ser parte de la discusión de consignas y elaboración del documento final.

Tras un arduo proceso de empoderamiento, que devino de la disputa por el espacio público en la llamada "Zona Roja”, se sentarán las bases para la construcción de lo que se transformará en la primera organización de travestis y trans, en la ciudad de La Plata. Así, en el 12 de Julio de 2012, nace OTRANS-La Plata, conformada y liderada solo por feminidades travestis y trans locales, con agenda propia y trabajo territorial de base.

En las primeras reuniones, se logró una amplia participación, donde asistieron casi un centenar de personas. La primera se hizo en el Centro Cultural Mamichula y, la segunda, por la cantidad de personas que no entraban en el local, se hizo afuera, en la placita ubicada frente a la Facultad de Periodismo y Comunicación Social (FPyCS) de la Universidad Nacional de la Plata, (UNLP) sede del bosque en calle 63 y diagonal 113:

(..) En Mamichula vimos unos videos sobre como violentaba la policía a unas com-

pañeras trans. En principio, surge todo denunciando a los policías, después a los motoqueros que venían con palos, piedras y botellas... nos daban a matar. Luego, a los vecinos $y$, por último, vamos organizar las marchas, donde exigimos al Estado que no nos vulneren más $(K C)$.

El objetivo de la convocatoria era acordar hacer una marcha pidiendo el cese de la violencia policial y el no traslado de la "Zona Roja” al bosque platense, iniciativa presentada a través de un proyecto de ordenanza municipal por el entonces concejal Javier Pacharotti. Ahí surge la idea de armar la organización, se acuerda por mayoría crearla en la próxima reunión. Para incentivar la participación y concurrencia, acordaron para entonces, realizar una chocolatada con facturas.

La organización OTRANS nace en el 2012 como resultado de la lucha de todas las compañeras, principalmente de las charapas, acá en La Plata por los atropellos que veníamos sufriendo por el Estado Municipal y la violencia policial. Allí empezamos a organizamos para no ser reubicadas de la llamada zona roja, nos querían mandar para la zona del bosque y para la zona de carretera a Punta Lara. Mediante las medidas de fuerza de la organización que tomamos nosotras, se crea Otrans. Soy una de las fundadoras, soy la primera Presidenta de OTRANS La Plata, y mediante nuestra organización, pudimos frenar la reubicación de la llamada zona roja (K). 
En esta segunda reunión, se realiza una convocatoria a los medios de comunicación con la finalidad de dar a conocer que las charapas se estaban organizando para denunciar la violencia policial y la de algunes miembres de la sociedad civil. El hostigamiento permanente a estas identidades, las detenciones arbitrarias, las vejaciones y el pedido de coimas por parte de la policía van a ser determinantes a la hora de dar la pelea por la subsistencia y la defensa de sus derechos.

La participación, en esta oportunidad, fue masiva. Las charapas llegaron a ser el 90\% de las asistentes. Después de tres horas de reunión, se resolvieron los cargos de la Junta Directiva, además, el nombre de la organización y color de las remeras. Por votación se resolvió que la organización se llame OTRANS La Plata, después de algunas otras propuestas que no tuvieron mucho respaldo. La $O$ por organización, TRANS porque es un término que aglutina a (travestis, transexuales y transgéneros), y La Plata, porque es la ciudad donde nace el movimiento. Allí también se acuerda que los colores de las remeras sean verdes, teniendo en cuenta que ninguna otra organización de travestis y trans o de la diversidad sexual lo tuviera ${ }^{30}$.

Para la confección de las primeras remeras, como para recaudar fondos para gastos operativos, se organizaron campeonatos de vóley, elaboración y venta de comidas típicas del Perú, en el bosque de La Plata, una práctica muy recurrente en las charapas, de la que hemos dado cuenta precedentemente. Esta estrategia, sirvió a los fines de consolidar la integración hacia adentro del mismo colectivo y, como para generar visibilidad de las identidades travestis y trans en La Plata, en el espacio público.

Más tiempo se tardó en ponerle el nombre a la organización y el color de las remeras, que en elegir la junta directiva. Como si todo hubiese estado pautado, a la hora de elegir la presidenta, una de las charapas, propuso a Bella Karola Macedo Flores, y otra, a Andrea Fernández, de nacionalidad argentina. Tras la votación, Macedo Flores obtuvo la mayor cantidad de votos, convirtiéndose en la presidenta y, la segunda, como vicepresidenta.

"Yo estoy desde el minuto cero, soy parte de las charapas que lo fundaron. Nos empezamos a reunir en la calle primero en una placita, después al frente de la Facultad del Periodismo, la que está en el bosque. Todo empezó porque los milicos casi todos los días no nos dejaban laburar en la calle, o nos levantaban y nos llevaban a la comisaría novena o espantaban a los clientes. Eran épocas terribles. Después empezamos a organizarnos, la Karola fue nombrada la primera presidenta, porque como la mayoría somos charapas y ella es una de las que nos organiza a todas nos informa de todo, si hay reunión o no, si hay vóley en el bosque, o si hay comidas de

30 La encargada de hacer el diseño de los logos, banner y otras piezas comunicacionales ad honorem, Tania Páez, -que en aquel entonces era estudiante de la Licenciatura en Diseño en Comunicación Visual en la UNLP- hizo varios bocetos, y en reunión, por voto mayoritario se eligió el logo que perdura hasta la actualidad. 
la selva para comprar y compartir. Y también porque es de nuestra confianza gano ella por mayoría. Después renunció por temas personales que nunca nos dijo $(T)$.

Sin embargo, este hecho histórico y político, a la luz de algunos medios de comunicación como el diario platense El Día, lo tituló: "Rechazo de travestis y transexuales a la mudanza de la zona roja". Allí describe de forma escueta solo el conflicto de la reubicación de las compañeras, dando a conocer que la reunión de las travestis y trans fue solo para sumar otro repudio. De esta manera, se invisibiliza la creación de la organización OTRANS en la ciudad de las diagonales.

Para cubrir los gastos de la organización, resolvieron colaborar con dinero a voluntad. Cada compañera aportó una ayuda con la cantidad que podía, revistiendo este acuerdo de carácter no obligatorio. También acordaron reunirse una vez por semana, todos los martes de 18 a 20 hs. Al no contar con espacio físico propio los encuentros se hacían en diferentes lugares- casas de compañeras, centros culturales y en la unidad básica de La Cámpora (6 e/62 y 63).

Pasadas las dos primeras semanas desde su conformación, Andrea Fernández desistiría del cargo de vicepresidenta, justificando que lo hacía por motivos personales. En ese mismo momento, se decidió convocar una nueva elección.

Después de un mes de estar reuniéndose en distintos lugares, por gestiones del Observatorio de Comunicación Género y Diversidad con Perspectiva en Derechos Humanos de la FP y CS-UNLP, la Decana de esa misma casa de estudios, Florencia Saintout concedió, a modo de préstamo, un aula en la sede del bosque, primero y, luego en la sede Miguel Bru, ubicado en calle 44e/8 y 9 n 676, donde hasta el día de hoy se realizan las reuniones de la organización.

\section{Cambios inesperados: crisis en OTRANS La Plata}

Para julio de 2013, Bella Karola Macedo Flores, plantea su renuncia como presidenta de la organización debido a que iba a viajar a Europa. Había incrementado la violencia policial, el proyecto de ordenanza municipal que aguardaba en el Concejo Deliberante de La Plata para el traslado de la "Zona Roja" aparecía como una constante en los medios de comunicación. Acá aparece un nuevo actor social que hasta el momento la organización no había identificado, los llamados vecinos de la calle 66. 
de nuestra confianza. Las charapas somos un círculo muy cerrado. No confiamos así nomás en cualquiera. Ahí la convencimos a $C$, entre todas que sea la presidenta porque ella no quería. Aparte $C$ sabe mucho esta no solo bien formada, sino también es de nuestra confianza, todas con el tiempo la fuimos conociendo y gracias a ella y todo el trabajo de todas hemos avanzado mucho. OTRANS se crea en 2012, somos muchas deberemos ser como 200 pero de ese total, más de la mitad somos charapas $(K C)$.

La organización, atravesó su primer momento crítico, estuvo a punto de disolverse. Unos meses antes manifestada la necesidad de contar con una tesorera, debido a que ninguna de las integrantes podía hacerse cargo de la recaudación de las actividades (aportes voluntarios o provenientes del campeonato de vóley y venta de comida), porque la policía les allanaba sus casas y llevaba todo su dinero, incluido el de la organización.

Una vez más las charapas debían votar un cargo de importancia: quién formaría parte de la conducción de la organización.

Esa reunión fue tensa, los silencios y las caras de las compañeras manifestaban sentimientos encontrados, donde se conjugaba la tristeza por un lado y la bronca por el otro (Nota de Campo \#7).

Pero el compromiso político era mayor, asumieron la responsabilidad colectiva de generar mecanismos horizontales de participación para todas las compañeras y establecer dinámicas de toma de decisiones, en reuniones y plenarios ordinarios y extraordinarios.

En esta etapa se va a sumar un tema más en la agenda de prioridades de la organización, se va a abocar a asesorar y acompañar a las travestis y trans migrantes a regularizar su situación migratoria, por cuanto se había advertido que un gran número de sus integrantes tenían más de cinco años viviendo en Argentina y no habían realizado sus trámites de radicación para obtener su Documento Nacional de Identidad (DNI).

No, en principio no iba a migraciones porque me habían dicho que te deportaban y tenía miedo. Después cuando fui a OTRANS, me dijeron que no había problemas, que había que hacerlo. Me acompañaron a iniciar los trámites, fui la semana pasada, había escaneado mal mis papeles. Me dijeron que vuelva en una semana y no fui. Porque me cuelgo, hay veces laburo hasta tarde y me cuesta levantarme a

la mañana para ir a hacerlo. Tengo que ir porque por ahí viajo a fin de año y después cuando vuelva me hagan problemas $(T)$. 
En este sentido, podemos advertir que los trámites para obtener su el DNI y acceder a la categoría de ciudadanía, se convierte en una necesidad en la medida en que, ellas no cuentan con ningún documento que acredite quiénes son y, por tanto, dificulta su acceso eficaz a los derechos y garantías, en el país receptor.

\section{Disputa por el espacio público: intentos de traslado de la "zona roja" al bosque platense}

La coyuntura social y política exigió que OTRANS, priorice en una agenda basada en poner los esfuerzos y recursos humanos en el reclamo por el cese a la violencia policial. La centralidad estaba puesta en la disputa por el espacio público en relación a la reubicación de la zona roja platense entre: los vecinos de calle 66 -quienes presionaban al poder político de turno y al judicial a través de sus denuncias en los medios de comunicación-, y por el otro lado las travestis y trans organizadas.

En este contexto, OTRANS fue experimentando modos de organización colectiva, procesos de toma de decisiones que expresaron la voluntad de la mayoría de sus integrantes. Después de varias reuniones y asambleas, el acuerdo era claro, el único responsable de lo que sucedía era el Estado. Hubo un acuerdo clave, no responder a ningún tipo de violencia o provocación por parte de algunos vecinos. Desde de esa primera lectura política, OTRANS comienza a tejer sus reclamos y a generar alianzas estratégicas. Es decir, como describimos anteriormente, va a priorizar en su agenda la regularización migratoria de sus integrantes en articulación con la Asociación civil Red de Migrantes y Refugiadxs en Argentina. Y también se convierte en la interlocutora del colectivo travesti y trans platense, encabeza los reclamos, en la disputa por el espacio público y el cese de la violencia institucional (policial y judicial).

Así se tornó necesario, en la organización la definición de una práctica político- comunicacional, capaz de visibilizar las demandas a través de medios de comunicación, que no tergiversen los hechos, y que pusieran el acento sobre la problemática desde una perspectiva de derechos humanos, y que contuviera la propia voz de las actoras implicadas. Desde esa demanda puntual se crea la fanpage de Facebook de OTRANS, lo que se consolidará como el espacio comunicacional por excelencia a través del cual la organización disputará sentidos en el espacio público. Allí se empieza a escribir comunicados de prensa para publicar desde ahí las denuncias, repudios, marchas, y dar a conocer la agenda de la organización. También se articula con otros medios para publicar notas de opinión como en: la página web de la FPyCS-UNLP, el diario Diagonales, el suplemento Soy del diario Página 12, el portal Info Blanco sobre Negro, Diario Contexto Digital, entre otros. 
Durante el 2013 las denuncias por parte de los vecines, -primero era por los "desnudos en la vía pública" y después por la "venta de drogas"-, se intensifican. Entre sus estrategias emplearon el escrache a través de una cuenta de twitter a los denominados "clientes", la recolección de firmas, la instalación de cámaras en las calles y la construcción de un discurso mediático que asociaba a las travestis y trans en situación de prostitución, con la delincuencia y la inseguridad. Estos mecanismos formaron parte de sus reclamos, agudizaron el enfrentamiento y se tradujeron en el incremento de la violencia policial, masivas detenciones arbitrarias, y constantes "operativos", en contra de las travestis y trans platenses.

En los documentos analizados, observamos que en los comunicados de prensa de la organización las denuncias sistematizadas consisten en, a saber: detenciones arbitrarias, persecución, requisas vejatorias, malos tratos, el no respeto a su identidad de género autopercibida- violación a Ley 26.743-, y la falta de información sobre el paradero de las travestis y trans detenidas. Asimismo, sostienen que existe una connivencia entre la policía y el poder judicial, y que estos procedimientos están amparados por "la investigación de venta de drogas y quejas por exhibicionismo, sin investigación previa, solo por denuncias telefónicas de vecines" (OTRANS, Comunicados de Prensa).

\section{COMUNICADO DE OTRANS ANTE LA DETENCIÓN DE 29 COMPAÑERAS}

Desde OTRANS LA PLATA hacemos público y repudiamos un nuevo episodio de persecución policial y judicial contra la comunidad trans platense con lo sucedido en la madrugada del miércoles 29 de enero, cuando 29 compañeras fueron detenidas por orden el fiscal Juan Cruz Condomi Alcorta y efectivos de la Comisaría Novena.

Las chicas detenidas sufrieron la discriminación por parte de los efectivos que las trataron como hombres y las llamaron con nombres masculinos, faltando al cumplimiento de la Ley de Identidad de Género 26743. A esta situación se le suma la falta de información brindada por la Policía y la DDI sobre el listado de las compañeras detenidas y el lugar donde se encuentran alojadas. Además de que fueron anotadas sin respetar la Ley de Identidad de Género.

Este hecho se enmarca en un mecanismo de la Policía y del Poder Judicial que se encarga de reprimir y perseguir a la comunidad trans impidiendo que puedan desarrollar prácticamente su única fuente laboral. Y forma parte de la compleja trama de violencia institucional que de manera sistemática viola los derechos humanos de nuestra comunidad.

Desde OTRANS nos movilizamos para saber en dónde están las compañeras y conocer la situación. Varias compañeras detenidas aseguraron que no se les encontró ningún tipo de droga (el procedimiento fue llevado adelante por supuesta venta de drogas). Luego de una serie de desatenciones, el Jefe Distrital, Adrián Castelli nos 
informó que las compañeras declararán mañana y serán liberadas. (...) Desde la Asociación Civil OTRANS reclamamos el cese de todo tipo de mecanismos represivos que vulneran, violentan, estigmatizan y contribuyen a la discriminación y exclusión de nuestra comunidad (OTRANS, Comunicado de prensa: 30-01-2014)

También en los documentos de OTRANS, consta que la totalidad de las detenidas eran migrantes, quienes no tenían cambio registral en su DNI, y figuraban con el nombre que se las había asignado al momento de su nacimiento. En las denuncias, la organización manifiesta que la policía, la justicia y algunos medios de comunicación, utilizan esto, como argumento, para no dar cumplimiento al artículo 12 de la ley 26.743 referido al trato digno:

“Trato digno. Deberá respetarse la identidad de género adoptada por las personas, en especial por niñas, niños y adolescentes, que utilicen un nombre de pila distinto al consignado en su documento nacional de identidad. A su solo requerimiento, el nombre de pila adoptado deberá ser utilizado para la citación, registro, legajo, llamado y cualquier otra gestión o servicio, tanto en los ámbitos públicos como privados"31.

"Cuando la naturaleza de la gestión haga necesario registrar los datos obrantes en el documento nacional de identidad, se utilizará un sistema que combine las iniciales del nombre, el apellido completo, día y año de nacimiento y número de documento y se agregará el nombre de pila elegido por razones de identidad de género a solicitud del interesado/a"32.

En el 2014 el Municipio de La Plata, a través de Gustavo Luzardo, entonces Director de la Subsecretaría de Control Urbano, quien como actor político e institucional sirvió de canal en las reuniones que mantuvo la organización OTRANS-La Plata, con otros actores sociales e institucionales como los vecinos de calle 66, integrantes de los colegios Albert Thomas de calle 1 entre 57 y 58 y, Nuestra Señora del Valle de 57 entre 1 y 2, quienes cada vez con discursos y prácticas virulentas, por un lado exigían la reubicación de "la zona Roja" $y$, por el otro, lo rechazaban en determinados lugares:

OTRANS vela por nuestros derechos, es muy importante estar unidas, organizadas. El problema del traslado de la zona donde trabajamos fue terrible, había vecinos que salían con palos y machetes a corrernos, la policía todos los días nos llevaba presas. Nos tenían ahí horas, hasta que llegaban nuestras compañeras de la organización a sacarnos. De allí organizamos marchas por el reclamo de nuestros derechos, y para que dejen de llevarnos presas, para poder trabajar porque no teníamos ni para comer. Después me acuerdo que fuimos a una reunión en un colegio de la zona, ese

31 Los párrafos citados corresponden al artículo 12 de la Ley de Identidad de Género -N²6.743-, sancionada en mayo de 2012. Lo allí dispuesto es aplicable a toda documentación y tramitación escrita pública, ya sean expedientes, dictámenes, citaciones, legajos, notas o certificados, entre otras

32 Idem. 
día fue feo, nos trataban mal, uno nos dijo: "para mi ustedes no son mujeres". Nos re discriminaban, nos trataba como hombres, y después cuando nuestra presidenta le dijo que no estaba respetando la ley de identidad de género, que todo estaba filmado, que lo íbamos a denunciar, entonces, pidió perdón, pero más por miedo a la denuncia. Después de ese comentario se ubicaron, empezaron a hablarnos bien $(N)$.

Durante ese periodo OTRANS, mantuvo reuniones con Gustavo Luzardo, en representación del Municipio de La Plata. También hubo reuniones en el espacio de OTRANS, con Eugenia Ullman y Paula Lorens, representantes de la "Asociación Vecinos de la calle 66", quienes plantearon sus preocupaciones a las compañeras, como también, ellas pudieron conocer por testimonios en primera persona la realidad que viven las travestis y trans en situación de prostitución. Allí también participaron algunas travestis y trans que no pertenecían a ninguna organización. Y gays y lesbianas, que manifestaron salir perjudicadas por la medida que quería implementar el Municipio de La Plata.

Esa reunión sirvió para que cada agrupación exponga su postura: hubo momentos de tensión, de gays y lesbianas con les vecines, este grupo que no estuvo de acuerdo con la "reubicación" se terminó yendo a los gritos. Mientras que las travestis y trans integrantes de OTRANS y las que no estaban nucleadas en ningún espacio, tomaron la decisión de continuar el diálogo, con les vecines por considerar que ellas eran las que ponen el cuerpo en la

calle todas las noches y no los gays y las lesbianas. Y por el otro lado querían ser ellas las interlocutoras en esa disputa y no ser mediados por personas cisgenero.

Después de la reunión, acordaron ir en ese momento a recorrer el bosque y determinar qué lugar les parecía el "más adecuado". La mayoría de ellas optó por el corredor ubicado atrás del colegio Albert Thomas en 115 y que abarcaba las calles de 52 a 60.

Después de varias reuniones con el Municipio y les vecines, y toma de decisiones en asambleas convocadas por OTRANS, las cuales contaron con amplia participación de actoras travestis y trans en situación de prostitución, se llegó a firmar un acuerdo de "reubicación" de la Zona Roja, entre: la Dirección de Control Urbano del Municipio de La Plata, los vecinos de calle 66 y OTRANS La Plata, donde existían varios puntos que el ejecutivo platense tenía que cumplir. Se priorizó una perspectiva basada en Derechos Humanos de personas travestis y trans.

\section{Rechazo al traslado de la "zona roja" al bosque platense.}

Ante el acuerdo firmado con el Municipio de La Plata, se sumaron otres actores que manifestaron su disconformidad como los directivos de los colegios Albert Thomas, Nues- 
tra Señora del Valle, representantes del Centro de Estudiantes, padres y madres de familia. Estos sostenían que el traslado al corredor de 115 generaría inseguridad, y una mala imagen para la Escuela, porque les estudiantes tenían que ver a las travestis y trans prostituyéndose, y que esa parte del bosque iba a estar lleno de preservativos, lugar donde sus hijos hacen educación física.

Las travestis y trans tienen como parada hace más de 20 años esas esquinas, incluso en la calle 1 entre 57 y 58. En un relevamiento realizado por OTRANS en el 2013, son alrededor de 220 las travestis y trans que se encuentran en las calles en situación de prostitución, en la ciudad de La Plata. OTRANS mantuvo una reunión con estos actores y el Municipio, en la escuela Nuestra Señora del Valle. Donde en principio las intervenciones de estos actores fueron violentas y discriminatorias hacia las personas travestis y trans. Todos los discursos y argumentos se basaron en perjuicios, y desconocimiento del tema en cuestión. Hubo planteos de algunos padres de familia al funcionario Gustavo Luzardo, que el Estado municipal debería darles a las travestis y trans un lugar cerrado y lejos de la ciudad de La Plata. Quedando en evidencia que no era solo los desnudos o la venta y consumo de estupefacientes, sino la presencia de las identidades travestis y trans, en ese espacio público.

Después de varias horas de debate, no se llegó a ningún acuerdo. Tras fracasar todo intento de traslado de la Zona Roja, las detenciones y el hostigamiento por parte de la policía bonaerense y la policía local incrementaron. Las echaban o ponían un patrullero en cada esquina para no dejarlas "trabajar" /prostituirse. El entonces concejal Javier Pacharotti, sostenía que la presencia de las travestis y trans en las calles donde ejercen la prostitución devaluaban el valor de las casas o departamentos de esa zona. Acá podemos advertir una lógica capitalista que prioriza la propiedad privada en contraposición de la vida de personas, que son en su totalidad, excluidas sociales.

También vemos cómo aparece el recorte ideológico del concepto vecino/a, las travestis y trans que están en situación de prostitución la mayoría viven en el barrio. Sin embargo, se las despoja de ese sentido de pertenencia, para criminalizarlas y construir un chivo expiatorio, 'sujete peligrose'.

En palabras de Eugenio Raúl Zaffaroni (2011), la criminología mediática crea la realidad de un mundo de personas decentes frente a una masa de criminales identificadas a través de estereotipos, que configuran un 'ellos' separado del resto de la sociedad, por ser un conjunto de diferentes y malos. Los ellos de la criminología mediática molestan, impiden dormir con puertas y ventanas abiertas, perturban las vacaciones, amenazan a los niños, ensucian en todos lados y por eso deben ser separados de la sociedad, para dejarnos vivir tranquilos, sin miedos, para resolver todos nuestros problemas. Para eso es necesario que la policía nos proteja de sus acechanzas perversas sin ningún obstáculo ni límite, porque nosotros somos limpios, puros, inmaculados 
En los relatos de las entrevistadas podemos observar cómo se instaló un discurso que estigmatiza y criminaliza las identidades travetis y trans, no atendiendo a las demandas de las actoras implicadas. El problema de fondo que es el narcotráfico y la inseguridad, queda de lado y se da paso a un doble marcaje de la discriminación, por un lado, la criminalización de la identidad de género y, por el otro lado, la sedimentación de un discurso xenófobo por su condición migrante:

Nuestra relación de trato con la policía siempre es y va a ser un problema, porque ellos se creen que tiene siempre el poder sobre nosotras. Porque somos chicas trans y porque somos migrantes. Entonces siempre nos quieren humillar. Pero ahora tenemos derechos y hemos aprendido cuáles son y a donde ir a denunciar con nuestra organización. Ellos vienen te quieren tocar, y ahora nosotras sabemos que tenemos que pedir una femenina. Ahora los hombres no se atreven ni a tocarnos. La calle siempre se presta para que nos violenten, utilizan el tema de las drogas para desnudarnos en plena vía pública. Nosotras ahí le decimos que los vamos a denunciar si nos tratan mal $(L)$.

A partir del 2014, uno de los temas de la agenda que va a priorizar OTRANS La Plata va a ser armar el padrón de sus miembras, mediante fichas técnicas. Allí van a inscribir 126 integrantes, el 98\% de ellas en situación de prostitución, y el 85\% migrantes del cono sur. La demanda surge en la medida que, durante las detenciones arbitrarias por parte de la policía, nadie sabía sus apellidos, dónde estaban, cuál había sido la carátula de la causa, qué fiscalía y juzgado habían intervenido, de qué país eran y si en caso de alguna emergencia, accidente o muerte, con quien había que comunicarse.

La organización no tiene libro de actas, la fanpage es lugar donde se registran a través de publicaciones y fotografías las reuniones. La agenda se arma de una semana para la otra de acuerdo con la coyuntura. Pero también hay temas que llevan un tiempo más largo como presentar y militar proyectos de cupo laboral/inclusión travesti y trans en el Municipio de La Plata, en la Universidad Nacional de La Plata, en la Cámara de Senadores de la Provincia de Buenos Aires. Elaborar informes sobre detenciones arbitrarias y situación de los DDHH de personas travestis y trans en Argentina para reportar a organismo internacionales de $\mathrm{DDHH}$, hacer gestiones para que las compañeras travestis y trans sean beneficiarias de programa de inclusión como el "Ellas Hacen" del Ministerio de Desarrollo Social de la Nación, trabajar en el armado de la Cooperativa de Trabajo “Las Charapas” de Peluquería y Belleza Integral, entre otras actividades.

\section{Núcleos de asociatividad}

La Asociación Civil OTRANS, es un espacio que trabaja sobre la problemática que atraviesa la comunidad travesti y trans en Argentina, la construcción de ciudadanía, la igual- 
dad de derechos y la defensa, promoción y fortalecimiento de los derechos humanos de este colectivo. Se crea como organización de la sociedad civil sin fines de lucro, pero recién a fines de 2018 se constituyó con personería jurídica. Su primer intento fue "rechazado" por el organismo que expide estas habilitaciones en La Plata, capital de la provincia de Buenos Aires, debido a cuestionamientos y observaciones del objeto jurídico. Al ser un tema complejo requirió la intervención del Dr. Gustavo Cursio, especialista en derecho público y societario, para la constitución y formalización de la organización, inscripción y, su respectivo, seguimiento. Finalmente, se logró obtener la figura jurídica con alcance nacional.

Este periodo en el que la organización no gozaba de estatus jurídico, puede ser analizado como lo sostiene la investigadora Adriana Archenti (2014) a través de la noción de núcleos de asociatividad no asimilables a formas más organizadas, con elencos estables y continuidad en el tiempo-. Esta categoría, da la posibilidad de abordar formas de organización/actuación/intervención que recuperan la trascendencia dada por los intersticios, los cuales responden a relaciones no formalizadas -coexistentes con las formales, insertadas en ellas o colaborantes con su operación (tales como parentesco, amistad, patronazgo, redes, cuasi-grupos, mediaciones, etc)-, y a su vez, a las maneras en que, habida cuenta de su peso constituyente junto a variables de pertenencia étnico nacional, regional, de clase, de género, de grupo etáreo, de matrices culturales, se producen -o se dificultan- formas de filiación/pertenencia/participación en iniciativas de organizaciones gubernamentales o no gubernamentales que intervienen o procuran intervenir sobre la incorporación, la promoción de derechos o la condición ciudadana de migrantes.

Más allá de no contar con la institucionalidad formal derivada de la obtención de su personería, no fue un obstáculo a la hora de poder incidir en sus reclamos y exigencias al Estado por la no violación a los derechos humanos de las compañeras. De este modo, la organización desde su creación, hasta la fecha no ha podido acceder a ningún tipo de financiamiento por parte del Estado, lo que ha generado la obtención de sus recursos e ingresos económicos a través de la autogestión y de las redes de solidaridad, lo cual les permite -no exento de dificultades -seguir sosteniéndose, desde hace ocho años.

La creación de este espacio fue impulsada y sostenida por el 85\% feminidades travestis y trans migrantes de países del Cono Sur: peruanas-en su mayoría-, ecuatorianas, y un 15\% de argentinas. De ese componente, el 79\% son charapas. Estas integrantes son el pilar de la organización, en el sentido que han construido modos de organización y redes de contención a partir de las experiencias previas durante los procesos de migración, tanto en su país de origen, como durante en el trayecto del viaje, la llegada y su arraigo a la Argentina. Las charapas son un colectivo que emigró desde la selva peruana y que eligió la ciudad de La Plata, entre otras, como Mar del Plata, Monte Grande y CABA, como su lugar para establecerse. 
La organización, en este sentido, se crea con el objetivo de denunciar y visibilizar la violencia institucional: para dar respuesta a las detenciones arbitrarias, los malos tratos, el hostigamiento, las vejaciones y las torturas a las travestis y trans por parte de la policía bonaerense, y el cobro de coimas de algunos efectivos policiales. También para denunciar a bandas de civiles llamados motoqueros y bicicleteros, quienes los días jueves y domingos salían por la noche a recorrer la "Zona Roja" a golpear, a personas travestis y trans.

\section{$r^{2}+x_{2} x$}

A lo largo del desarrollo precedente, dimos cuenta del contexto socio-político donde se inscriben las prácticas de las feminidades travestis y trans migrantes peruanas, las charapas. Para ello, indagamos acerca de las prácticas político-comunicacionales tanto informales como formales, en la disputa y articulación con otres actores institucionales y de la sociedad civil, en la construcción de estrategias de resistencia y visibilización en el espacio público.

Observamos, en este sentido que desde sus primeros pasos irrumpen en la arena política con una agenda propia, junto a los debates que conducen la discusión, puntualmente, en lo que respecta a la derogación de los edictos policiales y códigos contravencionales, represión policial, detenciones arbitrarias, acceso a la salud, a la educación, por el efectivo reconocimiento al derecho a la identidad de género. En este marco las charapas se arraigan en la ciudad de La Plata donde configuraron las bases políticas de su propia organización; principalmente, por el aumento de la criminalización por parte de la policía hacia las identidades travestis y trans en situación de prostitución, en la llamada "zona roja" platense.

En nuestra indagación, hemos reconocido la existencia previa de formas político- comunicacionales de subsistencia e institucionales, de accionar y proyectar una experiencia basada en lo común de quienes protagonizarán momentos trascendentales en diferentes épocas históricas, durante la construcción del movimiento travesti y trans en Argentina. Estas marcaron los lineamientos fundacionales a partir de los cuales, en su devenir, podemos contextualizar, en el presente trabajo, específicamente, las prácticas de las feminidades travestis y trans migrantes peruanas, en La Plata: las charapas, y que seguidamente se extendieron por otras ciudades del país, como CABA, Corrientes, Luján, Vicente López, Malvinas Argentinas, Merlo, Ensenada y Berisso.

La interpretación crítica de la experiencia organizacional gestada con nombre propio, permitirá dimensionar el alcance de las luchas que antecedieron y sedimentaron la militan- 
cia de las charapas; por ello, en el próximo capítulo, haremos una lectura a los procesos de gestación, propiamente dichos, de la ley de Identidad de género y la ley de cupo laboral travesti y trans, en la provincia de Buenos Aires; y a nivel nacional, la derogación del decreto 70/17, la ley de inclusión laboral formal travesti y trans Lohana Berkins, el pedido de justicia por el travesticidio de Diana Sacayán, la marcha contra los travesticidios y transfemicidios en Argentina, y los Encuentros Nacionales de Mujeres, entre otros.

Este recorrido analítico tendrá por objeto desnaturalizar y problematizar ciertos condicionamientos, lo cual es y será el imperativo a través del cual OTRANS ARGENTINA ha dado la pelea, junto a todo el colectivo travesti y trans en Argentina; resignificando todo aquello que aparece derivado de un elemento fundamental transversal a la grupalidad de las charapas: la interseccionalidad, expresada en las problemáticas relacionadas a la identidad y/o expresión de género. Por tanto, las páginas que siguen, se plasman, asimismo, en la intención de resignificar los sentidos en torno a la migración, la etnia y la clase y, poner en jaque los actos discriminatorios, racistas, xenófobos y aporofóbicos. 

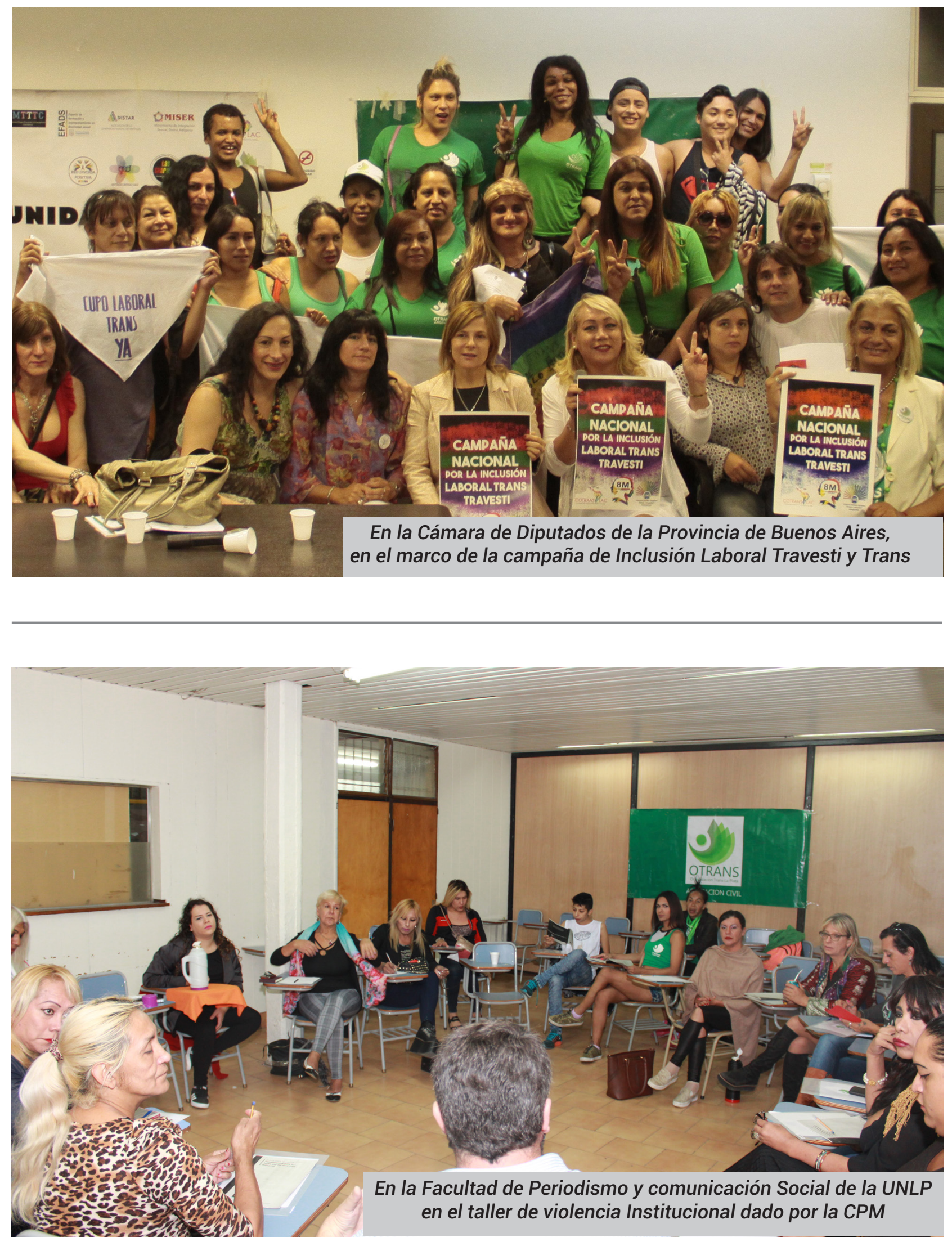

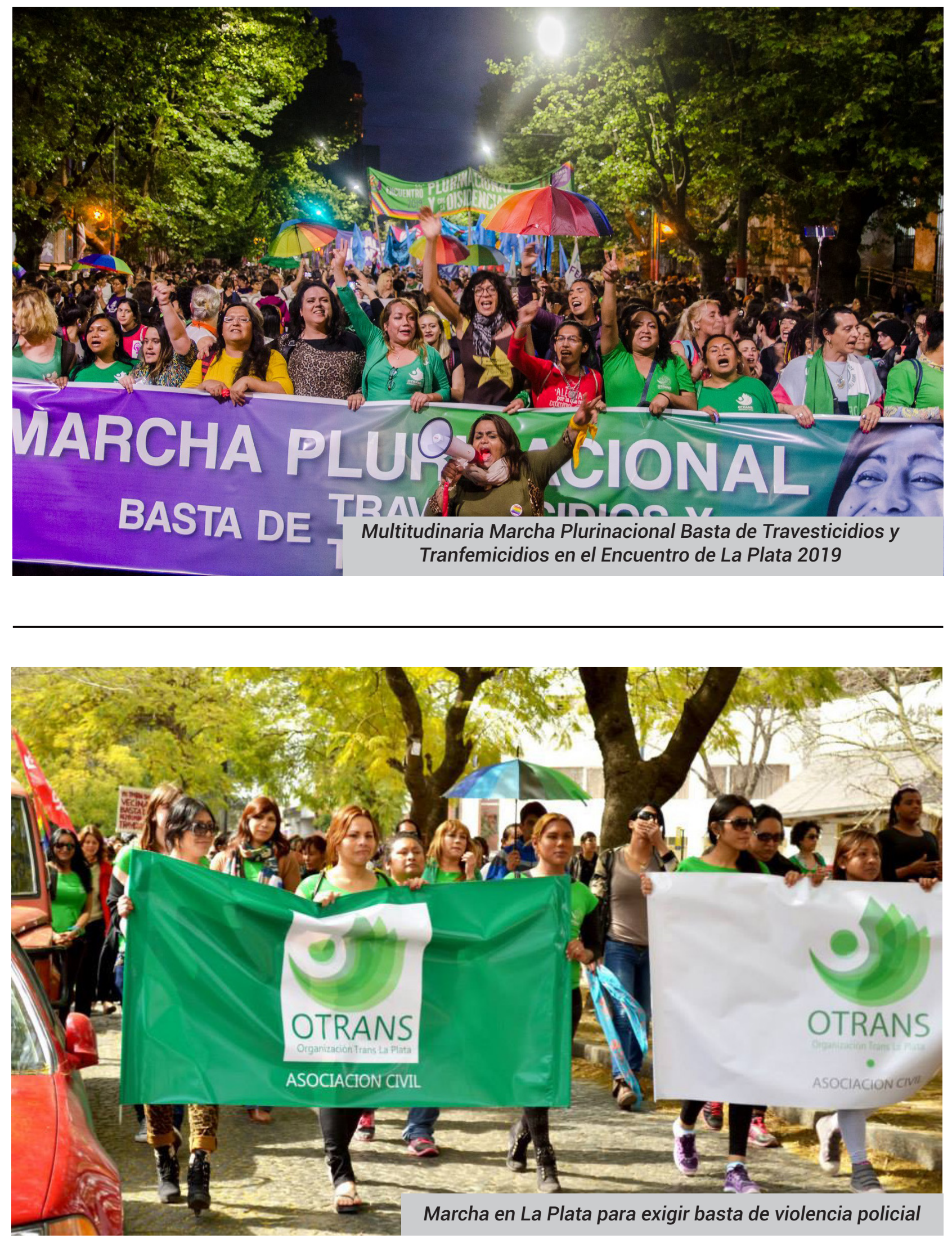
6
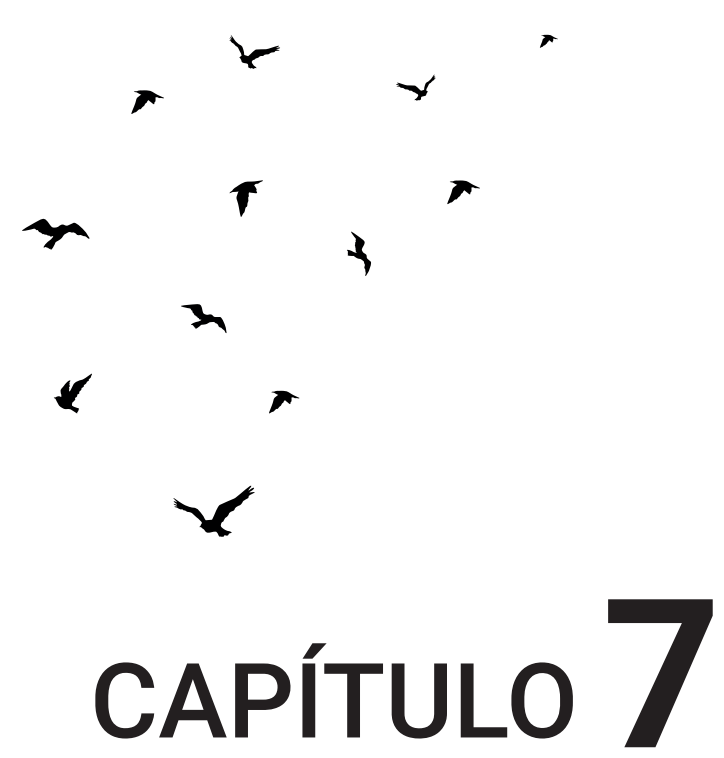

Coalicionar con otres: la construcción de alianzas y estratégicas colectivas 
Capítulo 7. Coalicionar con otres: la construcción de alianzas y estratégicas colectivas

En sentido gramsciano, la articulación de alianzas posibilita la conducción intelectual y moral de la sociedad, la construcción de un sentido común, cediendo lo considerado no esencial para preservar lo esencial. Es una contribución decisiva para pensar la política como construcción de consensos y aprobaciones, como disputas que se expanden en el sentido común, en el plano de las afirmaciones y las costumbres. Es conocida la contribución de autores gramscianos acerca de la posibilidad de relacionar heterogeneidades sociales y políticas, temas como la unión entre identidades distintas, cruces de paralelismos que forjan unidades en oposición a alteridades políticas, A. Grimson (2019).

El autor sostiene que la interdependencia de fuerzas entre las clases es una enunciación que sigue vigente, aunque no es exhaustiva, puesto que también se suman disímiles tendencias sociales, como el feminismo, los pueblos originarios, los movimientos por derechos humanos, ambientales, estudiantiles, TLGBI, entre otros. En esa relación de fuerzas, que involucra la facultad de un gobierno en medio de determinado contexto histórico, incurre en los grados de organización, las estrategias, las convicciones sociales, la legitimidad o ilegitimidad de ciertos discursos y políticas. Para las distintas agendas sociales y culturales hay etapas de visibilidad e invisibilidad, de avance o retroceso, de defensiva u ofensiva.

Allí inscribimos la dimensión del aporte de las feminidades travesti y trans migrante peruanas en la Argentina: las charapas, en general y, específicamente, de OTRANS ARGENTINA, que fue imprescindible para la construcción de la agenda política, así como también para la disputa, apropiación y consolidación desde dentro de los espacios feministas, que históricamente habían sido construidos, colectivamente por mujeres, lesbianas y otras identidades. Lo cual permitió inscribir en la historia de los movimientos políticos, una gesta construida desde los bordes, como sostiene la investigadora chicana Gloria Alzandúa. Una historia subversiva y alejada del mainstream. Esta es una batalla que, sin duda, tuvo que ver con la participación política de las adelantadas: Nadia Echazú, Lohana Berkins, Diana Sacayán, Claudia Pía Baudracco, entre otras; sumado a las que continúan ese legado de lucha en la actualidad.

Sin embargo, este camino no ha sido ni sigue siendo fácil. Aún hoy, una de las disputas fundamentales se da contra las nuevas olas dentro del campo del feminismo. Allí las 
denominadas "TERF" 33 toman como argumento la genitalidad travesti y trans excluyente, para enarbolar un discurso anti-derechos, el cual casualmente se inició en Perú a través de las campañas públicas "Con mis hijos no te metás"34. Los discursos esgrimidos por este movimiento parten desde una mirada biologicista, que entiende a la familia heterosexual nuclear como la única institución legítima. Esta campaña, tuvo amplias repercusiones en las sociedades de otros países de América Latina, como Colombia, Chile, Ecuador, entre otros. En Argentina, intentó incidir en los diferentes sectores sociales, no sólo porque cuestionó la Ley de Identidad de Género, sino también, la implementación de la Ley de Educación Sexual Integral, y la campaña por la Interrupción Voluntaria del Embarazo.

De esta manera, el presente y último capítulo de la investigación, tendrá por delante el desafío de reconstruir el tejido de alianzas estratégicas que desde OTRANS ARGENTINA se construyeron en coalición con otros institucionales, y consolidaron prácticas que concebimos como colectivas, plurales y subjetivizantes, en la intención de habilitar, desde un sentido de interdependencia y corresponsabilidad, una agencia ética y política.

\section{La primera gran aliada}

La militancia en La Plata por los derechos del colectivo TLGBI, surge principalmente en los pasillos y aulas de algunas facultades de la Universidad Nacional de La Plata (UNLP). La Facultad de Periodismo y Comunicación Social va a ser quien tome la iniciativa no solo por la demanda de sus estudiantes quienes empezaban a discutir la reproducción de la heteronorma, el binomio hombre y mujer y el sistema Sexo-género, sino también por parte de docentes, e investigadorxs de esa casa de estudios.

En el 2008 la Facultad de Periodismo y Comunicación Social de La Plata de la Universidad Nacional de La Plata se convertiría en la primera casa de estudios de Argentina, y de Latinoamérica y el Caribe en reconocer la identidad de género autopercibida de sus estudiantes, mediante una resolución votada por unanimidad por les concejeres académicos.

La decisión tuvo repercusión mediática que dio cita en La Plata a canales televisivos y prensa de alcance nacional y local, como Telefe, TN Noticias, Canal 9, Crónica TV, Página 12, diario El Día, entre otros. Si bien el documento no era vinculante, este hecho histórico va

33 Opuestas a la perspectiva de género y a los avances académicos y biológicos, esta porción dentro del feminismo radical sostiene que no existe la autopercepción del género. TERF significa Feminismo Radical Trans Excluyente (por sus siglas en inglés). https://www.filo.news/genero/De-donde-viene-el-feminismo-transfobico-20190128-0030.htm

34 "Con mis hijos no te metas" (CMHNTM) es un movimiento social que nació en Lima, Perú, el 26 de diciembre de 2016, como oposición a las políticas públicas del gobierno peruano por su implementación del enfoque de género en la educación y en otras áreas de la administración pública llamadas Currículo Nacional 2017. https://www.cels.org.ar/web/ opiniones/con-mis-hijos-no-te-metas-la-expresion-de-deseo-que-choca-contra-la-legalidad/ 
a instalar en la opinión pública el tema y generar consensos sobre la necesidad de una Ley donde el Estado reconozca la identidad de género autopercibida de las personas trans en el país.

Estos avances interpelaron al colectivo travesti y trans platense, la Facultad no solo se convertiría en la pionera respecto a estos reconocimientos, sino también sería la primera gran aliada quien posibilitó y formó parte de la construcción de OTRANS- La Plata. Desde sus inicios hasta la actualidad, la Facultad sigue contribuyendo al sostenimiento del espacio físico, junto a otras articulaciones, que han ido consolidando alianzas estratégicas de reciprocidad:

Una vez hicimos una marcha en plena veda electoral, marchamos solas sin ningún acompañamiento de ningún partido político, sindicato o agrupación estudiantil. Recuerdo que solo nos acompañó Rosita Bru, de la Asociación Miguel Bru. Cuando llegamos a 4 y 59 entró a la comisaría novena junto a C; nuestra presidenta a hablar con el comisario de turno. Mientras todo eso ocurría había policías que nos filmaban del primer piso, nos sacaban fotos. Creo que éramos como 50 chicas trans $(K C)$.

\section{Plan Patria Grande: hacia el proceso de regularización migratoria}

La mayoría de las entrevistadas admiten no tener su DNI argentino, es decir, desde el momento en que se arraigaron en la Argentina no han podido regularizar su situación migratoria. Es preciso explicar que la ley migratoria 25.871 permite realizar la regularización migratoria a personas que pertenezcan a países del Mercosur y asociados, sin ningún tipo de obstáculos, si cumplen con todos los requisitos que exige el ente regulador a cargo de la Dirección Nacional de Migraciones (DNM). Uno de ellos es no tener antecedentes penales en el país de origen o de destino.

Obtener el DNI argentino con la categoría de radicación permanente, tarda dos años. Cumplimentar este proceso tiene al menos tres etapas bien definidas. El primer trámite, consiste en llevar todos los requisitos que exige la DNM y pagar la tasa migratoria, allí se les otorga un documento llamado precaria, que como su nombre lo indica, dura solo tres meses. Luego hay que regresar a las oficinas de migraciones para gestionar el DNI con la categoría de temporaria, que se extiende con validez de dos años. En el último tramo, si todos los papeles están en regla, la cartera del ejecutivo a cargo de la Dirección Nacional de Migraciones, otorga por expediente, una resolución con la radicación permanente. Este trámite es el mismo para cualquier migrante que tiene que regularizar su situación en el país.

Tengo la radicación permanente, que me tardo años hacerlo, pero el DNI con mi nombre de mujer todavía está en trámite; así que no me queda otra, tengo que andar con ese. 
No tengo el que tenga mi verdadera identidad de género, me costó mucho tiempo obtenerlo, pero lo malo es que te hacen pasar vergüenza llamándote siempre por el nombre masculino, por eso muchas chicas no lo hacen $(T)$.

Tengo mi DNI argentino con mi radicación permanente, pero con el nombre masculino. Hice el trámite hace un año y medio para el cambio de nombre y género, y hasta el día de hoy, no puedo obtenerlo. Cada vez que iba algo faltaba, lo hacía y siempre veo que ponen una excusa, creo, para no darme, así que sigo esperando (R).

En el 2012 comencé a tramitar mi DNI. Fui a migraciones a hacer los trámites, pero con el nombre registral, masculino, no me daban pelota. A mediados del 2012, integro OTRANS, fui con $K$, ella me empezó a hablar sobre la organización y me interesó. Fui, escuché hablar sobre nuestros derechos, sobre como intervenir con la policía para que no nos violenten, que no nos persigan porque siempre hemos sido perseguidas. $Y$ allí empezaron a ayudar a las compañeras para tramitar el DNI, lo hice, conseguí que me dieran el DNI argentino, el permanente (KC).

Sin embargo, para las travestis y trans migrantes el recorrido es más largo, y muchas veces, impregnado de la violencia institucional encarnada en les efectores y funcionaries del Estado: a partir del llamado por el nombre de pila asignado al momento del nacimiento (al no contar con el cambio registral en su país de origen). Luego, someterse al escarnio público: otros migrantes que se encuentran haciendo la fila para realizar el mismo trámite voltean con asombro y con una mirada condenatoria, resultado del prejuicio y la discriminación hacia el colectivo.

Esta situación de hostigamiento y exposición obliga a varias de las charapas a abandonar, en este tramo, el trámite. Este primer paso es el filtro, que se presenta como barrera a trascender. En los trámites subsiguientes que tienen que realizar durante los dos años que conlleva obtener la radicación permanente, se encuentran sometidas al arbitrio y exigencias discrecionales de las instituciones del Estado.

Los mecanismos institucionales refuerzan la exclusión, por lo tanto, son pocas las que se someten a este proceso y logran obtener el documento de identidad. Lejos de ser el último tramo de esta carrera llena de obstáculos para las travestis y trans migrantes, para poder cambiar en el DNI, su nombre pila y sexo, además, deberán realizar otro trámite. Primero tendrán que llevar una carta emitida por el consulado peruano en Argentina, donde quede expresado que no existe ley de identidad de género en su país de origen. A esto se adjunta un formulario que provee la Dirección Nacional de Migraciones, donde se llenan datos para dar cumplimiento a la Ley de Identidad de Género 26743 y cambiar el nombre y sexo registral, por el nombre y género autopercibido. Mientras que otros trámites quedan 
truncos, porque han sido observados debido a que tienen antecedentes penales.

Después hice el otro trámite para que me respeten mi identidad de género autopercibida, así que hoy tengo por fin un documento que exprese mi identidad y mi género real, gracias a la organización lo logré. Ahora me siento más segura con mi cambio de género en el documento de identidad. La gente ve el DNI y es otra cosa. Porque me identifico como mujer trans, migrante y de pueblos originarios. Pero tarda un montón, y no todas lo tenemos. De todas las charapas que conozco, que somos como 70 en La Plata, solo 4 tenemos el nombre de mujer en el DNI, las demás ni siquiera tienen el DNI permanente. Hay algunas que no les interesa hacerlo, y a otras se le dificulta mucho, porque tienen causas judiciales, porque estuvieron presas. Es muy complicado todo (KC).

Como señala nuestra entrevistada, la mitad de las compañeras pudo obtener su documento argentino con radicación permanente, y sólo cuatro han sido beneficiadas con la ley de identidad de género. Las demás, al no tener DNI argentino, se dificulta su acceso a la salud, a la educación y al trabajo formal, como así también, poder acceder a cualquier política pública, como el Programa Ellas Hacen ${ }^{35}$, entre otras.

Entendemos que la migración es un componente distintivo de esta asociación, debido a que un $85 \%$ de sus integrantes son pertenecientes a Perú, y en menor medida, a Ecuador; lo que contribuye a la conformación de subgrupos, donde se pone de manifiesto las pertenencias identitarias en relación con la nacionalidad. En este contexto, las charapas crean un lazo social entre las que son pertenecientes solo a la selva peruana. Difícilmente integran en su grupo a las peruanas de la costa o la sierra, como tampoco a las de otros países, incluidas las argentinas que integran el espacio. Esta fragmentación, en algunos casos, constituye un obstáculo en los modos de organización colectiva.

\section{La migración como derecho humano}

EI DNU 70-201736, significó un retroceso en materia de derechos humanos para les migrantes en Argentina. Esta normativa va a contribuir a la estigmatización social, el rebrote de discursos xenófobos, racistas y, particularmente, va a criminalizar las identidades traves-

35 Es un programa del Ministerio de Desarrollo Social de la Nación que ofrece oportunidades de trabajo y formación a las mujeres y femenidades travestis y trans en situación de vulnerabilidad. Ellas Hacen trabaja en el acompañamiento a las mujeres para que puedan terminar sus estudios y promueve su acceso a estudios terciarios y/o universitarios: https://www.argentina.gob.ar/desarrollosocial

36 Este decreto aún sigue vigente, el cual propicia una política de selectividad, que pone a las personas en permanente sospecha: http://www.migraciones.gov.ar/pdf_varios/residencias/Decreto 70-2017.pdf 
tis y trans migrantes. Si bien OTRANS- Argentina, desde sus inicios, trabajó en contra de la violencia institucional, ejercida por las fuerzas policiales y la falta de acceso a la justicia; en este periodo profundizará su trabajo territorial debido al incremento exponencial de detenciones arbitrarias, vejaciones, torturas y muertes de compañeras charapas en situación de encierro. En este sentido, acentúan el reclamo y visibilizan la situación de las travestis y trans privadas de su libertad, en general. Y en particular, el doble marcaje por cuestiones de identidades de género y migración; es decir el perfilamiento, entendido como la persecución específica de un grupo de personas que comparten las mismas características: personas travestis y trans migrantes del cono sur $^{37}$.

En términos generales, el decreto introduce impedimentos concretos para el ingreso y permanencia de migrantes en el país, acelera los trámites de expulsión reduciendo las garantías procesales de las personas, vulnerando el derecho de defensa; elimina la unidad familiar como condición para evitar la expulsión, y restringe el acceso a la nacionalidad argentina.

El decreto está dirigido mayormente a evitar el ingreso de migrantes y facilitar los mecanismos de expulsión de aquellos que cuenten con antecedentes penales ampliando la posibilidad de hacerlo sin tener en cuenta la realidad de los migrantes, sus lazos con el país, el arraigo en Argentina, los contextos familiares y la posibilidad de desmembrar una familia. (...) la normativa amplía el concepto de antecedentes penales vulnerando los derechos de los migrantes (Amnistía Internacional. Algunas consideraciones sobre la modificación de la Ley de Migraciones: Decreto de Necesidad y Urgencia 70/2017. p.1).

Esta medida va a generar un cuestionamiento al poder político por parte de las organizaciones de migrantes y organismos de derechos humanos. Allí, las militantes de OTRANS Argentina van a tener una participación destacada junto a la Red de Migrantes y Refugiadxs en Argentina, a cargo de Lourdes Rivadeneyra, una organización creada en el año 2003 para promover los derechos humanos, civiles, políticos, económicos, sociales y culturales de las personas migrantes, refugiadas y sus familias residentes en la República Argentina, teniendo en cuenta la perspectiva de género y el empoderamiento individual, familiar y comunitario.

37 La prueba por estadísticas se utiliza para probar las prácticas de perfilamiento discriminatorio indirecto, es decir, “...aquellas que aparentemente son neutras pero que sin embargo están poniendo en 'desventaja particular' o tienen un 'impacto desproporcionado' sobre un grupo de personas (...) en base a uno o varios motivos prohibidos de discriminación" Informe de Perfilamiento - del medio OTRANS ARGENTINA: Impacto negativo desproporcionado de la ley 23.737 sobre mujeres trans y travestis privadas de su libertad en las cárceles de la provincia de Buenos Aires (OTRANS ARGENTINA- 2017). 


\section{Hacerse visibles: el feminismo, ese lugar incómodo.}

El 2013 va ser una fecha clave, se va a ir cristalizando la alianza estratégica de las travestis y trans con un sector importante del feminismo y el movimiento de mujeres, quienes comprenden que la lucha era colectiva, amplia y diversa, porque tienen el mismo opresor: al patriarcado y al capitalismo. Por primera vez, se crea un Taller de Mujeres Travestis, Transexuales y Trans en el marco del XXVIII Encuentro Nacional de Mujeres (ENM) ${ }^{38}$ realizado en la provincia de San Juan. Este hecho es el correlato, posterior, a la sanción de la ley de Identidad de Género (2012).

Previo a este acontecimiento histórico, algunas travestis y trans como Lohana Berkins entre otras, venían participando y habitando cada año el ENM. Sin embargo, algunos sectores del feminismo conservador y radical, en varias ocasiones, intentaron expulsarlas con argumentos biologicistas. El objetivo era obturar su participación política en los debates del Encuentro. Aquellos actos discriminatorios no fueron acompañados por parte de todo el feminismo; algunos sectores repudiaron e, incluso, cuestionaron el falso carácter resolutivo que pretendía arrogarse la Comisión Organizadora.

En ese marco, las charapas junto a su organización OTRANS van a participar, ininterrumpidamente, en los ENM cuyo espacio se va a constituir, por un lado, en un escenario político de debate, reflexión y armado de agenda del colectivo a nivel nacional. Allí llevarán sus demandas concretas para sumar a la lucha y potenciarla, desde un enfoque interseccional, temas como: la problemática de la migración y la etnia; las detenciones arbitrarias y su trabajo territorial sobre las travestis y trans privadas de su libertad, en las cárceles de la provincia de Buenos Aires y el ámbito federal; y el incremento de los travesticidios y transfemicidios, entre otros.

Por el otro, surge la necesidad de construir un espacio federal, capaz de contener a organizaciones de travestis y trans ya existentes, que conserve su propia identidad, y la construcción de una agenda política propia, que dé cuenta de cada uno de sus contextos y demandas territoriales de base. Es este el escenario donde empieza a gestarse un nuevo espacio que tenía características y dinámicas específicas, a diferencia de otras organizaciones. Este sería el resultado de un devenir potente, un encuentro de travestis y trans de diferentes provincias del país, que históricamente fueron formándose y accionado desde sus propios territorios y que, año a año, aparecía de manera descollante como un nuevo cuadro político.

38 El Encuentro Nacional de Mujeres (ENM) es un movimiento sociocultural, feminista y masivo, realizado anualmente en Argentina desde 1986. Desde sus inicios, tuvo como objetivo principal las demandas por la creación de políticas públicas, y la exigibilidad al Estado por el cumplimiento de las leyes vigentes que rigen en el marco nacional e internacional. 
En el 2014, el XXIX ENM se realiza en Salta capital. Lohana Berkins, va a estar como moderadora oficial, allí una de las figuras que destaca con una potencia particular en su alocución va a ser Casandra Sandoval, quien irrumpe con una demanda sentida desde su experiencia y trabajo militante en ADISTAR Tartajal, con la impronta de las travestis y trans de pueblos originarios. Allí también aparece con fuerza la figura de Bella Karola Macedo Flores, charapa integrante de OTRANS ARGENTINA, quien va a contribuir a la agenda con sus aportes del colectivo migrante radicado en Argentina.

En octubre de 2015, Mar del Plata va a ser el escenario del XXX ENM, donde Lohana Berkins, nuevamente, será una de las encargadas de moderar el Taller de travestis y trans. La participación va a ir creciendo, y se consolida las bases de un acuerdo consensuado entre todes: priorizar la palabra de travestis y trans, por considerar de vital importancia sus voces en primera persona, y aprovechar el espacio que promueve el Encuentro, una sola vez por año. Con amplia intervención en la lista para tomar la palabra, el espacio se dota de sentido y experiencias compartidas. Historias y trabajo de militantes que activan en cada territorio, como los testimonios de la violencia y la discriminación, que viven y transitan a diario. Allí también hay lugar para el llanto, que se hace presente como válvula de escape, a veces necesaria, y reparadora, el abrazo llega y el dolor es menos atroz, porque es compartido. Tres días de intenso intercambio y debate, que culmina con la elaboración de un documento final, resultado de cada taller, el cual será leído por una o dos travestis o trans; donde las demandas más recurrentes, giraban en torno al acceso a la educación, salud y trabajo.

En ese Encuentro, Lohana y sus compañeras esperaban a la activista Diana Sacayán, quien fue la impulsora y artífice de la ley de cupo laboral travesti trans en la Provincia de Buenos Aires, sancionada en septiembre de ese mismo año. Terminada la jornada, la noticia por el travesticidio de Diana se conoce a través de los medios de comunicación.

El 10 de diciembre, asume a la presidencia Mauricio Macri, cuyo gobierno se va a caracterizar por inaugurar políticas de mano dura, las que se traducen en un retroceso en términos de derechos para los colectivos más desfavorecidos en el país, y en particular para las travestis y trans. Ante estas medidas, la coyuntura política exigió desde las bases territoriales, el armado de otras sedes en distintas ciudades del país, momento en el cual OTRANS La Plata, pasa a llamarse OTRANS ARGENTINA ${ }^{39}$.

39 Las bases empiezan a organizarse y se abren sedes en Ciudad Autónoma de Buenos Aires (CABA) y en Malvinas Argentinas (Provincia de Buenos Aires), quedando en La Plata la sede principal. La organización cuenta con una junta directiva que es elegida en un plenario general, entre las mismas compañeras. Asimismo, una coordinadora en CABA, y otra en Malvinas Argentinas. En el último año se triplicó la cantidad de travestis y trans empadronadas con sus respectivas fichas técnicas, como resultado del trabajo que cada una de las coordinadoras desarrolla en su territorio. Cada dos años hay elecciones para ocupar esos cargos, se eligen nuevas compañeras o se reeligen, por su destacada 
Meses después, el 5 de febrero de 2016, muere Lohana Berkins, producto de una enfermedad. Ese año, el ENM se realiza en Rosario en el mes de octubre. Su ausencia denota el vacío de poder que dejaba tras la construcción de una figura personalista.

En ese contexto, las organizaciones de la diversidad sexual conformadas, principalmente, por travestis y trans, junto al Centro de Estudios Legales y Sociales (CELS) redactan el Primer Informe sobre la Situación de los Derechos Humanos de las Travestis y Trans en la Argentina, que se presenta en octubre del 2016, en el marco del $65^{\circ}$ Comité de CEDAW, en Ginebra, Suiza ${ }^{40}$. Allí, las charapas participan de forma activa, y su organización brinda información sobre detenciones arbitrarias, persecución, hostigamiento, y vejaciones. Como también, aportan datos para un capítulo específico sobre personas travestis y trans migrantes, con información producida por OTRANS ARGENTINA, que será clave al momento de denunciar la inconstitucionalidad uno de los primeros Decretos de Necesidad y Urgencia (DNU).

La coyuntura, indefectiblemente, reconfigura el escenario y los modos de organización social y política del aún creciente movimiento travesti trans en Argentina. Por un lado, las organizaciones de travestis y trans y la Comisión de Justicia de familiares y compañeres por el "asesinato" de Diana Sacayán, convocan a la primera Marcha contra los travesticidios de forma no oficial reclamando justicia por Diana, primero en CABA en el mes de junio, y luego en Rosario de ese mismo año en el marco del ENM. Asimismo emergen nuevos, y no tan nuevos cuadros políticos, que no eran visibles a nivel federal: referentas como Ivanna Aguilera (Córdoba), Jem Rodríguez (CABA), Florencia Guimaraes García (La Matanza, Provincia de Buenos Aires), Alma Fernández (Tucumán y CABA), Vicky Izquierdo (Malvinas Argentinas, Provincia de Buenos Aires), Dana Valiente (Misiones, Garupá), María Eugenia González (Corrientes), Jackeline Romero (Rosario), Alba Rueda (CABA), Marcela Tobaldi (CABA), Angélica Zambrano Pesante (La Plata), Koral Chota Flores (La Plata), Vicky Minaya (La Plata), La Toni Domínguez (La Plata), Aradia García Mujica (La Plata), Ornella Infante ( Rio Negro) entre otras.

labor. La rendición de cuentas es esencial en la organización, da seriedad y transparencia.

40 Primer informe, sobre la violación a los derechos humanos de travestis y trans producido por una coalición de organizaciones de la diversidad sexual y de derechos humanos: https:/thinternet.ohchr.org/Treaties/CEDAW/Shared\%20Documents/ARG/INT_CEDAW_NGO_ARG_25486_S.pdf 


\section{Reconfiguración del movimiento: Somos Plurinacional}

El travesticidio de Diana y la muerte de Lohana fueron recibidas de forma intempestiva. Ambas muertes dejan un vacío político en relación a la conducción del movimiento. Sinembargo, no existió un interregno. Todo ello, sumado a la violación a los derechos humanos de las travestis y trans en la gestión de Mauricio Macri, resultaron elementos constitutivos para la reconfiguración del panorama político en las organizaciones, dando lugar al surgimiento de nuevos liderazgos, y agendas propias.

En respuesta al decreto 70/2017 anteriormente descripto, entre otros avasallamientos de derechos, el colectivo travesti y trans crea el 21 de abril de 2017 la Convocatoria Federal Trans y Travesti Argentina (CFTTA) ${ }^{41}$, presentada en el Instituto PATRIA, un espacio social y político que contó con la participación de organizaciones y liderazgos travestis y trans de 18 provincias del país: Salta, Jujuy, Chaco, Tierra del Fuego, Santa Fe, Córdoba, Corrientes, Formosa, Entre Ríos, CABA, Buenos Aires, La Rioja, Tucumán, San Luis, Mendoza, La Pampa, Misiones y Neuquén. Esta organización es, además, un claro ejemplo de cómo la Argentina fue para la región un modelo en materia de avances en derechos para el colectivo de Travestis, Transexuales, Trangéneros, Lesbianas, Gays, Bisexuales e Intersexuales (TLGBI) durante los gobiernos de Néstor Kirchner y Cristina Fernández. Asimismo, su creación remarcó la importancia de que las personas travestis y trans ocupen cargos de representación política.

Nosotras marchamos para repudiar la cárcel para los migrantes, que creo Macri. Fuimos varias charapas, lo hicimos con nuestra organización OTRANS ARGENTINA, y con la compañera Lourdes Rivadeneyra, que es la referenta de la Red de Migrantes y Refugiadxs en Argentina, donde pertenece también nuestra organización. Con ella articulamos varias acciones, desde las marchas, información sobre cómo hacer el DNI, hasta la ayuda con los alimentos $(K C)$

En el marco de la Convocatoria Federal Trans y Travesti, en diálogo con otras organizaciones formales e informales fue fundamental la propuesta de la Ley Lohana Berkins de Inclusión Laboral Formal para Personas Trans y Travesti ${ }^{42}$, como así también, la creación de la primera Escuela de Formación Política de Liderazgos Trans y Travestis «Lohana Ber-

41 Un espacio creado a nivel federal, como respuesta a las políticas neoliberales del gobierno macrista https://www.facebook.com/Convocatoria-Federal-Trans-y-Travesti-Argentina-1283630001717879/

42 La iniciativa pertenece a la legisladora Nacional Gabriela Estévez (FpV-PJ), la Liga LGBTIQ+ de las provincias y la Convocatoria Federal Trans y Travesti Argentina y prevé reservar el 1,5\% de los puestos de trabajo en el ámbito público nacional para personas trans. El proyecto de ley lleva el nombre de la histórica militante Lohana Berkins y tiene como objetivo la Inclusión Laboral Formal Trans y Travesti, y contó con el acompañamiento de 60 diputados y diputadas nacionales de nueve bloques del campo nacional, popular, democrático y feminista. http://www.resumenlatinoamericano. org/2018/11/09/argentina-presentaron-ley-lohana-berkins-de-inclusion-laboral-trans-y-travesti/ 
kins» ${ }^{43}$, lanzada el 30 de septiembre de 2017, en el Instituto Patria. El primer encuentro de la Escuela de Formación Política fue resultado del trabajo colaborativo entre integrantes de CFTTA, la Dirección de Diversidad Sexual de la Facultad de Periodismo y Comunicación Social de la Universidad Nacional de La Plata (FPyCS-UNLP), y la Comisión de Mujeres y Géneros del Instituto Patria, a cargo de Judith Said.

En el mismo año, en el marco del ENM en Resistencia- Chaco, las integrantes de este espacio federal, van a tener una participación destacada, con representación de liderazgos de 18 Provincias del país. Allí desde la CFTTA y, específicamente, desde OTRANS ARGENTI$\mathrm{NA}$, se denuncia con potencia las muertes de las travestis y trans en situación de encierro en las cárceles de la provincia de Buenos Aires. Se destacan las figuras políticas de Dalex Gallozo y Úrsula Saberece (Chaco), Angeles Zuñiga (La Pampa), Paula Arraigada (CABA), entre otras. A partir de esta coalición se va a convocar a la Segunda Marcha contra los travesticidios de manera no oficial.

En el 2018, el Encuentro Nacional se realiza en Trelew, y el taller de Mujeres Trans y travestis cuenta con una participación de 1500 personas durante los tres días por los que se extendieron las jornadas. Por tercer año consecutivo se denuncia las políticas de ajuste y mano dura del gobierno de Mauricio Macri, que impacta de manera hostil en el colectivo travesti y trans, los sectores populares y la feminización de la pobreza. Asimismo, y por segundo año consecutivo, se pondrá sobre tablas la necesidad manifestada por les integrantes del taller sobre cambio de nombre del Encuentro, por considerarlo que sigue reproduciendo un orden hegemónico y heteronormativo al no contemplar a otras identidades disidentes. Destaca la presencia de cuadros políticos potentes: Agustina Ponce (Mar del Plata), Melisa de Oro, Aradia García (La Plata) entre otras. En este marco, se va a realizar la primera marcha oficial contra los Travesticidios y Transfemicidios, promovida desde el ENM.

\section{Cambio de Identidad en La Plata: XXXIV Encuentro Plurinacional de Mujeres Lesbianas Travestis Trans Bisexuales y No bineries}

Observamos, en esta lectura retrospectiva de los ENM como el colectivo travesti y trans en Argentina fue consolidándose, en términos de organización social y política. En este contexto, las feminidades travestis y trans de OTRANS ARGENTINA, como parte de la CFTTA, va a participar activamente en la construcción de la agenda, y en la definición de las estrategias político- comunicacionales que se tejerán con otras organizaciones formales e informales para el cambio de nombre en Encuentro, y así contribuir al fortalecimiento del movimiento.

43 El objetivo de la Escuela de Formación política Lohana Berkins, es brindar herramientas teóricas, conceptuales, actitudinales y metodológicas para la incidencia política y el fortalecimiento institucional de las organizaciones travestis y trans. La misma está pensada desde una perspectiva en Derechos Humanos y adopta una metodología participativa: es https://www.institutopatria.com.ar/comenzo-la-primera-escuela-de-formacion-politica-de-trans-y-travestis-en-argentina/ 
Para las charapas, en particular, las alianzas estratégicas con el feminismo y el movimiento de mujeres, serán clave. Como así también su participación en el Encuentro Nacional de Mujeres y la Campaña "Somos Plurinacional"44, que se venía discutiendo desde 2017 en estos espacios.

A pesar de la resistencia de un sector de mujeres conservadoras, escudadas en prácticas violentas que reproducen el patriarcado hacia parte del colectivo de travestis, trans, y de mujeres de pueblos originarios, en el último XXXIV Encuentro en La Plata los días 12, 13 y 14 de octubre de 2019, se logró reconocer el tan ansiado cambio de nombre a Encuentro Plurinacional de Mujeres, Lesbianas, Travestis, Trans, Bisexuales y No Binaries:

Para nosotras ha sido motivo de desbordante orgullo saber que por fin pudimos después tres años, de tanto debate, visibilizar con más fuerza el cambio de nombre en relación a la plurinacionalidad y que tenga en cuenta las identidades lésbicas, trans, travestis, bisexuales y de género no binarie. Es maravilloso saber que une siempre lucha por espacios más justos, pero también por el reconocimiento respecto al cambio de identidad (K).

Este gesto simbólico implicó una conquista política trascendental para el colectivo, puesto que, a través de éste se visibilizan las disidencias sexo-genéricas en su interseccionalidad con la pluriculturalidad, de la que abrevan las feminidades migrantes, pero también, las de pueblos originarios, las afrodescendientes, entre otras identidades que habitan desde hace tiempo los Encuentros.

Este logro es el resultado de un trabajo colectivo, el feminismo es ese el lugar incómodo, incluso pone a prueba a todes, en relación a sus propias contradicciones. Porque como movimiento amplio, plural, diverso y horizontal, no escapan a algunas prácticas que tiene que ver con la violencia y, sobre todo, con el autoritarismo. Esos micropoderes que se enquistan en las prácticas de ciertas mujeres.

"Esto es parte de nuestra historia y nuestra lucha, da cuenta de cómo las chicas trans y travestis migrantes y de pueblos originarios le ponemos el cuerpo día a día. Estamos re felices de haber cambiado el nombre del Encuentro, en la ciudad donde se funda nuestra organización OTRANS ARGENTINA (MS).

Esto es lo que nosotras venimos cuestionando y luchando, por un lado, en relación al coIonialismo de nuestras cuerpas, nuestras mentes, de nuestros saberes, la denostación de nuestras prácticas por un sector que es blanco que ha visto y que lo sigue haciendo, vien-

44 Campaña creada para visibilizar e instalar el reclamo por el cambio de nombre, de los Encuentros Nacionales de Mujeres a Encuentros Plurinacionales de Mujeres,lesbianas, travestis, trans, bisexuales y no binaries: https://somosplurinacional.wordpress.com/ 
do nuestras vidas como vidas que no son dignas de vivirlas. Por lo tanto, no son vidas que pueden expresar sus demandas en el ámbito público, pero yo creo que ahí hemos dado un trabajo enorme, durante un año en La Plata desde todos estos mecanismos de este grupo de mujeres que se ha apropiado de estos 33 años de Encuentros, de la Comisión Organizadora, y que, a través de prácticas que intentaban dejarnos en todo momento por fuera. Una de nuestras compañeras de OTRANS tuvo que saltar la valla, para subir el escenario y pronunciar el cambio de nombre. Eso tiene un simbolismo muy fuerte y una potencia tan grande que tiene que ver con romper las barreras, correrlas, traspasarlas. Las barreras del colonialismo, del patriarcado, de la heteronorma, del racismo, de la xenofobia, y de todo esto que sabemos muy bien quienes hemos vivido históricamente en los márgenes, desde el lugar de la exclusión, sabemos que se pone en juego (K).

El colectivo travesti y trans de esta tercera generación, que va desde 2010 en adelante, ha atravesado un proceso de empoderamiento, pero también de construcción de alianzas con otres. Esto quedó evidenciado en el Encuentro de 2019 en la ciudad de La Plata. Allí se pudo advertir que el cambio de nombre respecto de la identidad plurinacional y las identidades sexo genéricas no normativas de travestis, trans, lesbianas, bisexuales y de género no binaries, es el resultado de la materialización de un trabajo organizado y estratégico de la militancia territorial de las travestis y trans, en la articulación con otras compañeras de organizaciones que venían con el mismo reclamo, a través de una práctica político- comunicacional clave. OTRANS ARGENTINA, junto a la Convocatoria Federal Trans y Travesti de Argentina, la campaña somos plurinacional, entre otres pudieron traducir y visibilizar sus reclamos en los medios de comunicación.

Hoy leía la Agencia de Noticias Sudaka TLGBI, el suplemento SOY y el suplemento de Las Doce, del diario Página 12 y todos daban cuenta del cambio de nombre del Encuentro Plurinacional de Mujeres, Lesbianas, Travestis, Trans, Bisexuales y de Género no Binarie en La Plata (R).

Si hay algo que hemos aprendido las travestis y trans, es a no tener ni patrón, ni marido y sobre todo a no pedir permiso, porque sabemos que las luchas, y las conquistas, las hemos conseguido como pueblo, son el resultado de la lucha social, de los sectores más desventajados. Y las travestis y trans sabemos muy bien que los derechos no se mendigan, ni se plebiscitan, sino que se otorgan. Por lo tanto, hay un poder a quien le tenemos que arrancar esos derechos $(K C)$.

En los Encuentros, la Comisión Organizadora solo tiene el trabajo de garantizar la logística, no tiene poder resolutivo, ni tampoco de toma de decisiones en torno a 
los cambios que se van dando. Quienes producen sentidos respecto los cambios y transformaciones, son les sujetes que participan en el marco del Encuentro. En este sentido, el cambio de nombre ha sido un acto de reconocimiento y reparación a la existencia de los cuerpos que históricamente transitan y habitan ese espacio.

Este feminismo que viene desde los bordes, con una riqueza diversa, que empezó a cuestionar al feminismo hegemónico, tradicional, reduccionista, autoritario, y biologicista, que no tiene en cuenta a las diferencias que expresa múltiples formas de expresiones que habitan este Encuentro. Esos espacios también le pertenecen al feminismo interseccional. Esta es una práctica que se da en torno a la disputa de poder, y que se evidenciará en el próximo en Encuentro, en la provincia de San Luis 2020.

Para nosotras es una conquista, pero el poder es algo que siempre se camufla y, de alguna manera, se reconfigura y aparece. Creemos que esto no va a ser tan fácil, en el sentido que estamos disputando poder y estamos disputando el poder a ese feminismo de manual, que no tiene los pies en el barro, a ese feminismo que mira desde el escritorio, que cree que nosotras tenemos que recoger las migajas. Entonces creemos que tenemos un enorme desafío las mujeres trans, travestis, las de pueblos originarios, las mujeres piqueteras, las mujeres afro, racializadas y migrantes. Creemos que tenemos que ir pensando estrategias, y también hacia adentro de quienes pertenecemos a diferentes espacios políticos; también hacer que se hagan cargo, porque eso me parece algo a trabajar y una demanda que se presenta en el próximo XXXV EPMLTTBGN (K).

La agenda política en esta última etapa de estudio, estará signada por el reclamo respecto a la exigencia al Estado de políticas públicas específicas en torno a los travesticidios y transfemicidios, como así también, la implementación del Cupo Laboral Trans en la Provincia de Buenos Aires, la sanción de una ley nacional sobre inclusión laboral travesti y trans: Lohana Berkins, el cese de las detenciones arbitrarias, vejaciones, tratos crueles e inhumanos, torturas y muertes, puntualmente en situación de encierro en las cárceles de la Provincia de Buenos Aires y el ámbito federal, la exigencia de la implementación del Programa Nacional de Educación Sexual Integral (ESI), y el efectivo cumplimiento de la Ley de Identidad de Género, en materia de salud de las personas travestis y trans. 


\section{No estamos todas, faltan las travestis y trans presas}

La reconfiguración política a la que aludimos, como resultado de la ausencia física de las referentas que venían marcando las directrices del movimiento travesti y trans en Argentina, contribuyó a la emergencia de otres actores políticos con capacidad de agencia, otras estrategias y demandas de lucha.

Las feminidades travestis y trans migrantes nucleadas en OTRANS ARGENTINA, serán fundamentales a la hora de aportar a la agenda del movimiento travesti y trans y a las marchas contra los travesticidios, el reclamo por las compañeras travestis y trans en situación de encierro, en las cárceles de la provincia de Buenos Aires y el ámbito Federal. Esta problemática, hasta su inscripción en el movimiento, no aparecería como un trabajo sistematizado, de allí surge la consigna que será uno de los baluartes en las subsiguientes marchas del colectivo: "No estamos todas, faltan las travestis y trans presas".

En este periodo la Asociación Civil, va a denunciar la falta de respuestas por parte del Estado, amenazas policiales a sus integrantes, y el incumplimiento de los fallos judiciales a favor del colectivo travesti y trans, conseguidos por la organización, a través de la presentación de habeas corpus en relación a detenciones arbitrarias, vejaciones, falta de acceso a la salud y la creación de pabellones para travestis y trans en la unidad penitenciaria $\mathrm{N}^{\circ} 32$ de Florencio Varela. OTRANS ARGENTINA, intervino y se presentó como particular damnificado, en las causas judiciales por tres muertes de travestis y trans migrantes en las cárceles $(P, A, D)$. Asimismo, elaboró sistemáticamente informes, los cuales fueron reportados a diferentes comités de la Organización de Naciones Unidas (ONU).

El 16 de mayo de 2016 en su visita a Argentina de Mutuma Ruteree, Relator Especial sobre formas contemporáneas de racismo, xenofobia y formas conexas de intolerancia de la oficina del Alto Comisionado de las Naciones Unidas (ACNUDH), la organización hizo entrega de un Informe sobre la violación a los derechos humanos de la comunidad travesti y trans migrante en La Plata. Mientras que el 17 de noviembre del mismo año, en la visita a Argentina de la Relatora Especial de Violencia Contra las Mujeres de las Naciones Unidas, Dubravska Simonovic, la organización le entregó un informe sobre Criminalización de defensoras/es travestis y trans de derechos humanos. Las conclusiones definitivas formaron parte de un informe de situación y recomendaciones que elevó al Consejo de Derechos Humanos de las Naciones Unidas para el 2018.

En marzo de 2017 OTRANS ARGENTINA reportó al Comité Contra la Tortura (CAT)- ONU, el informe sobre Perfilamiento, detenciones arbitrarias, torturas y muertes de personas trans y travestis en las cárceles de la Provincia de Buenos Aires. En sus recomendaciones para 
Argentina, el CAT expresó su preocupación por la discriminación por perfilamiento, malos tratos, las requisas vejatorias a personas transgéneros y travestis en la vía pública, entre otras. El 4 de marzo del mismo año recibieron junto al Frente de Organizaciones TLGBI La Plata, Berisso y Ensenada, y la Dirección de Diversidad Sexual de la Facultad de Periodismo y Comunicación Social de la UNLP, al experto independiente de la ONU contra la Discriminación y la Violencia por Orientación Sexual e Identidad de Género,Vitit Muntarbhon. Las exposiciones que se llevaron adelante fueron utilizadas para la escritura del Informe Internacional por los Derechos de las Personas según su Orientación Sexual e Identidad de Género. Luego de la mesa de trabajo, el experto asistió a la Cooperativa de Peluquería y Belleza Integral “Las Charapas” ${ }^{45}$ y mantuvo un diálogo con las compañeras travestis y trans que trabajaban allí.

En marzo de 2017 OTRANS ARGENTINA envió su reporte para el Tercer Ciclo del Examen Periódico Universal (EPU) del Consejo de Derechos Humanos de Naciones Unidas. El informe se refiere a las Violaciones a sus derechos humanos que enfrentan las travestis $y$ mujeres trans migrantes de otros países latinoamericanos en la Provincia de Buenos Aires (PBA), que concentra la mayor población del país (39\%). Se centran en la PBA porque es allí donde existe mayor documentación sobre estas violaciones, generada por el activismo travesti y trans. Analizaron dichas violaciones desde una perspectiva interseccional, como discriminación por identidad y expresión de género, condición migratoria y situación socioeconómica, debido a que se trata de un sector social históricamente marginado ${ }^{46}$. Por último, en mayo del mismo año, en su visita a Argentina del Grupo de Trabajo sobre Detenciones Arbitrarias (GTDA) de Naciones Unidas, OTRANS ARGENTINA hizo entrega del Informe sobre la situación de travestis y mujeres trans privadas de su libertad en la Provincia de Buenos Aires.

En este contexto se da un retroceso en materia de política pública respecto la derogación de la resolución del Ministerio de Seguridad, N¹181/2011, el cual establece el respeto a la identidad de género autopercibida tanto para las personas travestis y trans integrantes de las fuerzas policiales y de seguridad, como para la que eran detenidas. Por la puesta en vigencia de una nueva resolución N 1149/2017 por parte de esta cartera conducida por Patricia Bullrich, la cual establece un Protocolo General de actuación de registros personales y detención para personas pertenecientes al colectivo L.G.B.T, que criminaliza y da un marco de simulada legalidad a prácticas abusivas y violatorias de los derechos humanos.

\footnotetext{
45 Desde la perspectiva de la economía social, este proyecto se crea en 2016 por las integrantes de la Asociación Civil OTRANS ARGENTINA, debido a que el 99\% de la comunidad travesti y trans en La Plata, se encuentra en situación prostitución. Sin embargo, la cooperativa cierra sus puertas debido a la crisis económica que afectaba al país.

46 Este informe se refiere a las violaciones a sus derechos humanos que enfrentan las travestis y mujeres trans migrantes de otros países latinoamericanos particularmente en la Provincia de Buenos Aires (PBA), que concentra la mayor población del país (39\%): https://www.sexualrightsinitiative.com/sites/default/files/resources/files/2019-05/Informe-EPU-Argentina-OTRANS-Final.pdf
} 
El trabajo de la organización respecto a las denuncias realizadas en el ámbito internacional por la violación a los DD.HH del colectivo trans y travesti, lo realizaron con recursos propios, resultado de la autogestión. Sin embargo, pese al reclamo, el Estado argentino hasta diciembre de 2019, hizo caso omiso y continuó sin dar ningún tipo de respuestas.

OTRANS ARGENTINA, redobló sus esfuerzos y empezó a enviar proyectos a organismos que otorgan financiamiento a organizaciones de la sociedad civil. La primera vez que recibe recursos va a ser en el 2017, por parte del Fondo Internacional Trans (FIT), quienes

observan y evalúan que la organización realiza un trabajo sistemático en torno detenciones arbitrarias, malos tratos, torturas y muertes de personas travestis y trans privadas de su libertad. Este organismo internacional financia a movimientos trans a nivel global, y tiene como una de sus prioridades, trabajar con comunidades trans que enfrentan mayores niveles de vulnerabilidad desde una perspectiva interseccional, donde se contemplen otros factores -que se suman a la identidad de género- como la etnia, migraciones, clase, HIV, situación de encierro, entre otras ${ }^{47}$.

Hasta el momento, OTRANS ARGENTINA envió tres aplicaciones al FIT en 2017, 2018 y 2019, todas fueron aprobadas: el primero fue otorgado para gastos generales y obtención de la personería jurídica; el segundo para realizar un informe diagnóstico -periodo 20182019 sobre personas travestis y trans en situación de encierro en las cárceles de la provincia de Buenos Aires y el ámbito Federal48; y el último para la creación de la Agencia de noticias SUDAKA TLGBI ${ }^{49}$.

\section{Por una comunicación transfeminista, interseccional desde una perspectiva de De- rechos Humanos}

La Agencia de Noticias Sudaka TLGBI se constituye en un espacio conformado por comunicadores sociales trans, travestis y de géneros no binarios, con el objetivo de producir contenido comunicacional crítico que dispute el monopolio de los discursos hegemónicos y heteronormativos, instalados en las grandes Agencias de Noticias como "verdad

47 El Fondo Internacional Trans (FIT) es una iniciativa de activistas y financiada por donantes. El FIT tiene como objetivo aumentar la capacidad del movimiento trans para autoorganizarse y abogar por los derechos de las personas trans, la autodeterminación y el bienestar. https://www.transfund.org/?lang=es

48 Este informe comunica los resultados de la investigación que surge del compromiso de la organización OTRANS ARGENTINA con las mujeres trans y travestis privadas de la libertad en las cárceles ubicadas en la Provincia de Buenos Aires y en el ámbito Federal. http://otransargentina.com.ar/wp-content/uploads/2019/10/INFORME-DIAGN\%C3\%93STICO-ACOTADO-OTRANS-ARGENTINA.pdf

49 Esta Agencia está conformado por comunicadorexs sociales-populares, investigadorxs y activistas, trans, travestis y géneros no binaries y tiene como objetivo generar contenido comunicacional crítico, que desplace el monopolio del discurso hegemónico patriarcal y heteronormativo que instalen los grandes medios de comunicación como "Verdad absoluta". http://sudakatlgbi.com.ar/ 
absoluta". Produce notas periodísticas, crónicas, relatos, notas de opinión, análisis, material audiovisual, gacetillas, formatos digitales, sonoros, entre otros, desde una perspectiva de derechos humanos, género y diversidad sexual. Apuesta a generar un espacio plural que permita la comunicación popular, democrática y transfeminista, en la que se abordan temas de Argentina, Latinoamérica y El Caribe.

La Agencia de Noticias, es el resultado de las prácticas político-comunicacionales de las feminidades trans y travestis nucleadas en la Asociación de la Sociedad Civil OTRANS ARGENTINA y financiada por el Fondo Internacional Trans.

La gestión de medios alternativos en los colectivos más vulnerados, como el TLGBI, sirve de herramienta para la visibilización de sus agendas políticas desde una perspectiva de derechos humanos. Asimismo, la Agencia de Noticias Sudaka es una propuesta novedosa que permite la posibilidad de imaginar y establecer vínculos sociales-comunitarios, donde la construcción de sentidos con otres dispute el monopolio de la enunciación a los medios de comunicación hegemónicos.

Este medio es un espacio que apuesta por la producción de insumos comunicacionales que permitan democratizar la generación de discursos y prácticas en sus distintos formatos. Busca el reconocimiento y visibilización de las demandas y exigencias al Estado sobre políticas públicas a favor del colectivo TLGBI. A su vez a partir de la reconfiguración política, cultural, social y económica en los distintos planos territoriales (nacional, regional y mundial), en el contexto actual, se torna necesaria la presencia de personas del colectivo TLGBI en espacios de producción de insumos comunicacionales desde sus propias voces. Los discursos y prácticas político-comunicacionales del colectivo de la diversidad sexual, en los medios hegemónicos se ven desplazados a lugares de subordinación, reforzando la criminalización y estigmatización del colectivo.

\section{Diversidad cultural e interseccionalidades del movimiento travesti y trans en Argen- tina: otra forma de concebir el Sur}

La presencia de feminidades travestis y trans migrantes de países del Cono Sur en la conformación del movimiento travesti y trans en la Argentina, ha sido fundamental para ampliar la mirada con respecto a las personas migrantes en una sociedad donde la xenofobia y el racismo se evidencian de múltiples maneras en la vida cotidiana. Al interior del propio colectivo estas prácticas también las permean, como resultado de esta sociedad que se piensa eurocéntrica, patriarcal y capitalista, puesto que observamos cómo estos enunciados y otros mecanismos discriminatorios se replican entre pares.

है


El colectivo siempre ha estado compuesto por compañeras migrantes, tanto internas como externas. Y también han realizado valiosos aportes en términos de organización de las marchas, tanto del Orgullo TLGBI, como contra los travesticidios/ transfemicidios, y otro tipo de manifestaciones políticas a la hora de reclamar por sus derechos.

Por eso, es indispensable desarrollar los aportes de las personas travestis y trans pertenecientes también a comunidades de pueblos originarios. Reconstruir una historia común, y salvaguardar una memoria propia, pero, a la vez, plural, ancestral y universal. La sabiduría y riquezas, desde el punto de vista pedagógico, comunicacional y antropológico que ofrecen, es una de las fortalezas del movimiento travesti y trans en Argentina. Allí el trabajo que ha desarrollado Casandra Sandoval a lo largo de más de una década con comunidades originarias del norte de Salta, es uno de los escenarios más valiosos en la configuración socio-política del movimiento y del propio colectivo ${ }^{50}$.

Ser migrante es una cuestión mucho más compleja que lo que se percibe desde los marcos normativos del sistema social y jurídico. Ello apareció complejizado en consonancia con otras manifestaciones identitarias, como el lugar de origen y las identidades sexo-genéricas, fundamentalmente la identidad de género autopercibida. En este sentido, la presencia de las feminidades travestis y trans migrantes significó el cuestionamiento a esos saberes enraizados en la forma tradicional en que concebimos la educación, la manera en que comprendemos la familia, las tradiciones y los comportamientos que hemos asumido como naturales en nuestras formas de organización como sociedad.

Para lo cual, resultó necesario problematizar con una idea de la colonización que atraviesa cosmovisiones eurocentristas, racistas, excluyentes, donde las identidades travestis y trans quedan por fuera, como también las lesbianas, las negras, las migrantes, las originarias, entre otras. Pareciera que todos los espacios pertenecen a la blanquitud total, donde esa hegemonía siempre decide por sobre todas las demás. Y en esto tiene que ver la colonización en todos los espacios, por eso es necesario construir con otres que puedan, como afirman Florencia Saintout y Andrea Varela (2014), dar cuenta de unos modos en plural, en tensión, emancipadores de hablar y, de pensar lo popular no sólo en su carácter de subalternidad, sino lo popular empoderado, ganando batallas.

50 A través de Aredete, Asociación Regional de Trabajadores en Desarrollo, Casandra comenzó a transitar un espacio donde compartir experiencias y conocimientos propios, y adquirir nuevas informaciones. Fue una vivencia enriquecedora, porque hasta ese momento no se hablaba de comunicadores indígenas, de la noticia indígena o de la necesidad de un medio que hablara sobre lo originario y lo autóctono. Estas experiencias fueron claves a la hora de conformar futuros lazos de organización. 
Por lo anterior, no fue posible pensar y pensarse como parte de un movimiento sin entender primeramente el mundo que él mismo representa, con su complejidad, profundidad, riqueza y poder. Es por ello que entendemos el movimiento travesti y trans en Argentina como un gran mosaico de identidades, culturas y formas diversas de existencias plurales.

Argentina, históricamente, ha sido un país de migrantes europeos, pero las nuevas oleadas migratorias provienen fundamentalmente de Latinoamérica, teniendo en cuenta lo que significaron las políticas de privatización del menemismo en Argentina, las políticas neoliberales y de privatización de Alberto Fujimori en Perú, y las dictaduras cívico-militares en otros países de la región que recrudecen la migración.

La presencia de las travestis y trans migrantes del Cono Sur cuestionan esa construcción del Estado-Nación, en relación estrecha con las condiciones que experimentan los pueblos originarios. La pregunta por el "¿qué somos?" es también la invitación a replantearnos nuestra identidad latinoamericana. El desafío de repensar al movimiento travesti y trans, y la potencia que ello implica en términos de diversidad y pluralidad de experiencias, hacen que el movimiento sea un referente internacional, aún con sus fisuras y contradicciones.

De allí que uno de los retos primordiales sigue siendo combatir el racismo y la xenofobia, lo cual se ha convertido en una deuda del movimiento. Por otro lado, también debemos tener en cuenta las herramientas pedagógicas que nos permiten reflexionar y deconstruir estos remanentes del patriarcado, a los que sumamos el machismo. Para lo cual, será necesario, entenderlo en términos de regulación cultural, puesto que las culturas van regulando ciertas prácticas en determinados momentos, lo cual es posible transformar con herramientas reflexivo-pedagógicas que nos va a permitir dar cuenta de la riqueza del movimiento travesti y trans, y de los modos de trabajo, con el objetivo a nivel macro de erradicar la discriminación.

En suma, considerando las interseccionalidades, entendemos que la identidad de género representa una red de contención más fuerte que la migración a la hora de enfrentar la violencia institucional. En este sentido, debemos tener en cuenta la nostredad como categoría analítica. Prevalece una heteronorma, cuyo comportamiento es similar en los países de la región, respecto a las identidades de género travesti y trans. Son patrones que siguen, igualmente las fuerzas represivas, sea la policía, la gendarmería, etc., más allá de que la nacionalidad de la persona con identidad de género diversa sea argentina o migrante. La violencia tiene su causa en la expresión de la identidad de género de quien es violentada. La identidad de género, por tanto, lejos de dividir, es mucho más fuerte en criterios de unidad. 
El movimiento travesti y trans es muy joven. Al trazar una línea de tiempo, vemos como esa historia, aún se está construyendo. En este sentido, la forma de reencontrar o repensar la memoria está directamente vinculada a las estructuras que conforman su basamento como movimiento en el presente.

\section{Desafíos del movimiento travesti y trans en Argentina}

Durante los 12 años de kirchnerismo, las personas travestis y trans devinieron sujetas políticas, lo cual fue concretado, además, a través de la sanción de la Ley $26743 d e$ Identidad de Género en el 2012. Fue el resultado también del cuestionamiento a la hegemonía de la diversidad sexual, conformada por las organizaciones de lesbianas y gays, quienes "desconocían" las muertes de las feminidades travestis y trans producto de la persecución policial y las políticas neoliberales de los noventa.

En este momento histórico en la Argentina, tras los últimos 4 años de gobierno de la gestión de Mauricio Macri51, en el que se ha agudizado el faltante de medicación para las personas que viven con $\mathrm{VIH}$ y de hormonas para las personas que se encontraban realizando su tratamiento, el recorte de presupuestos; y no se ha llevado a cabo la implementación de la Ley de Cupo Laboral Travesti y Trans en la Provincia de Buenos Aires, ni la sanción de la Ley Nacional de Inclusión Laboral Travesti y Trans, el colectivo se enfrenta a desafíos importantes.

Uno de ellos, sin duda, es sensibilizar a la sociedad en su conjunto para lograr interpelar sobre el estado de situación de estas feminidades, puntualmente, sobre el incremento de travesticidios y transfemicidios ocurridos en los últimos años. En este sentido, es imprescindible retomar la idea de Susy Shock acerca de la importancia de ocupar un espacio en la "agenda emocional de nuestro país".

Otro de los desafíos para el colectivo travesti y trans que podemos identificar es el de la reparación histórica en términos de genocidio. En este sentido, es posible relacionar ambos conceptos, si tenemos en cuenta que aparecen hilvanados entre sí en las biografías y relatos tanto individuales como colectivos, los cuales venimos exponiendo. Esta reconfiguración alberga en sus orígenes al genocidio y su contracara, la reparación, elementos constitutivos a la hora de pensar la construcción de una historia del movimiento travesti y trans en la Argentina, desde una perspectiva de derechos humanos.

51 Este período terminó el 10 de diciembre de 2019, el 27 de octubre Macri, se presentó como candidato, buscando la reelección por un nuevo periodo de cuatro años, pero pierde los comicios electorales y gana la Presidencia Alberto Fernández. 
En los párrafos anteriores hemos intentado explicar, recurriendo a fuentes orales y escritas las prácticas político -comunicacionales de las charapas, y su inscripción en el movimiento travesti y trans en Argentina. Sin embargo, advertimos que las prácticas que el Estado argentino, llevó adelante sobre esta comunidad en particular, de personas travestis y trans, dan cuenta de un genocidio.

En este sentido es posible pensar la figura de transgenocidio, entendida como la muerte sistemática de personas travestis y trans, motivado por su identidad de género autopercibida, porque cumple al menos con tres de las cinco condiciones para que se considere un crimen de genocidio.

La definición de la Convención de la ONU para la Prevención y la Sanción del Delito de Genocidio, en este sentido, abarca:

"Cualquiera de los actos mencionados a continuación, perpetrados con la intención de destruir, total o parcialmente, a un grupo nacional, étnico, racial o religioso como tal: a) Matanza de miembros del grupo; b) Lesión grave a la integridad física o mental de los miembros del grupo; c) Sometimiento intencional del grupo a condiciones de existencia que hayan de acarrear su destrucción física, total o parcial; d) Medidas destinadas a impedir nacimientos en el seno del grupo; e) Traslado por la fuerza de niños del grupo a otro grupo (Convención para la Prevención y la Sanción del Delito de Genocidio, 1948, p.1)

Consideramos que las tres primeras características de la convención, no sólo se redujo a las travestis y trans, pero las políticas llevadas a cabo contra ellas serían paradigmáticas y muestran esta realidad con mayor crudeza. Su eliminación física, concentración y confinamiento a la situación de prostitución, el borramiento de la identidad travesti y trans a través de mecanismos de homogeneización y reproducción del sistema sexo/género: hombre y mujer, son algunas de las características que entendemos asume el transgenocidio.

La Ley de Identidad de Género se asume como una ley paraguas, porque es el primer gesto del Estado de reconocimiento a la identidad. A partir de ahí, lo que necesariamente viene es la forma de aplicación, sumando el ingreso a ser partes concretas y reales de la redistribución de las riquezas. Se observa el reclamo a la sociedad actual, y también a las instituciones del Estado, de la necesidad de asegurar estas conquistas, y ese reconocimiento debe empezar por aceptar cada una de las atrocidades que se cometieron contra una comunidad, en cada individuo que la conforma. La comunidad travesti y trans demanda ser gestora de sus propios espacios de modo integral, y que ello pueda impactar en las políticas públicas. Es imprescindible, para completar un panorama social inclusivo, que pueda ser parte del diseño del país, el Estado y la justicia que queremos construir en la Argentina. La 
ley de paridad en el Congreso de la Nación vigente, es una ley incompleta puesto que solamente contempla hombres y mujeres cis.

\section{La academia como desafío: hacer de lo ajeno un espacio propio.}

Entendemos a los espacios de educación formal, como homogenizadores de ciudadanes, perpetuadores del orden instituido, mediante conocimientos y prácticas heteronormativas. Desde la perspectiva que plantea Michel Foucault (2005), es a través del discurso que se determinan las prácticas y los modos de ser de los individuos. En este sentido, las disciplinas no están ajenas a tal construcción y representarán, para el autor, el margen de referencia donde las verdades se circunscriben. En otras palabras, para que haya verdad o conocimiento, éste debe ser avalado por alguna disciplina que, en tanto principio de control de la producción del discurso, fija sus límites por el juego de una identidad que tiene la forma de una reactualización permanente de las reglas.

En estos espacios formativos las voces travestis y trans fueron acalladas, invisibilizadas y excluidas. No se tuvo en cuenta sus prácticas cotidianas, sus ideas y experiencias como parte de la producción de un conocimiento subjetivo, diferente al orden existente. Se sesgó el intercambio de saberes y el debate como constitutivo de lo público, desconociendo y restringiendo su rol político de sujetes. Ese acallamiento es producto de lo que "uno hace cuerpo", según el sociólogo francés Pierre Bourdieu (1986), quien sostiene que "el cuerpo cree en lo que juega" (págs. 40-44).

Como señala Blas Radi, los desarrollos de estas teorías, leídas a la luz de una pregunta epistemológica:

Nos proporcionan un detalle de las tramas de relaciones desiguales en la producción de conocimiento sostenidas por la objetificación epistémica, la desautorización y descalificación epistémica, el extractivismo académico, la dependencia epistémica, la división del trabajo intelectual, la construcción de unx 'otrx', las lecturas inapropiadas y distorsivas, el uso instrumental, las representaciones totalizantes y estereotipadas, y la lógica colonial (Blas Radi, 2019, p.31).

Recordando a Paulo Freire, (1970) quien sostiene que toda práctica educativa contiene una dimensión política, pero a la vez toda práctica política contiene una dimensión educativa.

En este sentido, vale destacar que, 
(...) la construcción de las normas de funcionamiento del sistema escolar fue creando (...) aquellas anormalidades que habría que identificar, señalar, encapsular, normalizar o bien expulsar en el caso de que no fuera posible su asimilación. [En este sentido], en vez de preguntar qué tienen que hacer los individuos para adaptarse a dichos sistemas, cuestionar qué tienen que hacer las instituciones para garantizar el acceso pleno e igualitario de las personas trans/travestis a esos espacios [educativos]. Esto exige un profundo replanteamiento de muchos de los principios, las prácticas y los saberes que han sostenido al sistema educativo desde su concepción hasta la actualidad (Martínez y Vidal Ortiz, 2018, págs. 18 y 29).

Como señala Saintout y Varela, la institucionalización de las ciencias en la Academia, no sólo ha importado las teorías, sino que también ha importado las preguntas y los caminos para las respuestas:

\begin{abstract}
"Nuestras academias, como academias colonizadas, han sido hegemónicamente blancas y machos. Es hora de hacerlas mestizas, indias, mujeres, transexuales y putas. Necesitamos una academia otra, pero en el centro de una sociedad de iguales. Autorizarnos con respecto al saber tiene que ver con el poder. Hemos trabajado teóricamente la crítica a la idea de que el saber es poder. Hemos dicho que el poder nos permite definir un saber. Tal vez se trate de darnos cuenta del poder que tenemos para autorizar nuestros saberes desde el sur" (Saintout y Varela, 2014, p.114).
\end{abstract}

En este derrotero, algunas universidades reconocieron la identidad de género antes de que fuera sancionada la Ley de Identidad de Género ${ }^{52}$, lo cual fue significativo para la construcción de espacios propicios a la formación en términos de herramientas discursivas, del conocimiento y la diversidad de saberes y, al mismo tiempo, como un espacio de resguardo. Casandra Sandoval, por ejemplo, fue una de las primeras compañeras travestis en entrar a la Universidad a fines de los años 90. Es imprescindible reconocer cómo fue dándose ese proceso en el espacio académico, en articulación con la militancia.

Es la sumisión a través de la imposición de la vergüenza, que queda como remanente del colonialismo y la iglesia. Pensamos al Estado como una entelequia, una instancia donde se debe pedir un favor. Sin embargo, es quien debe producir políticas públicas. Eso, a la vez, propicia un proceso de aprendizaje y reflexión constante. El papel de la sociedad civil es exigir a las instituciones del Estado, intenten erradicar la discriminación, la exclusión, la estigmatización, la criminalización, la xenofobia, el racismo, la aporofobia, entre otras desigualdades. Esa es una de las riquezas del movimiento travesti y trans en Argentina, puesto que la prioridad en su agenda política ha sido históricamente la exigencia de ser tenidas en cuenta como sujetas políticas de derecho y el acceso a la plena ciudadanía.

52 Algunas facultades y universidades del país se inspiraron en el caso de la FPyCS-UNLP para replicar esta iniciativa en sus respectivas casas de altos estudios, como fue el caso de la Facultad de Bellas Artes de la UNLP, las universidades de La Patagonia Austral, del Comahue, Córdoba, UBA, entre otras. 
El movimiento travesti y trans en Argentina ha sabido reconocer quién debe ser su verdadero interlocutor: el Estado, lo cual pudo demostrarse con la verdadera conquista que significó para el colectivo la promulgación de leyes favorables, como la Ley de Identidad de Género y el Cupo Laboral Trans en la Provincia de Buenos Aires. 
A través de la lectura de tensiones, formas de participar, de repensar la inclusión, hablar y vincularse con les otres, fue y será posible para las feminidades travestis y trans migrantes peruanas, generar alianzas y estrategias que contribuyan a unificar una memoria colectiva, plural y polifónica. En la actualidad, se presenta el compromiso de participar de un presente histórico, fundamental para las futuras generaciones del movimiento travesti y trans en Argentina, y el resto de nuestra América. Una política de la desmemoria podría tener consecuencias negativas en relación al desconocimiento de la historia del movimiento, por parte de las nuevas generaciones de identidades travestis y trans.

Es una responsabilidad histórica y, sobre todo, ética y política, que consiste en deconstruir ese individualismo, que tiene un origen marcadamente patriarcal. La necesidad que se impone es la de transmitir una historia de lucha sistematizada, verbalizada, traducida en una epistemología transfeminista, como un museo itinerante de la memoria travesti y trans local, proyecto que OTRANS ARGENTINA viene desarrollando desde 2019.

La clave pasado/presente desplaza, así, la cuestión de los derechos humanos del plano de los derechos, y la ubica en la dimensión de los contextos y los discursos. Teniendo en cuenta los derechos humanos vistos desde sus lógicas de funcionamiento, definidas por aquellos universos discursivos legitimados, en mayor o menor medida en cada época, podemos afirmar que las narrativas que acompañan estas reconfiguraciones están siendo constantemente atravesadas por la coyuntura socio-política. En este caso, además, es posible comprender las problemáticas relacionadas con los derechos humanos desde sus interseccionalidades y, fundamentalmente, desde una perspectiva comunicacional crítica como la que la desarrollada en la investigación del estudio de caso sobre las charapas. Lo que significará, un valioso aporte a nuestro campo, puesto que el discurso por la identidad, la disputa por el espacio público y las exigencias por la legitimación de una manera propia de existencia, podemos valorarla en la medida en que pertenece, en igual forma, a los discursos que dinamizan y habilitan prácticas que marcan una impronta sobre las subjetividades y la identidad, y que fortalecen procesos de emancipación social. 

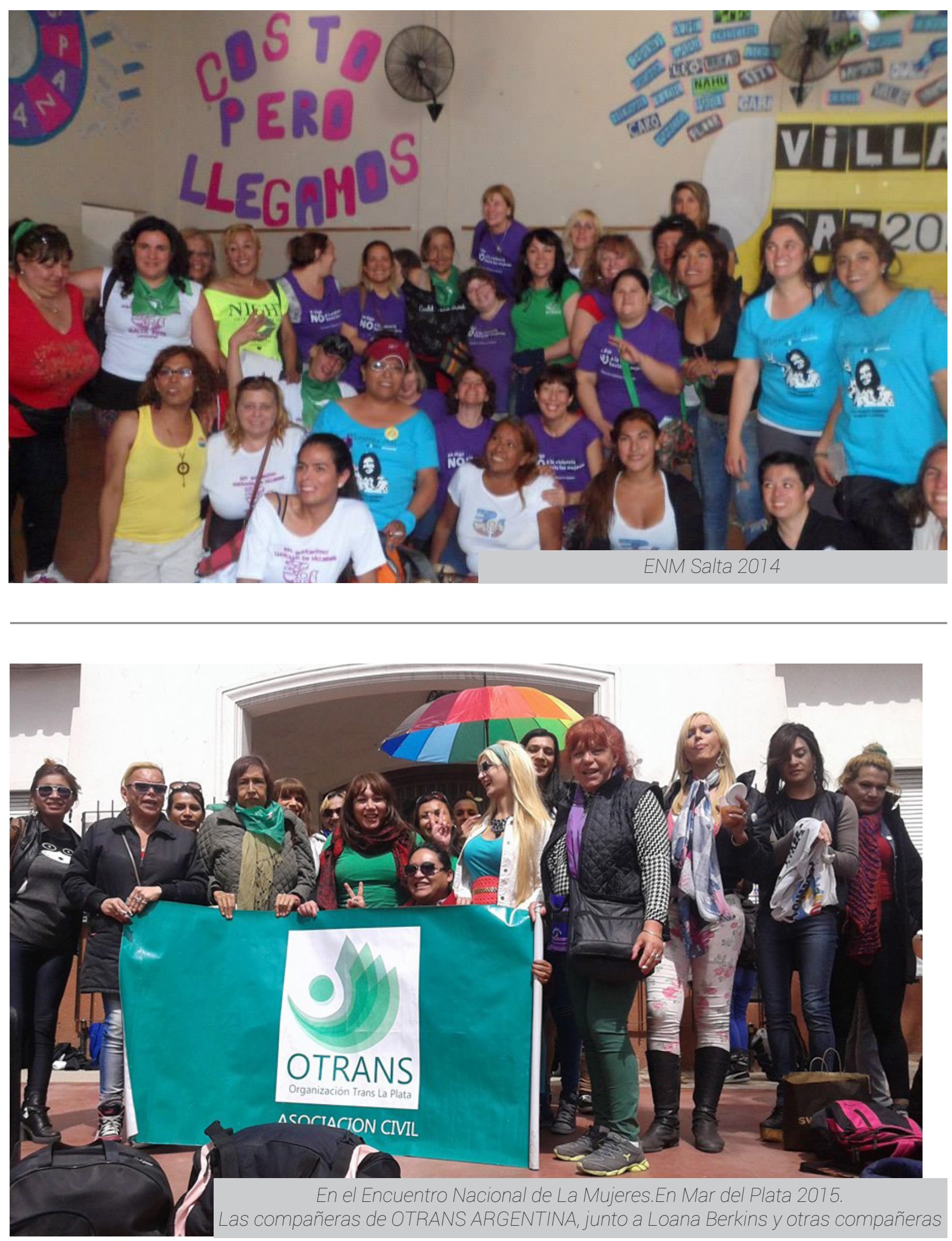

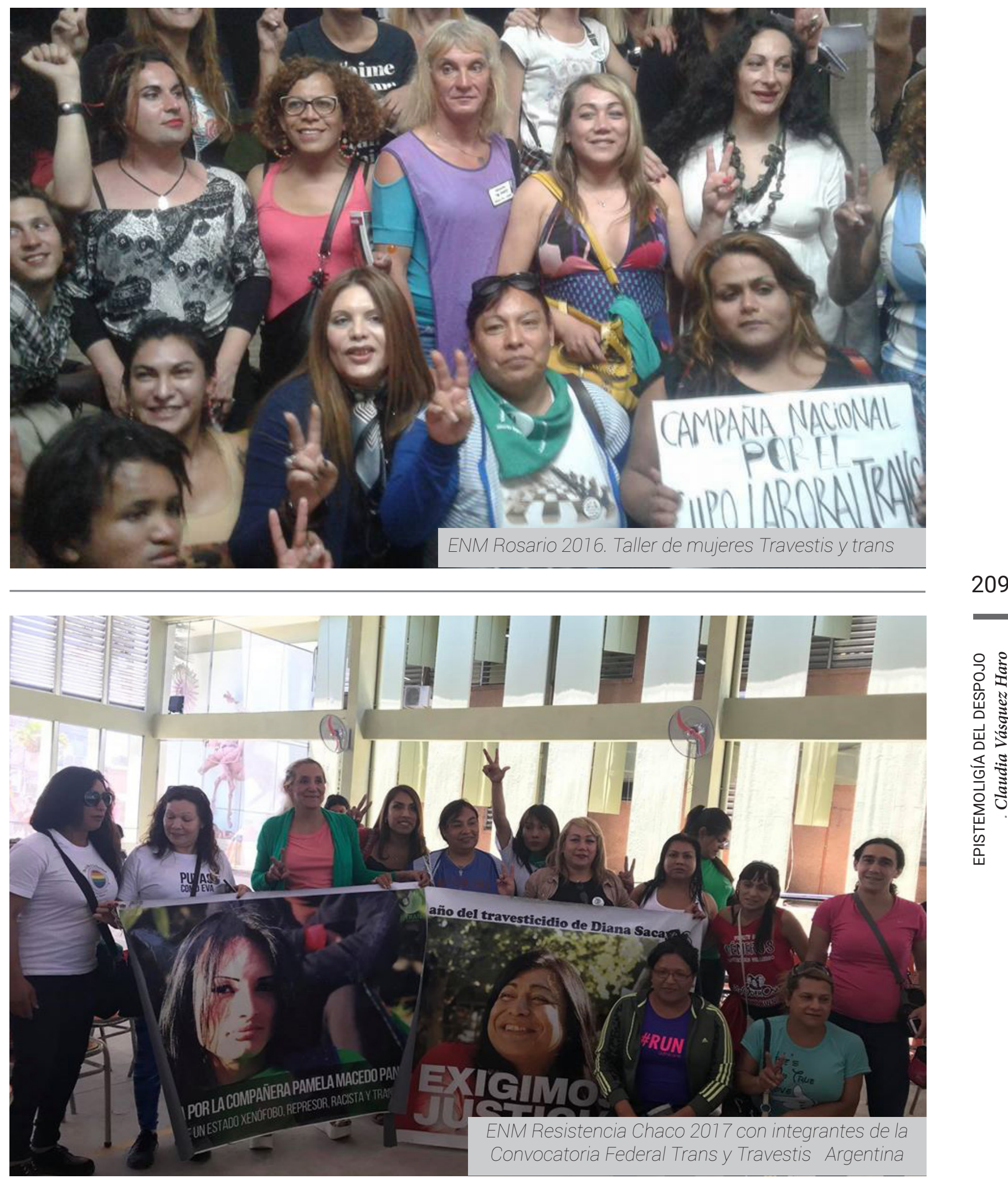

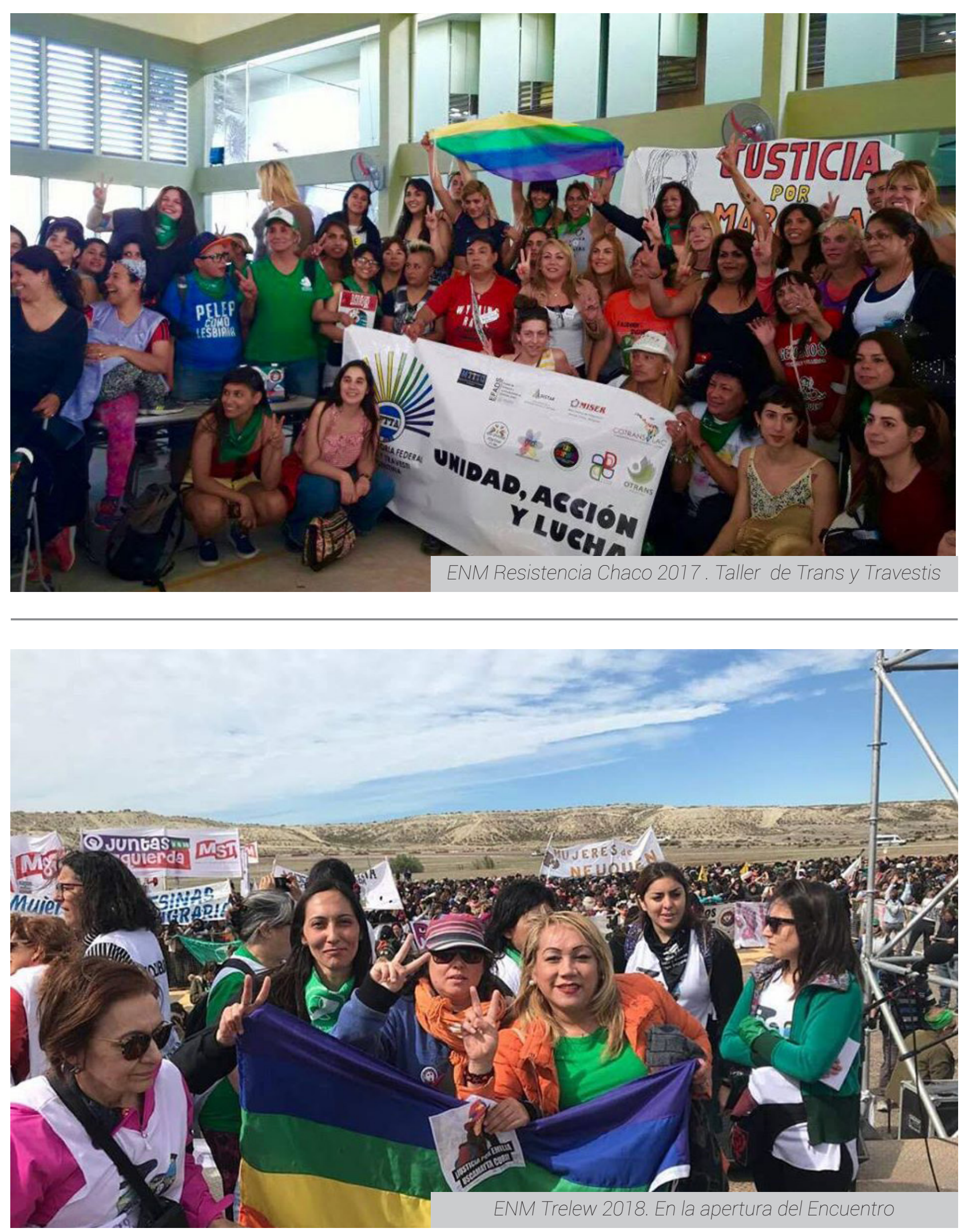

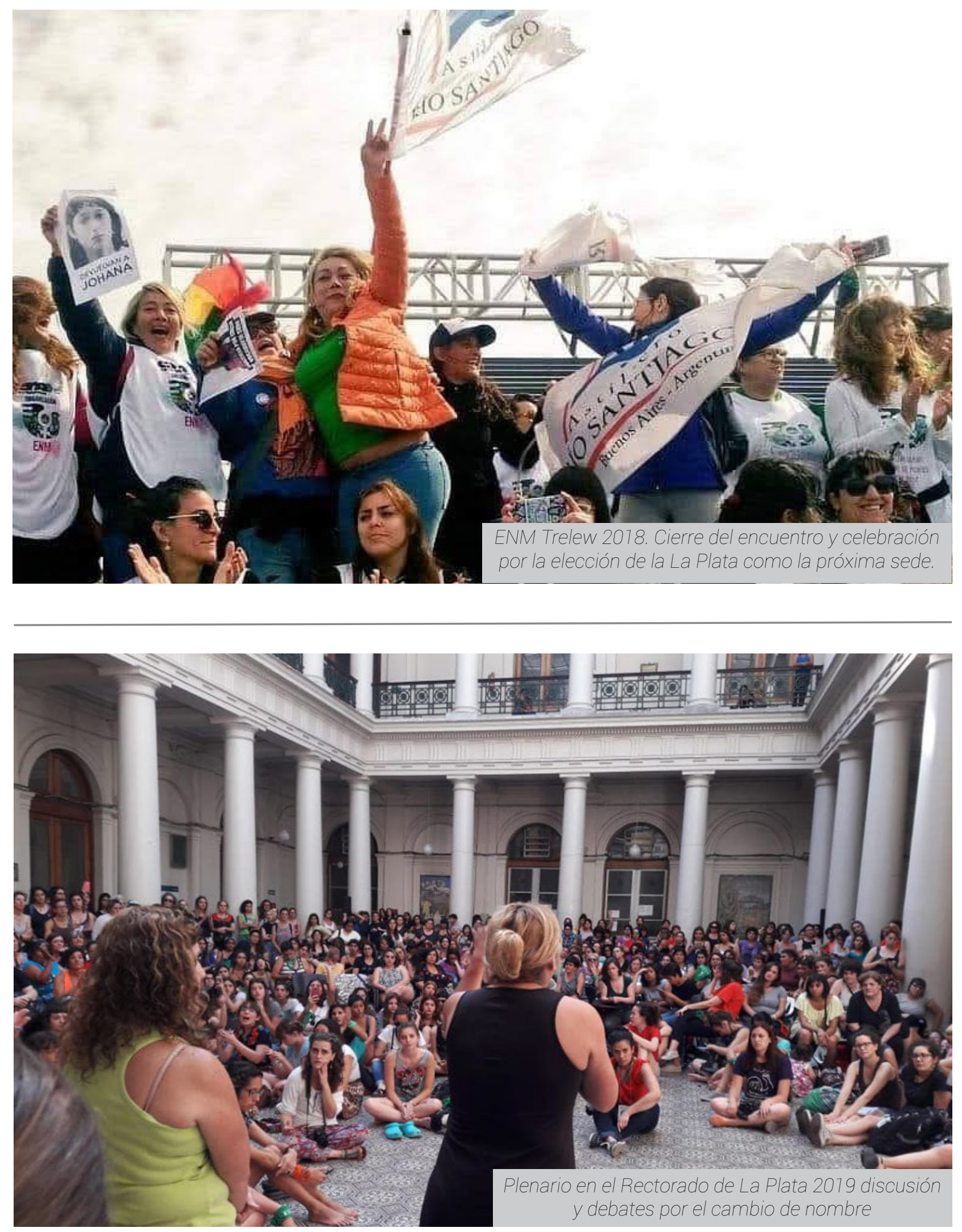

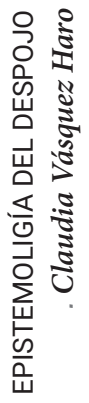




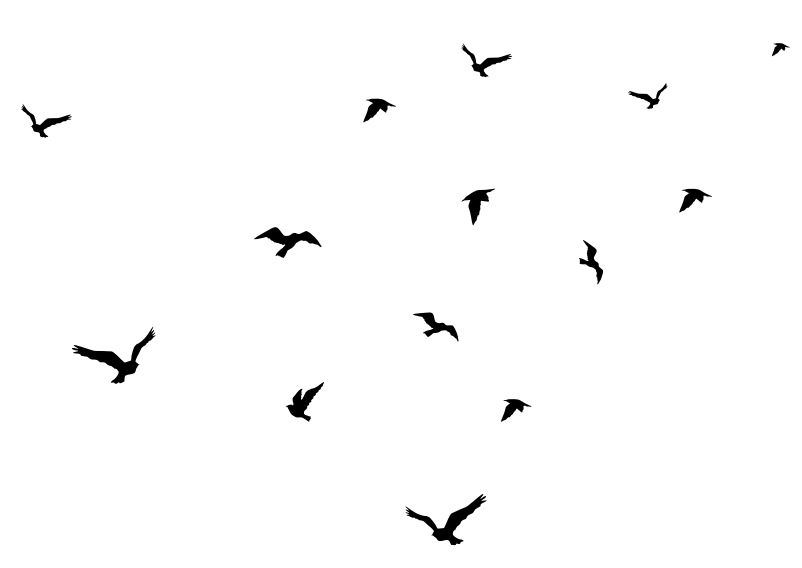

Identidades golondrinas desde una epistemología del despojo

Conclusiones Finales 
A lo largo de este proceso investigativo, nos propusimos dar cuenta de las prácticas político comunicacionales de las feminidades travestis y trans migrantes peruanas en la ciudad de La Plata: las charapas. En relación a ello, establecimos tres momentos analíticos: el inicio de su desarraigo en el país natal, el proceso migratorio y el arraigo en la Argentina.

En primer término, este trabajo exigió adoptar una mirada múltiple, compleja y de entrecruzamientos varios; atendiendo a la condición de común vulnerabilidad -la precariedad como humano- y la cadena de despojos que pudimos definir desde la perspectiva de Judith Butler, que padecen las sujetas de investigación, a partir de los primeros años de vida. De esta manera, y a través de un trabajo comprometido con el colectivo las charapas, pudimos dar cuenta cómo operó la maximización de la vulnerabilidad por parte del Estado, cómo tejieron sus resistencias y establecieron estrategias de coalición en alianzas con otres, para el reconocimiento de sus capacidades como sujetas políticas y de comunicación, las cuales generaron las condiciones para constituir colectivamente lo que conceptualizo como una epistemología del despojo.

De esta manera, advertimos como desde niñas, cuando inician el camino a expresar sus identidades de género autopercibidas, se origina "el conflicto", en torno a relaciones en el seno familiar, y las características propias que lo revisten. En la mayoría de los casos, pudimos dar cuenta cómo experimentaron violencia física y simbólica por parte de ciertos sujetos institucionales que les provocaron sus primeros marcajes. Estas prácticas "correctivas" heteronormativas se evidenciaron, en esa etapa de sus vidas, con el objetivo de regular "conductas", y disciplinar sus cuerpos descentrados o incongruentes con la norma. Prácticas que se reprodujeron con crudeza en sus hogares, en su paso por la escuela y otros trayectos educativos, en las comisarías, y en las calles de las ciudades donde transitaron su infancia.

Uno de los mecanismos de disciplinamiento y control del cuerpo que identificamos común a estas experiencias, es el escarmiento. Al respecto, percibimos el impacto psicosocial que éste genera: introyecta el miedo en la subjetividad de la víctima y, en les otres, colabora con la configuración de lo que provoca pánico o escándalo por el desorden que implica una afrenta a su moral pública. El escarmiento, tiene como finalidad última, aniquilar cualquier intento de asumir y expresar la identidad de género autopercibida. La reprimenda genera una carga emocional donde la culpa, se contrapone al deseo, y ésta las ubica en un lugar de inferioridad, y desventaja por no reproducir los mandatos establecidos por la cultura hegemónica heteronoramativa.

Estos mandatos culturales como pudimos analizar, sientan sus bases, por un lado, en el dogma vinculado a las creencias y los fundamentalismos religiosos; y por el otro, 
en un discurso biologicista patologizante, como presupuesto biopolítico subyacente a la administración y control (re)productivo de la especie humana. De tal manera que, en las instituciones educativas, sus experiencias estuvieron marcadas por prácticas violentas, donde se erige los discursos militares y religiosos en su formación, y el disciplinamiento anatomopolítico de sus cuerpos -; los cuales tienen por finalidad la producción de subjetividades dóciles y fragmentadas, a través de mecanismos de vigilancia, control e intensificación del rendimiento.

Por tanto, diremos que el punto de articulación entre las estrategias y tácticas biopolíticas y anatomopolíticas, radica en el control y regulación de la sexualidad como mecanismo de producción disciplinar del cuerpo. Dispositivos instrumentados, al servicio de producir una coherencia o correlación con el sexo biológico, acorde a las normas de un capitalismo global y voraz, que permea a través de la incorporación de ciertas tecnologías de adecuación.

En este contexto, observamos cómo a lo largo de la experiencia bajo estudio, que las charapas naturalizaron aquellas cuestiones que reproducen las relaciones, las ideologías y las formas propias de un sistema de dominación que sistemáticamente las niega e invisibiliza. Estas condiciones de vulnerabilidad resultan de la falta de políticas de discriminación positiva del Estado. Por consiguiente, al no garantizar una red de contención para salvaguardar estas vidas, se maximizan, discrecional y arbitrariamente, sus condiciones de común precariedad. Frente a ello, a ciertos sectores se les conferirá mayor reconocimiento como sujetos de derecho.

Así, las charapas desposeídas a una vulnerabilidad común, quedan expuestas a una condición política de precaridad en tanto vulnerabilidad maximizada, que implicará una exposición inducida a la violencia del Estado, por acción u omisión.

Todo lo cual, genera las condiciones para que las charapas abandonen sus hogares a temprana edad, en busca de lugares menos hostiles. En esa medida, en la totalidad de las entrevistadas, pudimos reconocer el tránsito por un mecanismo de desarraigo forzado durante esta etapa de sus vidas. Identificamos al respecto que, en ese marco, comenzaron sus primeras experiencias laborales no formales, tanto antes como después de dejar sus hogares; bajo condiciones de precarización laboral, y tal como evidenciamos, atravesadas casi en su totalidad, por el ejercicio de la prostitución. Sus trayectorias, estuvieron vinculadas a situaciones de violencia, sometimiento, destrato y discriminación por parte de sus empleadores, y particularmente, de los clientes a quienes les ofrecen un servicio sexual para sobrevivir. En esta etapa, la prostitución se presenta, indefectiblemente, como "destino" petrificado, único lugar donde se piensa y ubica a las travestis y trans, en tanto remota posibilidad de ser. 
Aquí advertimos un nodo central a lo largo de la investigación, ya que entendimos que todas comparten ciertos itinerarios, frecuentan espacios comunes y detentan, por antonomasia, el mismo destino. Ser travesti o trans se convierte en sinónimo de prostitución. La totalidad de las entrevistadas, expresaron que ingresaron en el circuito prostibulario por necesidad económica. Manifestaron que no hubo elección, sino una práctica de subsistencia que les permitió cubrir sus necesidades primordiales y, luego, las convirtió en sostén de familia. Así, este imperativo que adoptó la forma de hacer algo por obligación, es una práctica que se naturalizó en las charapas porque, como afirmamos, "el cuerpo cree en lo que juega". Ante tal estado de situación, no parece haber lugar para cuestionar el destino asignado, sino que se prioriza cubrir las necesidades básicas de subsistencia.

El cuerpo travesti y trans, observamos, abre potencialidades intertextuales y contingentes, que desestabilizan el binarismo del sistema sexo-género, que se ubica como una fabricación artificial y ficcional. Brega por la experiencia a la desidentificación, tanto de las categorías de hombre y mujer, como las de gay y heterosexual. Es un espacio heterogéneo, atravesado por una diáspora de sujetos abyectos, en dispersión, que, de un modo u otro, encarnan formas de vida no reducibles al binarismo, ni a los imperativos de la heteronormatividad.

Desafiar la reproducción de las prácticas, atributos y roles de género asignados para lo que se considera masculino y femenino, va en sentido contrario a la fenomenología predominante a la cultura heterosexual. De esta manera, dichas condiciones determinan la exclusión y una migración, implícitamente forzada, de las charapas. Advertimos que tanto la migración interna como externa se determinó, en sus vidas, por dos motivos principales: por razones económicas, -en la búsqueda de nuevas oportunidades-, y por la necesidad de reafirmar su identidad de género, en lugares menos hostiles. El viaje, para ellas se concibió como un acto de libertad para expresar y materializar su identidad de género: ser golondrinas, sin mecanismos que determinen o condicionen su deseo, e intenten disciplinar sus cuerpos, sexualidades e identidades no normativas.

En ese camino, identificamos cómo crean relaciones subterráneas y generan vínculos de confianza, los cuales les permitieron arribar a las ciudades de destino, a través de ciertas redes migratorias. Estas redes son conjuntos de lazos interpersonales que conectan a las migrantes, en las áreas de origen y destino, y habilitan la reconfiguración de lazos de parentesco no consanguíneos, de amistad y por compartir un origen común. Las mismas, dan cuenta de los beneficios que tiene para el desplazamiento hacia otros lugares, el tener contacto con personas que han pasado por un proceso similar. 
Así, las charapas dibujan un mapa subrepticio, basado en la experiencia de aqueIlas que las antecedieron, y cuyo trayecto implicó sortear los peligros y obstáculos que se desataron durante el proceso migratorio, cuando las fronteras, se presentan como el límite material de la ficción geográfica de las naciones, y restringen el ingreso o egreso a dichos territorios. La ilegitimidad de estos flujos tensiona los bordes haciendo, en su práctica, un trazado cotidiano y constante de los márgenes físicos y simbólicos. De esta manera, y siguiendo a Gloria Anzaldúa, definimos las fronteras más allá de lo geográfico y geopolítico; como un espacio que delimita, marca la diferencia y la similitud, y a la vez, produce intersticios e inaugura zonas disidentes.

A partir de la experiencia común del desarraigo, donde desplazaron los vínculos de consanguinidad, definimos que estas feminidades travestis y trans migrantes inscribieron nuevos vínculos entre madres e hijas putativas, desafiando los mandatos y roles de la familia nuclear. En esa cartografía, observamos cómo tejen y fortalecen los nuevos lazos de sociabilidad, lo que les permitió disputar y apropiarse del territorio que habitan, permanentemente.

El caso de las charapas, nos permitió entender el fenómeno de la migración desde una multidimensionalidad que se inscribe en lo social, sin ignorar los contextos más amplios y las múltiples articulaciones; a partir de las cuales podemos comprender el presente, siempre relacional y necesariamente provisorio que las atraviesa. En concordancia con el sujeto que plantea Alzandúa, híbrido e intersticial, fronterizo y periférico, las charapas se constituyen en tanto argamasa de entrecruzamientos varios, y de una vida en los filos de las fronteras. Una diáspora que se constituye por su pertenencia a los pueblos originarios y, a su condición de pobres, migrantes y mestizas.

Toda la experiencia descripta ha constituido en estas subjetividades, modos de resistencia, agencia y apropiación, por cuanto habilitaron procesos político comunicacionales basados, en una primera instancia, en estrategias de reterritorialización del espacio público, dibujando su propio mapa colectivo. A tales propósitos identificamos, en el arraigo a la Argentina y, más específicamente, en la ciudad de La Plata, un conjunto de prácticas informales de subsistencia como la prostitución, el vóley, la gastronomía y el entierro; que sedimentaron, en la praxis, a partir de prácticas formales, fundamentalmente, a la formación de OTRANS ARGENTINA y, el tejido de alianzas estratégicas con otres institucionales.

En este sentido, afirmamos que, las charapas, a través de dichas prácticas se apropian, disputan y resignifican el uso del espacio público. El vóley, como parte activa de sus vidas, implicó la posibilidad de arraigar sus tradiciones y costumbres que trajeron con la migración desde el Perú. Así, La Plata, capital de la provincia de Buenos Aires, resultó un lugar fecundo para conformar y consolidar un ritual de encuentro; y habilitar un espacio comunicacional y político para confraternizar, que todas tienen que cuidar. 
Además, la preparación y venta de comidas típicas de la región selvática peruana, en tanto materialización de un rasgo identitario de la cultura de cada una de las travestis y trans migrantes; significó, asimismo, la posibilidad de reconstruir y fortalecer sus vínculos sociales y culturales en el territorio. Estos rituales, les permitieron recrear las costumbres y tradiciones de sus pueblos, y rememorar prácticas ancestrales que se fueron transmitiendo, de generación en generación. Pero, además, la venta de comidas típicas será utilizada para recaudar fondos con los cuales las charapas pudieron llevar a cabo otros modos posibles de subsistencia. Y, de este modo, imaginar espacios de trabajo colectivos, autogestionados y sustentables capaces de generar una salida laboral, por fuera del circuito clandestino prostibular.

Finalmente, identificamos los velatorios y entierros como una práctica que, las charapas, también conservan como parte de sus tradiciones y culturas de sus pueblos. Desde la disposición del cuerpo, los adornos que ornamentan las salas, la comida que se sirve para quienes acompañan a les deudes; estos espacios se constituyeron, también, en territorios propicios para el tejido de redes comunitarias, y la construcción de estrategias colectivas frente a la gestión de sus muertes.

Por lo anterior, a lo largo de esta investigación procuramos brindar un aporte sobre las herramientas analíticas y conceptuales para abordar dichas prácticas político- comunicacionales, en donde advertimos el germen de una subjetividad colectiva. La misma, adquiere un valor inconmensurable, en términos sociales y culturales; por cuanto, las charapas confrontan y disputan sentidos desde los márgenes; construyen colectivamente prácticas subterráneas, gestadas en los bordes, visibilizando no solo su existencia, sino reconfigurando los modos posibles de existencia y aparición en el espacio público.

Con esto afirmamos que, desde la asunción de modos de producción alternativos, plantean un desafío en la producción de conocimiento con les otres, pensando juntes cuáles son sus problemáticas, y los posibles modos de transformar su situación. Así, reconocimos que la importancia de ese ser colectivo, anida en la gestación de modos otros que tienen relevancia para la consolidación de una práctica social y política. Una dimensión comunicacional que se constituye en un estar y hacer permanente en relación a otres.

Por lo tanto, las charapas se inscribieron e involucraron en prácticas político-comunicacionales informales de subsistencia, y transformaron ciertos condicionamientos, reconociéndose y autodeterminándose como sujetas de palabra y de acción. Para ello, planificaron cuidadosamente la producción de cada evento, en una dinámica que les permitió recuperar sus saberes y compartir sus experiencias.

Concebimos dichas prácticas comunicacionales junto a Nidia Abatedaga, en el modo en que inciden en la constitución del sujeto colectivo: las charapas. Un proceso que ocurre, por un lado, en el plano de la toma de conciencia de las sujetas, y por el otro, en el 
pasaje al hacer práctico donde actúan colectivamente y concertadamente, generando un cambio de actitud. De esta manera, revalorizamos la idea de una comunicación como práctica e intercambio de significados que se incorpora en las sujetas; facilitando la asunción de dichas formas a una conciencia, ya no ingenua, sino posibilitada por la configuración de intereses concretamente definidos, y la apertura de posibilidades para intervenir sobre su propia realidad.

Pero, además, las entendimos en tanto prácticas políticas, porque operan en un terreno de disputa por la aparición y apropiación en el espacio público, habilitando desde el hacer, modos diversos de enunciarse. Este nosotros colectivo, observamos se consolidó a través de un proceso performativo en el que, a la vez que genera el encuentro y la común-unidad con otras; en el mismo acto, rompe con aquellas hetero-significaciones con las que se des-identifican.

Asimismo, demostramos cómo aquella cadena de despojos que lleva a las charapas a migrar a la Argentina encontró, privilegiadamente, en la figura de OTRANS ARGENTINA, un sujeto político que se consolidó, también, a través de otras prácticas político-comunicacionales formales institucionales. Porque se constituyen y crean en coalición con otres; la organización de demandas al Estado por su reconocimiento como sujetas políticas y de derecho; y, por tanto, generan las condiciones para disputar su visibilidad, es decir, una esfera de aparición que les había sido sistemáticamente negada.

Estas prácticas se cimentaron en modalidades y estrategias que definimos en términos colectivos, plurales y subjetivizantes. A partir de acciones institucionales específicas, y desde un espacio de militancia y trabajo territorial formal, analizamos cómo las charapas planificaron y tejieron tales estrategias de resistencia y visibilización, demandas de derechos y políticas públicas, y memorias de la resistencia.

OTRANS ARGENTINA, fue fundamental, entre otros momentos que se describieron a lo largo de la investigación, en el marco de la disputa por el espacio público respecto a la reubicación de la zona roja platense, con el objetivo de denunciar la violencia institucional a la que eran sometidas en el ejercicio de la prostitución; de dar respuesta a las detenciones arbitrarias, el hostigamiento, las vejaciones y torturas a las travestis y trans por parte de la policía bonaerense; y en el cobro de coimas de algunos efectivos policiales. También para denunciar a los vecinos de calle $\mathrm{N}^{\circ} 66$, -quienes presionaban al poder político y al judicial de turno, a través de la exposición en los medios de comunicación, para reubicar la zona roja-; y a las bandas de civiles llamados motoqueros y bicicleteros, quienes salían por la noche a maltratar y agredir a las travestis y trans. 
Señalamos cómo, ante este tipo de políticas centradas en la individualidad, se promueve una ética de la violencia que tiende a la desarticulación. De allí que estos modos de implicarse en una condición de común vulnerabilidad, sea oportunidad, para estas sujetas de entender los cuerpos desde un marco de relacionalidad o interdependencia que las hace, ontológicamente, posibles. Admitir y reconocerse en ese nivel de opacidad, es lo que les permitió gestar un desplazamiento en la lógica de la performatividad; y así, romper el marco, filtrarse, colar su resistencia, y activar una política de la precariedad.

Para comprender la capacidad de agencia de estas sujetas políticas, recurrimos a la noción de núcleos de asociatividad de Adriana Archenti, por cuanto nos posibilitó abordar formas de organización/actuación/intervención que recuperan la trascendencia dada por los intersticios. Tal como fue descripto, éstos responden a relaciones no formalizadas que suelen coexistir con las formales, están insertas en ellas o ser colaborantes, lo cual, para el caso de las charapas, entendimos interviene sobre la incorporación, la promoción de derechos y/ o la condición ciudadana de migrantes.

En esa misma línea, comprendimos la identidad en tanto elemento en permanente construcción y reconstrucción -no como algo estanco o reificado-; sino que implica, un movimiento de identificación/des-identificación. De ahí que la identidad signifique un proceso de construcción del sentido atendiendo a un atributo cultural, o un conjunto relacionado de atributos culturales, al que se da prioridad sobre el resto de las fuentes de sentido.

Este desplazamiento nos permitió, de acuerdo con Verónica González, (re)pensar el exilio socio-corporal como una producción performativa que se traduce en el borramiento sistemático de ciertas subjetividades, mediante una pretendida normatividad y perpetuidad de argumentos morales; que condicionan cuáles son las 'sexualidades' posibles de aparición en el espacio urbano y operan, a través de su invisibilización, mecanismos de violencia arbitraria sedimentados en las estructuras institucionales legales que maximizan su vulnerabilidad.

De esta manera advertimos necesario, desde una lectura butleriana, no sólo que tales vidas sean reconocidas como tal, sino que la precariedad sea reconocida como un aspecto constitutivo de estas vidas. Porque es, justamente, en la performatividad donde se abre la posibilidad de un acto de insurrección política y de interpelación a tales normas. Desde allí que las charapas articularon sus demandas al Estado -quien tiene acciones con finalidad de poder y totalidad-, y disputaron el espacio público mediante ciertas tácticas, en una hábil utilización del tiempo, ante la carencia de lugares y espacios propios.

Por eso decimos que, en tales procesos, la construcción de alianzas estratégicas, fue fundamental, como lo fue su articulación con la Facultad de Periodismo y Comunicación Social de la UNLP, la Red de Migrantes y Refugiadxs en Argentina, entre otros. Asimismo, la creación de la Convocatoria Federal Trans y Travesti Argentina (CFTTA); donde OTRANS ARGENTINA cumplió un rol clave para la construcción de una agenda política propia y en la 
definición de las estrategias político- comunicacionales específicas. En el tejido con otras organizaciones formales e informales de la sociedad civil, destacamos la conquista por el cambio de nombre del Encuentro Nacional de las Mujeres (ENM), el cual desde 2019, pasó a denominarse "Encuentro Plurinacional de Mujeres, Lesbianas, Travestis, Trans, Bisexuales y Géneros no Binaries".

Allí inscribimos el aporte político del colectivo travesti y trans migrante en la Argentina, en general y, particularmente, de OTRANS Argentina, que fue imprescindible en la disputa, apropiación y consolidación desde adentro de los espacios feministas, que históricamente habían sido orquestados colectivamente por mujeres, lesbianas y otras identidades. Esto permitió inscribir en la historia de los movimientos políticos, una gesta construida desde los bordes, una historia subversiva y alejada del mainstream.

En este sentido la agenda política, se construyó en torno a la exigencia al Estado de políticas públicas específicas contra los travesticidios y transfemicidios, la sanción de una ley nacional sobre inclusión laboral formal travesti y trans; y el efectivo cumplimiento de la Ley de Identidad de Género, en materia de salud integral de las personas travestis y trans. Como también, del reclamo por la reparación económica a travestis y trans mayores de 40 años víctimas de violencia institucional, y políticas destinadas a las infancias travestis y trans libres de violencia y discriminación.

Esta construcción desde los bordes o fronteras, entendimos, fue resultado de la hibridación de culturas y mestizajes. En esta misma línea, recuperar esta experiencia se tornó relevante a la hora de ampliar la mirada con respecto a las personas migrantes en una sociedad eurocéntrica, patriarcal y capitalista, donde la xenofobia y el racismo se evidencian de múltiples maneras en la vida cotidiana. Las charapas, al provenir del Perú y de la región selvática con mayoría poblacional de pueblos originarios, donde las imposiciones del hombre blanco condicionó sus historias de vida, y dejó huellas indelebles en la cosmogonía de su comunidad; nos hizo dirigir una mirada crítica a los aportes de Guiseppe Campuzano, respecto al travestismo y al control del cuerpo en el Perú. Es historia antigua afirmó, por cuanto, la primera prohibición al travestismo en el país hermano, pudo rastrearse en el año 1566; desde el incanato, pasando por la República, y hasta la actualidad. Por lo tanto, diremos que la colonialidad que atravesó, transversalmente, las prácticas de las charapas, es una de las características constitutivas y fundantes de la epistemología del despojo.

La mirada de este filósofo peruano, aportó una condición vital, en su compromiso con la praxis del travestismo. En su obra avizoramos el contexto histórico peruano, pero también una reflexión filosófica de lo que es el travestismo, que parte desde las travestis de carne y hueso, hasta los múltiples significados que puede tener, tanto en el Perú como en la Argentina. De allí que insistamos en que la presencia de feminidades travestis y trans 
migrantes de países del Cono Sur, en la conformación del movimiento travesti y trans en la Argentina, ha sido fundamental. No será posible volver una mirada hacia el movimiento, sin entender, primeramente, el mundo que él mismo representa, con su complejidad, profundidad, riqueza y poder. Es por ello que, en adelante, debe ser necesariamente entendido como un gran mosaico de identidades, culturas, formas diversas y plurales de existencias.

Identidades que cuestionaron, históricamente, la construcción del Estado-Nación, en relación estrecha con las condiciones que experimentaron, también, las personas de pueblos originarios. La pregunta por el "¿qué somos?" definida en ese sentido, invitó a replantearnos nuestra identidad regional, la que construimos quienes habitamos en Latinoamérica y el Caribe. El desafío es repensar al movimiento travesti y trans, y la potencia que ello implica en términos de diversidad y pluralidad de experiencias, como un referente internacional sin precedentes, aún con sus fisuras y contradicciones.

Es pues, desde estas múltiples y complejas interseccionalidades, que la identidad de género, en el caso de las charapas, representa una red de contención más sólida que la migración, la raza, la clase social, la etnia, entre otras; pensadas particularmente, a la hora de enfrentar la violencia institucional. Entendimos la interseccionalidad, en este sentido, no como una suma de desigualdades, sino de lo que cada una de éstas transversaliza de forma específica en este grupo social. Aquí, cobra vigor la nostredad como categoría política, en los términos que plantea Marlene Wayar, pues habilita una repregunta sobre ¿qué no somos? más que lo que sí somos.

Además, en nuestra indagación, hemos reconocido, también, la existencia previa de prácticas político- comunicacionales informales de subsistencia y, prácticas político- comunicacionales formales institucionales, en el accionar y proyectar una experiencia basada en lo común de quienes protagonizaron momentos trascendentales en diferentes épocas históricas, durante la construcción del movimiento travesti y trans en Argentina.

Por eso, a través de la lectura retrospectiva no exenta de tensiones, de diferentes formas de participar, y de pensar la inclusión, de hablar y vincularse con les otres; fue y será necesario partir de la construcción de alianzas y estrategias que contribuyan a evidenciar y unificar una memoria colectiva, plural y polifónica. En la actualidad, se presenta el desafío y el compromiso de participar de un presente histórico, fundamental, para las futuras generaciones del movimiento travesti y trans en Argentina, y el resto de nuestra América. Porque concebimos que una política de la desmemoria podría tener consecuencias negativas en relación al desconocimiento de la historia del movimiento, por parte de las nuevas generaciones de identidades travestis y trans. Pero, además, porque constituye un compromiso y una responsabilidad, sobre todo, ética y política, el deconstruir ese individualismo, que tiene un origen marcadamente patriarcal. 
La necesidad que se impone es la de sistematizar una historia de las resistencias que se transmite, generalmente, a través de relatos orales; y que habilite la construcción o resignificación de nuevos espacios, como el museo itinerante de la memoria travesti y trans local, proyecto que OTRANS ARGENTINA viene desarrollando desde 2019. Podemos afirmar, con toda seguridad, que las narrativas que acompañan estas configuraciones, y que son constantemente atravesadas por la coyuntura socio-política, constituyen prácticas concretas que marcan una impronta en su subjetividad, y fortalecen procesos de emancipación social; que encuentra en la consolidación de un discurso identitario, la disputa por esos espacios negados y por la inteligibilidad de una manera propia de existencia.

El desafío, en adelante, también está puesto en el reconocimiento por parte del Estado del transgenocidio, a la hora de pensar la construcción de una historia y memoria del colectivo travesti y trans de Argentina. Porque pensar en estos términos, permitirá entender la muerte de personas travestis y trans, motivada por su identidad de género autopercibida, para dar cuenta de la eliminación sistemática, como la concentración y confinamiento, con el objetivo del borramiento a la identidad travesti y trans, -y de allí su relación a la figura de identicidio-; sea a través de mecanismos de homogeneización y reproducción del sistema sexo/género, como de su desaparición o exterminio.

Este proceso no debe hacerse por fuera de la Academia y de otras instituciones educativas. En estos ámbitos, las voces travestis y trans fueron acalladas, invisibilizadas y excluidas, como señalamos junto a Florencia Saintout y Andrea Varela. No se tuvieron en cuenta sus prácticas cotidianas, sus ideas y experiencias como parte de la producción de conocimiento subjetivo, diferente al orden existente. En ellos, se sesgó el intercambio de saberes y el debate como constitutivo de lo público, desconociendo y restringiendo su rol político; de allí que es necesario, partir del desconocimiento al reconocimiento como sujetes cognoscentes.

Esta violencia simbólico-interpretativa sirvió a los fines de una invisibilidad, una recusa a la producción travesti y trans de conocimiento, en tanto representación del transodio en la producción intelectual, por rehuir a su capacidad de producir saberes. Pensar como resinificar esa práctica, -que también viene siendo sistemática por sobre el colectivo- al no reconocimiento a su capacidad de habla y de producir teoría sobre sus propias realidades, implicará concebir el impulso productivo de estos desplazamientos subversivos.

La posibilidad de inaugurar o construir una epistemología permitirá, en este sentido, habilitar modos insurgentes de ser, existir y habitar el mundo, reconocerse desde esa común vulnerabilidad, y desbaratar los marcos normativos. Apostamos a una agencia performativa y plural que, en definitiva, inaugure una práctica política insurreccional y de resignificación positiva. 
Finalmente, pensar la epistemología del despojo implicará, no olvidarse de eso que las constituye desde los primeros años de vida. Un despojo que les permitió ser charapa como una subjetividad de trinchera. $Y$ en tanto tal, organizarse y coalicionar con otres para ser tenidas en cuenta como sujetas parlantes, al decir de Jacques Rancière; y desde ese lugar común, potenciar la agencia.

Reflexionar en torno a cómo el no-reconocimiento generó cierta disposición a establecer un nuevo sentido de la ética, a convertir la vulnerabilidad en una fuerza que cualquier política emancipadora debe asumir y, así, comprender los lazos sociales y solidarios que nos unen. Reconocer, que le otre de la relación de conocimiento o gnoseológica es un sujeto igual a mí, y que ya no hay solo un sujeto para un objeto; producir conocimiento y gestar teoría. Une sujete que, si no es charapa igual a mí, reúne mis mismas condiciones de vulnerabilidad: es una migrante, pobre, o una persona de pueblos originarios, o afrodescendiente, entre otras infinitas posibilidades de ser.

Para fundar una epistemología del despojo, es clave partir de algunos pilares comunicacionales: un trabajo sobre un ejercicio crítico a la interdependencia que nos une, de la memoria activa de les otres, del autoconocimiento o cuidado de si, y un profundo sentido de interrelación o corresponsabilidad.

La contracara del transepistemicidio, nos implicará en una oportunidad de hablar desde y para nosotras mismas, y generar, a su vez, fecundos espacios transfeministas. Inscribirnos en el reconocimiento de lo que nos constituye, y me constituye.

Por eso, hablo desde y por mi diferencia, desde los múltiples atravesamientos de mí existencia travesti, trans, migrante, descendiente de pueblos originarios, negra, pobre y sudaka.

Soy cada una de mis hermanas asesinadas producto del odio a la identidad de género, encarnada en los travesticidios y transfemicidios;

Soy cada una de las que viven en contextos de encierro;

Soy memoria;

Soy charapa;

Soy golondrina. 


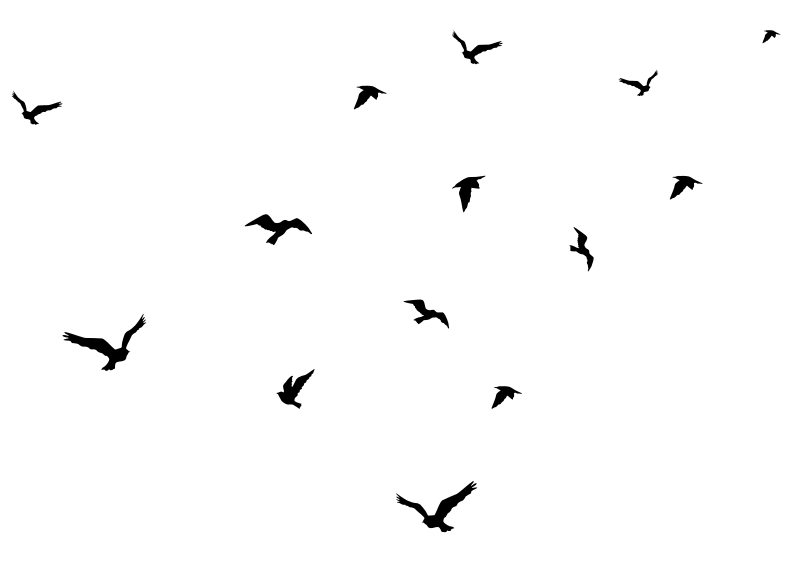

BIBLIOGRAFÍA 


\section{BIBLIOGRAFÍA:}

Abatedaga, Nidia y Siragusa, Cristina. (2012). Comun(ic)axión Cooperativa. Estrategias, Herramientas y Reflexiones. Cordoba: Corintios.

Abatedaga, Nidia y Ordoñez, María. (2017). Praxis Comunicativa y Narrativas Identitarias de los Emergentes Laborales en el Espacio Público. XXXI Congreso Alas. Las encrucijadas abiertas de América Latina. La Sociología en Tiempos de Cambio. Montevideo, Uruguay.

Abatedaga, N., Alcaraz, C., Armano, B., Ayala, C., Calderón, P., Carranza, V \& González, V. (2014). IAP Investigación-Acción-Participativa. Metodologías para organizaciones de gestión horizontal. Córdoba: Editorial Brujas.

Abeles, Marc. (2002). El campo y el sub campo, en: Ghasarian, Cristian et al: De la etnografía a la antropología reflexiva. Buenos Aires: Ediciones del Sol.

Althabe, Gerard y Valeria Hernández. (2005). Implicación y reflexividad en Antropología, en: Hernández, V.; Hidalgo, C. y A. Stagnaro: Etnografías Globalizadas. Buenos Aires: Sociedad Argentina de Antropología.

Amaro Quintas, Ángel Manuel. (2010). Triplemente Vulnerabilizadas Prostitutas, inmigrantes y transexuales. Beca de Iniciación a la Investigación. España: Vicerrectorado de Investigación de la Universidad de Alicante.

Amnistía Internacional. (2017). Algunas consideraciones sobre la modificación de la Ley de Migraciones (Decreto de Necesidad y Urgencia 70/2017). https://amnistia.org.ar/wp-content/uploads/delightful-downloads/2017/02/Migraciones-QyA-1

Anahí, Farji Neer. (2017). Travestismo, transexualidad y transgeneridad en los discursos del Estado Argentino, Buenos Aires.

Anzaldúa, Gloria. (2016). Borderlands/La Frontera. La Nueva Mestiza. Madrid.Capitán Swing Libros, S.L.

Archenti, A. (2003). "Comunicación, prácticas socio-culturales y subjetividad”. En: Trampas de la Comunicación y la Cultura. FPyCS. UNLP. Agosto. 
(Coordinador) (2006). Nosotros y los otros: una mirada antropológica y comunicacional sobre las migraciones. Revista Trampas de la Comunicación y la Cultura № 43. FPyCS. UNLP. Marzo.

(2007). "Imaginarios de la Inmigración en un contexto local". Programa IDEI. (Programa Iberoamericano de Estudios sobre Imaginarios), UNLP.

Archenti, A. y Ametrano, L. (2015). "Posicionamientos, estrategias e intervenciones ciudadanas en contextos de migración". En: AtekNa. Buenos Aires: Programa de Estudios Patagónicos. CENPAT-CONICET. vol.1 n4. P 143 - 178.

Archenti, Adriana. (2016). En Proyecto de investigación "Formas diferenciales de participación, derechos y producción de ciudadanía en situación de migración". Facultad de Periodismo y Comunicación Social. Centro de Estudios Aplicados en Migraciones, Comunicación y Relaciones Interculturales. UNLP.

Barbero, Jesús Martín. (1988). Procesos de comunicación y matrices de cultura. México: Gustavo Gili.

Barrancos, Dora. (2014). Géneros y sexualidades disidentes en la Argentina: De la agencia por derechos a la legislación positiva. Buenos Aires: Cuadernos Intercambio sobre Centroamérica y el Caribe Vol. 11, No. 2.

Barth, Frederik. (1976). Los grupos étnicos y sus fronteras. México: Fondo de Cultura Económica.

Bazán, Osvaldo. (2006). Historia de la homosexualidad en la Argentina. De la conquista de América al siglo XXI. Buenos Aires: Marea bolsillo.

Benhabib, Seyla. (2006). Las reivindicaciones de la cultura. Igualdad y diversidad en la era global. Buenos Aires: Katz Editores.

Benítez Eyzaguirre, Lucía. (2006). Comunicación y Migración: El caso de Ecuador. Universidad de Cádiz, España.

Berkins, Lohana. (2003). Un itinerario político del travestismo. En Diana Mafía (compiladora). Sexualidades migrantes. Género y transgénero. Buenos Aires: Scarlett Press.

Berkins, Lohana y Fernández Josefina. (2005). La gesta del nombre propio. Buenos Aires: Ediciones Madres de la Plaza de Mayo.

Berkins, Lohana.(2007). Cumbia, copeteo y lágrimas: un informe nacional sobre la situación de las travestis, transexuales y transgéneros. Buenos Aires: Ediciones Madres de Plaza de Mayo.

Bonfil Batalla. (1992). Identidad y Pluralismo Cultural en América Latina. Buenos Aires: 
Fondo Editorial del CEHASS.

Bourdieu, Pierre. (1986). Habitus, Código y Codificación en Actes de la Recherche en Sciences Sociales, $N^{\circ} 4$, septiembre.

Bourdieu, Pierre. (2000). La dominación Masculina. Barcelona: Editorial Anagrama, S.A.

Bourdieu, Pierre. (2007). El sentido práctico. Buenos Aires: Siglo XXI editores.

Bornstein, Kate. (1994). Gender Outlaw: On Men, Women, and the Rest of Us. Routledge. New York City.

Butler, Judith. (2006). Deshacer el género. Barcelona: Paidós.

Butler, Judith y Spivak, Gayatri. (2009) ¿Quién le canta al Estado-Nación? Buenos Aires: Paidós.

Butler, Judith.(2010). Cuerpos que importan. Sobre los límites materiales y discursivos del «sexo». Buenos Aires: Ediciones Paidós.

Butler, Judith.(2016). El género en Disputa. Buenos Aires: Paidós.

Butler, Judith.(2017). Cuerpos aliados y lucha política." Hacia una teoría performativa de la asamblea. Buenos Aires: Paidós

Cabral, Mauro.(2003). Ciudadanía (trans) sexual. [En línea]. [Consulta: 3 de septiembre de 2014].

Campuzano Giuseppe. (2007). Museo travesti del Perú. Publicado por el auspicio de Institute of Development Studies.

Castells, Manuel. (1999). El poder de la identidad, en La era de la información, vol. II. México: Siglo XXI.

Chávez Carapia \& Julia del Carmen. (2004). Perspectiva de Género. Plaza y Valdes. Ciudad de México.

Crenshaw, Kimberlé. (1995). Mapping the Margins: Interseccionality, Identity Polítics and violence Againts Women of Color en K. Crenshaw; N. Cotanda; C. Peller; K. Thomas (eds.) Critical Race Theory. The key.

Comisión Interamericana De Derechos Humanos. (2015). Violencia contra Personas Lesbianas, Gay, Bisexuales, Trans e Intersex en América. 
Comité contra la Tortura. (2017). Observaciones finales sobre el quinto y sexto informe conjunto periódico de Argentina:

https://tbinternet.ohchr.org/Treaties/CAT/Shared\%20Documents/ARG/INT_CAT_COC_ARG_27464_S.pdf

De Certeau, Michel. (1996). La invención de lo cotidiano. Artes de hacer.I. Universidad Iberoamericana, Ciudad de México.

Deleuze, Gilles y Guattari, Félix. (2002). Mil mesetas. Capitalismo y esquizofrenia. España: Pre-Textos.

Delfino, Silvia. (1993). La mirada oblicua. Estudios culturales y democracia. Buenos Aires: Ediciones La marca.

Faist, Thomas y Christian Ulbricht. (2013). Doing National Identity through Transnationality: Categorizations and Mechanisms of Inequality in Integration Debates. Nueva York, Russell Sage Foundation.

Fals Borda, O. (1985). Conocimiento y poder popular. Lecciones con campesinos de Nicaragua, México y Colombia. Colombia: Editorial Siglo XXI.

Fallo del Poder Judicial de la Nación. (2018). Condena de Gabriel David Marino por el travesticidio de Diana Sacayán. file:///C:/Users/claud/Downloads/DianaSacayan-Fundamentos.pdf

Foucault, Michel. (1976). Genealogía del racismo. Altamira.

Foucault, Michel. (1979). Microfísica del poder. Madrid: Ediciones La piquetera.

Foucault, Michel. (1999). Estrategias de poder. Buenos Aires: Ediciones Paidós.

Foucault, Michel. (2000). Vigilar y castigar: nacimiento de la prisión. Siglo XXI.

Foucault, Michel. (2001). Historia de la sexualidad. Vol. 3. Siglo XXI.

Foucault, Michel. (2005). El orden del discurso. Buenos Aires: Tusquets Editores.

Foucault, Michel. (2007). Nacimiento de la bio-política, trad. Horacio Pons, Buenos Aires: FCE.

Freire, Paulo. (1970). La Educación como práctica de la libertad. Montevideo: Tierra Nueva. 
Goffman Erving. (2006). Estigma: la identidad deteriorada. Buenos Aires: Amorrortu Editores.

Grimson, Alejandro. (2011). Los límites de la cultura. Crítica de las teorías de la identidad. Buenos Aires: Siglo XXI.

Grimson, Alejandro. (2019). ¿Qué es el peronismo? Editorial Siglo XXI. Buenos Aires.

Guber, Rosana. (2014). La etnografía. Método, campo y reflexividad. Buenos Aires: Siglo XXI Editores.

Hall, Stuart. (1994). Estudios Culturales: dos paradigmas. En Causas y Azares No. 1.

Halberstam, J. (1997). Techno-homo: on bathrooms, butches, and sex with furniture, in Jenifer Terry and Melodie Calvert Eds., Processed Lives. Gender and Technology in the Everyday Life, Routledge, London and New York.

Hall, Stuart. (2003). ¿Quién necesita= identidad? en: Hall. Stuart y Du Gay, Paul (comps.) Cuestiones de identidad cultural, Buenos Aires: Amorrortu.

Haraway, Donna. (1984). Manifiesto Ciborg. El sueño irónico de un lenguaje común para las mujeres en el circuito integrado. New York: Routledge.

Haraway, Donna. (1991). Ciencia, ciborgs y mujeres. La reinvención de la naturaleza. Valencia : Ediciones Cátedra.

Hartley, John. (1997). Conceptos Clave en comunicación y Estudios Culturales. Buenos Aires: Armorrurtu. Editores.

Hernández Sampieri. (2010). Metodología de la investigación. México: Interamericana Editores.

Hirschfeld, Magnus. (2018). Die Transvestiten: eine Untersuchung über den erotischen Verkleidungstrieb. Los travestidos: una investigación del deseo erótico por disfrazarse. Londres, Inglaterra: Forgotten Books.

Ianni, Octavio. (1998). La sociedad global, México: Siglo XXI.

Instituto Nacional de Estadística e Informática, INEI. (2017). Censo nacional del 2017. https://www1.inei.gob.pe/

Karasik, Gabriela. (2000). Tras la genealogía del diablo. Discusiones sobre la nación y el 
Estado en la frontera argentino-boliviano. En Grimson A. (comp.) Fronteras, naciones e identidades. La periferia como centro. Buenos Aires: La Crujia.

Kaufman, Alejandro. (2011). Historia y memoria: algunas indagaciones teóricas para el marco analítico Latinoamericano, en Juicios por crímenes de Lesa Humanidad en Argentina. Buenos Aires: Ediciones Cara o Seca.

Kosofsky Sedgwick, Eve (1990). The Epistemology of the Closet. University of California Press, Los Ángeles.

Lewkowicz, Ignacio. (2004). Pensar sin Estado. La subjetividad en la era de la fluidez. Buenos Aires: Editorial Paidós.

Ley $N^{\circ} 26.743$ (2012). Identidad de Género.

https://www.tgeu.org/sites/default/files/ley_26743.pdf.

Magariños de Morentin, Juan Angel. (1991). El mensaje publicitario y Nuevos ensayos sobre semiótica y publicidad. Buenos Aires: Edicial.

Martínez, Juliana. (2014). Travesti, transexual, transgénero... Algunas definiciones útiles. Recuperado de https://sentiido.com/travesti-transexual-transgenero-algunas-definiciones-utiles/

Martínez, Juliana; Vidal-Ortiz, Salvador. (2018). Travar el saber. Educación de personas trans y travestis en Argentina. EDULP. La Plata.

Massey Douglas S., Graeme Joaquín Arango Hugo, Kouaouci Alí, Pellegrino Adela y Taylor J.E. (2000). Teorías sobre la Migración Internacional: Una resen̄a y una evaluación; en Migraciones y Mercados de Trabajo, Año 2, N³, México.

Mattio Eduardo. (2012). Introducción en Moran, Sgró y Vaggioni. Sexualidades-desigualdades-y-derechos, Reflexiones en torno a los derechos sexuales y reproductivos. Córdoba: Editorial Ciencia, Derecho y Sociedad.

Monnet, Jérôme. (1999). La ville et le pouvoir en Amérique: les formes de l'autorité. Paris: L『Harmattan.

Nash, Mary \& Marre, Diana. (2001). Multiculturalismos y género. Un estudio interdisciplinar. Barcelona: Ediciones Bellaterra.

Pacecca, María Inés. (2019). Personas, papeles, políticas y derechos: las migraciones contemporáneas en Argentina desde la perspectiva de CAREF, 2004-2015 1a ed. Ciudad Autónoma de Buenos Aires: CAREF - Comisión Argentina para Refugiados y Migrantes.

Peirce, Charles Sanders. (1974). La ciencia de la semiótica. Buenos Aires: Nueva Visión. 
Portes, Alejandro y Guarnizo, Luis.(1991). Tropical capitalists: U.S. -bound immigration and small enterprise development in the Dominican Republic. Mexico: Development: and Caribbean Basin Countries, Boulder, CO.

Portes, Alejandro y Landolt, Patricia (1996). The downside of social capital', US: The American Prospect.

Preciado, Paul. (2002). Manifiesto contra-sexual. Editorial Opera Prima. Madrid.

Preciado, Paul. (2013). Basura y Género Mear/Cagar. Masculino/Femenino. Recuperado en https://www.iztacala.unam.mx/errancia/v0/PDFS/POLIETICAS\%20DEL\%20CUERPO\%201\%20BASURA\%20Y\%20GENERO.pdf

Radi, Blas. (2019). "Políticas del conocimiento: hacia una epistemología trans", en López Seoane, Mariano, Los mil pequeños sexos, Sáenz Peña, Ed. UNTREF.

Rancière, Jacques. (1996). El desacuerdo: política y filosofía. Buenos Aires: Nueva visión. Reguillo, Rosana. (1998). Un malestar invisible: derechos humanos y comunicación.

Rockwell, Elsie. (2009). La experiencia etnográfica. Historia y cultura en los procesos educativos. Buenos Aires, Paidós.

Saintout, Florencia. (2003). Abrir la comunicación: tradición y movimiento en el campo académico. Facultad de Periodismo y Comunicación Social Universidad Nacional de la Plata.

Segato, Rita. (2013). La escritura en el cuerpo de las mujeres asesinadas en Ciudad Juárez. Territorio, soberanía y crímenes de segundo estado. Buenos Aires: Ediciones Tinta Limón.

Shulamith Firestone. (1976). La dialéctica del sexo. En defensa de la revolución feminista. Barcelona, España: Kairós.

Stefoni, Carolina. (2004). Inmigración y Ciudadanía: La formación de comunidades peruanas en Santiago de Chile y la emergencia de nuevos ciudadanos. FLACSO, Chile.

Stone, Sandy. (1987). The Empire Strikes Back: A Posttranssexual Manifesto. EE.UU: Indiana University Press.

Stryker, Susan. (1994). My Words to Victor Frankenstein above the Village of Chamounix Performing Transgender Rage.Duke University Press. 
Temblay, M. (1982). The key informant Technique: a non-ethnographic application. En Burgess, R, (ed). Field research: a sourcebook and field manual. London: Allen an Unwin,

Tratados Internacionales Con Jerarquía Constitucional. (1948). Convención para la Prevención y la Sanción del Delito de Genocidio. Aprobada por la III Asamblea General de las Naciones Unidas el 9 de diciembre de 1948: https://www.senado.gob.ar/bundles/senadoparlamentario/pdf/70/con-prev-san-genocidio.pdf

Trinchero, Héctor Hugo. (2009). Pueblos originarios y políticas de Reconocimiento en Argentina. Buenos Aires: Centro de Estudios Interdisciplinarios en Etnolingüística y Antropología Socio-Cultural.

Vain, Pablo. (2018). Los rituales escolares y las prácticas educativas. Posadas: Editorial Universitaria de la Universidad Nacional de Misiones.

Zaffaroni, Raúl. (2011). La cuestión criminal, “La criminología mediática”. Editorial Planeta.

\section{ARTICULOS DE REVISTA}

Aguirre Baztán, Ángel. (1999). La identidad cultural, en Anthropológica, Revista de Etnopsicología y Etnopsiquiatría. España: Instituto de Antropología de Barcelona, Centro de Psicología INFAD, Sociedad Española de Antropología Aplicada.

Amado, Ana. (2000). Cuerpos intransitivos. Los debates feministas sobre la identidad. Debate Feminista, p.233-243. Recuperado de http://www.debatefeminista.pueg.unam.mx/ wp-content/uploads/2016/03/articulos/021_12.pdf

Argumedo, Alcira. (1996). El Imperio del Conocimiento. En Encrucijadas, año II, n 4, mayo 1996.

Butler, Judith. (2009c). Performatividad, precariedad y políticas sexuales". AIBR. Revista de Antropología Iberoamericana, Madrid, v. 4, n 3. Recuperado de: http://www.aibr.org/antropologia/04v03/criticos/040302.pdf

Caletti, S. (2001). Siete tesis sobre comunicación y política. Diálogos de la Comunicación, 63. Recuperado el 20 de mayo de 2014 de http://dialogosfelafacs.net/

Delfino, Silvia. (1998). Desigualdad y diferencia: retóricas de identidad en la crítica de la cultura. En Revista Estudios Nº. 7. CEA, Universidad Nacional de Córdoba, pp. 28-44.

Delfino, Silvia. (1998). Desigualdad y diferencia: retóricas de identidad en la crítica de la 
cultura". En revista Doxa No 18, pp. 28-44.

Haber, Alejandro. (2011). “Nometodología Payanesa: Notas de Metodología Indisciplinada”. En Revista de Antropología N²3, 1er Semestre, p. 9-49.

Haraway, Donna. (1999). Las promesas de los monstruos. Una política regeneradora para otros inapropiados/bles. En Revista Política y Sociedad No. 30.

Jelin, Elizabeth. (2014). Memoria y democracia: Una relación incierta. Revista mexicana de ciencias políticas y sociales.

Macluf, J., Delfín, L., \& Gutiérrez L. (2008). El estudio de caso como estrategia de investigación en las ciencias sociales. Ciencia Administrativa Ensayos.

Lock, Margaret; Scheper Hughes, Nancy. (1987). El cuerpo mindful (pensante): prolegomenos hacia el futuro trabajo en la Antropología Medical. En: Medical Anthropology Quarterly No 1. Recuperado de https://docplayer.es/87149766-El-cuerpo-mindful-pensante-prolegomenos-hacia-el-futuro-trabajo-futuro-en-la-antropologia-medica.html

Péchin, Juan E. (2013). ¿Cómo construye varones la escuela? Etnografía crítica sobre rituales de masculinización en la escena escolar. Revista Iberoamericana de Educación, № 62.

Revista Migraciones Internacionales. (2002). Reflexiones desde Argentina. Organización Internacional para las Migraciones. Buenos Aires.

Saintout, Florencia y Varela, Andrea. (2014). Los saberes académicos en contextos de compromisos: la epistemología del barro. Oficios Terrestres, (30), 109-117.

Vespucci, Guido. (2015). Del armario a la pareja. La promoción de un ethos proto familiar para la homosexualidad en la revista Diferentes (Buenos Aires, 1984-1985). Revista Contemporánea. Historia y problemas del siglo XX | Año 6, Volumen 6, 2015, ISSN: 1688-7638.

\section{ARTÍCULOS DE DIARIOS}

Lohana de Lejos (10 de agosto de 1997). Página 12. Recuperado de https://www.pagina12. com.ar/diario/suplementos/radar/subnotas/11731-2565-2016-08-22.html

La identidad de los claustros (30 de mayo de 2008). Página 12. Recuperado de 
Las adelantadas (9 de noviembre de 2012). Página 12. Recuperado de https://www.pagina12.com.ar/diario/suplementos/soy/1-2697-2012-11-09.html

Rechazo de travestis y transexuales a la mudanza de la zona roja (12 de julio de 2012). El Día. Recuperado de https://www.eldia.com/nota/2012-7-12-rechazo-de-travestis-y-transexuales-a-la-mudanza-de-la-zona-roja

Hartazgo e impotencia en los barrios que conviven con la zona roja (3 de noviembre del 2013). El Día. Recuperado de https://www.eldia.com/nota/2013-11-3-hartazgo-e-impotencia-en-los-barrios-que-conviven-con-la-zona-roja

La zona roja platense en la mira de los vecinos (02 de noviembre de 2013). El Día. Recuperado de https://www.eldia.com/nota/2013-11-2-la-zona-roja-platense-en-la-mira-de-los-vecinos

En Cana. (31 de junio de 2014). Página 12. Recuperado de https://www.pagina12.com.ar/ diario/suplementos/soy/1-3478-2014-06-13.html

Trasladan la zona roja a un corredor del Bosque (29 de abril de 2014). El Día. Recuperado de http://www.eldia.com/nota/2014-4-29-trasladan-la-zona-roja-a-un-corredor-del-bosque

Luciano Arruga: la condena por tortura reclama políticas activas contra la violencia institucional (15 mayo 2015). CELS Centro de Estudios Legales y Sociales. Recuperado de https://www.cels.org.ar/web/2015/05/luciano-arruga-la-condena-por-tortura-reclama-politicas-activas-contra-la-violencia-institucional/

“No voy más a la calle" (12 de febrero de 2016). Página 12. Recuperado de https://www. pagina12.com.ar/diario/suplementos/las12/subnotas/10369-980-2016-02-12.html

Una cárcel para extranjeros (26 de agosto de 2016). Página 12. Recuperado de

https://www.pagina12.com.ar/diario/elpais/1-307814-2016-08-26.html

Visita Relator Especial ONU sobre formas contemporáneas de racismo, discriminación racial, xenofobia e intolerancia (23 de mayo de 2016). PNUD Argentina. Recuperado de https:// www.ar.undp.org/content/argentina/es/home/presscenter/pressreleases/2016/05/23/ visita-relator-especial-onu-sobre-formas-contempor-neas-de-racismo-discriminaci-n-racial-xenofobia-e-intolerancia.html

Migrantes transgénero en México: éxodo de violencia y discriminación (21 de agosto de 2017). Cienciamx Noticias. Recuperado de http://www.cienciamx.com/index.php/reporta- 
Maite Amaya: el adiós a la guerrera libertaria (15 de junio de 2017). Agencia Presentes. Recuperado de http://agenciapresentes.org/2017/06/15/maite-amaya-adios-la-guerrera-libertaria/

Más de un millón de peruanos no profesan ninguna religión (27 de octubre de 2018). El Comercio. Recuperado de https://elcomercio.pe/peru/millon-peruanos-sigue-religion-noticia-571715-noticia/?ref=ecr

\section{CONGRESOS}

Rosales, Ma. Belén Rosales y Ledesma Lucas. (mayo 2012). Procesos de Comunicación, Educación y Género: desde una perspectiva de la diversidad. Trabajo presentado en el Congreso de Periodismo, Medios y Comunicación, Buenos Aires, La Plata.

\section{TESIS}

Abalo, Facundo. (2015). "Lecturas insurgentes: práctica y significación en trayectos biográficos de sujetos trans". [Tesis de doctorado]. Recuperado de http://sedici.unlp.edu.ar/ handle/10915/46641

Butler, Andrea y Bertulo, Lucas. (2010). "Voces trans ... Solo ellas". [Tesis de grado]. Facultad de Periodismo y Comunicación Social, UNLP.

Chávez, Gracia, Teresa. (2006). La Enseñanza de la Historia del Perú en la educación secundaria durante la segunda mitad del S. XX. [Tesis de doctorado]. Fondo Editorial de la Pontificia Universidad Católica del Perú.

Corneli, Bárbara. (2011). Mi cuerpo... i¿qué no ha dado?! El cuerpo travesti como espacio de comunicación. [Tesis de grado]. Facultad de Periodismo y Comunicación Social, UNLP.

Flores Caldas Edgar C. (2016). Libertad Religiosa y la Enseñanza de la religión católica en el ordenamiento jurídico peruano y en el acuerdo con la santa sede de 1980. [Tesis de doctorado]. Madrid: Ediciones Universidad San Dámaso, 2018. 
González, Verónica. (2015). Precaridad, (in)visibilización y exilio. Una lectura crítica sobre las ontologías sociocorporales trans desde la perspectiva de Judith Butler. [Tesis de Maestría]. Facultad de Ciencias Sociales y Humanidades. Universidad Nacional de Quilmes.

Vásquez Haro, Claudia (2012) Configuraciones de identidades trans en medios gráficos argentinos: nociones identitarias en disputa. [Tesis de grado]. Facultad de Periodismo y Comunicación Social, UNLP.

\section{APUNTE DE CATEDRA}

Huergo, Jorge. (2009). Hegemonía: un concepto clave para comprender la comunicación. [Apunte de cátedra]. Cátedra de Comunicación y Educación, Facultad de Periodismo y Comunicación Social, Universidad Nacional de La Plata. La Plata, Argentina.

Delfino, Silvia (2013). Seminario de doctorado "Prácticas y saberes de la Comunicación". Universidad Nacional de La Plata. Apuntes de clase.

\section{VIDEO DE YOUTUBE}

Edición del día (23 de junio de 2012). Claudia Vásquez Haro: Chocolatada contra el traslado de las compañeras trans al bosque Platense [archivo de video]. https://www.youtube.com/ 236 watch?v=iOAPqUwpmKk 


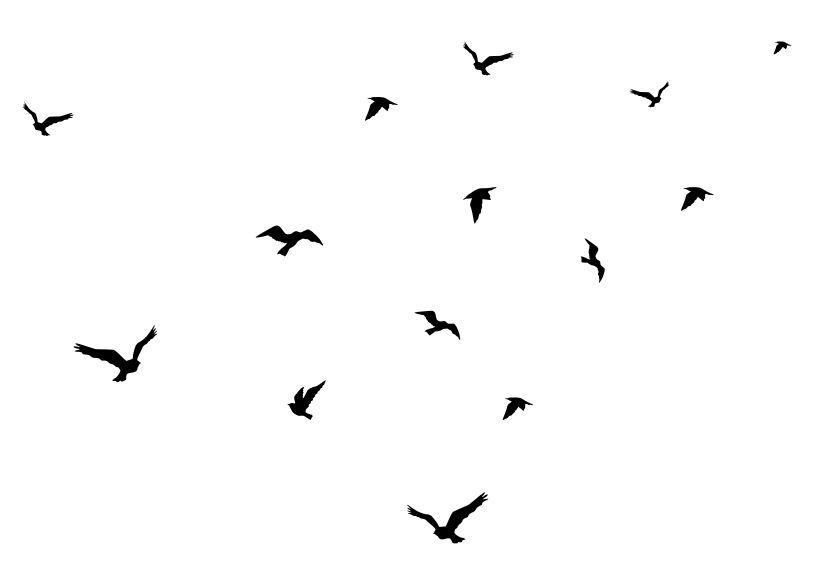

ANEXOS DIGITALES

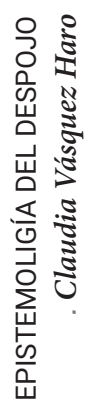




\section{ANEXOS DIGITALES}

Para acceder a los anexos digitales, adjuntamos el código QR.

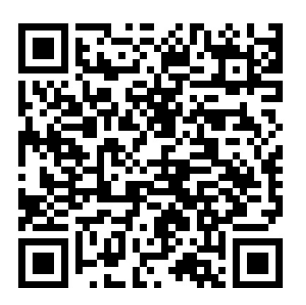

1. Fallos, Habeas corpus y denuncias judiciales de OTRANS ARGENTINA

2. Informes locales y nacionales enviados a organismo internacionales de derechos humanos producidos por OTRANS ARGENTINA.

3. Registros audiovisuales y audios sobre debates por la reubicación de la "zona roja" (2014)

4. Registros de flyers y comunicados de prensa.

5. Registro fotográfico de actividades de voley y venta de comidas típicas de la selva peruana.

6. Registro fotográfico y audiovisual de los Encuentros Nacionales de las Mujeres (ENM) (Salta 2014, Mar del Plata 2015, Rosario 2016, Chaco 2017, Trelew 2018) y del $34^{\circ}$ Encuentro Plurinacional de Mujeres, Lesbianas, Travestis, Trans y No binaries en La Plata (2019).

7. Registro fotográfico proyecto cárceles "Sobre travestis y trans privadas de su libertad en unidades penitenciarias de la provincia de Buenos Aires y ámbito Federal”. 
8. Registro fotos marchas y reuniones de OTRANS ARGENTINA

9. Registro de fotos chocolatada y creación de OTRANS LA PLATA

10. Registro de fotos velatorio y entierros de las Charapas.

11. Documento proyecto cooperativa Las Charapas de peluquería y belleza integral.

12. Documentos y comunicados de prensa de OTRANS ARGENTINA

13. Documento entrevista en profundidad

14. Documento entrevista estructurada

15. Documento proyecto Escuela de Formación Política para fortalecer liderazgos travestis $y$ trans en Argentina.

16. Documento notas periodísticas OTRANS ARGENTINA

17. Documento registro del trabajo de campo.

18. Documentos finales de talleres de travesti y trans en el marco de los Encuentros. 